\title{
Route and grade sensitive modeling of fuel efficiency and emissions for diesel buses
}

\author{
ABM Siddiqur Rahman Khan \\ West Virginia University
}

Follow this and additional works at: https://researchrepository.wvu.edu/etd

\section{Recommended Citation}

Khan, ABM Siddiqur Rahman, "Route and grade sensitive modeling of fuel efficiency and emissions for diesel buses" (2009). Graduate Theses, Dissertations, and Problem Reports. 4484.

https://researchrepository.wvu.edu/etd/4484

This Dissertation is protected by copyright and/or related rights. It has been brought to you by the The Research Repository @ WVU with permission from the rights-holder(s). You are free to use this Dissertation in any way that is permitted by the copyright and related rights legislation that applies to your use. For other uses you must obtain permission from the rights-holder(s) directly, unless additional rights are indicated by a Creative Commons license in the record and/ or on the work itself. This Dissertation has been accepted for inclusion in WVU Graduate Theses, Dissertations, and Problem Reports collection by an authorized administrator of The Research Repository @ WVU.

For more information, please contact researchrepository@mail.wvu.edu. 


\title{
Route and Grade Sensitive Modeling of Fuel Efficiency and Emissions for Diesel Buses
}

\section{ABM Siddiqur Rahman Khan}

\author{
Dissertation submitted to the \\ College of Engineering and Mineral Resources \\ At West Virginia University \\ In Partial Fulfillment of the Requirements \\ For the degree of
}

\section{Doctor of Philosophy \\ In \\ Mechanical Engineering}

\author{
Nigel N. Clark, Ph.D., Chair \\ Mridul Gautam, Ph.D. \\ David R. Martinelli, Ph.D. \\ Jacky C. Prucz, Ph.D. \\ W. Scott Wayne, Ph.D. \\ Gregory J. Thompson, Ph.D. \\ Department of Mechanical and Aerospace Engineering \\ West Virginia University \\ Morgantown, West Virginia \\ 2009
}

Keywords: Transit Bus, Fuel Consumption, Average Speed,

Passenger Weight, Road Grade

Copyright 2009 ABM S Khan 


\section{ABSTRACT \\ Route and Grade Sensitive Modeling of Fuel Efficiency and Emissions for Diesel Buses}

ABM Siddiqur Rahman Khan

The growing population in urban areas necessitates sustainable transportation policies that encourage reduction of vehicle miles traveled (VMT) through the use of energyefficient vehicles, efficient land-use planning, and use of public transportation including transit bus. Transit buses in the United States are powered most frequently with diesel engines, followed by compressed natural gas, liquefied natural gas, and hybrid-electric diesel engines. Transit operators seek to reduce fuel consumption (FC) of their buses and also reduce emissions of criteria pollutants and greenhouse gas (GHG). The FC of transit buses and their emissions are mostly influenced by drive cycle characteristics, passenger loading, and terrain conditions, including road grade. This dissertation developed a model for predicting FC of transit buses from average speed, passenger weight, and road grade. Chassis dynamometer bus emissions and FC data, collected from thirteen 40-foot transit buses driven with diesel, lean-burn compressed natural gas (CNG), and diesel hybrid-electric technologies were analyzed in this dissertation.

The study first analyzed the characteristics of twenty-three chassis duty cycles to determine the most important parameters that affected $\mathrm{FC}$ and emissions. The analysis showed that cycle properties such as standard deviation of average speed, percentage of idle, characteristic acceleration, kinetic intensity, and stops per unit distance were closely related with cycle average speed. A cycle with low average speed contained stop-and-go behavior, with multiple accelerations and decelerations, whereas a high vehicle speed cycle was steadier. In this way, average speed was found to be inter-related to other cycle properties.

The experimental data were collected on a subset of twenty-three test cycles. Average speeds of these cycles were found to have substantial effect on distance-specific emissions of some species and FC from the thirteen buses. Distance-specific oxides of nitrogen (NOx) and FC demonstrated a good correlation with average speed. The highest NOx emissions and FC were observed on the slowest speed cycle, the New York Bus Cycle. The highest speed cycle, the Commuter Cycle, exhibited the lowest NOx and had the lowest FC. Hydrocarbon (HC) emissions from diesel and hybrid-electric buses and carbon monoxide $(\mathrm{CO})$ and particulate matter $(\mathrm{PM})$ from all these buses were too low to permit reliable determination of a trend. It was realized that more cycles with average speed greater than $25 \mathrm{mph}$ were needed to better predict this correlation. Therefore, some artificial cycles were created with average speed greater than $25 \mathrm{mph}$. These new cycles also demonstrated strong correlation between NOx emissions and FC from these buses and their average speeds. 
Passenger weight effect on emissions and FC was examined using the road-load equation and a simple model for drivetrain efficiency and auxiliary loads. Analysis showed that FC was affected by the power demanded of the engine, which was also governed by the operating weight of the bus. A prediction model was developed to project the ratio of FC of an empty passenger bus and to FC of a full passenger bus. This predictive model was then compared with emissions and FC data collected on three drive cycles from 40-foot diesel and natural gas buses at empty passenger weight, half passenger weight, and full passenger weight. The experimental data showed that a $28 \%$ increase in weight yielded about $12 \%$ increase in FC but no significant increase in NOx emissions from natural gas buses, while for the diesel bus a 32\% increase in weight yielded about a 19\% increase in $\mathrm{FC}$ and about a $14 \%$ increase in NOx emissions, on average. However, changes in NOx emissions for corresponding small change in passenger weight did not follow any clear trend. $\mathrm{CO}, \mathrm{HC}$, and PM from these buses also did not follow any trend with passenger weight.

Weight effect was followed by analyzing the effect of road grade and terrain on FC of a transit bus. Two inputs, the type of terrain and the percentage of grade, needed to be determined in order to compute the increase in FC for grade. While it was comparatively simple to determine the terrain type, it was complex to determine the road grade for a bus route. This problem was compounded by the fact that all bus routes started and ended at the same point so that no grade could be ascertained. This model addressed this issue by assigning a sinusoidal road grade with a specified maximum positive or negative grade. It was observed from the road-load equation that grade effect depended only on the ratio of power demanded with grade to power demanded without grade provided the vehicle operated at a fixed weight and had uniform auxiliary power during its operation. This analysis was then applied to a number of drive cycles to determine the effect of road grade on FC for varying grades on rolling and mountainous terrain. The analysis showed that the effect of road grade on FC was also speed dependant.

These analyses were combined to construct a predictive model for FC for a 40-foot diesel bus for a particular route, where the average speed was determined by an empirical relationship involving cycle duration, maximum speed, and number of stops per unit distance. The average speed was then used to calculate FC from the relationship developed in speed analysis, followed by determination of the weight correction factor for full as well as no passenger weight buses. Finally, a grade correction factor was applied to complete the FC model. The predictive FC model was expected to provide an insight into the planning and selection of bus technologies for route choice. It was noted that this model was developed for 40-foot diesel buses. Therefore, development of FC models for 40-foot CNG and hybrid-electric buses and 60-foot articulated buses of all technologies were recommended for cost-effective procurement of bus technologies and efficient bus scheduling. 


\section{TABLE OF CONTENTS}

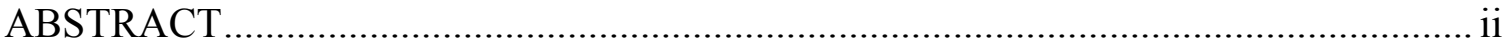

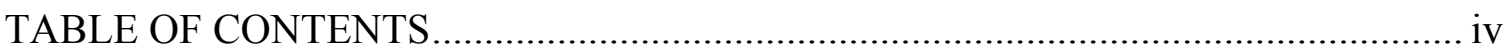

LIST OF TABLES ………....................................................................................... vii

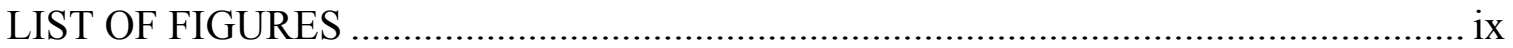

LIST OF ABBREVIATIONS AND SYMBOLS …………........................................

ACKNOWLEDGEMENTS ................................................................................

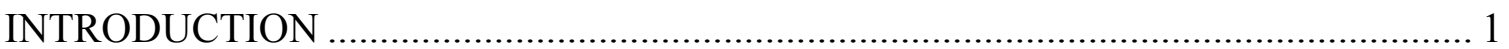

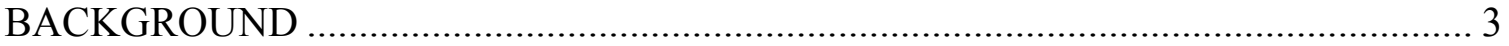

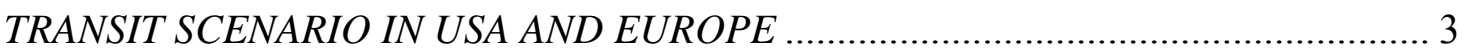

REGULATED AND NON-REGULATED EMISSIONS FROM TRANSIT BUSES ......... 3

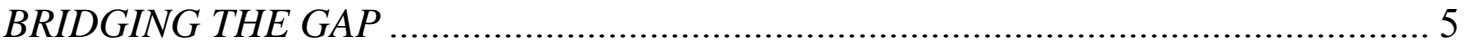

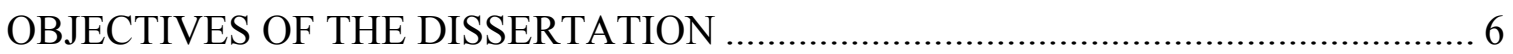

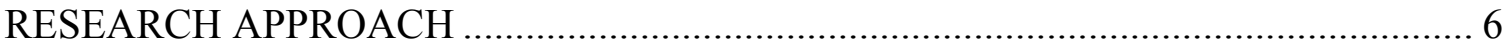

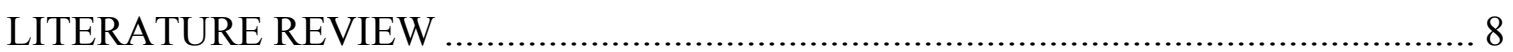

THE ROAD-LOAD EQUATION ……………………………………………….... 11

ANALYSIS OF THE CHASSIS DUTY CYCLE ..................................................... 13

EMISSIONS DATA CONSIDERED FOR THE DISSERTATION................................ 19

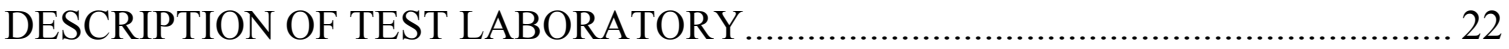

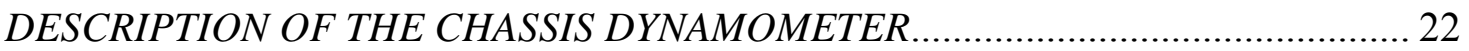

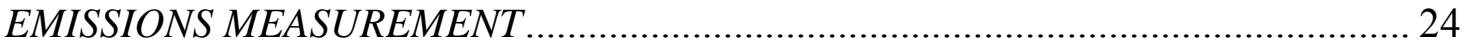

SPEED EFFECT ON EMISSIONS AND FUEL CONSUMPTION ............................... 25 


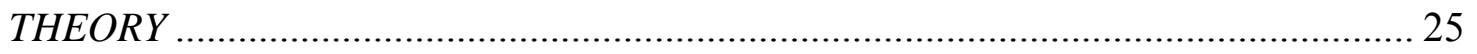

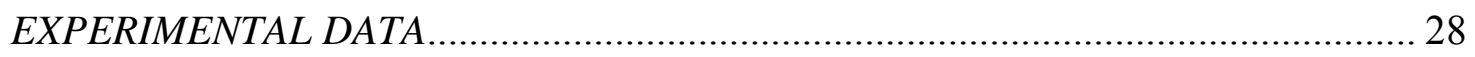

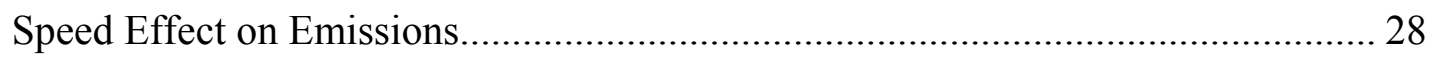

Speed Effect on Fuel Consumption ......................................................................... 31

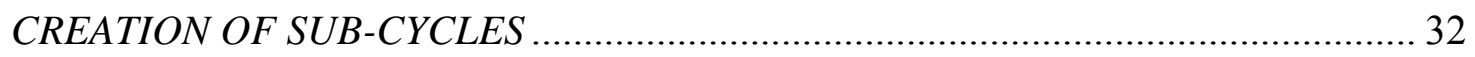

RE-EXAMINATION OF EMISSIONS AND FUEL CONSUMPTION TREND WITH

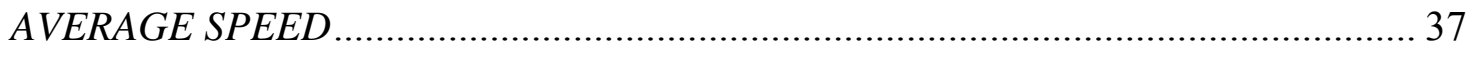

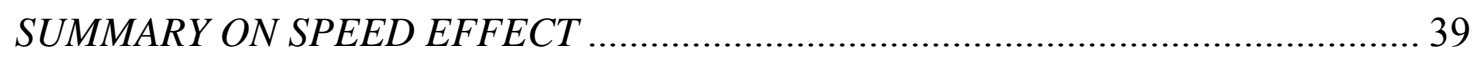

EFFECT OF PASSENGER WEIGHT ON FUEL CONSUMPTION AND EMISSIONS

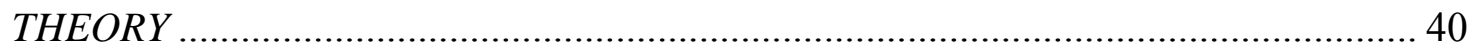

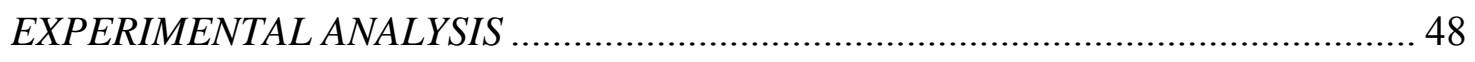

John Deere CNG Bus ......................................................................................... 48

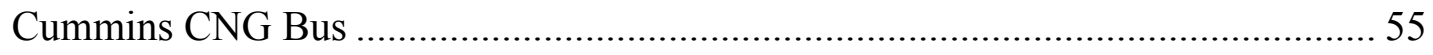

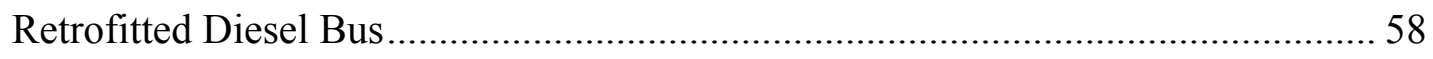

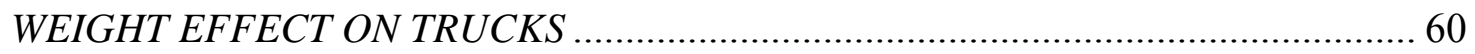

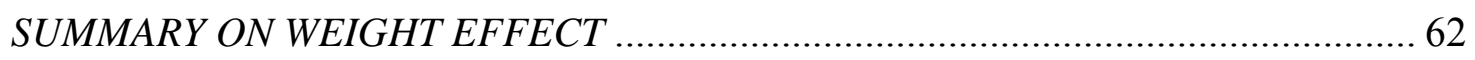

EFFECT OF ROAD GRADE AND TERRAIN ON FUEL CONSUMPTION ................ 64

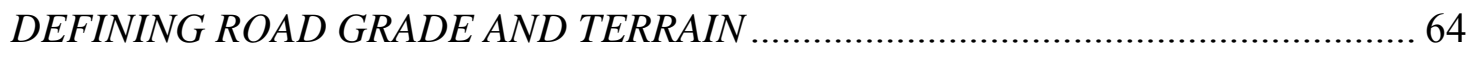

MODELING ROAD GRADE EFFECT ON FUEL CONSUMPTION N......................... 67

EFFECT OF ROAD GRADE ON FUEL CONSUMPTION FOR SELECTED DUTY

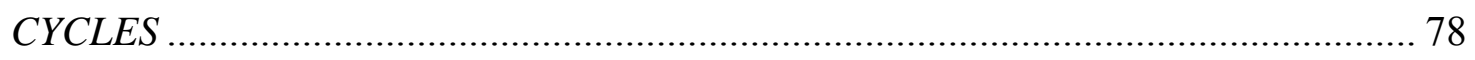

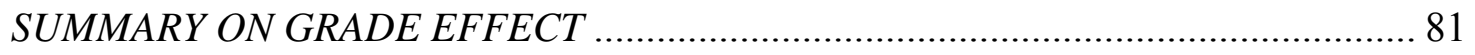


MODELING FUEL CONSUMPTION FOR A DIESEL TRANSIT BUS .................... 82

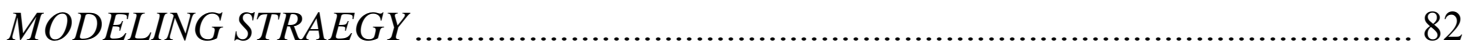

STEP I: DETERMINING AVERAGE SPEED FROM TRIP DURATION, SPEED

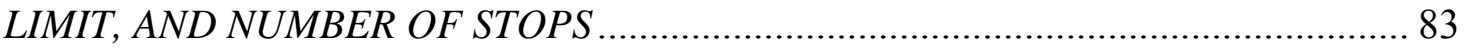

STEP II: DETERMINING FUEL CONSUMPTION FROM AVERAGE SPEED........ 85

STEP III: DETERMINING CORRECTION FACTOR FOR PASSENGER WEIGHT.. 86 STEP IV: DETERMINING CORRECTION FACTOR FOR TERRAIN AND ROAD

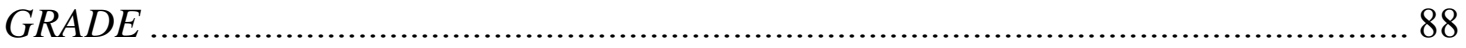

STEP IV: VALIDATING THE MODEL WITH REAL-WORLD FC DATA ................. 91

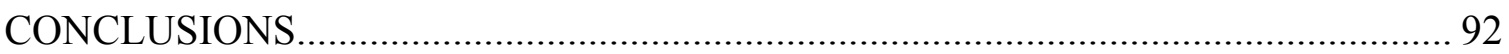

RECOMMENDATIONS FOR FUTURE RESEARCH........................................... 95

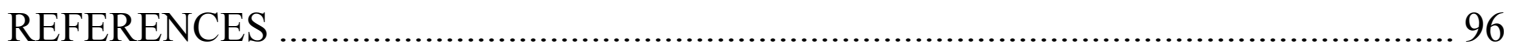

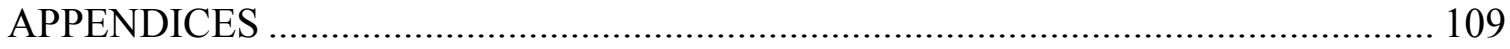

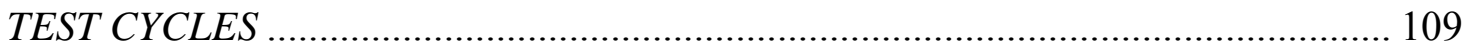

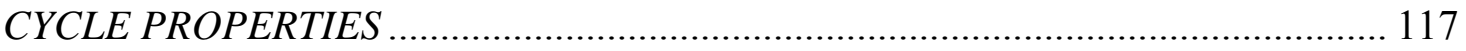

EMISSIONS AND FUEL CONSUMPTION (FC) DATA....................................... 118 


\section{LIST OF TABLES}

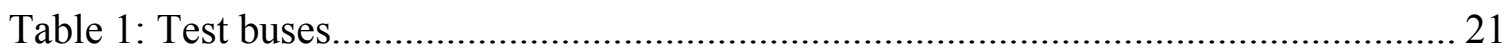

Table 2: Wind drag, rolling resistance, inertia, and total load at empty weight, half weight, and full weight over the OCTA Cycle

Table 3: Wind drag, rolling resistance, inertia, and total load at empty weight, half weight, and full weight over the Paris Cycle

Table 4: Wind drag, rolling resistance, inertia, and total load at empty weight, half weight, and full weight over the Braunschweig Cycle 42

Table 5: Percentage increase in FC due to road grade on the NYBus Cycle................... 79

Table 6: Percentage increase in FC due to road grade on the Paris Cycle........................ 80

Table 7: Percentage increase in FC due to road grade on the OCTA Cycle.................... 80

Table 8: Percentage increase in FC due to road grade on the Braunschweig Cycle......... 80

Table 9: Percentage increase in FC due to road grade on the KCM Cycle .................... 81

Table 10: Projected FC for diesel buses for selected average speed ........................... 86

Table 11: GCF developed for 3\% road grade on a rolling terrain ................................ 90

Table 12: GCF developed for 3\% road grade on a mountainous terrain ........................ 90

Table 13: Relevant properties of drive cycles, in order of ascending average speed .... 117

Table 14: Summary of emissions and FC data from the three John Deere lean-burn CNG

buses (cycle name is followed by bus number mentioned in Table 1).

Table 15: Summary of emissions and FC data from the three Cummins lean-burn CNG

buses

Table 16: Summary of emissions and FC data from the two Retrofitted DDC diesel buses 
Table 17: Summary of emissions and FC data from the two Cummins ISM diesel buses

Table 18: Summary of emissions and FC data from the three diesel hybrid-electric buses 


\section{LIST OF FIGURES}

Figure 1: The ADEME-RATP Paris Cycle................................................................. 14

Figure 2: The Orange County (OCTA) Cycle .............................................................. 14

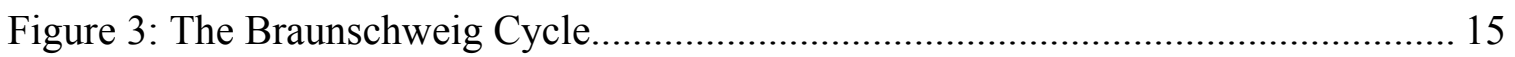

Figure 4: The King County (KCM) Cycle with Road Grade........................................... 15

Figure 5: Variation of percentage idle, stops per mile, and standard deviation of speed

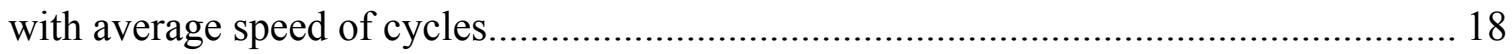

Figure 6: Correlation of aerodynamic speed, characteristic acceleration, and kinetic

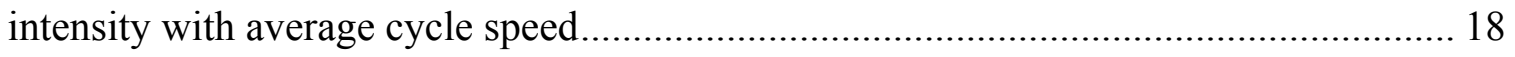

Figure 7: The Mexico City Schedule (MCS), the MX1, MX2, and MX3 cycles............. 19

Figure 8: View of a John Deere natural gas bus placed on the dynamometer.................. 23

Figure 9: Hub adapters connect vehicle's drive axle directly to the power absorber unit 23

Figure 10: Instantaneous wind drag, rolling resistance, inertia, and total load during the

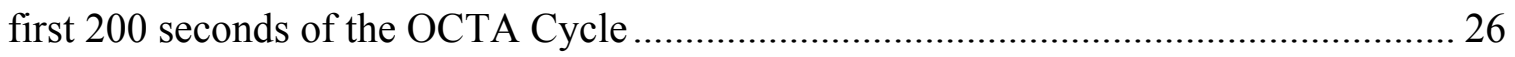

Figure 11: Instantaneous wind drag, rolling resistance, inertia, and total load during the

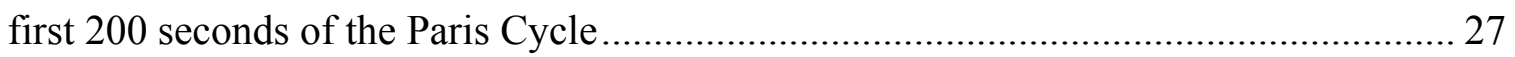

Figure 12: Instantaneous wind drag, rolling resistance, inertia, and total load on the Commuter Cycle

Figure 13: Distance-specific CO emissions from the hybrid-electric, Cummins ISM diesel, Retrofitted diesel, John Deere CNG, and Cummins CNG buses ........................... 29

Figure 14: Distance-specific HC emissions from the hybrid-electric, Cummins ISM diesel, Retrofitted diesel, John Deere CNG, and Cummins CNG buses . 
Figure 15: Distance-specific NOx emissions from the hybrid-electric, Cummins ISM diesel, Retrofitted diesel, John Deere CNG, and Cummins CNG buses ........................ 30

Figure 16: Distance-specific PM emissions from the hybrid-electric, Cummins ISM diesel, Retrofitted diesel, John Deere CNG, and Cummins CNG buses 30 Figure 17: Fuel consumption in diesel equivalent gallon per mile (gal/mile) from the hybrid-electric, Cummins ISM diesel, Retrofitted diesel, John Deere CNG, and Cummins CNG buses .

Figure 18: Comparison of FC from hybrid buses with diesel and CNG buses and their

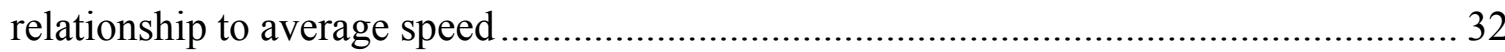

Figure 19: Average speed of chassis cycles used in WMATA program ........................ 33

Figure 20: The KCM2 Cycle with the first 950 seconds of the KCM Cycle.................... 34

Figure 21: The KCM3 Cycle with the first 770 seconds of the KCM Cycle.................... 35

Figure 22: The KCM4 Cycle with the first 570 seconds of the KCM Cycle.................... 35

Figure 23: Variation of percentage idle and stops per mile with average cycle speed when $\mathrm{KCM} 2, \mathrm{KCM} 3$, and KCM4 cycles were included. 36

Figure 24: Correlation of standard deviation of speed and square root of the ratio of kinetic energy and average speed with cycle average speed when KCM2, KCM3, and KCM4 cycles were included.

Figure 25: NOx trend with average speed. Note that NOx emissions calculated for the new KCM sub-cycles fit well with the trend 38 Figure 26: FC trend with average speed. Note that FC calculated for the new KCM subcycles fit well with the trend 38 
Figure 27: Comparison of rolling resistances for the three test weights on the first 100 seconds of the Braunschweig Cycle

Figure 28: Comparison of inertia loads for the three test weights on the first 100 seconds of the Braunschweig Cycle....... 43

Figure 29: Comparison of total loads for the three test weights on the first 100 seconds of the Braunschweig Cycle 44

Figure 30: Predicted ratio of fuel consumption per unit time between empty weight and full weight with auxiliary power on the OCTA Cycle with drivetrain efficiency of $70 \%$, $75 \%$, and $80 \%$

Figure 31: Predicted ratio of fuel consumption per unit time between empty weight and full weight with auxiliary power on the OCTA, the Paris, and the Braunschweig cycles, with assumed drivetrain efficiency of $75 \%$.

Figure 32: Ratio of emissions and fuel consumption at empty weight and half weight to those at full test weight from the John Deere CNG bus on the OCTA Cycle

Figure 33: Ratio of emissions and fuel consumption at empty weight and half weight to those at full test weight from the John Deere CNG bus on the Paris Cycle

Figure 34: Ratio of emissions and fuel consumption at empty weight and half weight to those at full test weight from the John Deere CNG bus on the Braunschweig Cycle ...... 51 Figure 35: Comparison of the percentage of engine speed distribution for three test weights on the OCTA Cycle.

Figure 36: Comparison of the percentage of engine speed distribution for three test weights on the Paris Cycle 
Figure 37: Test-to-test variability of emissions from the John Deere bus at full weight on the OCTA Cycle. Note that the CO and PM scales were increased a 100 and a 1000 fold, respectively, while the $\mathrm{CO}_{2}$ scale was reduced a 100 fold 54 Figure 38: Test-to-test variability of emissions from the John Deere bus at half weight on the OCTA Cycle. Note that the CO and PM scales were increased a 100 and a 1000 fold, respectively, while the $\mathrm{CO}_{2}$ scale was reduced a 100 fold 55

Figure 39: Ratio of emissions and fuel consumption at empty weight and half weight to those at full test weight from the Cummins CNG bus on the OCTA Cycle. 56 Figure 40: Ratio of emissions and fuel consumption at empty weight and half weight to those at full test weight from the Cummins CNG bus on the Paris Cycle

Figure 41: Ratio of emissions and fuel consumption at empty weight and half weight to those at full test weight from the Cummins CNG bus on the Braunschweig Cycle

Figure 42: Ratio of emissions and fuel consumption at empty weight and half weight to those at full test weight from the retrofitted diesel bus on the OCTA Cycle.

Figure 43: Ratio of emissions and fuel consumption at empty weight and half weight to those at full test weight from the retrofitted diesel bus on the Paris Cycle ......

Figure 44: Ratio of emissions and fuel consumption at empty weight and half weight to those at full test weight from the retrofitted diesel bus on the Braunschweig Cycle 60 Figure 45: Theoretical ratio of FC between $30,000 \mathrm{lbs}, 56000 \mathrm{lbs}$, and 66,000lbs from thirty-six HHDDT calculated from the road load equation with 70\% drivetrain efficiency

Figure 46: Ratio of FC between 30,000lbs, 56000lbs, and 66,000lbs from thirty-six HHDDT 
Figure 47: Representation of road grade on OCTA Cycle against cycle duration for different terrains.

Figure 48: Representation of road grade on OCTA Cycle against distance traveled for different terrains. 66

Figure 49: Representation of road grade on OCTA Cycle for mountainous terrain determined from cycle time. 67

Figure 50: The Commuter Cycle with 5\% maximum road grade on a mountainous terrain

Figure 51: Comparison of the total load for a transit bus with and without road grade on the Commuter Cycle

Figure 52: Continuous rolling, inertia, and grade load for 5\% maximum road grade with no phase shift on the OCTA Cycle 70

Figure 53: Continuous rolling, inertia, and grade load for 5\% maximum road grade with 1.1 mile distance shift on the OCTA Cycle 71

Figure 54: Continuous rolling, inertia, and grade load for 5\% maximum road grade with no distance shift on the UDDS Cycle 72

Figure 55: Actual power demand to follow the speed-time trace on a flat grade..... 73

Figure 56: Actual (unrealistic) power demand to follow the speed-time trace with grade74 Figure 57: Modified (realistic) power demand to follow the speed-time trace with grade

Figure 58: Adjustment of grade load with service braking demonstrated on the KCM

Cycle from 1200 to $1600 \mathrm{sec}$ 
Figure 59: Relationship between the actual average speed and the projected average speed of selected cycles

Figure 60: Ratio of fuel consumption between full and half passenger weights and between half and no passenger weights. 87

Figure 61: Percentage increase in FC for different grade on rolling terrain....................89

Figure 62: Percentage increase in FC for different grade on mountainous terrain 89

Figure 63: The Arterial Cycle 109

Figure 64: The Beeline Cycle 109

Figure 65: The Central Business District (CBD) Cycle... 110

Figure 66: The City Suburban Heavy-Duty Vehicle Cycle (CSHVC)

Figure 67: The Commuter Cycle 111

Figure 68: The Cruise Mode of the HHDDT Schedule

Figure 69: The Dutch Urban Bus Driving Cycle (DUBDC)

Figure 70: The European Transient Cycle (ETC), segment 1 (ETC-URBAN). 112

Figure 71: The Japan Transient Driving Cycle (JE05)

Figure 72: The Manhattan Cycle 113

Figure 73: The New York Bus (NYBus) Cycle. 114

Figure 74: The New York Composite (NYComp) Cycle. 114

Figure 75: The Transient Phase of the HHDDT Schedule ..... 115

Figure 76: The Urban Dynamometer Driving Schedule (UDDS) 115

Figure 77: The Washington Metro Area Transit Authority (WMATA) Cycle 116

Figure 78: The WVU 5-Peak Cycle. 116 


\section{LIST OF ABBREVIATIONS AND SYMBOLS}

\section{Symbol}

A

$\mathrm{C}_{\mathrm{D}}$

$\mathrm{C}_{\mathrm{w}}$

$\mathrm{g}$

$\mathrm{HP}_{\text {Aux }}$

$\mathrm{m}$

$\mathrm{m}_{\mathrm{f}}$

Ns

$\mathrm{Pt}$

QHV

$\mathrm{S}_{\mathrm{a} / \mathrm{d}}$

$\mathrm{S}_{\mathrm{T}}$

$\mathrm{t}$

$\mathrm{T}_{\mathrm{a} / \mathrm{d}}$

$\mathrm{T}_{\text {cycle }}$

$\mathrm{T}_{\mathrm{s}}$

$\mathrm{V}$

$\mathrm{V}_{\text {avg }}$

$\mathrm{V}_{\max }$

Z

$\eta_{\mathrm{d}}$

$\eta_{\mathrm{f}}$

$\mu$

$\rho$

\section{Description}

Frontal Area of Bus in $\mathrm{m}^{2}$

Aerodynamic Drag Coefficient

Wind Speed Coefficient

Acceleration due to Gravity in $\mathrm{m} / \mathrm{sec}^{2}$

Auxiliary Horsepower

Mass in $\mathrm{kg}$

Fuel Consumption per Unit Time

Total Number of Stops

Total Power in $\mathrm{kW}$

Fuel Heating Value

Distance Covered in Acceleration/Deceleration in mile

Total Distance of a Cycle in mile

Time in seconds

Average Time Taken for Acceleration and Deceleration in $\mathrm{hr}$

Duration of a Cycle in hr

Duration of a Stop in $\mathrm{hr}$

Velocity in $\mathrm{m} / \mathrm{sec}$

Projected Average Speed in mph

Speed Limit or Maximum Speed of a Cycle in mile per hr

Road Grade in \%

Drivetrain Efficiency

Fuel Conversion Efficiency

Rolling Resistance Coefficient

Air Density in $\mathrm{kg} / \mathrm{m}^{3}$ 


\section{Abbreviations}

AASHTO

ACEEE

ADVISOR

AFV

AHP

ANN

APTA

BHP

BWI

CAFEE

CARB

CBD

CFR

$\mathrm{CH}_{4}$

$\mathrm{CNG}$

$\mathrm{CO}$

$\mathrm{CO}_{2}$

CSHVC

DDC

DFNG

DUBDC

EIA

ESS

EMFAC

EPA

ETC

EW

FC
American Association of State Highway and Transportation

Officials

American Council for an Energy-Efficient Economy

Advanced Vehicle Simulator

Alternative Fueled Vehicles

Axle Horsepower

Artificial Neural Network

American Public Transportation Association

Brake Horsepower

Baltimore/Washington International Airport

Center for Alternative Fuels, Engines, and Emissions

California Air Resources Board

Central Business District

Code of Federal Regulations

Methane

Compressed Natural Gas

Carbon Monoxide

Carbon Dioxide

City Suburban Heavy Vehicle Speed Distance Cycle

Detroit Diesel Corporation

Dual Fuel Natural Gas

Dutch Urban Bus Driving Cycle

Energy Information Administration

Energy Storage System

Emission Factors

Environmental Protection Agency

European Transient Cycle

Empty Test Weight

Fuel Consumption 


\begin{tabular}{ll} 
FTA & Federal Transit Administration \\
FW & Fully Loaded Test Weight \\
GCF & Grams per Hour \\
GHG & Grade Correction Factor \\
GVW & Greenhouse Gas \\
HC & Gross Vehicle Weight \\
HEB & Hydrocarbons \\
HHDDS & Hybrid-electric Buses \\
HW & Heavy Heavy-Duty Truck Driving Schedule \\
IAPT & Half Loaded Test Weight \\
IBIS & International Association of Public Transport \\
KCM & Integrated Bus Information System \\
kW & King County Metro \\
LNG & Kilowatts \\
MCS & Liquefied Natural Gas \\
MOVES & Mexico City Schedule \\
mph & Mobile Vehicle Emission Simulator \\
MY & Miles per Hour \\
NGV & Model Year \\
NMHC & Natural Gas Vehicles \\
NOx & Non-Methane Hydrocarbons \\
NREL & Oxides of Nitrogen \\
NTD & National Renewable Energy Laboratory \\
NTE & National Transit Database \\
NYBus & Not-to-Exceed \\
NYComp & New York Bus Cycle \\
O3 & New York Composite Cycle \\
OCTA & Ozone \\
PEMS & Orange County Transit Authority Cycle \\
PM & Portablens Measurement Systems \\
\hline & Particule \\
\hline
\end{tabular}




$\begin{array}{ll}\text { PSAT } & \text { Powertrain System Analysis Toolkit } \\ \text { rpm } & \text { Revolutions per Minute } \\ \text { SCF } & \text { Speed Correction Factor } \\ \text { SING } & \text { Spark-Ignited Natural Gas } \\ \text { UDDS } & \text { Urban Dynamometer Driving Schedule } \\ \text { VMT } & \text { Vehicle Miles Traveled } \\ \text { WCF } & \text { Weight Correction Factor } \\ \text { WMATA } & \text { Washington Metropolitan Area Transit Authority } \\ \text { WVU } & \text { West Virginia University }\end{array}$




\section{ACKNOWLEDGEMENTS}

I take this unique opportunity to thank and salute my friend Dr. Nigel Clark, George B. Berry Chair of Engineering and Professor, Department of Mechanical and Aerospace Engineering. I am grateful for his continued academic and financial support during my Ph.D. program at the West Virginia University. His opinions, suggestions, and continued guidance in completing this dissertation are highly appreciated. I would also like to convey my gratitude to Drs. Mridul Gautam, David R. Martinelli, Gregory J. Thompson, and W. Scott Wayne and Graduate Program Director, Dr. Jacky Prucz, who were kind enough to serve in my committee. Their suggestions and constructive criticisms were highly valuable in making this final product.

I gratefully acknowledge the support from the sponsors of this Study; the U.S. Department of Energy (DE-FG26-90CH10451) and the U.S. Department of Transportation (WV-26-7006-00). I am also grateful to all engineers and technicians of the CAFEE Transportable Laboratories including David McKain, who despite their busy schedule gave their valuable time to provide me with bus emissions data. I am also indebted to Dr. Therese Langer, my supervisor at the American Council for an EnergyEfficient Economy (ACEEE), for allowing the requisite time from office work in order to complete my graduation.

Finally, I would like to pay special tribute to my family members who sacrificed a lot for me. My special thanks to my father, father-in-law, and my wife who helped me realize my dream. May God bless them all! 


\section{INTRODUCTION}

According to the United States (U.S.) Census Bureau [1] the world population is expected reach the nine billion mark by 2043 with nearly all of these growth concentrated in urban areas [2]. Molina et al. [2] have projected that about $60 \%$ of the world population would live in urban areas by 2030. In the U.S. there will be about twenty million additional urban residents by 2050 [3]. High concentration people coupled with their high income, and concentration of wealth in urban areas generate high economic growth in urban areas [2]. This economic growth necessitates sustainable transportation system in urban areas that encourages the use of energy-efficient but cost-effective vehicle technologies and reduction of vehicle miles traveled (VMT). Sustainable transportation also encompasses the integration of land use transportation planning, the use of less polluting public transit systems, integration of transportation modes, and improvement in environmental quality [4-5].

Public transportation in the form of buses and light rail service provides efficient transportation to urban population. Bus transport is the most desirable and sustainable system from societal perspective because a well designed bus system can provide high level of mobility to large population with least cost [6]. The buses are also the dominant form of public transportation in cities and urban areas. They carried more than half of public transport riders and accounted for about $40 \%$ of the transit passenger miles in the U.S. in 2007 [7].

Most buses in the U.S. are operated by public agencies. The primary purpose of these operators is to present an efficient mobility at low cost. Transit operators seek to reduce the fuel consumption (FC) of their buses in order to minimize operating costs and maximize revenue. Transit agencies also need to make a delicate balance with some generic concerns including the choice of appropriate bus technology, selection bus size for route optimization, diversification of energy, and improving emissions of criteria pollutants. Consider a transit agency faced with a procurement choice. It may need to operate its buses in a variety of duty cycles including stop-n-go traffic, medium and high 
speed cycles, and rural road network. These duty cycles may have occasional or continuous road grade with varying terrains and may generate variable ridership. The choice of buses is likely to vary by route. For example, hybrid-electric technology is well suited to city traffic with repeated stop-n-go behavior. Also, a 60-foot articulated bus can be employed in routes with high ridership turnout. Transit agencies, therefore, need to consider carefully the procurement of new buses and their application. Emissions and FC models for each bus technology for different applications can assist transit operators in selecting appropriate bus technology for efficient route management. For the optional selection of the buses for procurement, an overarching model which can be used to execute and compare purchase scenarios is desirable. This overarching model would necessarily include sub-models addressing performance of each type of commercially available bus technology.

This dissertation develops a FC sub-model for the most common technology, diesel transit bus with conventional drive. Average speed, passenger loading, and road grade are primary inputs for this model. This model is intended for transit managers and operators that can be used in their procurement decision and route scheduling. It can be utilized for the optimization of bus routes and help operate a cost-effective fleet.

WVU is engaged in developing a comprehensive transit bus procurement tool which will allow users to predict FC and emissions for transit bus fleet through a cooperative agreement with the Federal Transit Administration (FTA). The FC sub-model, proposed in this dissertation, will lead to the development of a comprehensive procurement tool when combined with similar models addressing other available bus technologies. That comprehensive model will be an online tool named 'The Integrated Bus Information System (IBIS)' [8]. It will help fleet managers in purchasing appropriate new technology buses and assess their FC and emissions footprint. 


\section{BACKGROUND}

\section{TRANSIT SCENARIO IN USA AND EUROPE}

Diesel buses dominate the transit fleets across the United States. Transit fleets with alternative fueled vehicles (AFV) including compressed natural gas (CNG), liquefied natural gas (LNG), and hybrid-electric drive systems have made significant penetration in recent years, although biodiesel penetration in the transit sector is still very low. The 2007 National Transit Database (NTD) published by the FTA in October 2008 showed that about $22 \%$ of transit agencies used AFV in their fleet in 2007 compared to $6 \%$ in 1998 [9]. A 2005-2006 survey by the American Public Transportation Association (APTA) revealed that approximately $81 \%$ of transit buses are powered by conventional and clean diesel engines while $\mathrm{CNG}$ was the second-most used power source, driving approximately $7.5 \%$ of the transit buses and LNG was employed to power approximately $1.5 \%$ of transit buses [10] in the United States. The survey also revealed that demand for hybrid-electric buses (HEB) had increased significantly in recent years. Transit data released in 2009 by the Energy Information Administration (EIA) [11] showed that about $970 \mathrm{CNG}$ buses were introduced in 2007, while in 2008 it increased by about $3.5 \%$ to 1004 buses. During the same period, diesel hybrid-electric buses increased by about $30 \%$, from 686 in 2007 to 891 in 2008. In Europe, over 90\% of the urban transit fleet was diesel powered while the remaining $10 \%$ was shared by CNG, LNG, biodiesel, and electric vehicles [12]. There, the hybrid-electric buses represented a very small share (about $0.25 \%$ ) of the total bus fleet although they were making increased penetration.

\section{REGULATED AND NON-REGULATED EMISSIONS FROM TRANSIT BUSES}

Diesel vehicles including transit buses are a known source of carbon monoxide (CO), carbon dioxide $\left(\mathrm{CO}_{2}\right)$, hydrocarbons $(\mathrm{HC})$, oxides of nitrogen ( $\left.\mathrm{NOx}\right)$, particulate matter (PM), and other toxic gases and pollutants. NOx, HC, and PM are precursors to ozone $\left(\mathrm{O}_{3}\right)$ and $\mathrm{PM}$ contributes to urban and regional smog [13]. CO and PM have been linked to toxic effects and PM is a possible carcinogen. 
Three types of natural gas vehicles (NGV) are generally available. The first type, called Bi-Fuel NGV, operate either on natural gas or gasoline. These types of vehicles are popularly adopted in third world countries and also represented some of the early lightduty CNG fleet in USA. The second type is called dual-fuel natural gas (DFNG), where the vehicle can be fueled with diesel alone or combination of diesel and natural gas. The third type includes dedicated NGV, which are spark-ignited natural gas (SING) vehicles employing either stoichiometric or lean-burn air-fuel (A/F) management systems. $\mathrm{CNG}$ buses produce far less PM than diesel buses on a mass basis without exhaust filtration, and have historically produced lower NOx than diesel buses. They have also produced comparatively lower $\mathrm{CO}$ emissions but suffered from a fuel economy penalty when the calculation is based on energy equivalence of diesel and natural gas. CNG vehicles have also produced more HC mass than their diesel counterparts. However, most of the HC mass consists of methane, which is a greenhouse gas (GHG), but does not contribute to smog formation. Emissions from $\mathrm{CNG}$ vehicles across North America and Europe have been well documented in numerous published studies [14-35].

A hybrid-electric vehicle combines the internal combustion engine of a conventional vehicle with the high-voltage battery and electric motor of an electric vehicle [36]. It includes a power unit, such as a diesel, gasoline or CNG engine, one or more electrical machines (motors or generators), and an energy storage system (ESS) that can be charged by the engine or by regenerative braking [33]. As a result, hybrid-electric buses offer FC reduction and produce lower PM and NOx emissions than their diesel counterparts. Emissions and FC benefits from diesel hybrid-electric vehicles have also been well documented in published studies [37-44]. Results of these studies showed that average NOx emissions from hybrid-electric buses were about 25-30\% lower than those from conventional diesel buses while average fuel economy of the hybrid-electric buses was about $20-25 \%$ higher than that from diesel buses. However, the percentage of FC benefit from the hybrid buses is route dependant. It has been found that the percentage of FC benefits from hybrid-electric buses is more than their diesel counterpart at low speed operation with more stops per unit distance. 
Emissions from heavy-duty on-road diesel engines in the U.S. are regulated by the Environmental Protection Agency (EPA) through a set of standards that limits the engine out emissions expressed in grams per brake horsepower-hour (g/bhp-hr) [45]. The engine for this purpose is exercised through an engine speed-torque schedule while emissions are collected and analyzed, and expressed per unit of brake horse power (bhp). However, this method has inherent limitations. The engine is tested without its chassis and without considering freight or passenger weights, accessories, or real-world driving characteristics [46]. In order to test the complete vehicle in real-world conditions a chassis dynamometer is used where a test can be performed conveniently and repeatedly. In chassis dynamometer testing a complete vehicle is exercised through a speed-time schedule and emissions are collected and analyzed. Collected emissions are expressed per unit distance in grams per mile (g/mile) or per unit time in grams per hour $(\mathrm{g} / \mathrm{hr})$. However, chassis dynamometer data are not accepted for certification purpose for transit buses.

Also, speed-time schedules of drive cycles used in chassis dynamometer testing may not truly represent the real-world driving characteristics. Chassis results may not incorporate the effect of road grade and varying passenger weight on fuel consumption (FC) and emissions. Therefore, there is a need for a correction factor on the chassis data so that they accommodate the effect of varying passenger weight and road grade terrain. 


\section{OBJECTIVES OF THE DISSERTATION}

The primary objective of this dissertation was to model FC for diesel-powered transit buses to assist in bus selection for specific routes. Other major objectives associated with this dissertation are listed as follows.

a. To examine the effect of speed, weight, and road grade on FC and emissions from transit buses tested on chassis dynamometers.

b. To analyze available chassis duty cycles with a view to determining the most important parameters affecting the development of a duty cycle and vis-à-vis FC and emissions.

c. To develop a methodology in order to predict average speed of transit bus for particular route from the speed limit of that route, its duration, and the number of bus stops on that route.

d. To create a set of sub-cycles with average speed greater than 20 miles per hour (mph) that facilitates better prediction of emissions and FC with average speed.

e. To develop a prediction model in order to project the change in $\mathrm{FC}$ for a corresponding change in passenger weight.

f. To observe the effect of varying road grade and terrain on FC and develop a model to predict change in FC due to road grade.

\section{RESEARCH APPROACH}

The research structure for the above mentioned objectives was developed as follows:

Phase 1. Speed effect on emissions and FC

a. Analysis of the road-load equation.

b. Analysis of the available chassis duty cycles.

c. Examination of the effect of average speed on emissions and FC.

d. Creation of sub-cycles and further examination of emissions and FC. 
Phase 2. Effect of passenger weight on FC and emissions

a. Development of a prediction model to account for the effect of passenger weight on emissions and FC.

b. Validation of this model with emissions data collected from 40-foot transit buses and heavy-duty diesel trucks.

Phase 3. Analysis of road grade and terrain and their effects on FC

a. Defining road grade and terrain and analyze their effect on FC.

b. Development of a prediction model to show the effect of road grade on FC for diesel buses for varying road grade and terrain.

These phases were preceded by a comprehensive literature search on the effects of vehicle speed, weight and road grade on emissions and FC. 


\section{LITERATURE REVIEW}

Effects of average speed on distance-specific emissions from light-duty and heavy-duty diesel vehicles have been well documented [47-55]. However, limited research has been published to show the effect of driving cycle speed on cycle-averaged emissions and FC from heavy-duty NGV. In recent years research has addressed development of emissions models for heavy-duty vehicles. Ramamurthy et al. [49] explored the relationship between a heavy-duty vehicle's tailpipe emissions and its axle power. For diesel vehicles both $\mathrm{CO}_{2}$ and NOx have shown a reliable relationship with axle power, but $\mathrm{CO}$ emissions, being cycle specific, could not be modeled reliably. Ramamurthy et al. acknowledged that it was possible to estimate emissions for one driving cycle using a model developed from other driving cycles, but some cycle-specific events could take place due to the unique speed-acceleration characteristics of that cycle, which was explained in detail by Taylor et al. [56]. Some efforts were also made to understand the effect of drive cycles on emissions and FC. Clark et al. [50] examined a speed correction factor (SCF), a power based model, and an artificial neural network (ANN) model to predict emissions from diesel-powered heavy-duty trucks. The SCF, power based model, and ANN approach yielded about 27\%, 19\%, and 10\% errors, respectively. Prior research [51-55] has also established that the nature of a chassis dynamometer test cycle affected the emissions level. Yanowitz et al. [51] compared emissions from three cycles and found distance-specific emissions were higher on slow speed cycles and lower on high speed cycles. However, when emissions were converted to fuel specific units of grams per gallon (g/gal), effects of driving cycles on NOx and PM emissions were eliminated. Clark et al. [52] concluded that the test cycle had a profound effect on PM emissions and a significant effect on NOx emissions and singled out drive cycles as one of the parameters that most heavily affected emissions from heavy-duty diesel vehicles. Brodrick et al. [54] observed that $\mathrm{NOx}, \mathrm{CO}$, and $\mathrm{HC}$ emissions were affected by operating characteristics including speed. They also developed a NOx prediction model based on weight and operating mode, which yielded closer agreement with actual values. Nine et al. [55] evaluated emissions from two heavy-duty diesel trucks using a number of cycles and observed that NOx from a truck varied by nearly a factor of seven, being the highest for a 
low speed, high idle content cycle, and the lowest for a highway cycle. Both the EPA Motor Vehicle Emission Simulator (MOVES) [57] emissions model and the California Air Resources Board (CARB) EMission FACtors (EMFAC) model [58] acknowledge the effects of average vehicle speed on emissions and FC.

Research using chassis dynamometers and on-board portable emissions measurement systems (PEMS) has begun to provide insight into the effect of driving cycle, vocation or activity on heavy-duty vehicles, but the effect of vehicle weight on emissions is still not well recorded. Clark et al. [18] examined the effect of bus weight on emissions and FC from a 1996 New Flyer, Detroit Diesel Corporation (DDC) Series 50, 275 horsepower (hp) diesel bus in Flint, Michigan. That bus was tested on the Central Business District (CBD) Cycle at its curb weight of 27,758 pounds (lbs), at customary test weight $(32,843$ $\mathrm{lbs}$ ), and at the gross vehicle weight (GVW) of 38,072 lbs. FC from this bus was found to increase with increasing test weights. Distance-specific NOx emissions in grams per mile ( $\mathrm{g} /$ mile) were less affected by test weight while $\mathrm{HC}$ did not vary at all under these load conditions. $\mathrm{CO}$ and PM increased with increasing test weights. Gajendran et al. [59] provided an analysis for the effect of weight on FC and emissions and observed that NOx emissions from a 1989 DDC6V-92TA transit bus tested on the CBD Cycle and the New York Composite Cycle [60] and three tractor trucks (1994 Cummins M11-330E, 1995 Mack E7-350, and 1998 Cummins N14 Celect), tested on the City Suburban Heavy Vehicle Speed Distance Route (CSHVR) [61] had a nearly linear correlation with vehicle weight. Brodrick et al. [54] also observed the increasing trend of NOx with increasing weight from a 1999 Class 8 diesel truck. Strimer et al. [62], using on-board measurement techniques, examined the relationship between $\mathrm{NOx}$ and $\mathrm{CO}_{2}$ emissions and test weight, in the not-to-exceed (NTE) zone [63]. $\mathrm{NOx}$ and $\mathrm{CO}_{2}$ were evaluated driving a 1996 Peterbilt tractor truck powered by a Caterpillar $3406 \mathrm{E}$ engine on four different routes. Data showed that NOx increased by almost $50 \%$ for doubling of weight on two routes with high speed cruise. On another route with substantial hill climb, NOx increased almost in direct proportion to weight. These data were important because the use of NTE excluded low power operation and therefore, reflected the highest influence of weight on 
NOx and $\mathrm{CO}_{2}$ emissions. Clark et al. [64] presented limited data on weight effects for emissions from CNG buses.

Unlike vehicle speed and weight effect, road grade effect on FC and emissions from heavy-duty trucks and transit buses has not received much attention. Limited research has been accomplished to determine the road grade for a particular route and show theoretically the effect of road grade on FC. Pelkmans et al. [65] compared emissions and FC from three bus technologies at different road grade while Conley and Clark [66] considered the contribution of road grade in evaluating power and energy requirements to find the optimal method of sizing hybrid-electric vehicle components. Kern et al. [67] tested a 1998 model year (MY) International Tractor Truck fitted with a Cummins N-14 $435 \mathrm{hp}$ engine at 46,000 lbs test weight. Results showed that moderate road grade (less than 5\%) had little bearing while steep grade (more than 5\%) had considerable effect on NOx emissions. Thompson et al. [68] made an effort to include the effect of uphill driving on a chassis dynamometer and observed that $\mathrm{CO}, \mathrm{HC}, \mathrm{NOx}$, and FC increased at uphill driving but PM did not change much. However, their research acknowledged the uneasiness of drivers following an inclined trace during dynamometer testing. Samuel et al. [69] observed more than $100 \%$ increase in $\mathrm{CO}, \mathrm{HC}$, and $\mathrm{NOx}$, and about $45 \%$ increase in $\mathrm{CO}_{2}$ on a 1.4 liter, $100 \mathrm{hp}$ gasoline vehicle with simulated road grade of $+3 \%$. 


\section{THE ROAD-LOAD EQUATION}

Total power needed at the wheels was expressed by the road-load equation [70-74] applied to a transit bus as:

$P_{t}=m v(d v / d t)+0.5 C_{D} \rho A v^{3}+\mu m g v+m g v Z$

(Equation 1)

where, $\mathrm{m}$ was mass of the bus $(\mathrm{kg})$, $\mathrm{v}$ was speed of the bus $(\mathrm{m} / \mathrm{sec})$, A was frontal area of the bus $\left(\mathrm{m}^{2}\right)$, g was acceleration due to gravity $\left(9.81 \mathrm{~m} / \mathrm{sec}^{2}\right), \mathrm{C}_{\mathrm{D}}$ was aerodynamic drag coefficient, $\mu$ was tire rolling resistance coefficient, $\rho$ was air density, and $Z$ was road gradient $(\%) . \mathrm{P}_{\mathrm{t}}$ was the total power needed at the wheels and was expressed in kilowatts $(\mathrm{kW})$. In this equation the first term was referred to as the Inertia Load, the second term as the Wind Drag, the third term as the Rolling Resistance, and the last term was the Grade Load. Summation of these loads resulted in the "total load or total power." This was also termed as 'tractive force' needed to propel the vehicle at any prescribed velocity and acceleration [75]. For the case of chassis dynamometer testing no road grade was incorporated in the vehicle load.

The wind drag in Equation 1 was defined as the force required to overcome the resistance to vehicle motion. It could also be expressed as $0.5 \mathrm{C}_{\mathrm{D}} \rho \mathrm{Av}^{3}\left(1+\mathrm{C}_{\mathrm{w}}\right)$ where, $\mathrm{C}_{\mathrm{w}}$ was wind speed coefficient which ranged from 0 to 0.2 [76]. The value of drag coefficient, $C_{D}$ for a standard bus used in the literature varied from 0.40 to 0.79 [77-79]. For a transit bus the drag force was found to be smaller compared to its inertia load, in the order of $3 \%$ on the Paris Cycle [14] to 20\% on the Commuter Cycle of SAE J1376 [80].

The rolling resistance was defined as the force needed to roll a vehicle over a surface and expressed as $\mu \mathrm{mgv}$. The rolling resistance coefficient, $\mu$ was influenced by tire size and pressure, axle geometry, and the amount of load applied to tires. The rolling resistance force was found to dominate the wind drag and inertia forces at low and steady operation while at high speed operation the wind drag dominated. The rolling resistance contributed to about $20 \%$ of the total load on the Orange County Transit Authority Cycle (OCTA) 
[81]. A reduction in rolling resistance contributed to decrease in FC. Previous research demonstrated that a $20 \%$ reduction in rolling resistance could yield as much as $2.5 \%$ reduction in FC [82]. The rolling resistance coefficient for a transit bus was found to vary from 0.005 when vehicle speed approached zero mile per hour (mph) speed to 0.011 when vehicle speed approached $56 \mathrm{mph}$ [77].

The road gradient, $Z$ was referred to as the slope between two adjacent points of intersection and it was expressed as \% [83]. The numerical value of $Z$ was calculated as the vertical rise $(+)$ or fall $(-)$ in meters $(\mathrm{m})$ for every $100 \mathrm{~m}[84,85]$. The gradient resistance in Equation 1 was defined as the force that was needed to overcome the force that the vehicle's weight produced where vehicle weight was always directed in the downward direction [76].

In this dissertation the variables in the road-load equation were considered as follows: the drag coefficient was assumed to be 0.79 , given in the Code of Federal Regulations (CFR) [79], rolling resistance coefficient was assumed to be 0.008 [35], air density was taken as $1.2 \mathrm{~kg} / \mathrm{m}^{3}$, and the bus frontal area, A was taken as $8.3 \mathrm{~m}^{2}$ for a typical 40 -foot transit bus. For the rolling resistance coefficient, a value of 0.008 was considered because a recent study in Mexico City included coast-down data that suggested 0.008 was a suitable value [86]. 


\section{ANALYSIS OF THE CHASSIS DUTY CYCLE}

Analysis of the characteristics of available drive cycles was expected to help in understanding the important properties of these cycles that affected emissions and FC and in examining inter-relationships among these properties. The drive cycles were identified with their speed-time characteristics. It was observed that average speed was one of the most important criteria that might be useful in defining any drive cycle.

The researcher has analyzed more than twenty chassis cycles widely used across the world for chassis dynamometer emissions testing. These cycles included the New York Bus Cycle (NYBus) [50], the ADEME-RATP Paris Cycle (Paris) [14], the Manhattan Cycle [81], the Washington Metropolitan Area Transit Authority (WMATA) Cycle [87], the Orange County Transit Authority Cycle (OCTA) [81], the Braunschweig Cycle [88], the New York Composite Cycle (NYComp) [89], the Central Business District Cycle (CBD) [80], the City Suburban Heavy Vehicle Cycle (CSHVC) [61], the first segment of the European Transient Cycle (ETC-Urban) [88], the Beeline Cycle [89], Transient and Cruise modes of the Heavy Heavy-Duty Truck Driving Schedule (HHDDTS) [90], the Urban Dynamometer Driving Schedule (UDDS), also known as “Test D” [79], the King County Metro Cycle (KCM) [44], the Arterial (ART) and Commuter (COMM) phases of SAE J1376 [80], the low speed (MX1), the medium speed (MX2), and the bus rapid transit designated (MX3) cycles of the Mexico City Schedule (MCS) [86], the Dutch Urban Bus Driving Cycle (DUBDC) [91], the Japan transient driving cycle for emissions testing from heavy-duty diesel and gasoline vehicles, the JE05 Cycle [88], the West Virginia University 5 Peak Cycle [88], and an Idle mode [92]. Speed-time traces of the Paris, the OCTA, the Braunschweig, and the KCM cycles are presented in Figure 1, Figure 2, Figure 3, and Figure 4, respectively. The KCM Cycle also included the road grade in percentage. Speed-time traces of the rest of the cycles are presented in an appendix to this dissertation. 


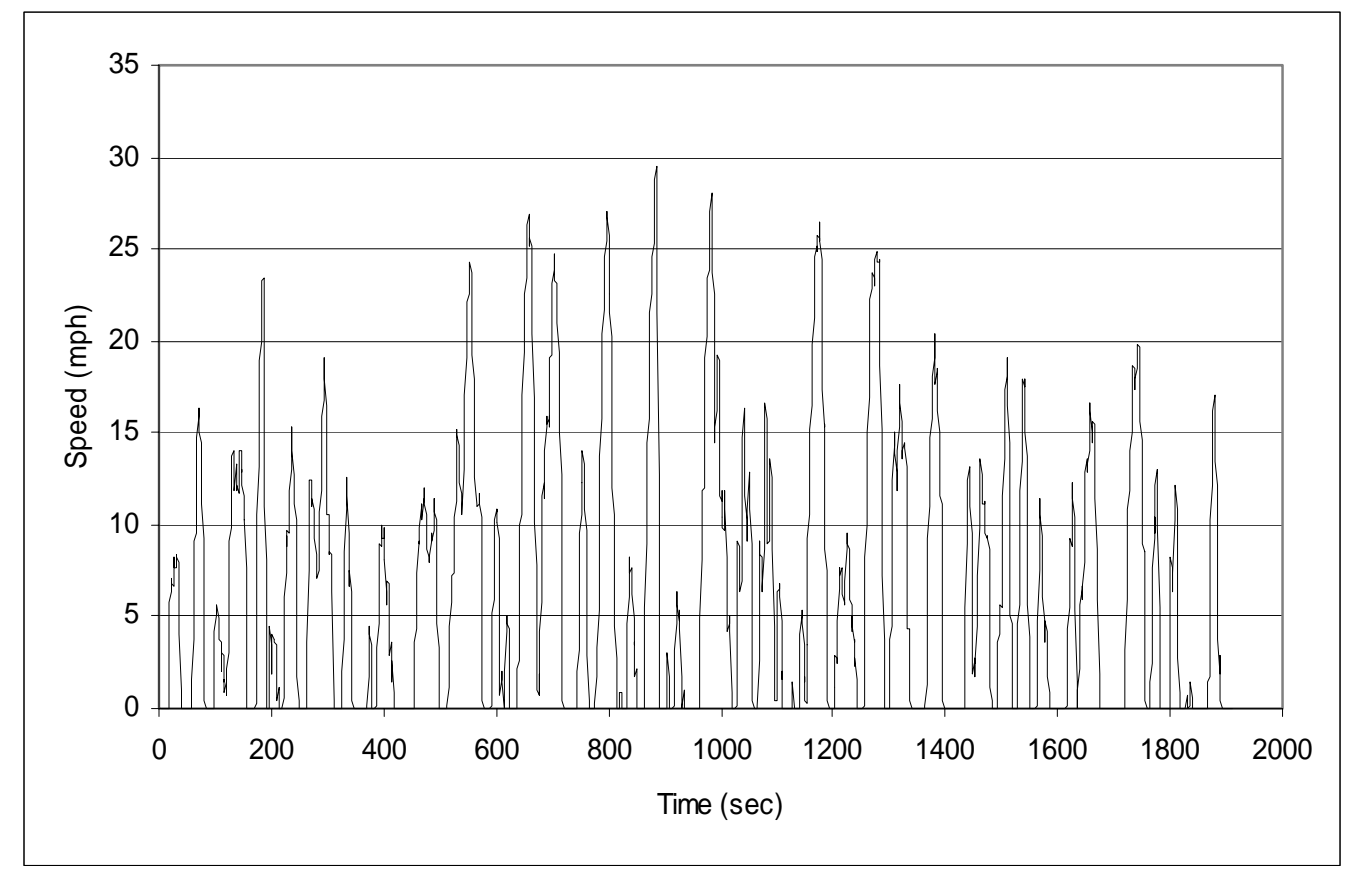

Figure 1: The ADEME-RATP Paris Cycle

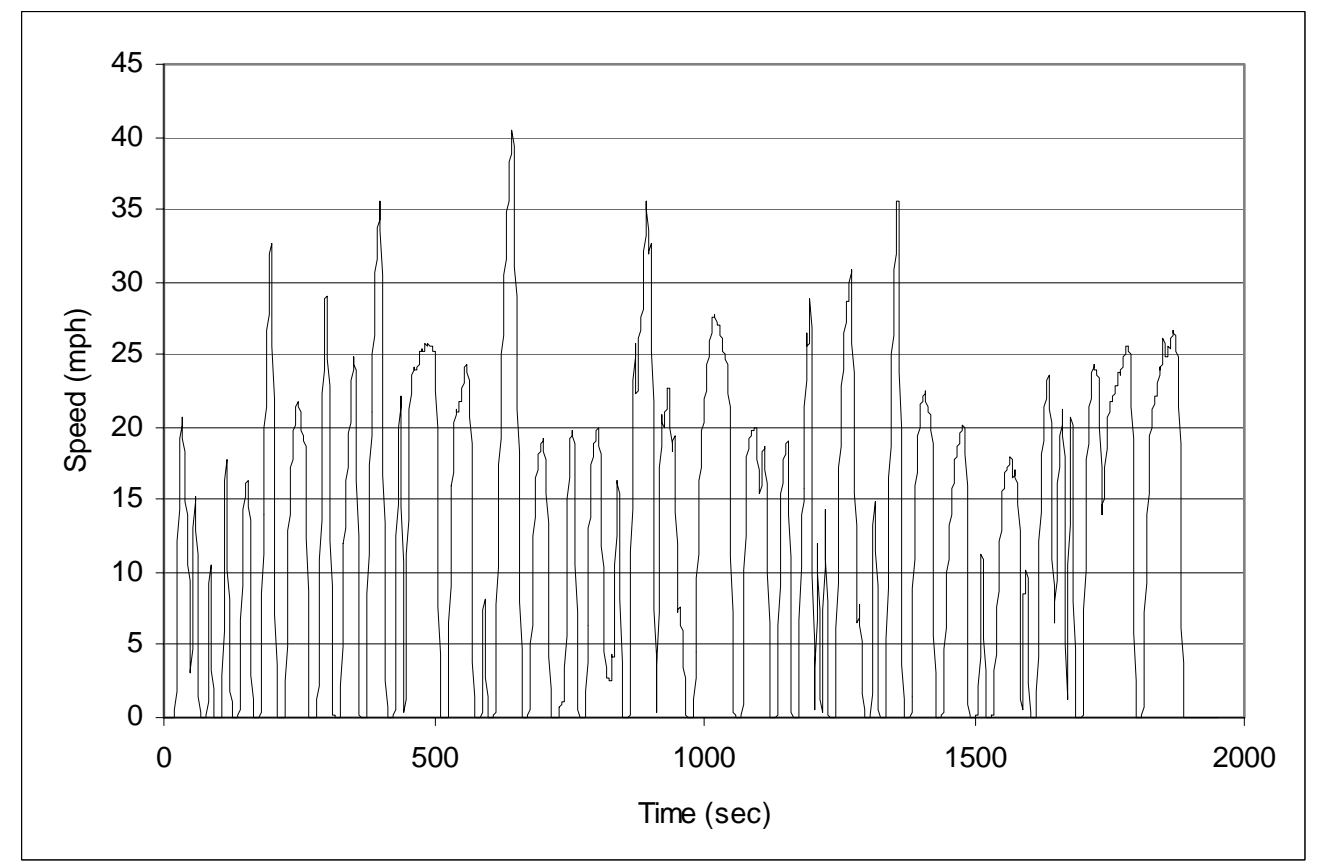

Figure 2: The Orange County (OCTA) Cycle 


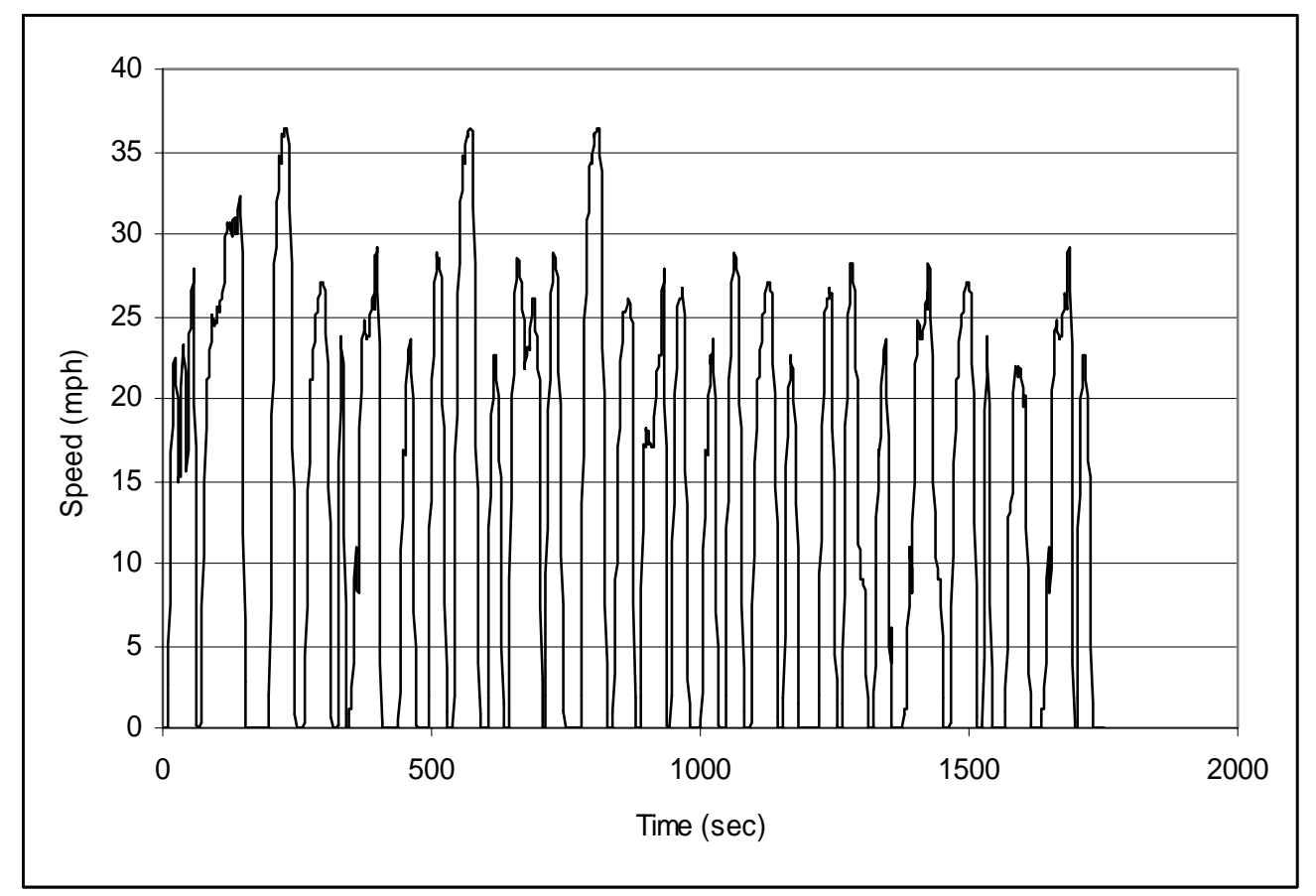

Figure 3: The Braunschweig Cycle

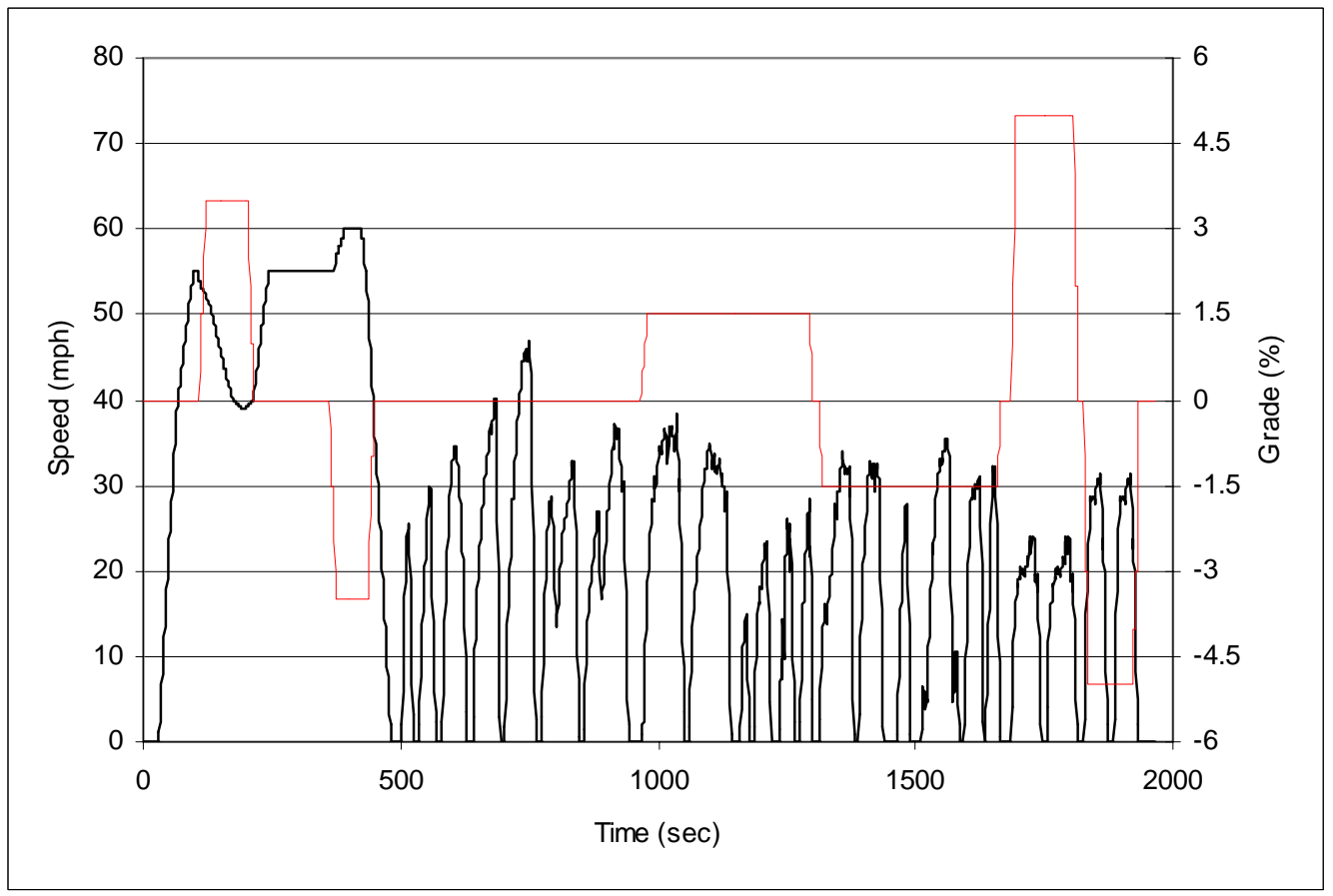

Figure 4: The King County (KCM) Cycle with Road Grade 
Each driving cycle mentioned above had its own unique speed-time characteristics. Each of these cycles also had unique idle events and a unique number of stops per unit distance. Differences in average cycle speed could be representative of the differences in acceleration, deceleration, and cruise events. Average speed was also affected by the percentage of idle and stops per unit distance. When a vehicle was in idle for about ten consecutive seconds, it was considered a stop in this analysis acknowledging that any stop even with smaller time duration would have also affected emissions and FC. However, this analysis did not intend to examine stop effect on emissions but pointing out that it was an important parameter. These events affected power demand from the vehicle and in turn affected emissions and FC from tested vehicles.

It was observed that these cycles had average speed ranging from $3.69 \mathrm{mph}$ on the NYBus Cycle to 43.6 mph on the Commuter Phase of SAE J1376, whereas the U.S. average transit speed was $13.7 \mathrm{mph}$ in 2002 [93]. The majority of the cycles analyzed in this study had average speed below $15 \mathrm{mph}$, which supported the U.S. national average transit bus speed.

Analyses of drive cycles demonstrated that the cycle properties such as aerodynamic speed, characteristic acceleration, kinetic intensity, and percentage of idle were closely related with cycle average speed. This is also corroborated by O'Keefe et al. at the National Renewable Energy Laboratory (NREL) [94]. Generally, a cycle with low average speed included stop-and-go behavior, with multiple accelerations and decelerations, whereas a high speed cycle tended to be steadier. In this way, average speed was a moniker of other aspects of the vehicle behavior, and average speed effects were very different than would be seen if a set of steady-state speeds were used to acquire data. Figure 5 shows the relationship between average speed of seventeen cycles with their percentages of idle, stops per mile, and standard deviation of speed, while Figure 6 demonstrates the relationship of aerodynamic speed, characteristic acceleration, and kinetic intensity with average speed of the cycles.

The NYBus Cycle had the lowest average speed while the Commuter Cycle had the highest average speed. The NYBus Cycle also covered less distance than all cycles used 
in this analysis and was identified to have the maximum percentage of idle and stops per mile. The ETC-Urban Cycle had the minimum percentage of idle and fewer stops per mile in comparison to other cycles with similar average speed. It also had fewer acceleration and deceleration events than other cycles. These characteristics of ETCUrban have weakened the relationship between average cycle speed with percentage of idle and stops per mile. The $\mathrm{R}^{2}$ values for the relationship of average cycle speed with percentage of idle and stops per mile improved further to 0.81 and 0.88 , respectively, if the ETC-Urban Cycle was removed from these analyses. Exclusion of the ETC-Urban also improved the $\mathrm{R}^{2}$ value for the relationship between standard deviation of average speed and average speed to 0.83 .

The speed-idle relationships shown in Figure 5 and Figure 6 were compared with the three Mexico City cycles (MX1, MX2, and MX3). These three cycles when combined together were known as Mexico City Schedules (MCS) presented in Figure 7, developed from the real operations in Mexico City, Mexico [35]. The MX1, MX2, and MX3 cycles with average speed of $7.15 \mathrm{mph}, 12.8 \mathrm{mph}$, and $13.5 \mathrm{mph}$, respectively had 25\%,29\%, and $42.5 \%$ of idle respectively, which showed an upward trend in idle percentage with average speed, in contrast to the relationship developed from the cycles used in this dissertation. A summary of the cycle properties are presented as an appendix to this dissertation. 


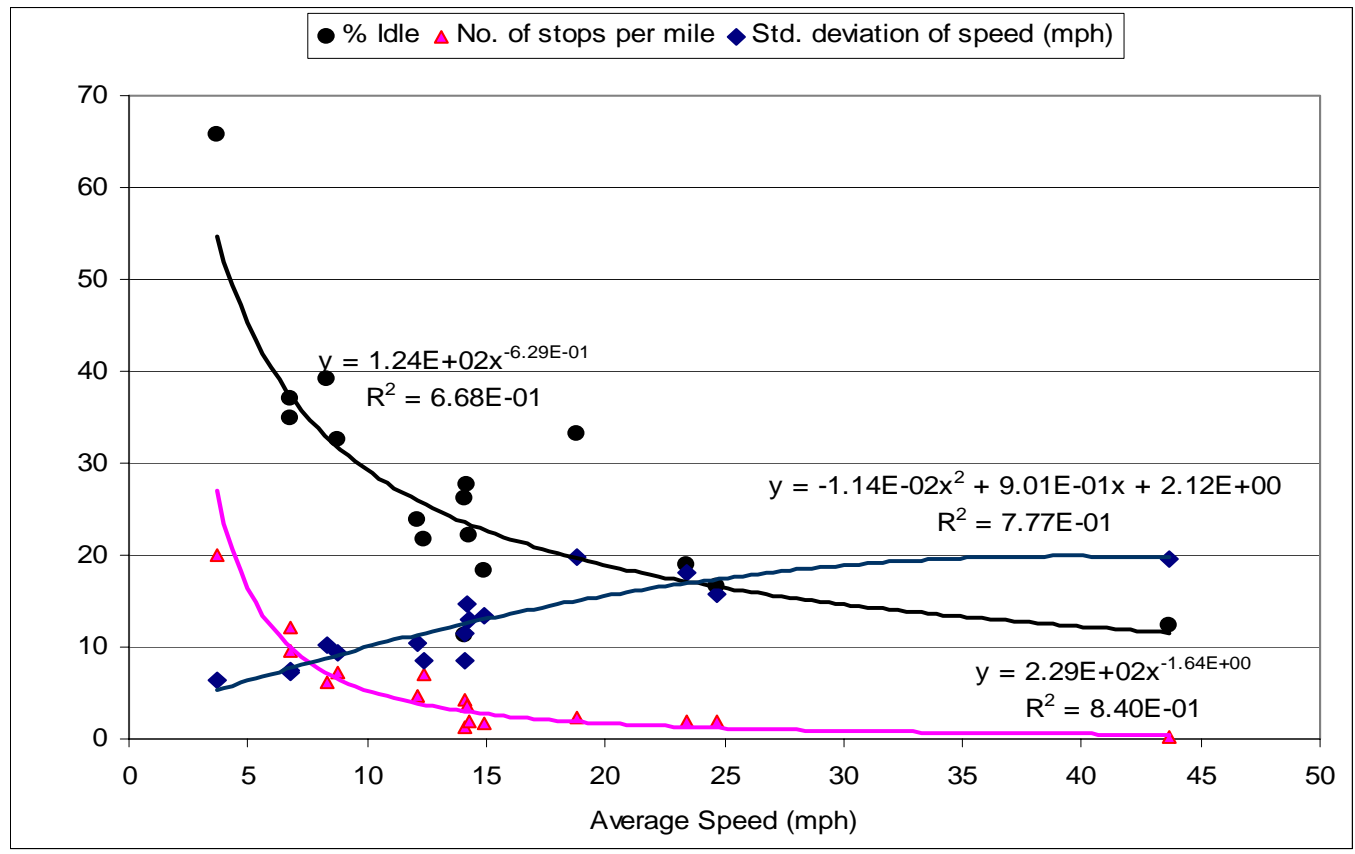

Figure 5: Variation of percentage idle, stops per mile, and standard deviation of speed with average speed of cycles

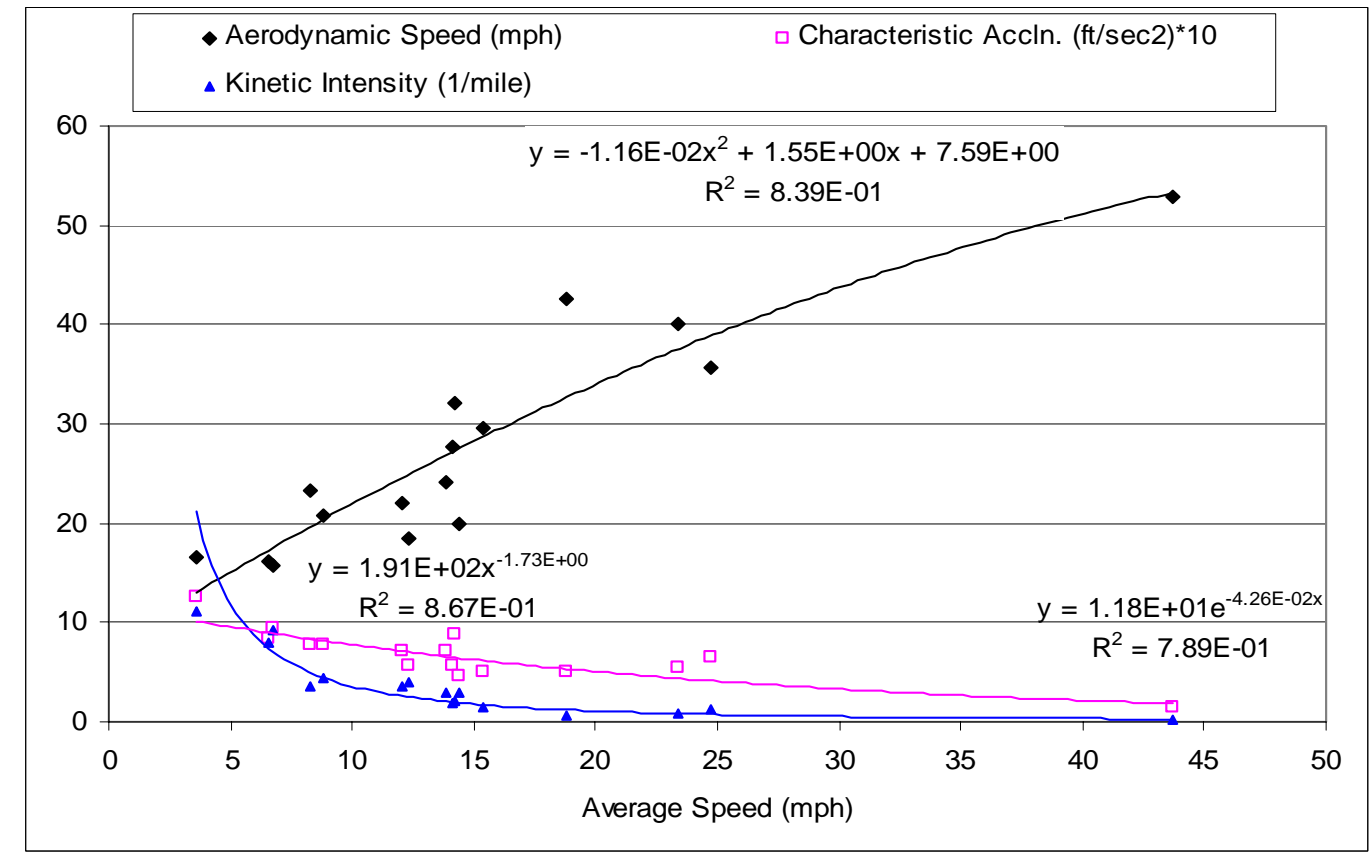

Figure 6: Correlation of aerodynamic speed, characteristic acceleration, and kinetic intensity with average cycle speed 


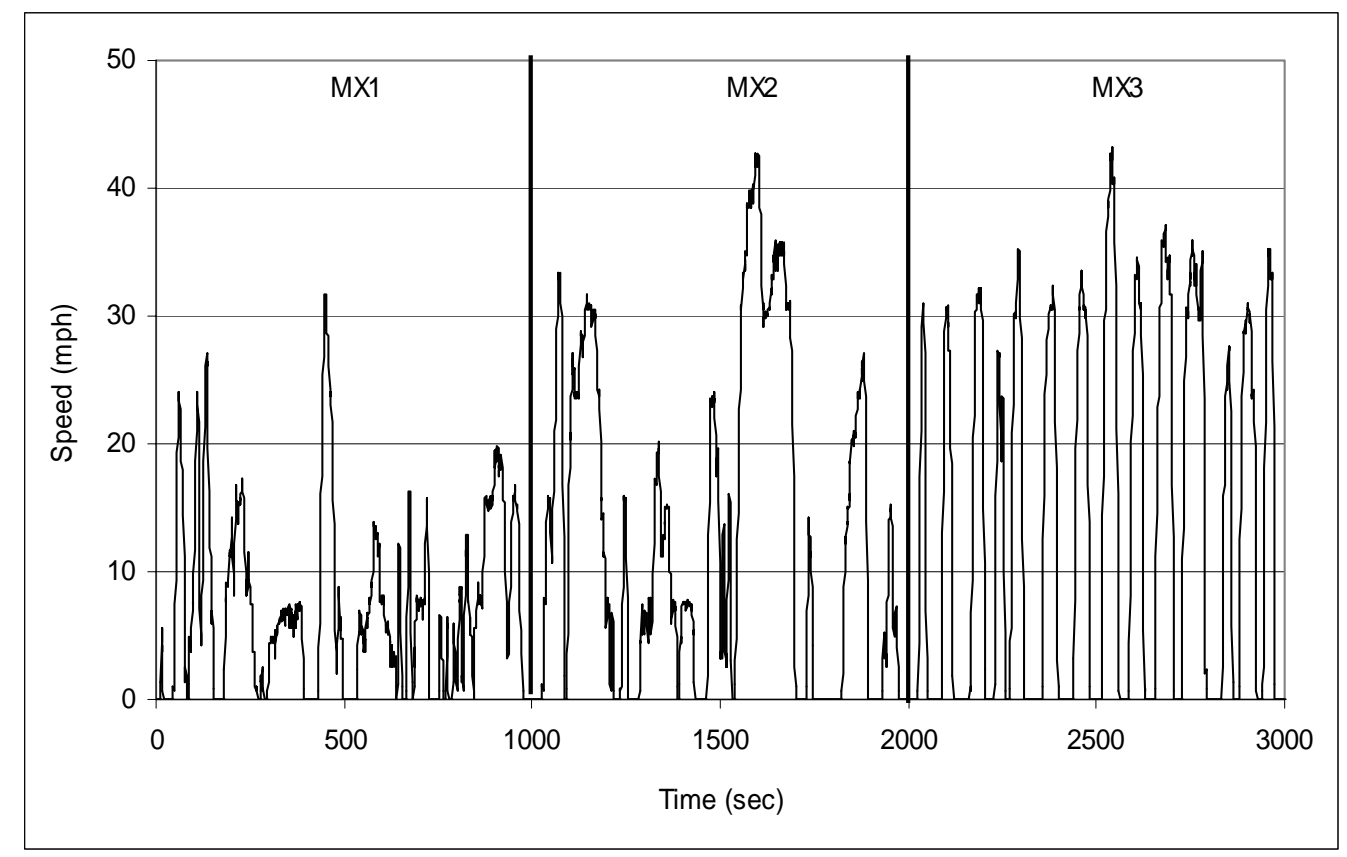

Figure 7: The Mexico City Schedule (MCS), the MX1, MX2, and MX3 cycles

\section{EMISSIONS DATA CONSIDERED FOR THE DISSERTATION}

Emissions and FC data collected during the WMATA Bus Emissions Characterization program in 2006 were considered for this research. The U.S. Department of Energy (DOE) and the U.S. Department of Transportation (DOT) sponsored the Center for Alternative Fuels, Engines, and Emissions (CAFEE) of West Virginia University (WVU) to conduct the program in cooperation with WMATA. A total of thirteen 40-foot transit buses representing two retrofitted diesel, two clean diesel with 2006 MY Cummins ISM engines, three CNG buses with John Deere lean-burn CNG engines, three CNG buses with Cummins lean-burn CNG engines, and three hybrid-electric buses with Cummins ISL engines combined with Allison $\mathrm{E}^{\mathrm{P}} 40$ transmissions were tested during this program at WMATA test site at Landover, Maryland. Details of the test vehicles are presented in Table 1. The two 1992 MY Orion diesel buses were retrofitted with 2003 MY DDC series 50 engines and termed as retrofitted buses. Emissions from these buses were characterized with the WVU Transportable Heavy-Duty Vehicle Emissions Testing Laboratory [95-97]. One bus each from these technologies was tested on seventeen test 
cycles where repeat runs were performed for some representative cycles. However, the first two buses representing hybrid-electric, and John Deere and Cummins natural gas technologies, and the first bus representing conventional diesel and clean diesel technologies were tested only on six test cycles each. Emission tests were not repeated for these buses. For every test, $\mathrm{CO}, \mathrm{CO}_{2}, \mathrm{NOx}, \mathrm{HC}$, and $\mathrm{PM}$ were determined. Methane $\left(\mathrm{CH}_{4}\right)$ and non-methane hydrocarbons (NMHC) were also evaluated from the $\mathrm{CNG}$ buses. Summary of emissions and FC data from these buses are presented in as Appendices to this dissertation. 
Table 1: Test buses

\begin{tabular}{|c|c|c|c|c|c|c|c|}
\hline Bus ID & $\begin{array}{l}\text { Bus } \\
\text { No. }\end{array}$ & $\begin{array}{l}\text { Bus } \\
\text { Type } \\
\& \text { MY } \\
\end{array}$ & $\begin{array}{l}\text { Engine Type, } \\
\text { MY, and } \\
\text { Transmission }\end{array}$ & $\begin{array}{l}\text { GVW } \\
\text { (lb) }\end{array}$ & $\begin{array}{l}\text { After- } \\
\text { treatment }\end{array}$ & $\begin{array}{l}\text { Curb } \\
\text { Wt. (lb) }\end{array}$ & $\begin{array}{l}\text { Odometer } \\
\text { Mileage }\end{array}$ \\
\hline JD\#1 & 2639 & \multirow{3}{*}{$\begin{array}{l}\text { Orion } \\
2005\end{array}$} & \multirow{3}{*}{$\begin{array}{l}\text { RG6081 } \\
280 \text { hp, 2005, } \\
\text { with } \\
\text { Voith D864.3 }\end{array}$} & \multirow[t]{3}{*}{42540} & \multirow{3}{*}{$\begin{array}{l}\text { Catalytic } \\
\text { Converters }\end{array}$} & 32050 & 4225 \\
\hline JD\#2 & 2621 & & & & & 31660 & 3148 \\
\hline JD\#3 & 2640 & & & & & 32320 & 7717 \\
\hline Cummins\#1 & 2501 & \multirow[t]{3}{*}{$\begin{array}{l}\text { Orion } \\
2005\end{array}$} & $\begin{array}{l}\text { Cummins } \\
\text { CG- } 280 \text { hp, } \\
\text { 2004, with } \\
\text { Voith D864.3 }\end{array}$ & \multirow[t]{3}{*}{42540} & \multirow[t]{3}{*}{$\begin{array}{l}\text { Catalytic } \\
\text { Converters }\end{array}$} & 32160 & 18593 \\
\hline Cummins $\# 2$ & 2502 & & \multirow{2}{*}{$\begin{array}{l}\text { Cummins } \\
\text { CG- } 280 \mathrm{hp} \text {, } \\
\text { 2005, with } \\
\text { Voith D864.3 }\end{array}$} & & & 32560 & 26858 \\
\hline Cummins $\# 3$ & 2503 & & & & & 32300 & 4719 \\
\hline Retrofitted\#1 & 9643 & \multirow[t]{2}{*}{$\begin{array}{l}\text { Orion } \\
1992\end{array}$} & \multirow{2}{*}{$\begin{array}{l}\text { DDC S50 } \\
275 \mathrm{hp} \\
\text { 2003, with } \\
\text { Voith D863 }\end{array}$} & \multirow[t]{2}{*}{39375} & $\begin{array}{l}\text { Engelhard } \\
\text { DPX }\end{array}$ & 29820 & 509065 \\
\hline Retrofitted\#2 & 9654 & & & & $\begin{array}{l}\text { Johnson- } \\
\text { Matthey } \\
\text { CCRT }\end{array}$ & 29660 & 586458 \\
\hline Hybrid\#1 & 6001 & $\begin{array}{l}\text { New } \\
\text { Flyer } \\
2006\end{array}$ & $\begin{array}{l}\text { Cummins ISL } \\
280 \\
2006, \text { with } \\
\text { Allison E } 40 \\
\text { Transmission }\end{array}$ & \multirow[t]{3}{*}{40600} & \multirow[t]{3}{*}{$\begin{array}{l}\text { Engelhard } \\
\text { DPX }\end{array}$} & 31360 & 18551 \\
\hline Hybrid\#2 & 6002 & \multirow{2}{*}{$\begin{array}{l}\text { New } \\
\text { Flyer } \\
2005\end{array}$} & \multirow{2}{*}{$\begin{array}{l}\text { Cummins ISL } \\
280 \\
2005, \text { with } \\
\text { Allison E } 40 \\
\text { Transmission }\end{array}$} & & & 31660 & 15460 \\
\hline Hybrid\#3 & 6003 & & & & & 31780 & 20373 \\
\hline $\begin{array}{l}\text { Cummins } \\
\text { ISM\#1 }\end{array}$ & 6146 & \multirow{2}{*}{$\begin{array}{l}\text { New } \\
\text { Flyer } \\
2006\end{array}$} & \multirow{2}{*}{$\begin{array}{l}\text { Cummins ISM } \\
280 \mathrm{hp} \\
2006, \text { with } \\
\text { Voith D864.3 }\end{array}$} & \multirow[t]{2}{*}{40600} & \multirow[t]{2}{*}{$\begin{array}{l}\text { Catalytic } \\
\text { Converters }\end{array}$} & 29960 & 5635 \\
\hline $\begin{array}{l}\text { Cummins } \\
\text { ISM\#2 }\end{array}$ & 6150 & & & & & 30280 & 7171 \\
\hline
\end{tabular}




\section{DESCRIPTION OF TEST LABORATORY}

Bus emissions were characterized with the WVU Transportable Heavy-Duty Vehicle Emissions Testing Laboratory (Translab). The Translab was moved to the WMATA test site at Landover, Maryland. The Translab consisted of a chassis dynamometer, an emissions analyzer trailer, and a mobile workshop to support them. It was designed to conduct emissions characterization in accordance with the provisions prescribed by the United States Code of Federal Regulations (CFR) Title 40, Subpart B \& N of Part 86 [79]. Detailed description of the Translab can be found in technical papers by Clark et al. [95], Lyons et al. [96], and Gautam et al. [97].

\section{DESCRIPTION OF THE CHASSIS DYNAMOMETER}

The bus was positioned on the chassis dynamometer while being characterized as shown in Figure 8. Its drive wheels were placed on two sets of rollers, which were 12.6 inches in diameter. Axle power from the vehicle was taken directly to the dynamometer units by replacing the rear outer wheels with a hub adapter on each side of the vehicle connected to the dynamometer through drive shafts, as shown in Figure 9. Each dynamometer unit consisted of a flywheel assembly, an eddy current power absorber, and a Lebow torque transducer. Flywheel sets consisted of a series of discs that allowed simulation of inertial load. During the testing of the bus, torque cells and speed transducers measured the vehicle load while the power absorbers were used to mimic tire losses and wind drag. A human driver controlled the vehicle following the speed-time trace presented on a monitor and placed inside the driver cabin. In this research, the vehicle losses were set using a coast down on the dynamometer. The coast down curve was created using the road load equation. 


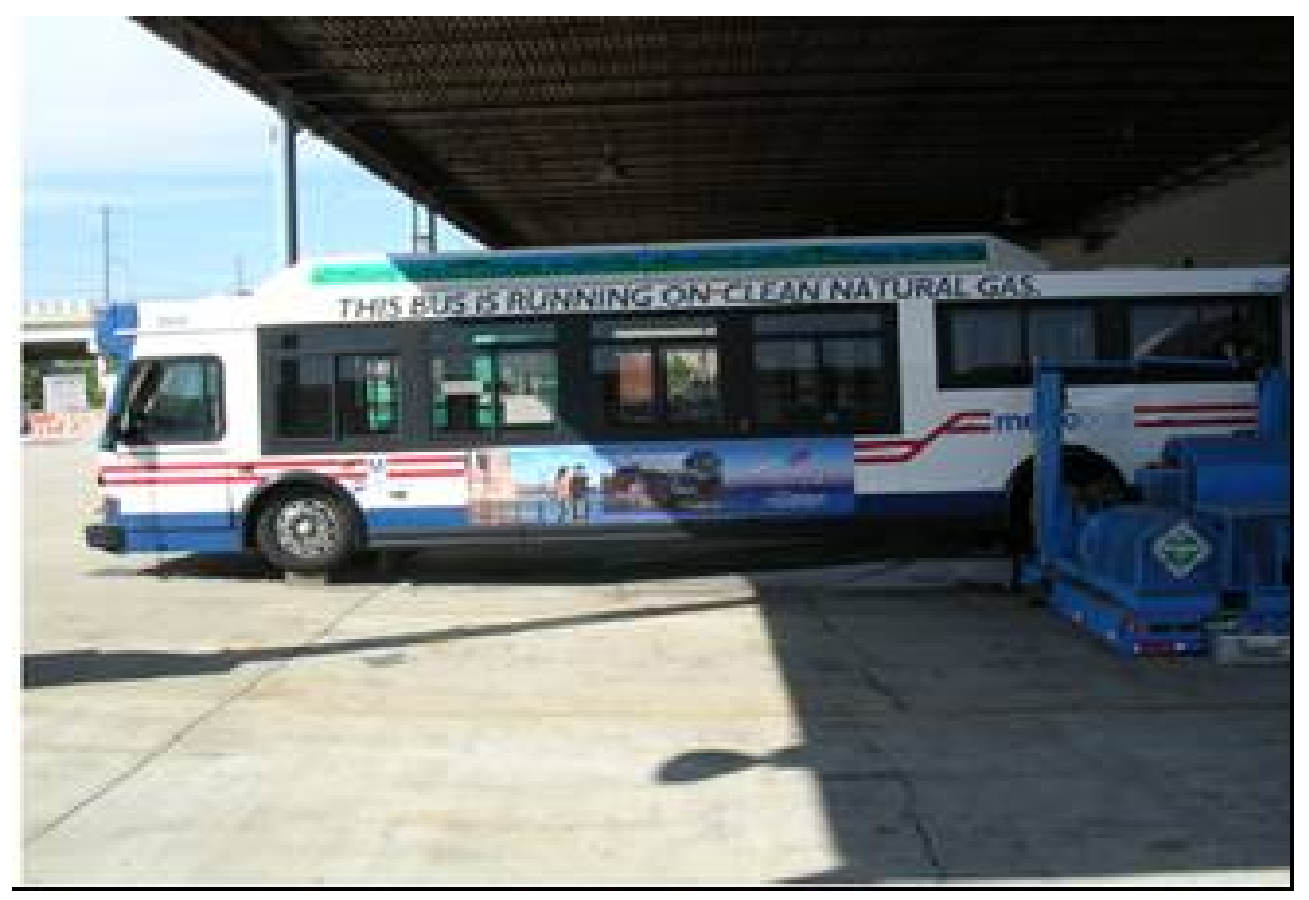

Figure 8: View of a John Deere natural gas bus placed on the dynamometer

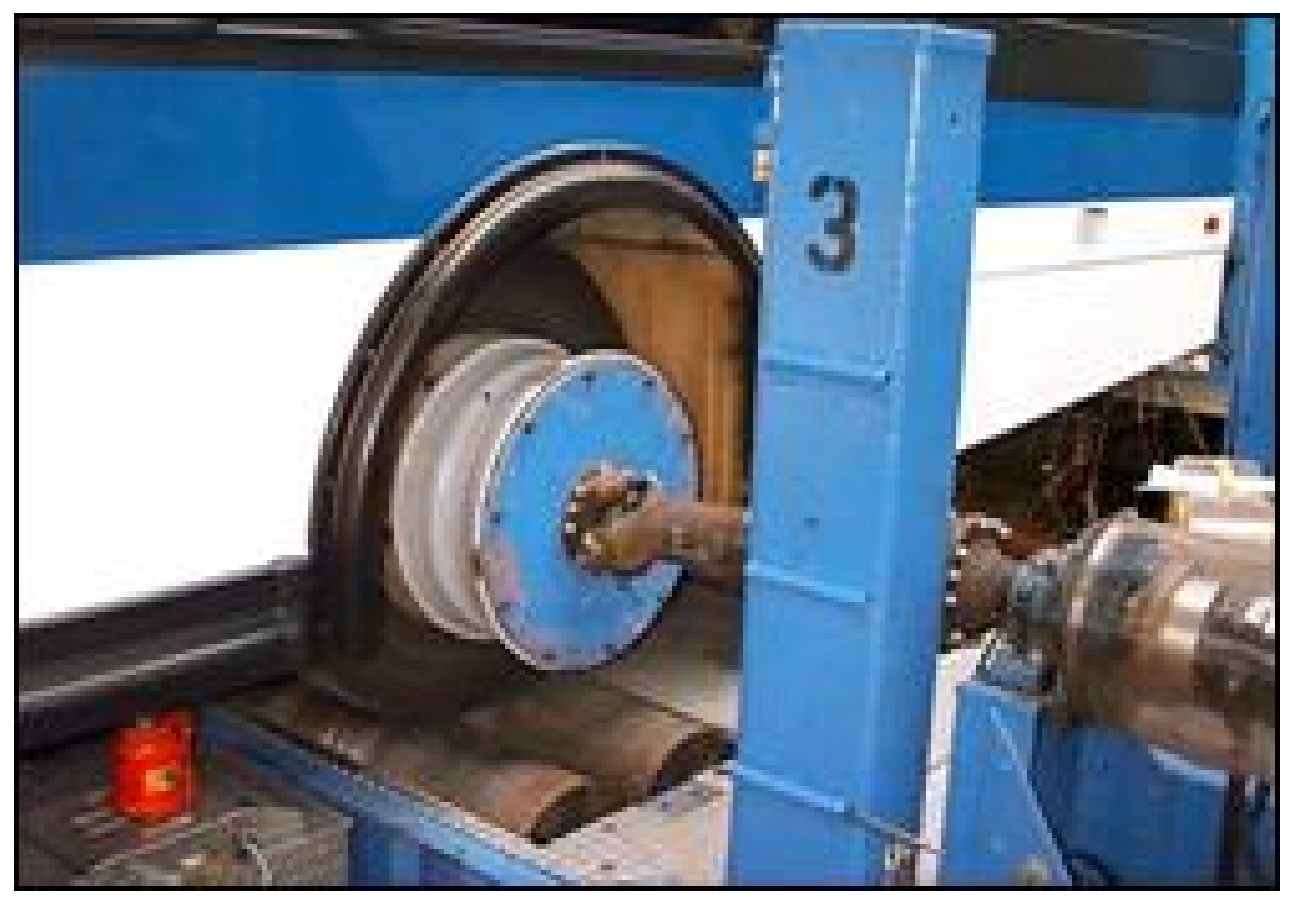

Figure 9: Hub adapters connect vehicle's drive axle directly to the power absorber unit 


\section{EMISSIONS MEASUREMENT}

Exhaust from the vehicle's tailpipe was ducted into a full-scale dilution tunnel. The tunnel was 18 inches in diameter and 20 feet in length. HEPA filtered ambient air was mixed with the exhaust in the primary dilution tunnel in order to ensure that PM sample filter temperature was below $125^{\circ} \mathrm{F}$ for PM sampling. Heated lines were used to convey the samples from the dilution tunnel to research grade analyzers. All data were corrected for background levels in the dilution air. Both $\mathrm{CO}$ and $\mathrm{CO}_{2}$ were measured using nondispersive infrared analyzers (NDIR). CO data may be processed using either integration of continuous data or concentrations from a Tedler bag of dilute exhaust gas, collected over the duration of the cycle. Bag CO data have been used. These samples were passed through a refrigerator/dryer before they reached the analyzers. NOx was measured using a wet chemiluminescent analyzer while $\mathrm{HC}$ was measured using heated flame ionization detection (HFID) method. The $\mathrm{HC}$ probe and line were maintained at $375^{\circ} \mathrm{F}$ while all other lines were maintained at $250^{\circ} \mathrm{F}$ to prevent condensation of moisture in the system. PM samples were taken through three sets of parallel filters located after the secondary dilution tunnel, which was attached to the primary dilution tunnel. The PM samples were collected gravimetrically in one $70 \mathrm{~mm}$ and two $47 \mathrm{~mm}$ fluorocarbon coated glass-fiber filter holders, each holding two filters in series. PM weights from the $70 \mathrm{~mm}$ filers are used in this dissertation. These filters were conditioned before and after each test and and were pre and post-test weighed in a class 1000 clean thermal stabilization and weighing enclosure located at the CAFEE at WVU [98]. 


\section{SPEED EFFECT ON EMISSIONS AND FUEL CONSUMPTION}

\section{THEORY}

The road-load equation showed that instantaneous power demanded by the vehicle was influenced by four main factors: vehicle speed, acceleration/deceleration, vehicle weight, and road grade. For a single vehicle with constant mass and driven on level terrain, it was only the vehicle speed and acceleration/deceleration that influenced the instantaneous power demand, and hence, instantaneous emissions. The speed-time traces of the drive cycles were applied to the road load equation to yield instantaneous values for wind drag, tire rolling resistance, inertia load and total load. Figure 10 and Figure 11 show these four loads, in units of power (kW) over the first 200 seconds (sec) duration of the OCTA Cycle and the Paris Cycle, respectively. Here, vehicle weight was taken as 14,728 kilograms (kg) which was the curb weight for a Orion bus equipped with a Cummins CNG engine. These loads were drive cycle dependant since instantaneous speed differs from cycle to cycle, as shown in for the Paris Cycle in Figure 11 and for the Commuter Cycle in Figure 12. Figure 12 explicitly shows the importance of wind drag on the high speed cycle and the effect of cruise mode on the inertia and total load. During severe decelerations the total load becomes negative, corresponding to engine braking and the application of the service brakes or a retarder. In the case of hybrid electric buses some of this braking effort may also be regenerative.

In this analysis efforts were made to understand the relative effect of drag coefficient and rolling resistance coefficient on total load over a cycle. For example, reducing rolling resistance coefficient from 0.008 to 0.005 yielded about $40 \%$ reduction in rolling resistance load on the OCTA Cycle, which corresponded to about $10 \%$ reduction in total load on that cycle while reducing drag coefficient from 0.79 to 0.40 yielded about $50 \%$ reduction in average drag force which corresponded to about $5 \%$ reduction in total load on the OCTA Cycle. However, on the Commuter Cycle, reducing drag and rolling resistance coefficient to 0.40 and 0.005 yielded about $30 \%$ and $10 \%$ reduction in total load, respectively, which signified the importance of aerodynamic design of transit buses 
for higher speed applications. However, most transit buses operate at lower speeds where aerodynamic drag is less significant.

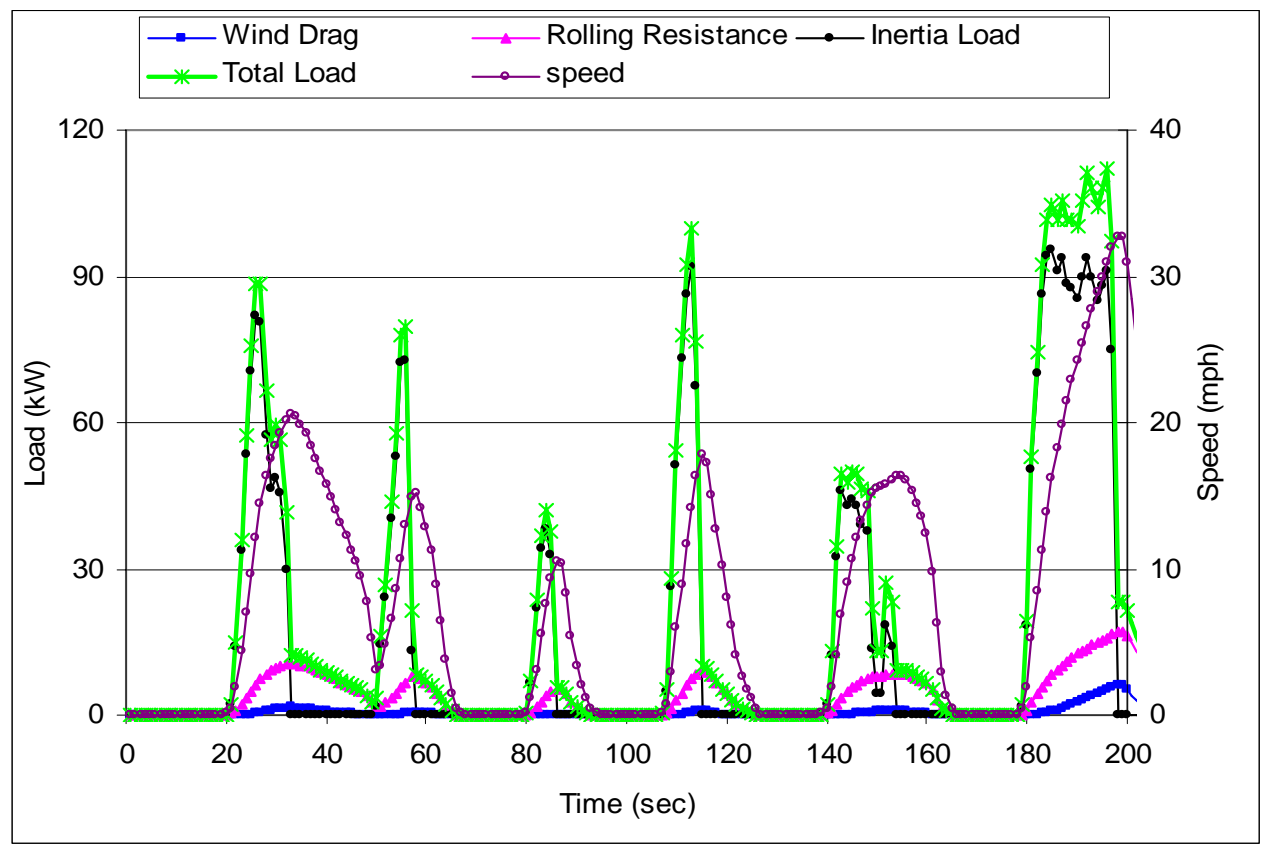

Figure 10: Instantaneous wind drag, rolling resistance, inertia, and total load during the first 200 seconds of the OCTA Cycle 


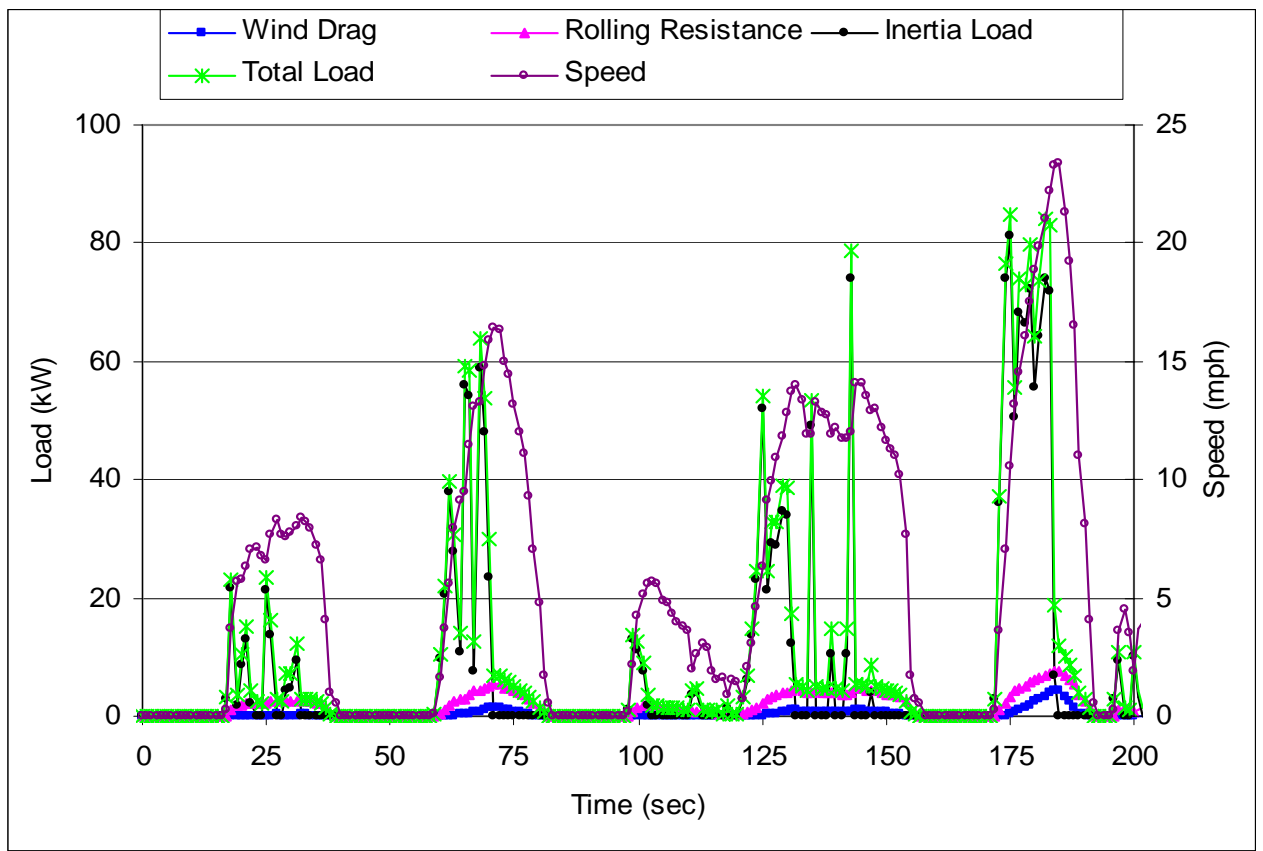

Figure 11: Instantaneous wind drag, rolling resistance, inertia, and total load during the first 200 seconds of the Paris Cycle

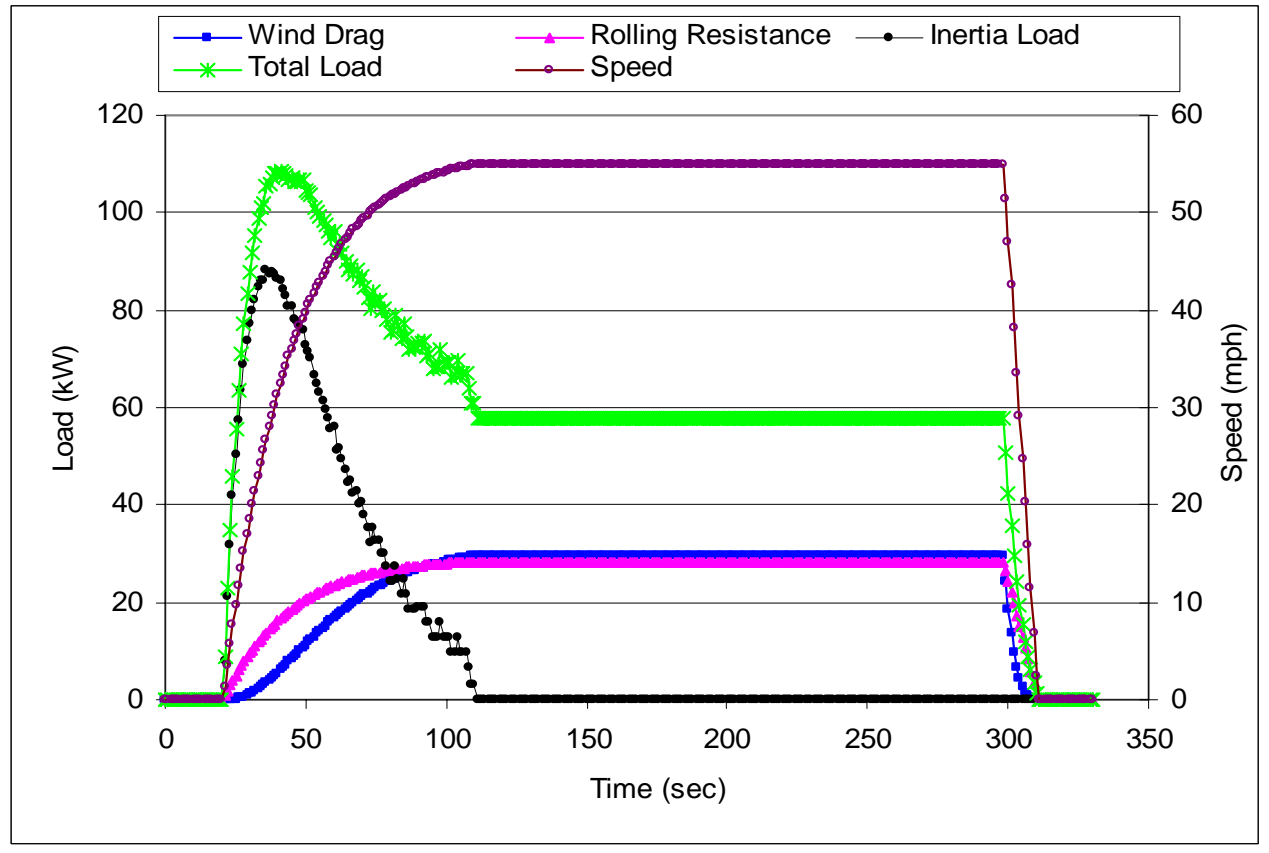

Figure 12: Instantaneous wind drag, rolling resistance, inertia, and total load on the Commuter Cycle 


\section{Speed Effect on Emissions}

The effect of average speed on emissions was examined using the WMATA data where thirteen buses representing conventional and clean diesel, $\mathrm{CNG}$, and hybrid-electric technologies were tested. Distance-specific emissions of CO, HC, NOx, and PM from these buses are presented in Figure 13, Figure 14, Figure 15, and Figure 16, respectively. $\mathrm{CO}$ and $\mathrm{HC}$ from these buses were the highest on the NYBus Cycle while they were lowest on the Commuter Cycle. CO from hybrid-electric, John Deere CNG, and retrofitted diesel buses were very low. No correlations could be observed for $\mathrm{CO}$ with average speed from these buses. However, $\mathrm{CO}$ emissions from Cummins ISM diesel and Cummins CNG buses presented a good correlation with average speed. HC, on the other hand were high from the $\mathrm{CNG}$ buses and presented a good correlation with average speed of cycles. But $\mathrm{HC}$ emissions from the remaining buses were low and did not present any trend. Similarly, PM emissions from all buses were low except from Cummins ISM diesel buses, which exhibited about ten times higher PM emissions than the rest of the buses on average. PM from the two ISM diesel buses exhibited a good trend with average speed. The relationship of PM from Cummins ISM diesel buses with average speed on a power fit induced an $\mathrm{R}^{2}$ value of 0.72 . However, $\mathrm{PM}$ emissions in $\mathrm{g} / \mathrm{mile}$ from other buses were little affected by average speed. For example, the KCM Cycle exhibited the highest PM from the retrofitted diesel buses while the WMATA Cycle exhibited the lowest PM from them. Since no trend could be established for distance-specific CO, HC, and PM emissions from these buses with average speed, the prediction model will not consider these pollutants and will focus on FC only.

Distance-specific NOx from all buses were high on the NYBus Cycle and gradually decreased with average speed. The Commuter Cycle, the highest speed cycle in the mix exhibited the lowest NOx emissions from these buses. However, this finding was supported by insufficient data since only one cycle had average speed more than $25 \mathrm{mph}$ (the Commuter cycle, $43.64 \mathrm{mph}$ average speed). 


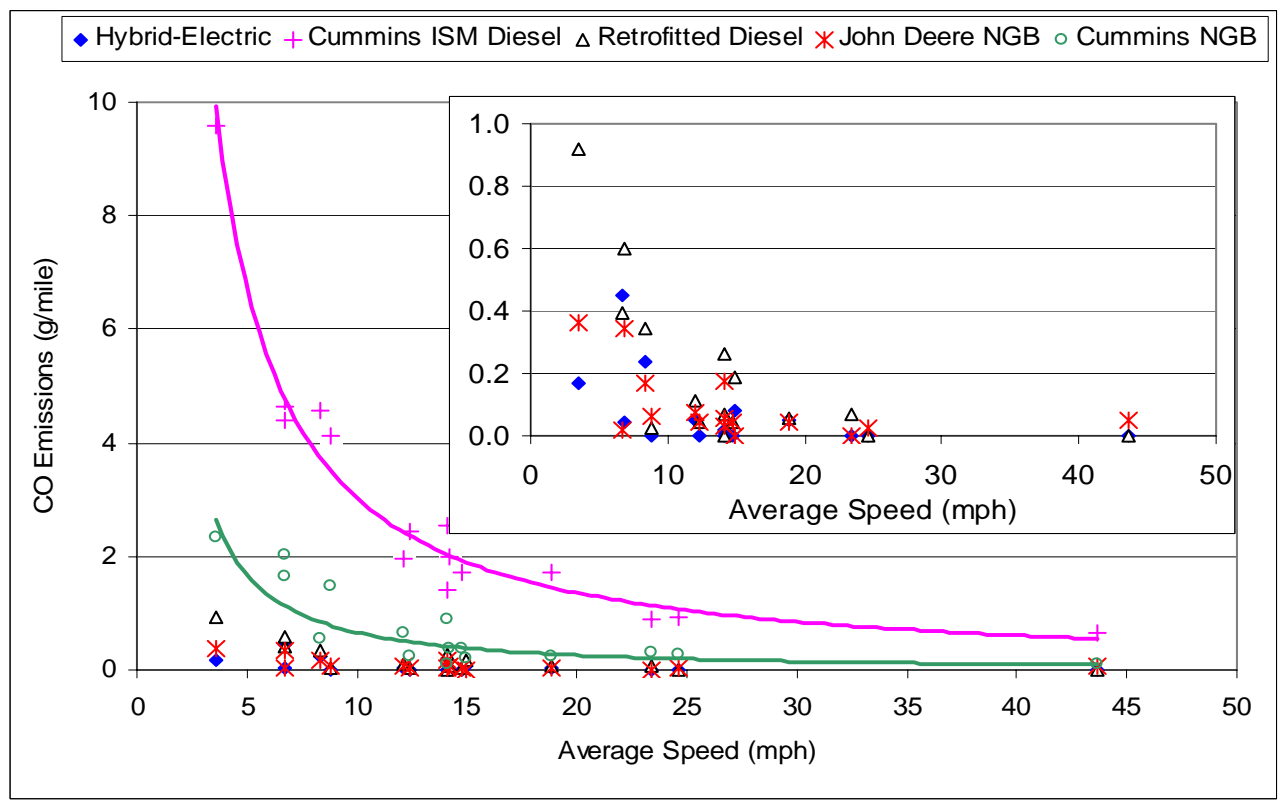

Figure 13: Distance-specific CO emissions from the hybrid-electric, Cummins ISM diesel, Retrofitted diesel, John Deere CNG, and Cummins CNG buses

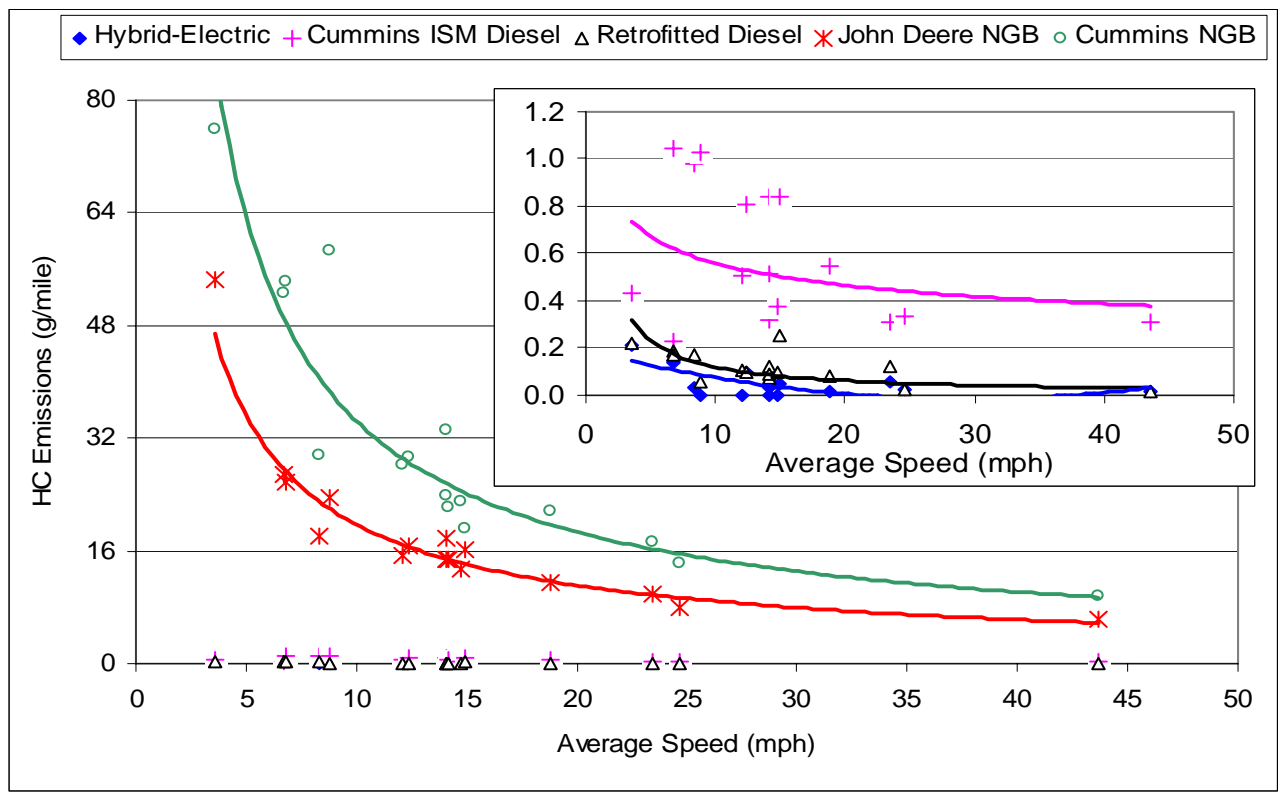

Figure 14: Distance-specific HC emissions from the hybrid-electric, Cummins ISM diesel, Retrofitted diesel, John Deere CNG, and Cummins CNG buses 


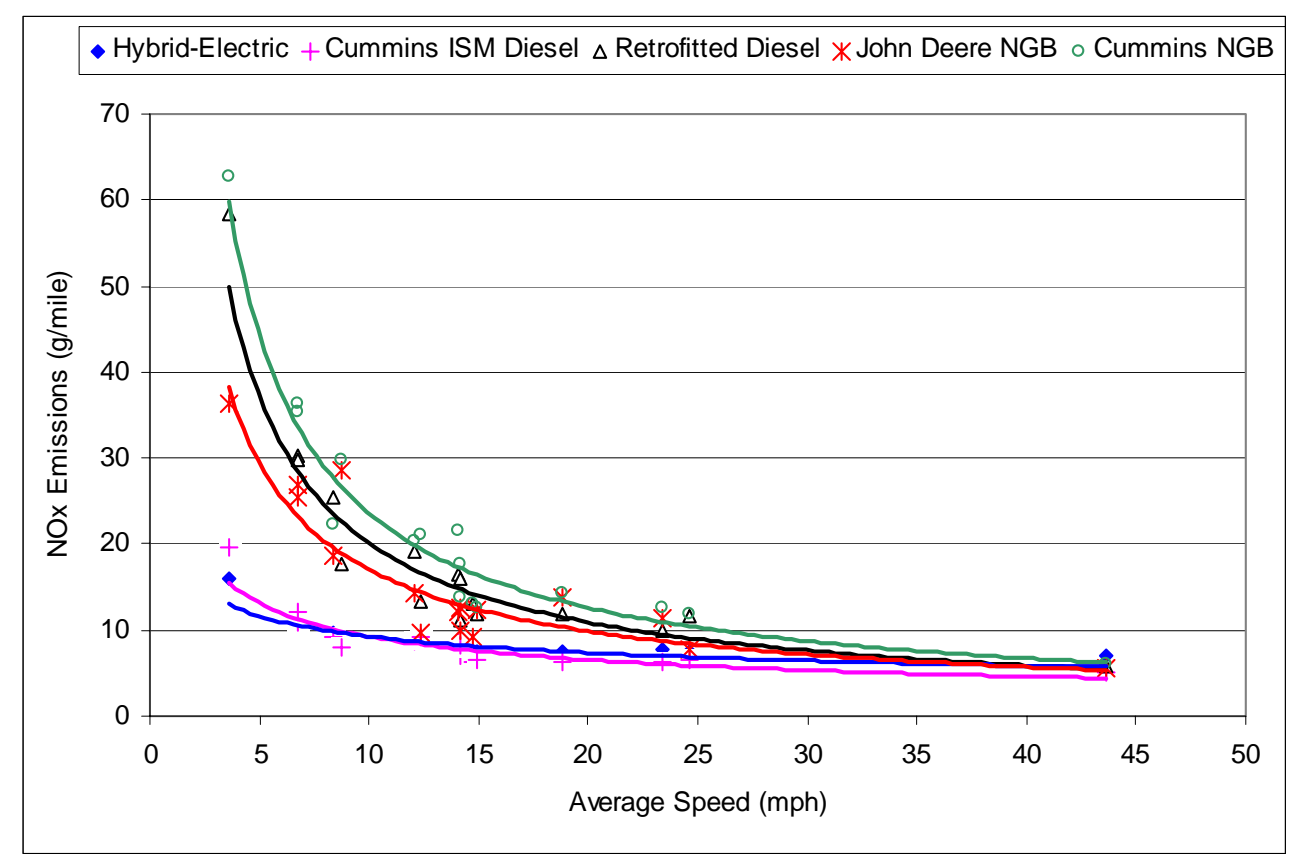

Figure 15: Distance-specific NOx emissions from the hybrid-electric, Cummins ISM diesel, Retrofitted diesel, John Deere CNG, and Cummins CNG buses

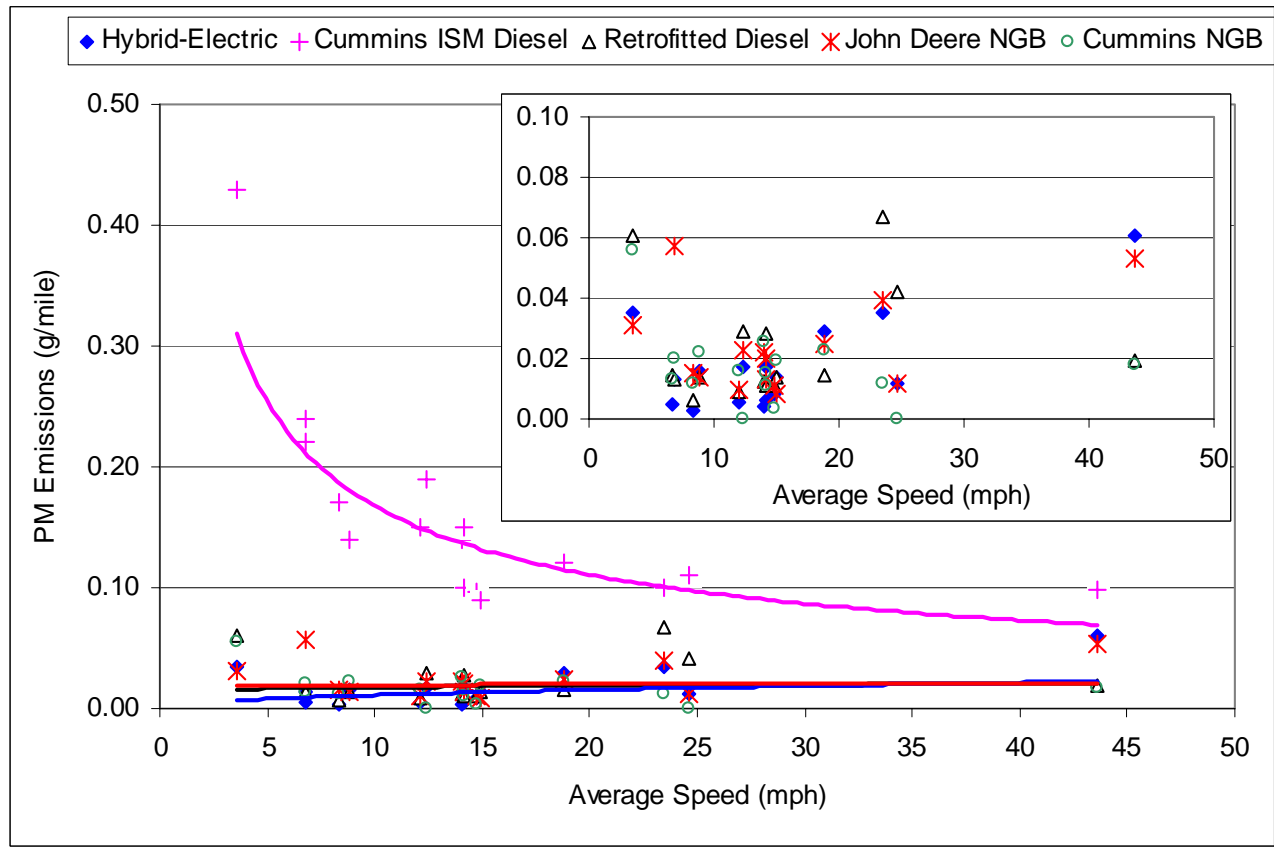

Figure 16: Distance-specific PM emissions from the hybrid-electric, Cummins ISM diesel, Retrofitted diesel, John Deere CNG, and Cummins CNG buses 


\section{Speed Effect on Fuel Consumption}

FC was inferred from the $\mathrm{CO}, \mathrm{HC}$, and $\mathrm{CO}_{2}$ emissions using carbon balance [81].

Distance-specific FC from these buses, expressed in diesel equivalent gallons per mile, was compared with the average speed of cycles and is shown in Figure 17. FC from all buses exhibited a good correlation with average speed. These buses had the highest consumption on the NYBus Cycle while they consumed the lowest fuel at the Commuter Cycle on a distance-specific basis. The relationship of FC with average cycle speed on a polynomial fit induced an $\mathrm{R}^{2}$ value more than 0.70 on all buses. However, the relationship of FC and cycle average speed improved when observed with a power fit. FC showed an upward trend once the average cycle speed exceeded approximately $30 \mathrm{mph}$, but this could be an artifact of the parabolic fit to the data. Lack of sufficient FC data after 30 mph speed (only the Commuter Cycle) was a limiting factor in establishing this trend.

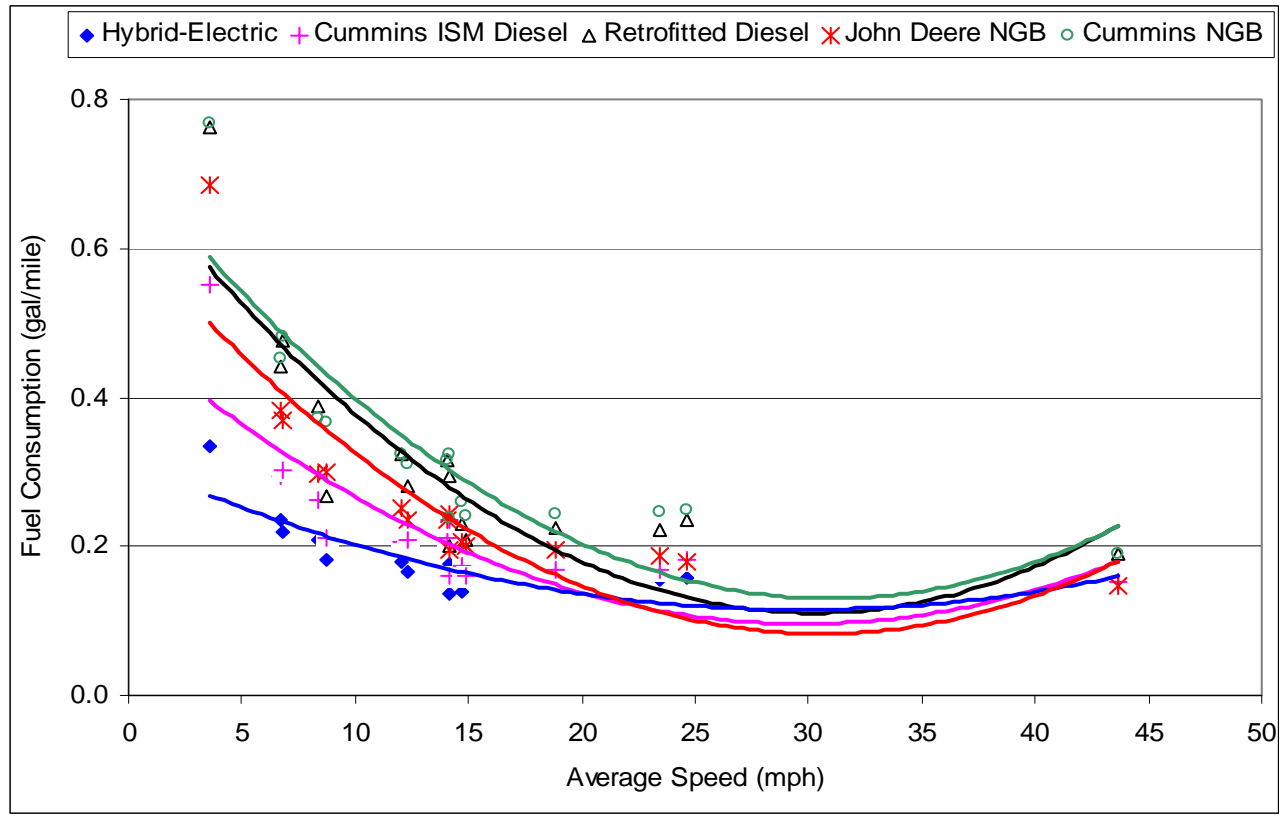

Figure 17: Fuel consumption in diesel equivalent gallon per mile (gal/mile) from the hybrid-electric, Cummins ISM diesel, Retrofitted diesel, John Deere CNG, and Cummins CNG buses 
This analysis was extended further to show that average speed could be used to project the benefit of hybrid-electric technology over diesel and CNG technologies. Hybrid buses had better advantages in $\mathrm{FC}$ at low speed cycles, which provided them with efficient regenerative braking as shown in Figure 18. This advantage, however, diminished when the average speed was high. Note that hybrid-electric buses exhibited about $40 \%$ FC benefit at the US average transit bus speed of $13.7 \mathrm{mph}$ over CNG buses and about $20 \%$ FC benefit over its diesel counterparts at the same speed.

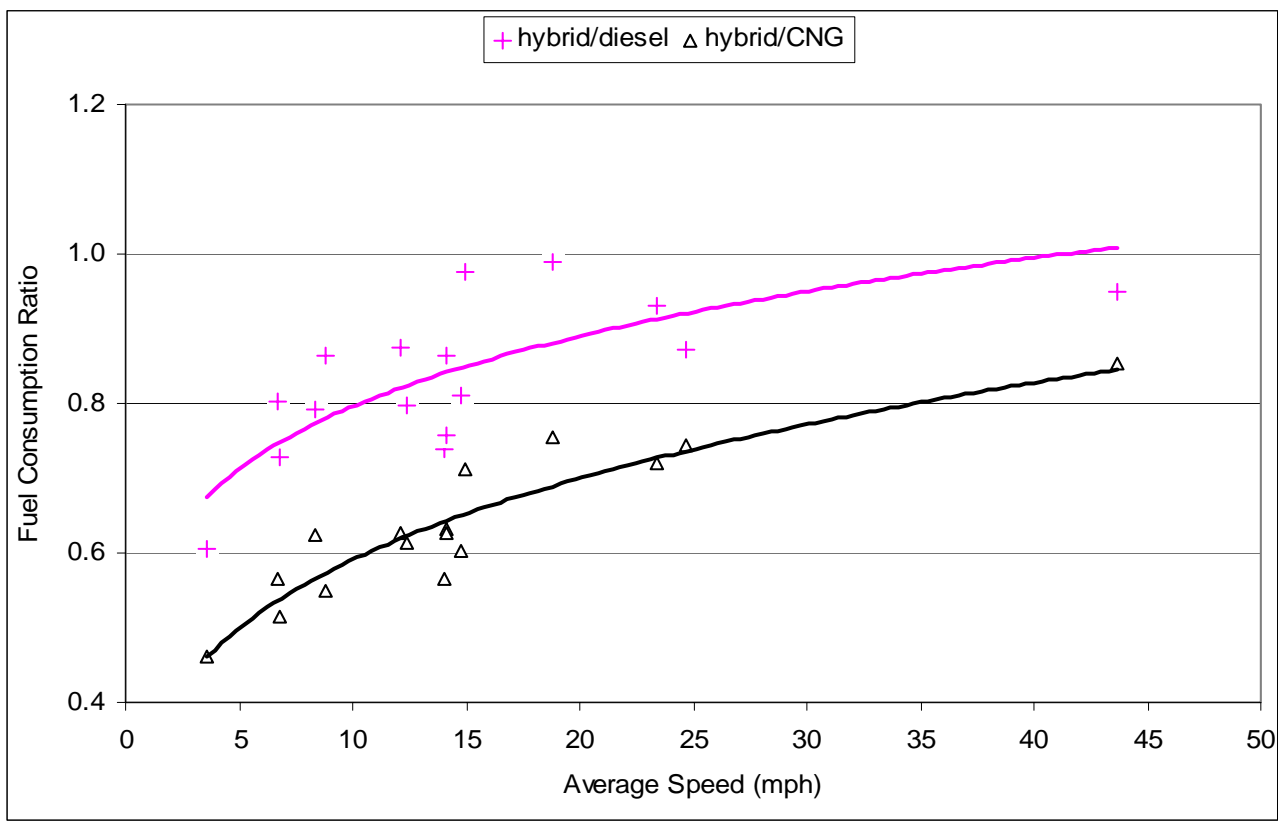

Figure 18: Comparison of FC from hybrid buses with diesel and CNG buses and their relationship to average speed

\section{CREATION OF SUB-CYCLES}

Some artificial sub-cycles with average speed above $25 \mathrm{mph}$ were created to evaluate the speed effect on emissions and FC. Since the majority of the cycles used in this research had average speed less than $25 \mathrm{mph}$ as shown in Figure 19, creating some cycles with average speed greater than $25 \mathrm{mph}$ would provide constructive conclusion as to the effect of average speed and was also expected to provide better trend between emissions and FC. The WMATA Program recorded emissions and FC data on seventeen test cycles 
mentioned in this dissertation. The author was aware that there were a number of chassis cycles available in the market. Therefore, instead of creating new cycles the author created some sub-cycles from the cycles that were used in the WMATA program. This allowed extracting emissions and FC data from the continuous data of the original test cycles.

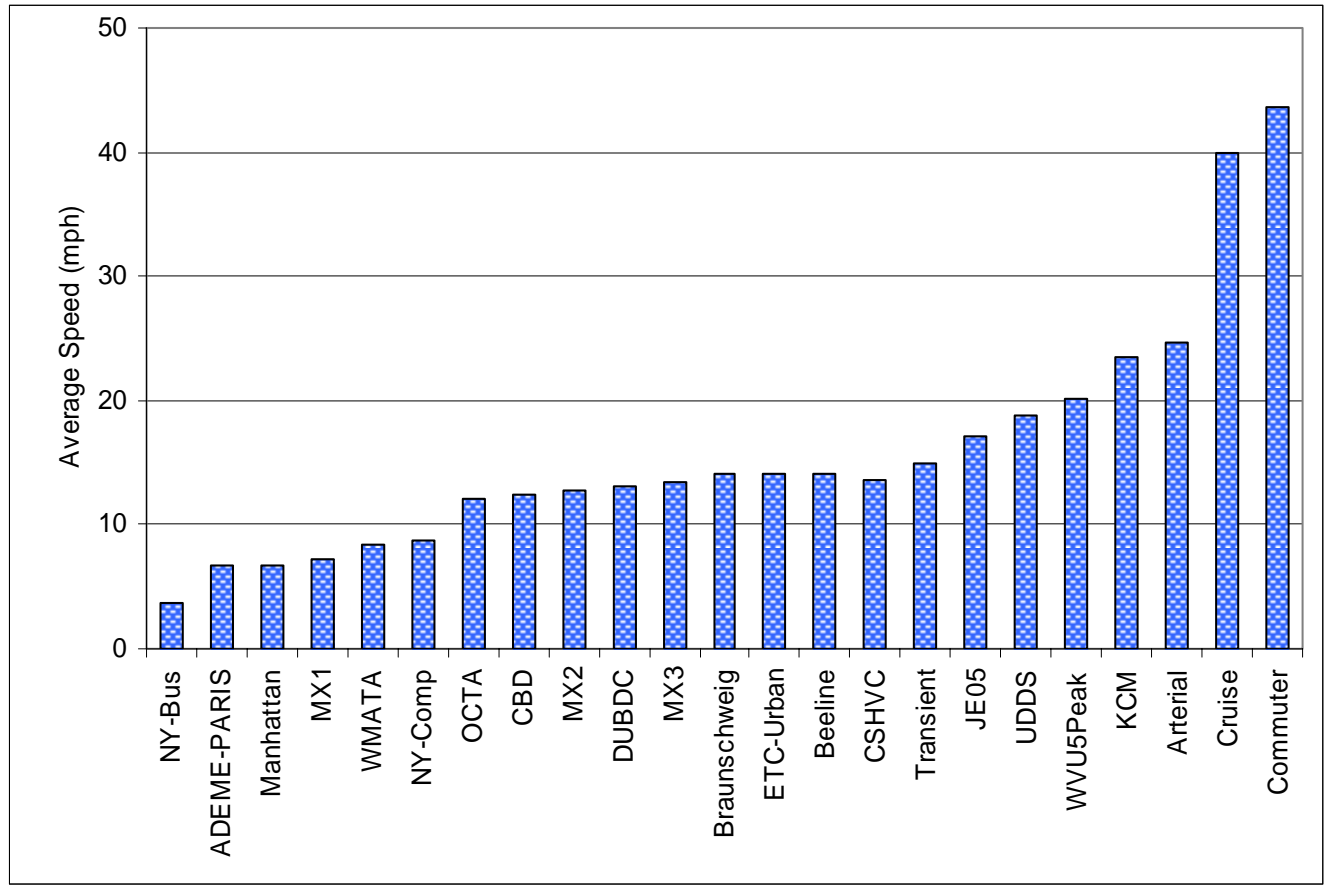

Figure 19: Average speed of chassis cycles used in WMATA program

Therefore, the King County Metro Cycle (KCM) [44], used in the WMATA program, was chosen to develop some sub-cycles which resulted in average speeds more than 30 mph. Accordingly three cycles; KCM2, KCM3, and KCM4, shown in Figure 20, Figure 21, and Figure 22, respectively, were developed using the first $950 \mathrm{sec}, 770 \mathrm{sec}$, and the first $570 \mathrm{sec}$, respectively. $\mathrm{KCM} 2, \mathrm{KCM} 3$, and $\mathrm{KCM} 4$ covered about 8.3 miles, 7.3 miles, and $6.1 \mathrm{miles}$ and had average speeds of $31.51 \mathrm{mph}, 34.13 \mathrm{mph}$, and $38.29 \mathrm{mph}$, respectively. These three cycles also had more than $10 \%$ idle duration and about one stop per mile in their respective routes. It may be mentioned that $\mathrm{Tu}$ et al. created more than 
three hundred new virtual cycles with some specific criteria including duration range, travel distance, and limiting repetition of the same micro trip in the cycle and examined their relationship to emissions and FC [99]. However, here the effort was to maintain the continuity of the cycle that has been used in WMATA program in order to use the continuous emissions data for the designated time. Alternately average speed of these cycles could have been increased or decreased by removing or adding idle events but continuous emissions data, collected from the chassis testing could not be used.

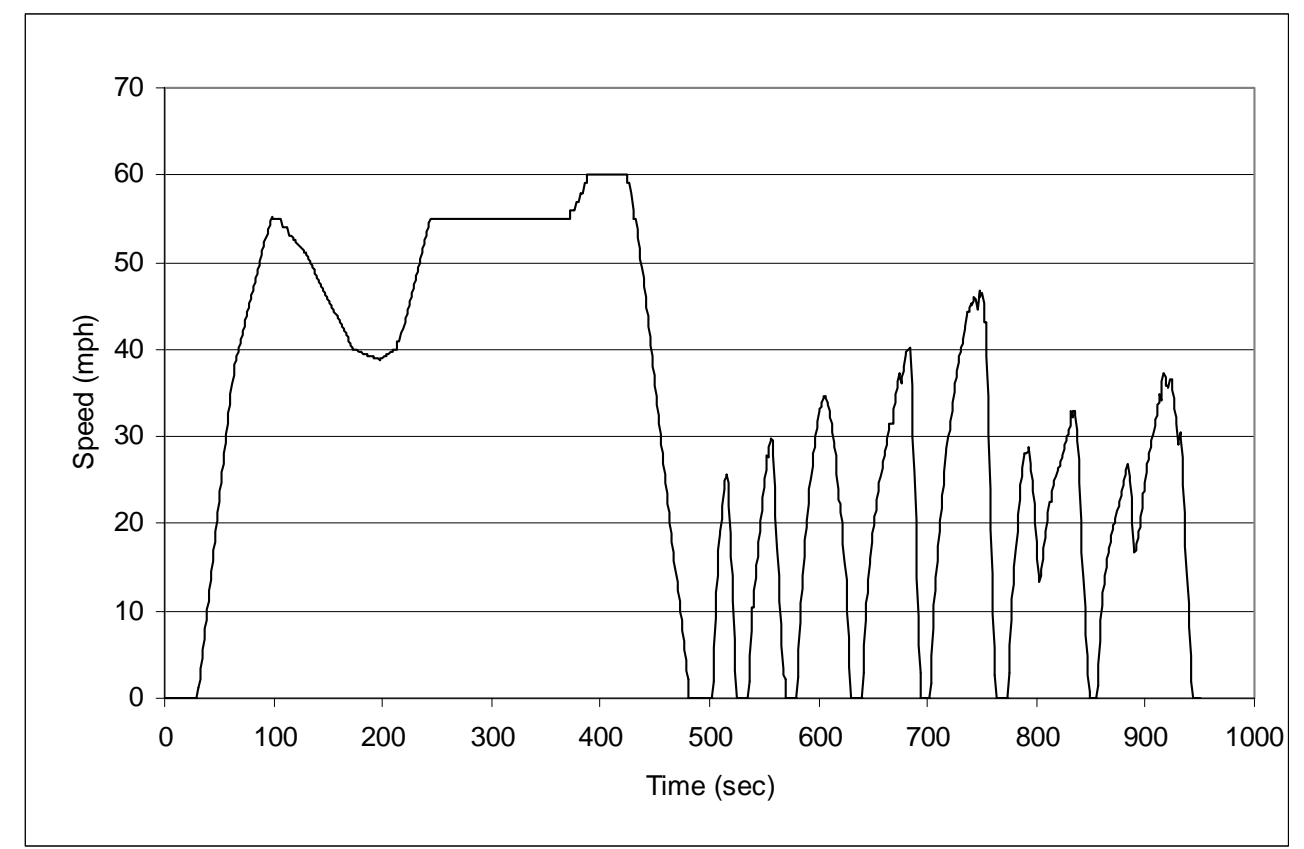

Figure 20: The KCM2 Cycle with the first 950 seconds of the KCM Cycle 


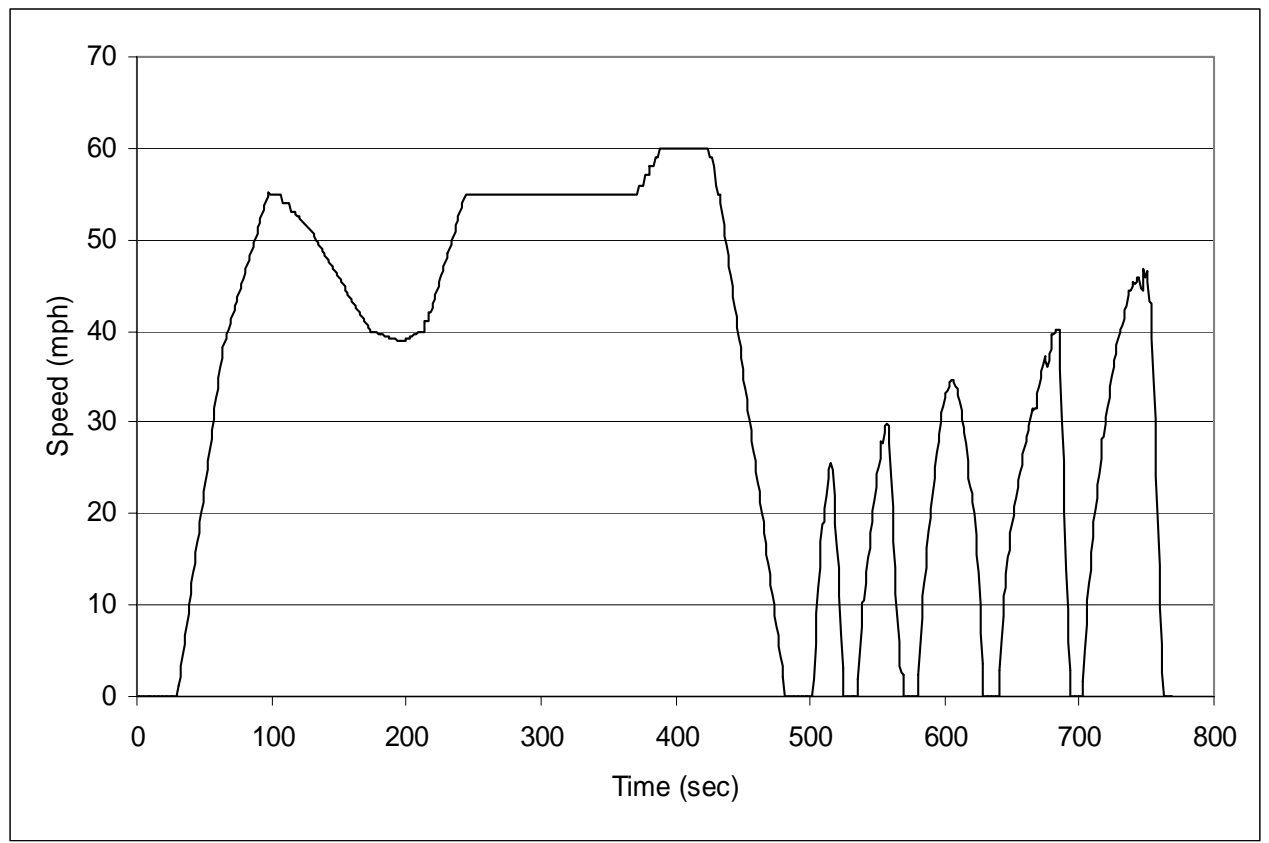

Figure 21: The KCM3 Cycle with the first 770 seconds of the KCM Cycle

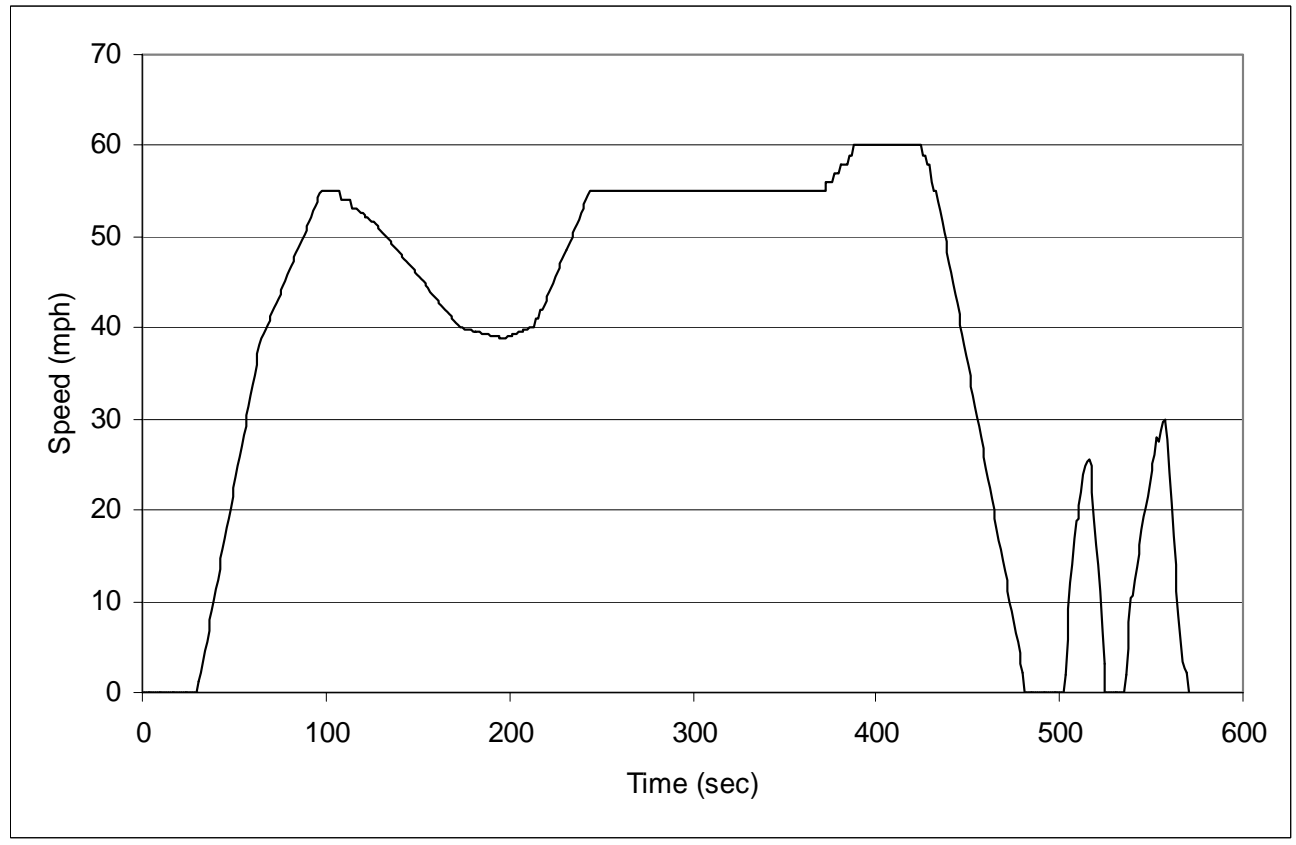

Figure 22: The KCM4 Cycle with the first 570 seconds of the KCM Cycle 
Figure 23 and Figure 24 demonstrates the relationship between average cycle speed of all drive cycles including $\mathrm{KCM} 2, \mathrm{KCM} 3$, and $\mathrm{KCM} 4$ with their percentages of idle and stops per mile, and standard deviations of average speeds, respectively. Inclusion of these three cycles improved the $\mathrm{R}^{2}$ values for the relationship of average cycle speed with percentage of idle and stops per mile from 0.64 and 0.85 to 0.71 and 0.86 , respectively. Inclusion of these three cycles also improved the $\mathrm{R}^{2}$ value for the relationship between standard deviation of average speed and average speed from 0.81 to 0.86 .

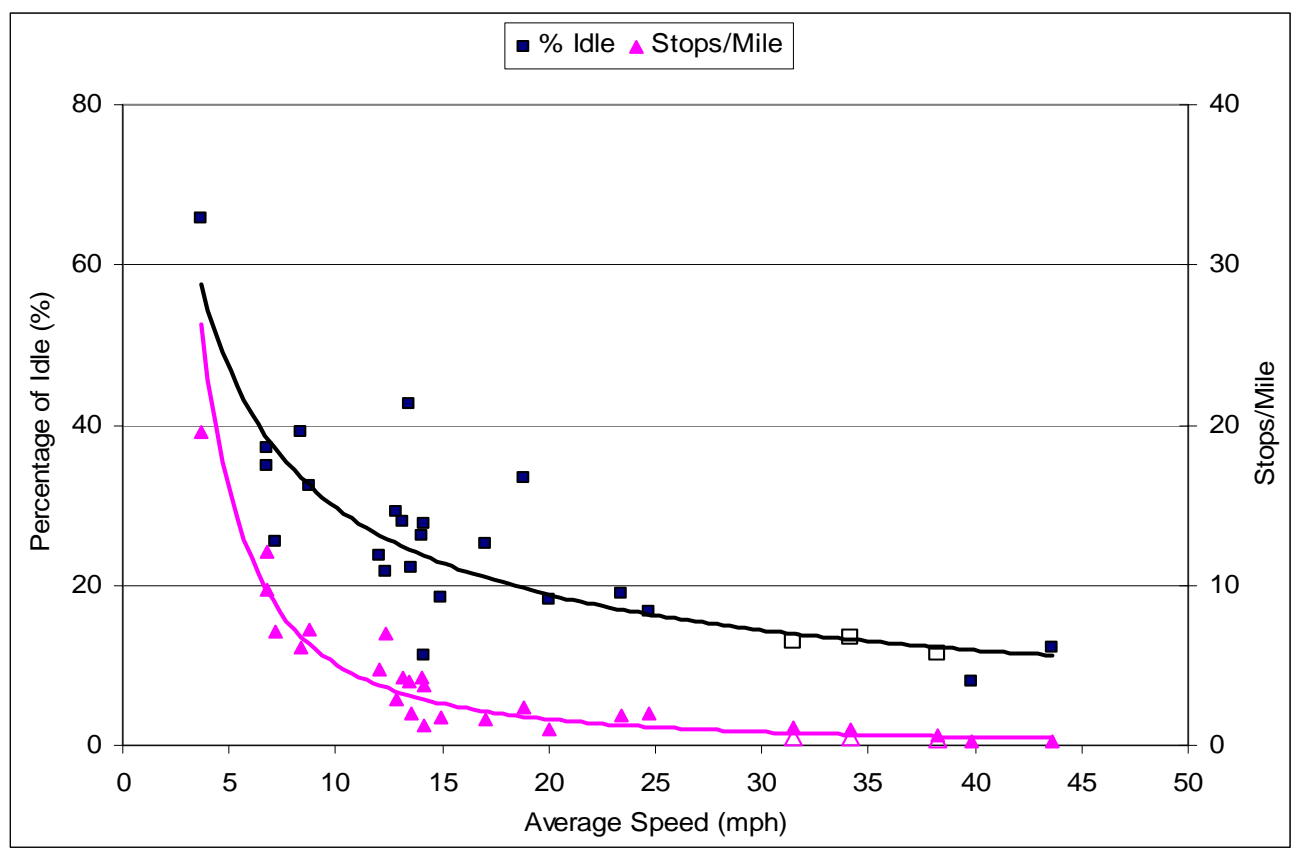

Figure 23: Variation of percentage idle and stops per mile with average cycle speed when KCM2, KCM3, and KCM4 cycles were included (as shown in blank markers) 


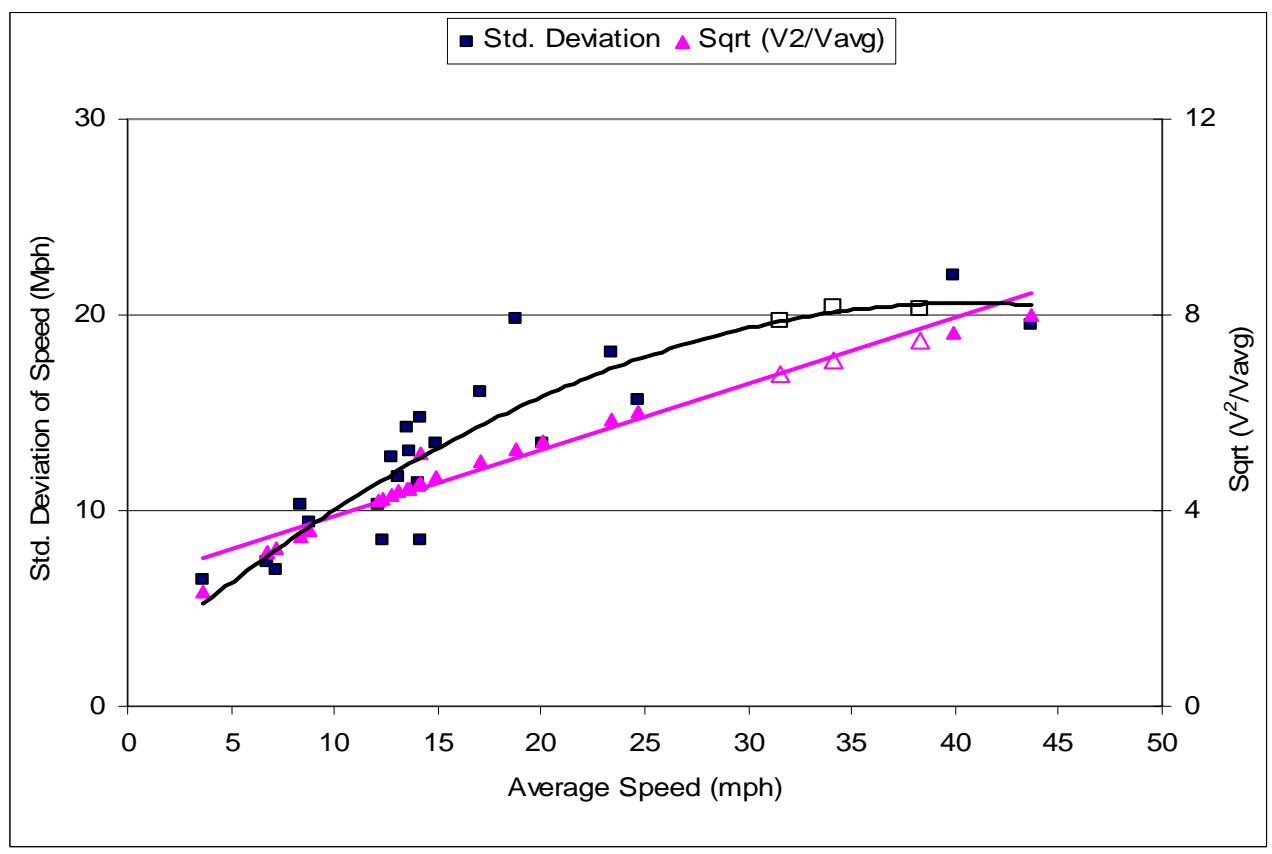

Figure 24: Correlation of standard deviation of speed and square root of the ratio of kinetic energy and average speed with cycle average speed when KCM2, KCM3, and KCM4 cycles were included (as shown in blank markers)

\section{RE-EXAMINATION OF EMISSIONS AND FUEL CONSUMPTION TREND WITH} AVERAGE SPEED

NOx emissions and FC from the second Cummins ISM diesel bus (Bus \# 6150 in Table 1) were plotted against the average speed of cycles that also included the newly created three sub-cycles. Cycle-average distance-specific emissions for these sub-cycles were determined from the continuous data collected over the KCM Cycle. FC was inferred by carbon balance. NOx emissions and FC from this bus are presented in Figure 25 and Figure 26. NOx emissions presented a strong correlation with cycle average speed that induced an $\mathrm{R}^{2}$ value of 0.94 while FC generated an $\mathrm{R}^{2}$ value of 0.84 . 


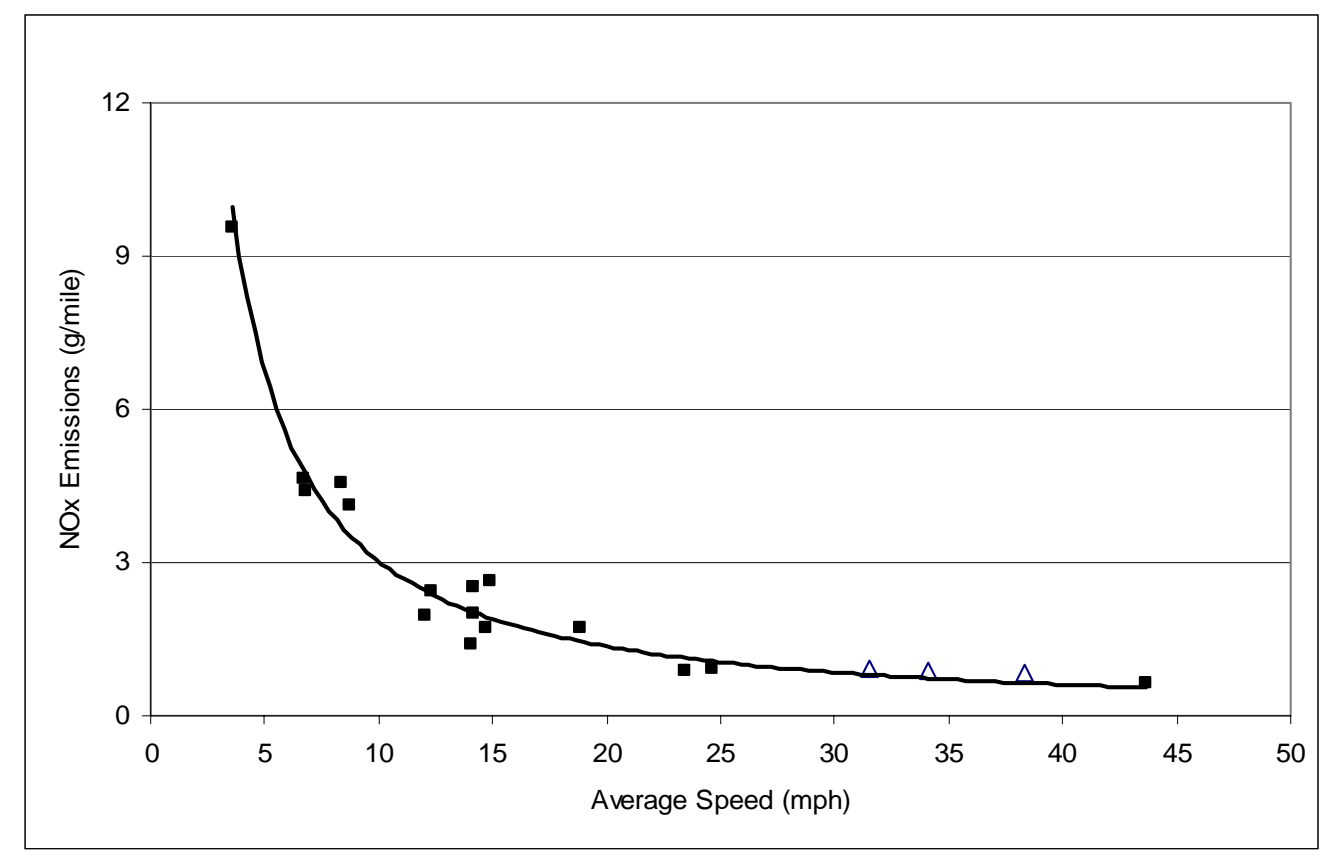

Figure 25: NOx trend with average speed. Note that NOx emissions calculated for the new KCM sub-cycles (shown in blank triangle) fit well with the trend

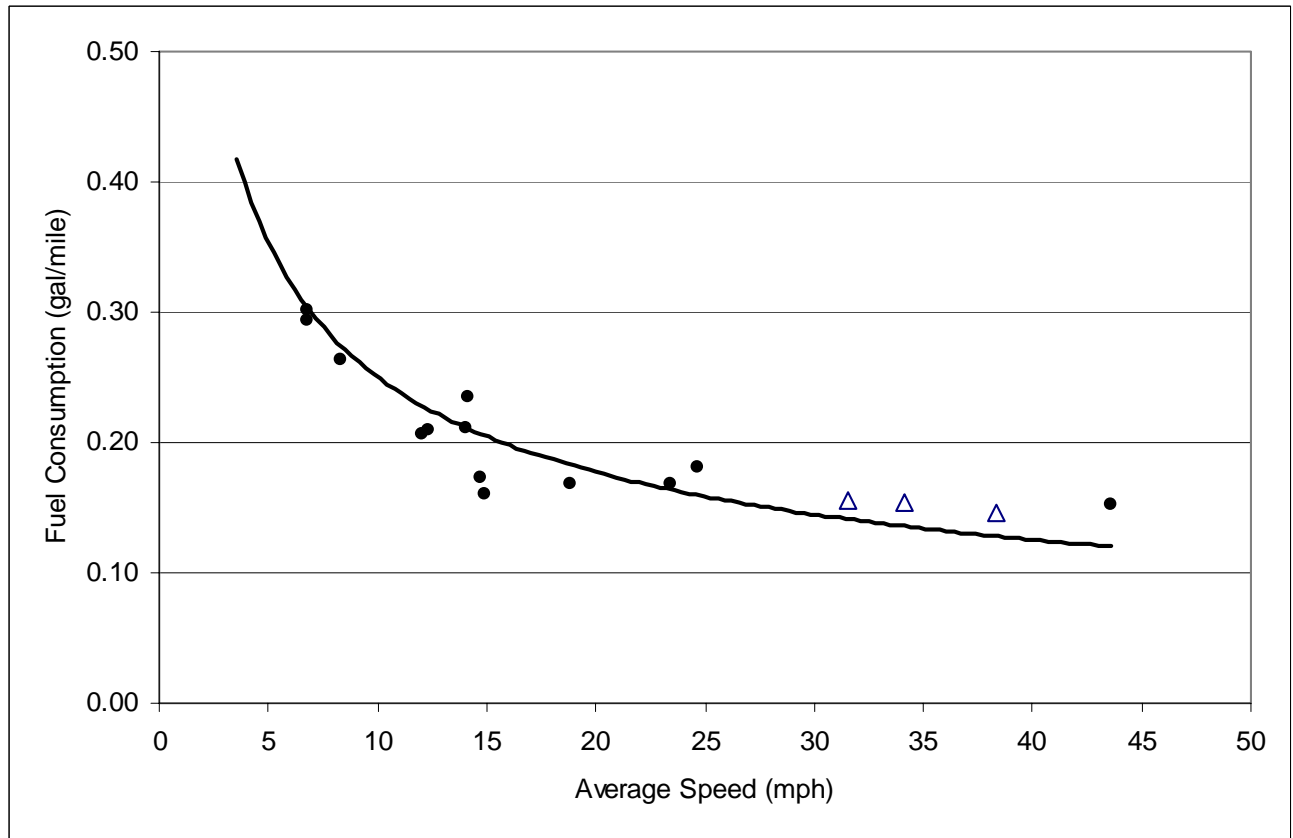

Figure 26: FC trend with average speed. Note that FC calculated for the new KCM sub-cycles (shown in blank triangle) fit well with the trend 


\section{SUMMARY ON SPEED EFFECT}

Effect of speed on distance-specific emissions and FC was first explained using the roadload equation. It was observed that vehicle speed and its acceleration and deceleration affected emissions and FC from a single bus when it was operating on level terrain and constant weight. It was also observed that reducing rolling resistance coefficient resulted in uniform reduction in total load for all cycles while reducing drag coefficient resulted in significant reduction in total load from high speed cycles.

This analysis was followed by observing the speed effect on experimental emissions and FC data collected from diesel, CNG, and hybrid-electric buses tested on seventeen drive cycles. These cycles had average speed ranging from $3.69 \mathrm{mph}$ on the NYBus Cycle to $43.64 \mathrm{mph}$ on the Commuter Cycle. Distance-specific NOx and FC were highly affected by the average cycle speed and demonstrated an inverse trend with increasing speed. Distance-specific HC and PM from diesel and CNG buses followed similar trend but from hybrid buses they were too low to follow any trend. This finding was supported by creating some artificial sub-cycles with average speed more than $30 \mathrm{mph}$ since only one cycle (the Commuter Cycle) in this analysis had average speed more than $40 \mathrm{mph}$. A total of three sub-cycles were created from the KCM Cycle used in the WMATA program. Emissions and FC for these sub-cycles, interpreted from continuous data collected on the $\mathrm{KCM}$ Cycle, further demonstrated that average speed of cycles established good correlations with FC and emissions, especially NOx. 


\section{EFFECT OF PASSENGER WEIGHT ON FUEL CONSUMPTION AND EMISSIONS}

THEORY

The weight effect was examined using the road-load equation without the road grade.

$\mathrm{AHP}=\mathrm{mv}(\mathrm{dv} / \mathrm{dt})+0.5 \mathrm{C}_{\mathrm{D}} \rho \mathrm{Av}^{3}+\mu \mathrm{mgv} \quad$ [Equation 2]

The road-load equation was integrated over the duration of a cycle to project total power demanded on the rear axle of the vehicle over the cycle. This integration did not include negative values (deceleration) that implied service braking, because the engine could not use this energy constructively. Arguing the crossover points where the axle torque and flywheel torque change sign was complex, it was reasonable to integrate only positive values in the equation, even though some more arguments could be made for the threshold below which one should not integrate. The integral values for the OCTA Cycle, the Paris Cycle, and the Braunschweig Cycle, for a 40-ft transit bus at three test weights: empty or no passenger weight, half passenger weight, and full passenger weight, are shown in Table 2, Table 3, and Table 4, respectively. The empty weight was calculated by combining the driver's weight and the vehicle curb weight, while the full weight was determined by combining the vehicle's curb weight with $100 \%$ passenger weight and the driver's weight. Similarly, half weight was determined by combining the vehicle's curb weight with the driver's weight plus $50 \%$ of the full load passenger's weight. 
Table 2: Wind drag, rolling resistance, inertia, and total load at empty weight, half weight, and full weight over the OCTA Cycle

\begin{tabular}{|l|c|c|c|}
\hline \multirow{2}{*}{$\begin{array}{l}\text { OCTA } \\
\text { Cycle }\end{array}$} & \multicolumn{3}{|c|}{ Passenger Loading [kg] } \\
\cline { 2 - 4 } & $\begin{array}{c}\text { Empty } \\
\text { Weight } \\
{[14,700]}\end{array}$ & $\begin{array}{c}\text { Half } \\
\text { Weight } \\
{[16,800]}\end{array}$ & $\begin{array}{c}\text { Full } \\
\text { Weight } \\
{[18,800]}\end{array}$ \\
\hline $\begin{array}{l}\text { Average Vehicle } \\
\text { Speed (mph) }\end{array}$ & \multicolumn{3}{|c|}{12.1} \\
\hline Wind Drag (kW-hr) & \multicolumn{3}{|c|}{1.12} \\
\hline $\begin{array}{l}\text { Rolling } \\
\text { Resistance (kW-hr) }\end{array}$ & 3.38 & 3.85 & 4.32 \\
\hline Inertia Load (kW-hr) & 8.61 & 9.80 & 11.0 \\
\hline Total Load (kW-hr) & 13.1 & 14.8 & 16.4 \\
\hline
\end{tabular}

Table 3: Wind drag, rolling resistance, inertia, and total load at empty weight, half weight, and full weight over the Paris Cycle

\begin{tabular}{|l|c|c|c|}
\hline \multirow{2}{*}{$\begin{array}{l}\text { Paris } \\
\text { Cycle }\end{array}$} & \multicolumn{3}{|c|}{ Passenger Loading } \\
\cline { 2 - 4 } & $\begin{array}{c}\text { Empty } \\
\text { Weight }\end{array}$ & $\begin{array}{c}\text { Half } \\
\text { Weight }\end{array}$ & $\begin{array}{c}\text { Full } \\
\text { Weight }\end{array}$ \\
\hline $\begin{array}{l}\text { Average Vehicle } \\
\text { Speed (mph) }\end{array}$ & \multicolumn{3}{|c|}{6.74} \\
\hline Wind Drag (kW-hr) & \multicolumn{3}{|c|}{0.32} \\
\hline $\begin{array}{l}\text { Rolling } \\
\text { Resistance (kW-hr) }\end{array}$ & 1.81 & 2.06 & 2.31 \\
\hline Inertia Load (kW-hr) & 5.18 & 5.90 & 6.62 \\
\hline Total Load (kW-hr) & 7.30 & 8.27 & 9.24 \\
\hline
\end{tabular}


Table 4: Wind drag, rolling resistance, inertia, and total load at empty weight, half weight, and full weight over the Braunschweig Cycle

\begin{tabular}{|l|c|c|c|}
\hline \multirow{2}{*}{ Braunschweig Cycle } & \multicolumn{3}{|c|}{ Passenger Loading } \\
\cline { 2 - 4 } & $\begin{array}{c}\text { Empty } \\
\text { Weight }\end{array}$ & $\begin{array}{c}\text { Half } \\
\text { Weight }\end{array}$ & $\begin{array}{c}\text { Full } \\
\text { Weight }\end{array}$ \\
\hline $\begin{array}{l}\text { Average Vehicle } \\
\text { Speed (mph) }\end{array}$ & \multicolumn{3}{|c|}{14.1} \\
\hline Wind Drag (kW-hr) & 3.51 & 4.00 & 4.48 \\
\hline $\begin{array}{l}\text { Rolling } \\
\text { Resistance (kW-hr) }\end{array}$ & 9.13 & 10.4 & 11.7 \\
\hline Inertia Load (kW-hr) & 14.1 & 15.8 & 17.6 \\
\hline Total Load (kW-hr) & & & \\
\hline
\end{tabular}

For the same vehicle on a dynamometer, over a drive cycle, the wind drag remained constant over these test weights. The differences in rolling resistance, inertia load, and the total load due to the three test weights of the bus on the first 100 seconds duration of the Braunschweig Cycle are presented in Figure 27, Figure 28, and Figure 29, respectively. 


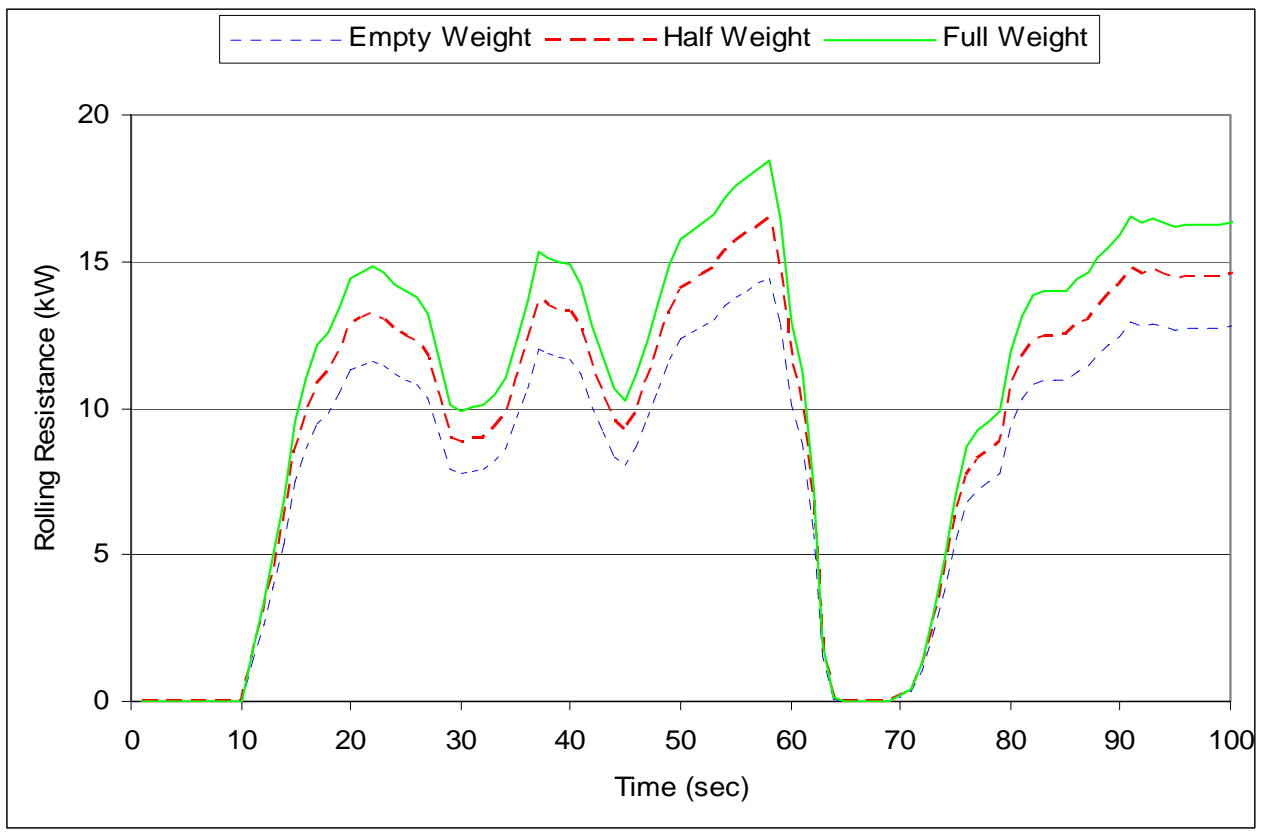

Figure 27: Comparison of rolling resistances for the three test weights on the first 100 seconds of the Braunschweig Cycle

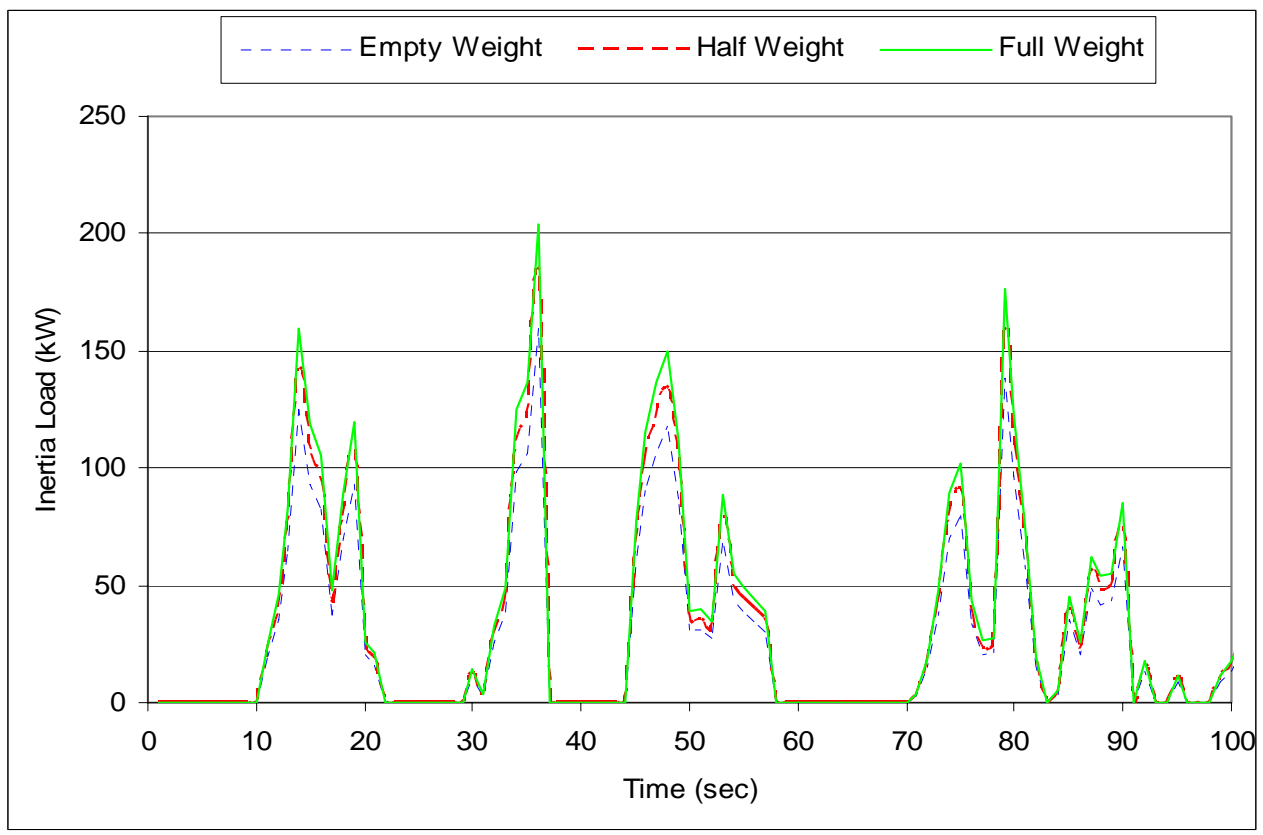

Figure 28: Comparison of inertia loads for the three test weights on the first $\mathbf{1 0 0}$ seconds of the Braunschweig Cycle 


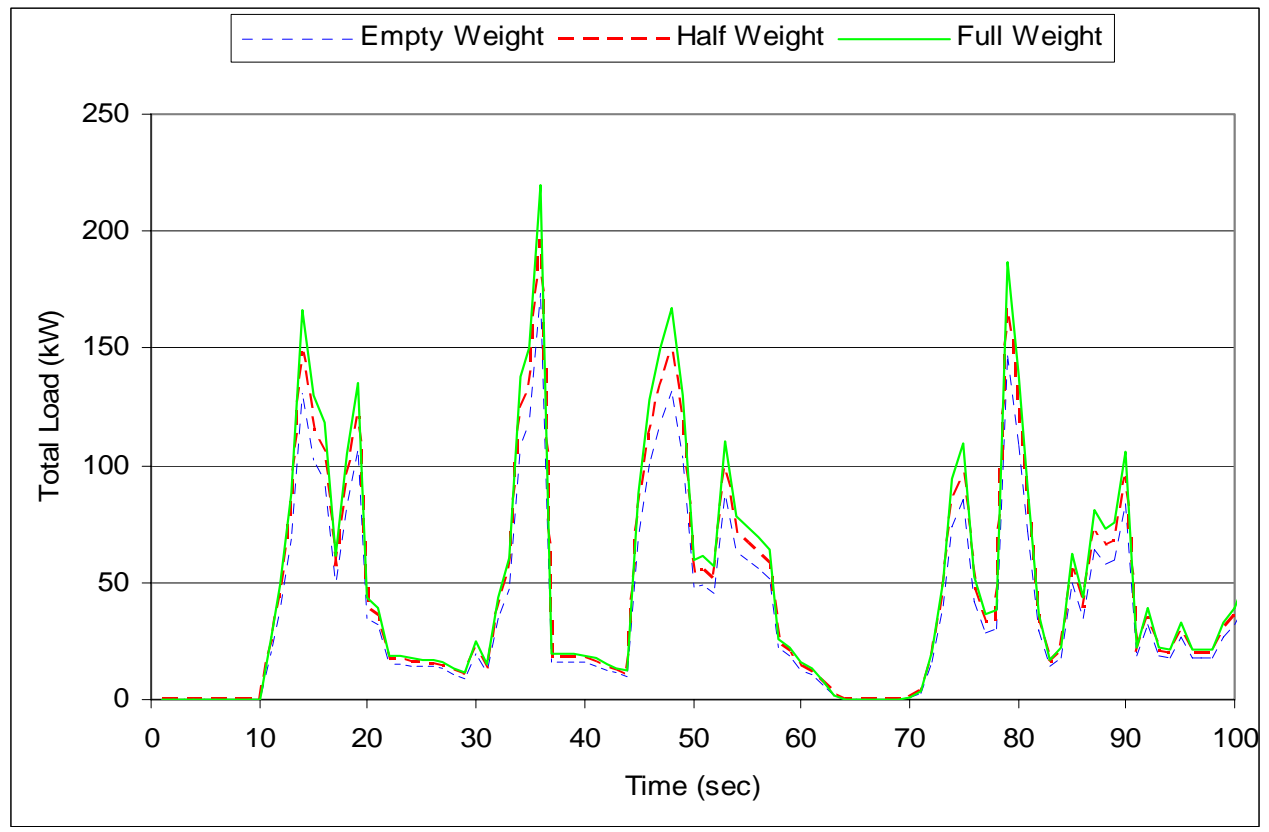

Figure 29: Comparison of total loads for the three test weights on the first 100 seconds of the Braunschweig Cycle

The load experienced by the engine would differ substantially from the total load, as shown in Table 2, Table 3, and Table 4. First, the drivetrain efficiency was considered. The transmission played a major role in consuming drivetrain energy. Conventional North American transit buses had automatic transmissions, and the efficiency of the transmission would vary widely over the operating envelope. One might have expected the transmission efficiency to be high during high speed operation, especially if the torque converter was locked, but far lower efficiency could be expected during low speed acceleration. Second, the engine would be burdened with auxiliary loads, including the alternator and air compressor loads, and the fan load. Fan loads might have been substantial in rear-engine buses, where little natural cooling occurs. Transmission of power from the engine to the fan might also be inefficient. 
Systems modeling of vehicle energy flow was possible using models such as the Advanced Vehicle Simulator (ADVISOR) [100] and the Powertrain System Analysis Toolkit (PSAT) [101,102], but in this research a simplified approach was used to illustrate relative bus weight effect. It was assumed that the automatic transmission had a constant value for efficiency over the whole operating range, and it was assumed that the auxiliary load on the engine was constant. Then, the brake horse power (bhp) demand of the engine was given by:

$\mathrm{BHP}=1 / \mathrm{n}_{\mathrm{d}}(\mathrm{AHP})+\mathrm{HP}_{\mathrm{Aux}} \quad$ [Equation 3]

Where, $\eta_{d}$ was the drivetrain efficiency that encompassed power transfer from the flywheel to the rear wheel rim and $\mathrm{HP}_{\text {Aux }}$ was the power demanded by the auxiliary loads including the fan load. It was simplistic to characterize drivetrain losses with a fixed value of $\eta_{d}$, because some drivetrain losses were proportional to speed, rather than load. Losses that were proportional to speed for a given cycle would appear more like auxiliary loads because they were insensitive to test weight. When the auxiliary load was calculated from bus data later in this dissertation, some of the losses which were proportional to speed were lumped with $\mathrm{HP}_{\text {Aux }}$.

The fuel consumed by the engine would not be in proportion to the power demand, because the engine operated more efficiently at high load, and suffered proportionally higher losses to friction at low load. One might model the fuel consumed by the engine using an equation very similar to that used for instantaneous power. However, the constant value would have accounted not only for auxiliary loads, but also for frictional losses which were most significant at light loads. In the case of throttled engines, used for natural gas buses, the constant value would also need to account for pumping losses across the throttle. Fuel consumption, therefore, was expressed as:

$$
\mathrm{m}_{\mathrm{f}}=\left[1 / \mathrm{y}_{\mathrm{d}}(\mathrm{AHP})+\mathrm{HP}_{\text {Aux }}\right] /\left(\mathrm{y}_{\mathrm{f}} * \mathrm{Q}_{\mathrm{HV}}\right) \quad \text { [Equation 4] }
$$

Where, $\mathrm{m}_{\mathrm{f}}$ was the amount of fuel consumed per unit time, $\mathrm{Q}_{\mathrm{HV}}$ was the heating value of fuel, and $\mathrm{y}_{\mathrm{f}}$ was the fuel conversion efficiency [103]. In this simplified model for fuel 
consumption, three parameters were unknown, namely the drivetrain efficiency, fuel conversion efficiency, and the auxiliary power.

Auxiliary load for transit buses might typically include operating cooling fan, oil pump, coolant pump, fuel pump, steering fluid pump, hydraulic pump, alternator, air compressor, and A/C compressor. Auxiliary load could be about 20 hp for class 8 tractor trucks [104]. For transit buses this load was higher because of the placement of bus engine at its rear, thus inducing greater fan load than trucks. Auxiliary loads for a transit

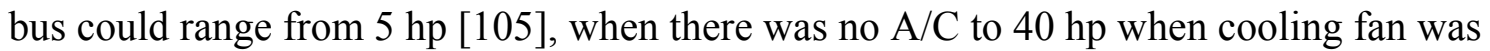
engaged and the $\mathrm{A} / \mathrm{C}$ was in operation. Virden et al. [106] demonstrated that auxiliary load for transit buses could be as high as 40 to $50 \mathrm{hp}$ if the operation of bus doors, compartment fans, communication equipment, computer, and multiplex system were also considered.

In this research, the major focus was on the way in which the fuel consumed and the emissions produced were affected by bus weight. Therefore, the ratio of fuel consumption between empty test weights (EW) and fully loaded test weights (FW) was expressed as follows:

$\mathrm{m}_{\mathrm{f}(\mathrm{EW})} / \mathrm{m}_{\mathrm{f}(\mathrm{FW})}=$ $\left(1 / \mathfrak{y}_{\mathrm{d}}(\mathrm{AHP})_{\mathrm{EW}}+\mathrm{HP}_{\mathrm{Aux}}\right) /\left(1 / \mathrm{y}_{\mathrm{d}}(\mathrm{AHP})_{\mathrm{FW}}+\mathrm{HP}_{\mathrm{Aux}}\right) \quad$ [Equation 5]

If a fixed value for auxiliary load and a value for the drivetrain efficiency (such as $75 \%$ ), was chosen then the ratio of FC between empty test weight and full test weight could be computed using the total load estimated for these two test weights, as shown in Table 4, Table 5, and Table 6, for the OCTA, the Paris, and the Braunschweig cycles, respectively. Considering that the auxiliary load demanded from the engine were in the range of $5 \mathrm{hp}$ to about $40 \mathrm{hp}$ (with fan), the predicted ratios of FC between these two weights for the OCTA Cycle with three drivetrain efficiencies $(70 \%, 75 \%$, and $80 \%)$, are shown in Figure 30 while Figure 31 shows the predicted ratios with auxiliary load in horsepower (hp) for the OCTA, the Paris, and the Braunschweig cycles with assumed drivetrain efficiency of $75 \%$. The predicted ratios in FC at empty test weight and full test 
weight ranged from about 0.83 to about 0.91 for the OCTA and the Braunschweig cycles, while for the Paris Cycle this ratio ranged from 0.84 to 0.94 . This was reasonable since the average speed of the OCTA and the Braunschweig cycles $(5.40 \mathrm{~m} / \mathrm{sec}$ and 6.26 $\mathrm{m} / \mathrm{sec}$ ) were similar, and both were substantially higher than the average speed of the Paris Cycle $(2.95 \mathrm{~m} / \mathrm{sec})$. However, auxiliary load was an important parameter in determining this ratio. The difference in FC between empty weight and full test weight decreased as the auxiliary load increased, as shown in Figure 30 and Figure 31.

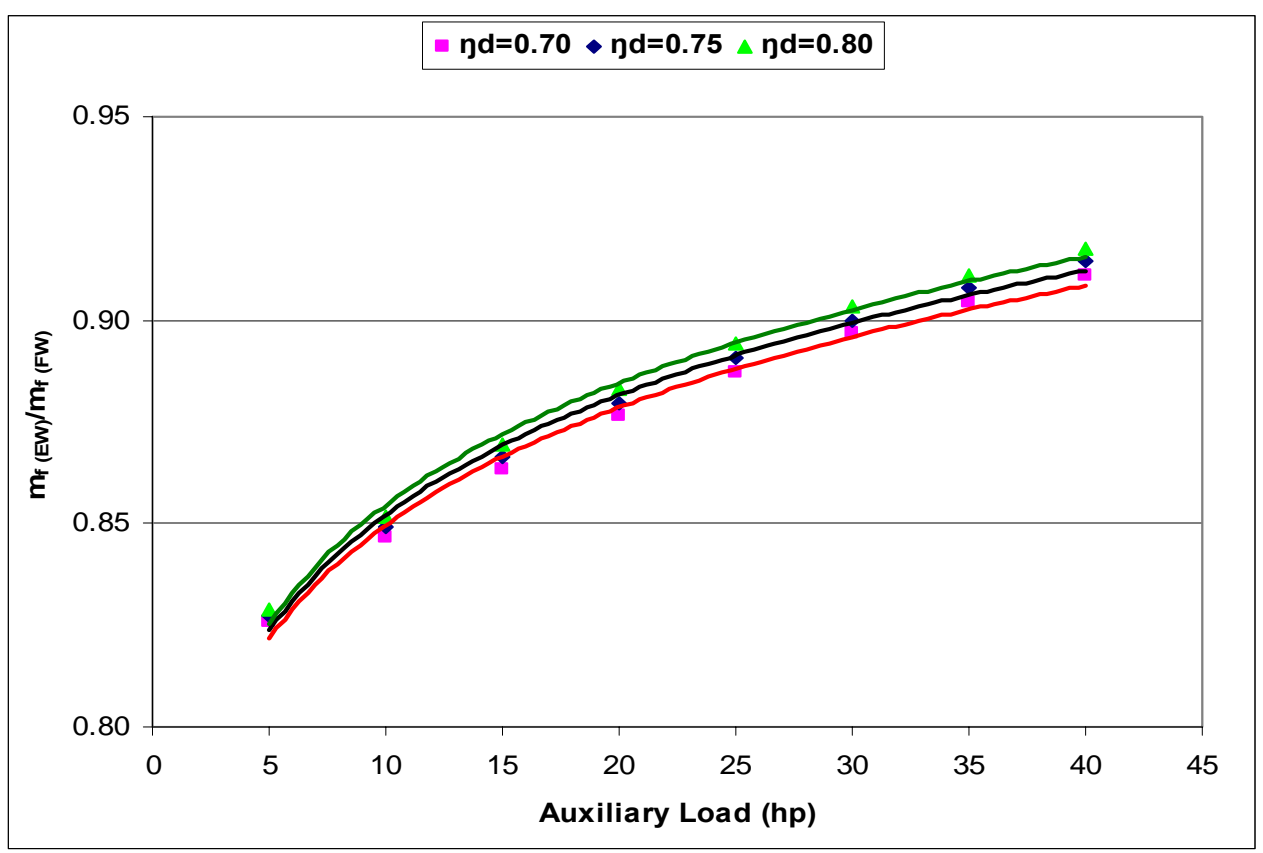

Figure 30: Predicted ratio of fuel consumption per unit time between empty weight and full weight with auxiliary power on the OCTA Cycle with drivetrain efficiency of $70 \%, 75 \%$, and $80 \%$ 


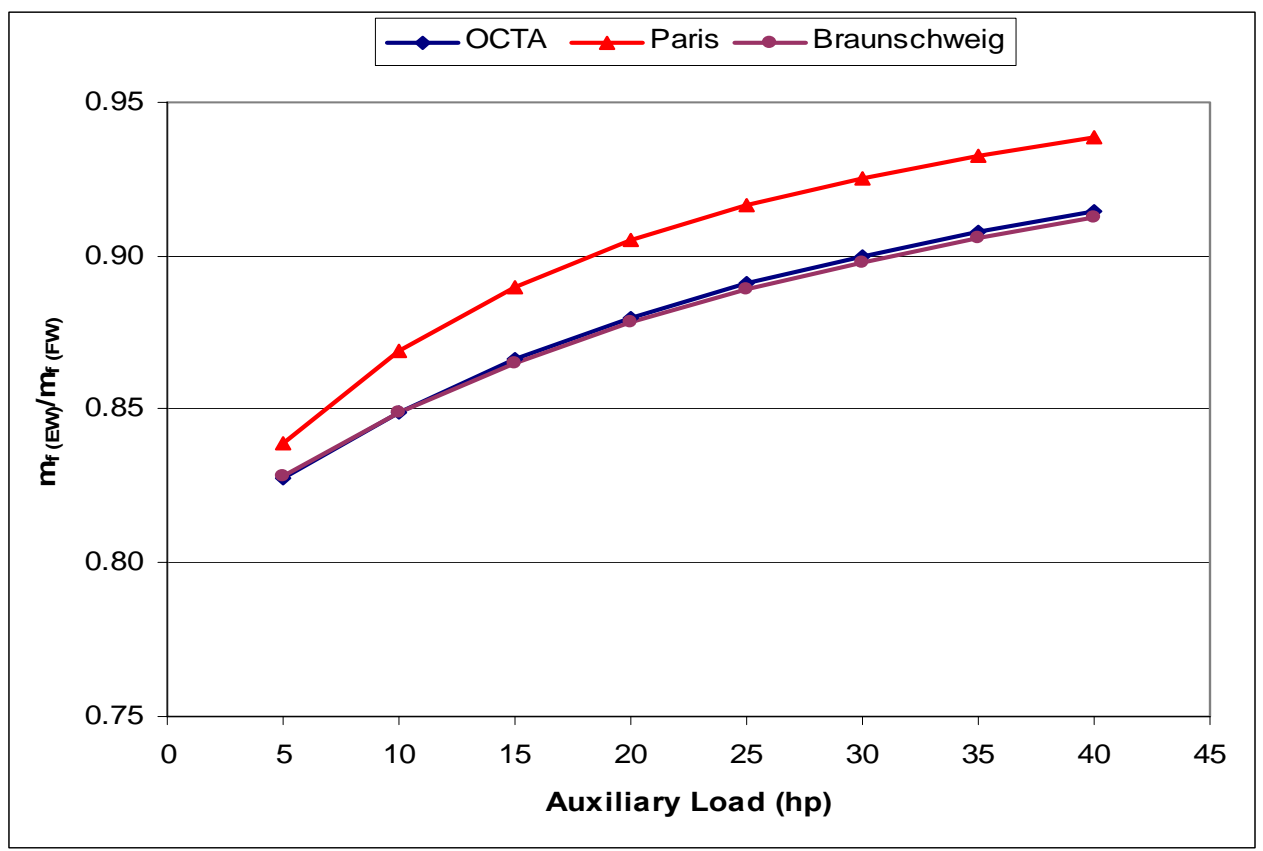

Figure 31: Predicted ratio of fuel consumption per unit time between empty weight and full weight with auxiliary power on the OCTA, the Paris, and the Braunschweig cycles, with assumed drivetrain efficiency of $75 \%$

\section{EXPERIMENTAL ANALYSIS}

Weight effect was observed using the emissions and FC data from the John Deere CNG (Bus \# 2640), the Cummins CNG (Bus \# 2503), and the Retrofitted diesel (Bus \# 9654) buses.

\section{John Deere CNG Bus}

The relative effect of the three test weights on emissions and FC from the John Deere CNG bus on the OCTA, the Paris, and the Braunschweig cycles are presented in Figure 32, Figure 33, and Figure 34, respectively. The blank spaces in these figures indicated that respective data were not reported as they were below the detectable limit of the analyzers. Distance-specific NOx emissions from this bus were slightly higher at empty weight than at full weight, which did not follow the modeled FC trend. However, NOx 
from this bus was the highest at half weight on all cycles. However, test weight in this research increased by about $28 \%$ from the empty weight to the full test weight. This small difference might not have been sufficient to project the difference in NOx emissions due to the test weight.

$\mathrm{CO}$ and PM were very low, variable, and showed no strong trend to test weights. This bus emitted about $0.08 \mathrm{~g} / \mathrm{mile}$ of $\mathrm{CO}$ and $0.01 \mathrm{~g} / \mathrm{mile}$ of PM on the OCTA Cycle, on average. $\mathrm{HC}$ emissions at full weight were higher than those at empty and half test weights except on the Braunschweig Cycle, where they were higher by a small margin. $\mathrm{CO}_{2}$ emissions at empty weight were less by $7-10 \%$ than those at full weight on all cycles. However, no difference in $\mathrm{CO}_{2}$ emissions was observed between half weight and full weight on the OCTA and the Paris cycles. FC followed the same trend as $\mathrm{CO}_{2}$ emissions. The ratios of FC from this bus between empty weight and full weight were $0.93,0.91$, and 0.91 for the OCTA, the Paris, and the Braunschweig cycles, respectively. These ratios, suggested from the simple model (Figure 31) that the bus experienced a high auxiliary load, about $25 \mathrm{hp}$ during the Paris Cycle and about 35 hp during the Braunschweig Cycle. During the OCTA Cycle this bus demanded auxiliary power in excess of $40 \mathrm{hp}$. As noted for Equation 3 above, this auxiliary load term might have included some losses in the drivetrain which were reflective of low drivetrain efficiency associated with CNG technology. The assumption of constant drivetrain efficiency might not have accounted for these losses and were lumped with auxiliary losses. In other words, the auxiliary losses and constant drivetrain efficiency assumption led to a linear model, which attempted to fit a non-linear system dependent on engine and drivetrain efficiency maps. It needed to be mentioned here that chassis testing did not include $\mathrm{A} / \mathrm{C}$ effect on emissions and FC. 


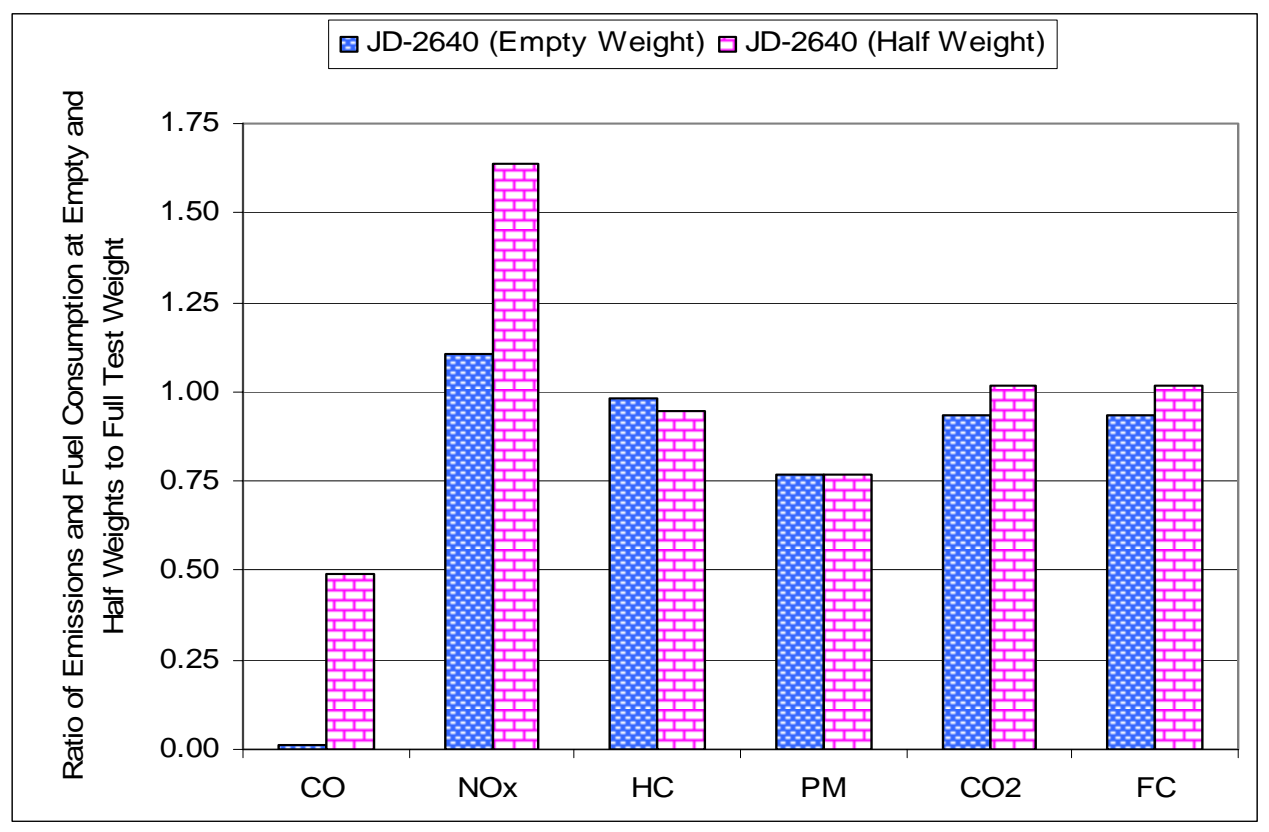

Figure 32: Ratio of emissions and fuel consumption at empty weight and half weight to those at full test weight from the John Deere CNG bus on the OCTA Cycle

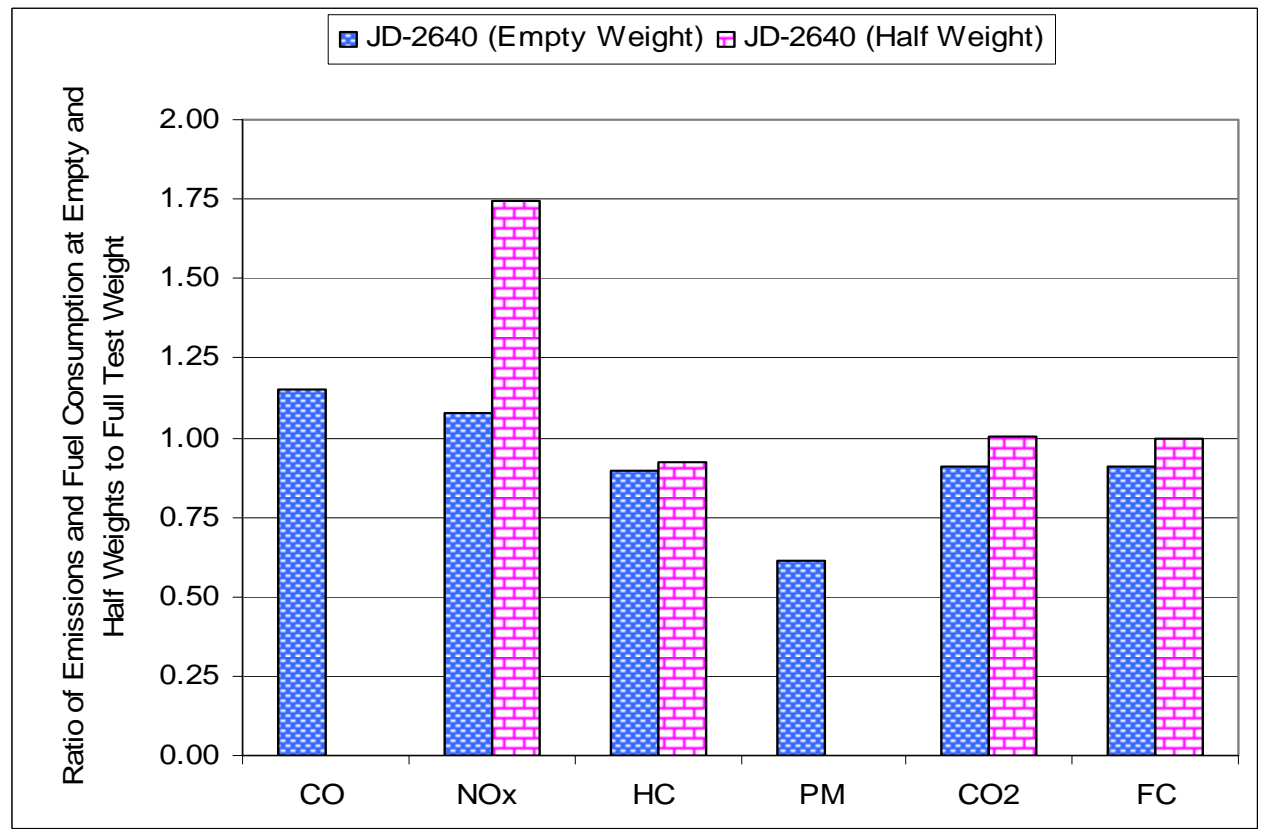

Figure 33: Ratio of emissions and fuel consumption at empty weight and half weight to those at full test weight from the John Deere CNG bus on the Paris Cycle 


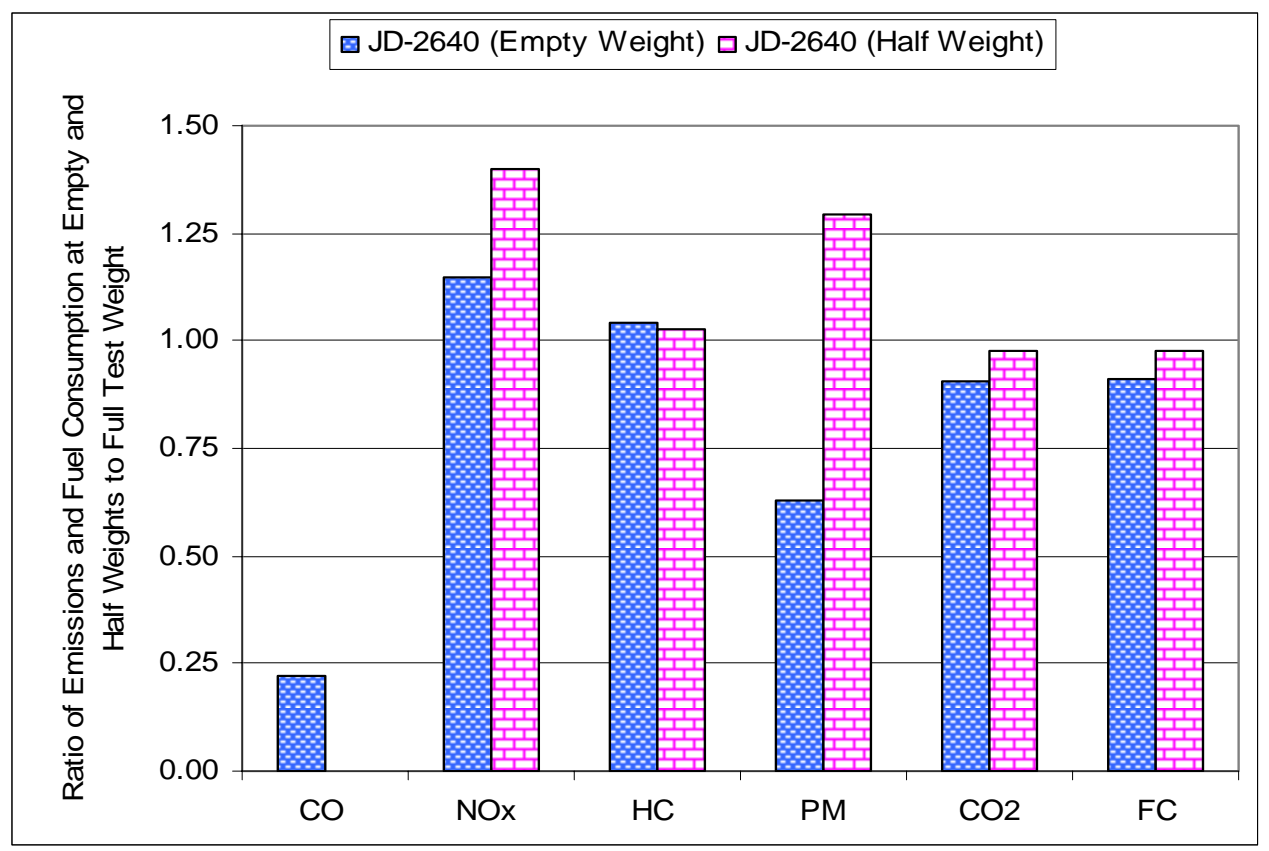

Figure 34: Ratio of emissions and fuel consumption at empty weight and half weight to those at full test weight from the John Deere CNG bus on the Braunschweig Cycle

There were some reasons that emissions from a bus varied other than due to the test weights. These reasons included FC, specific changes in laboratory configuration, human driving variability, effect of test weight on automatic transmission behavior, weather conditions, and test-to-test variability.

The John Deere bus was not refueled during the testing. No reconfiguration of the Translab occurred, and no analyzer replacement was carried out. The same driver, who has about twelve years of experience in dynamometer driving, was used at all test weights.

The spectrum of engine speeds measured during operation at the three test weights was examined. Figure 35 showed that the engine spent a small fraction of time at high engine speed at empty and half weights relative to full weight on the OCTA Cycle. For example, during the test the engine spent about 129 seconds (about $7 \%$ of total operation) above 
1800 revolutions per minute (rpm) at full weight but only 101 seconds (about 5\%) at half weight. Noting that NOx production was dependant on the degree of throttling on spark ignited engines, it was credible that the engine speed could have precipitated differences in NOx levels. However, examination of Figure 35 and the corresponding figure for the Paris Cycle (Figure 36) showed that there was no systematic difference between the half weight and the average of the empty and full weights engine speeds, and therefore, an explanation based on changes in engine operating envelope was not supported by the data.

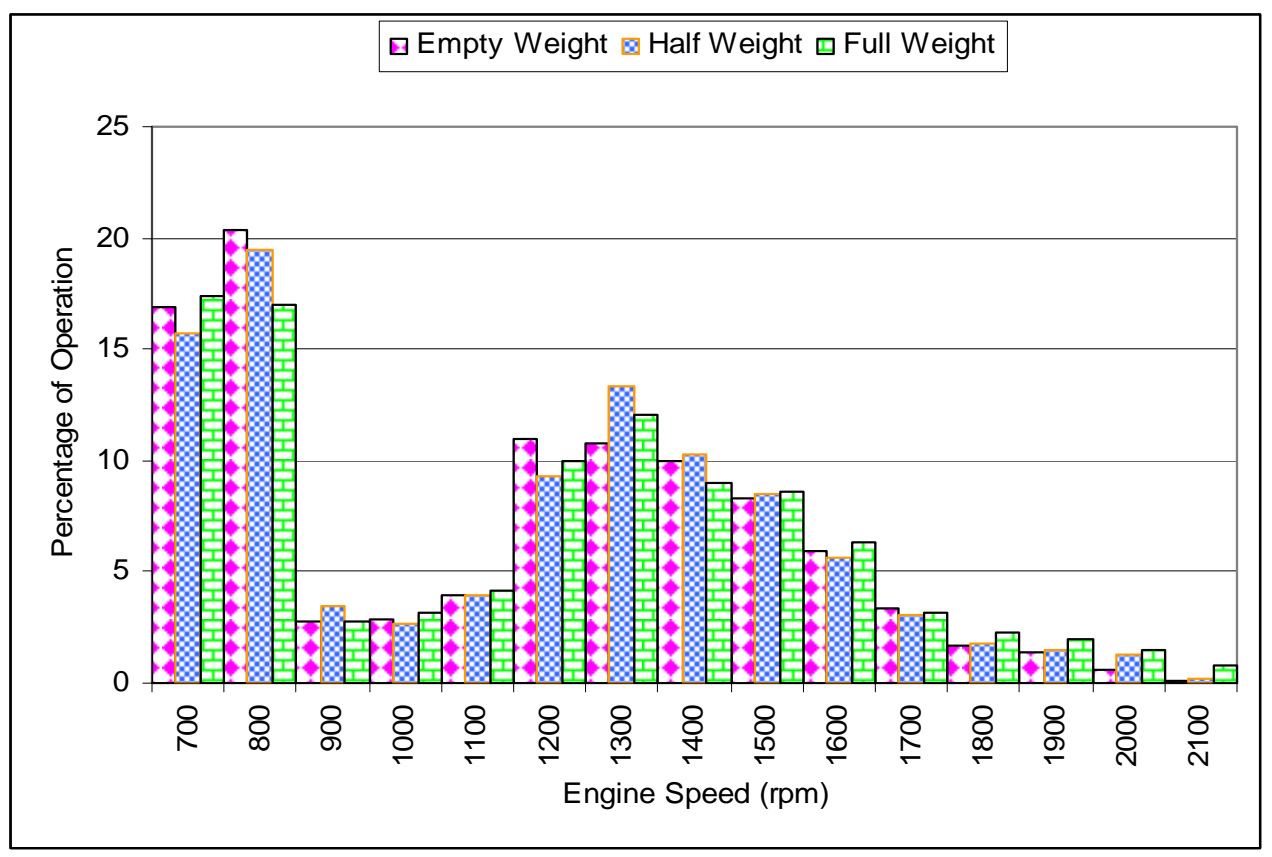

Figure 35: Comparison of the percentage of engine speed distribution for three test weights on the OCTA Cycle 


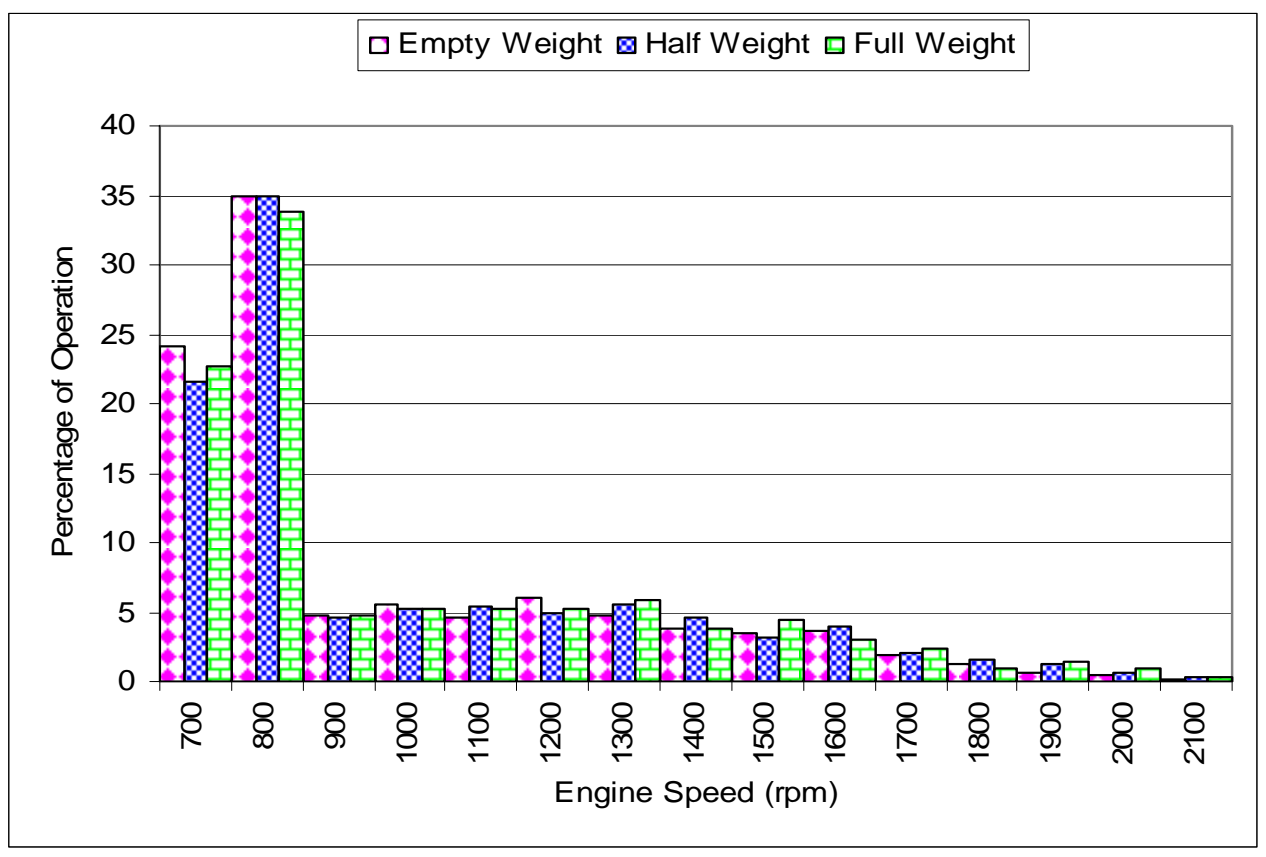

Figure 36: Comparison of the percentage of engine speed distribution for three test weights on the Paris Cycle

There was also a significant change in weather between full weight and half weight testing. Ambient weather records available for the nearest location, the Baltimore/Washington International Airport (BWI), indicated that temperature and humidity during the testing of this bus at full weight were $70^{\circ} \mathrm{F}$ and $61 \%$, respectively while at half weight they were $85^{\circ} \mathrm{F}$ and $49 \%$, respectively [107]. Higher temperature might have increased fan loads, but the FC data did not reflect an increase in NOx at half weight (higher ambient temperature test). Higher ambient temperatures might also increase NOx production directly (although simple calculations showed that the $70^{\circ} \mathrm{F}$ to $85^{\circ} \mathrm{F}$ effect would be on the order of $1 \%$ for NOx production rate in the cylinder), or by interacting with the engine controls.

Test-to-test variability was also taken into consideration. At full weight the NOx varied between the two runs by about $11 \%$ as shown in Figure 37. But the $\mathrm{CO}_{2}$ varied by less than $2 \%$. At half weight the NOx varied by $2 \%$ while the $\mathrm{CO}_{2}$ varied by $4 \%$ as shown in Figure 38. This NOx variability was far below the difference in NOx emissions between full weight and half weight. Therefore, the difference between full weight and half weight 
NOx could be attributed partly to the variations between test runs, partly to the weather differences, and partly to the change in transmission behavior. However, without knowledge of the precise engine control technology, it was not possible to determine the exact cause of this variation.

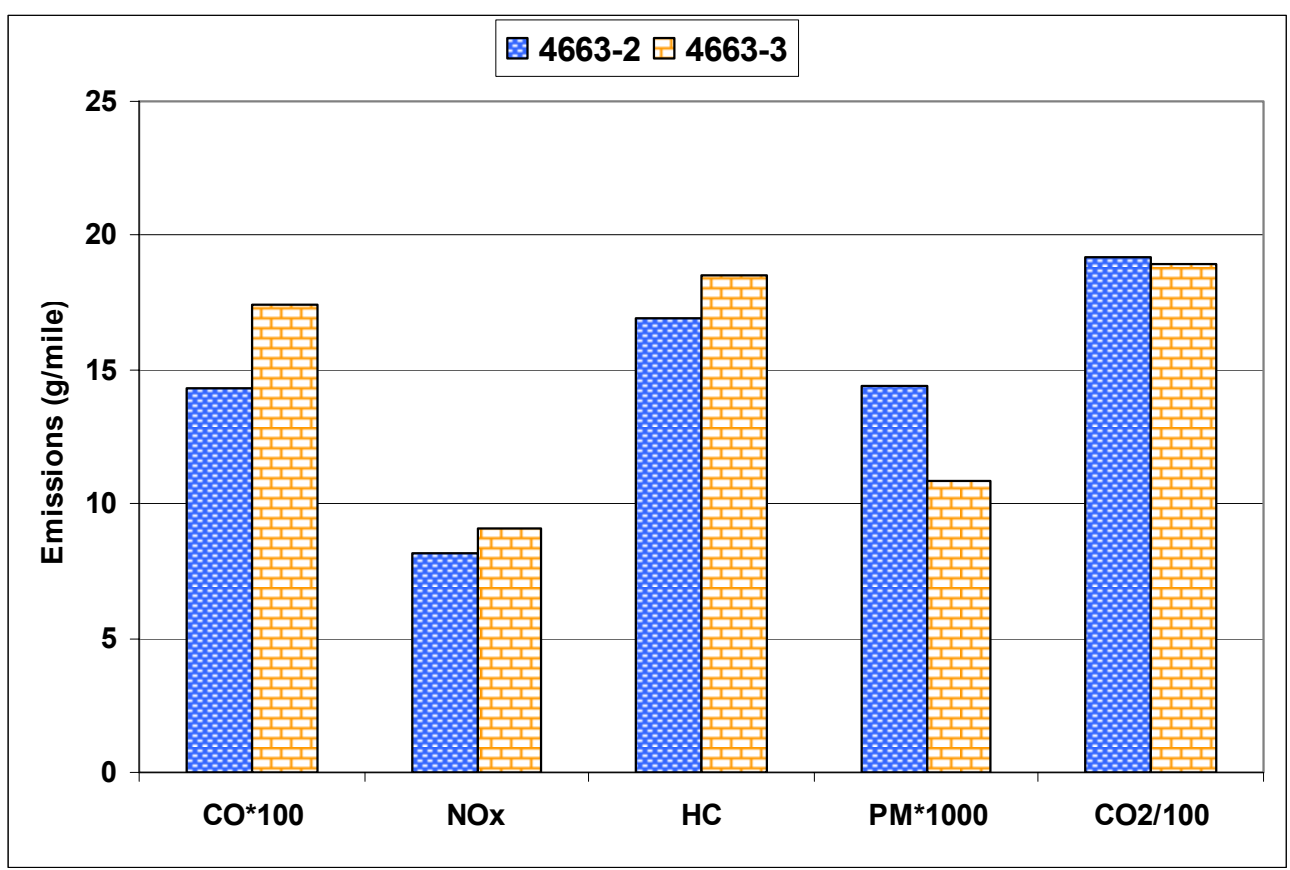

Figure 37: Test-to-test variability of emissions from the John Deere bus at full weight on the OCTA Cycle. Note that the CO and PM scales were increased a 100 and a 1000 fold, respectively, while the $\mathrm{CO}_{2}$ scale was reduced a 100 fold 


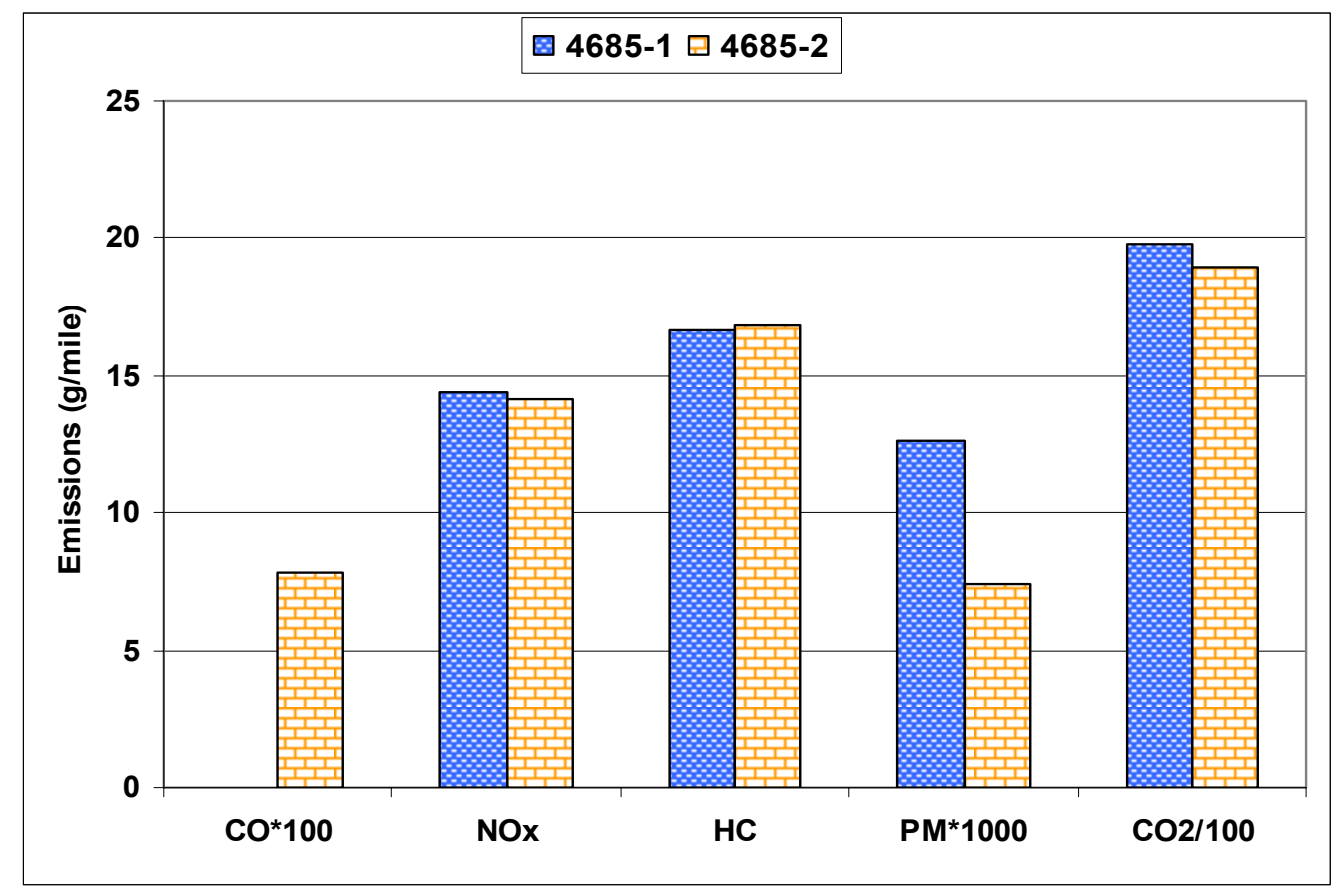

Figure 38: Test-to-test variability of emissions from the John Deere bus at half weight on the OCTA Cycle. Note that the CO and PM scales were increased a 100 and a 1000 fold, respectively, while the $\mathrm{CO}_{2}$ scale was reduced a 100 fold

\section{Cummins CNG Bus}

Figure 39, Figure 40, and Figure 41, present the relative effect of test weight on emissions and FC from the Cummins CNG bus on the OCTA, the Paris, and the Braunschweig cycles, respectively. Mixed effects were observed for distance-specific $\mathrm{CO}, \mathrm{NOx}, \mathrm{HC}$, and $\mathrm{PM}$ emissions from this bus with varying test weights. $\mathrm{HC}$ emissions from this bus were high at half weights on all cycles while CO and PM emissions were insensitive to test weights. $\mathrm{CO}$ and PM emissions from this bus were about $0.54 \mathrm{~g} / \mathrm{mile}$, and $0.01 \mathrm{~g} / \mathrm{mile}$, respectively, on the OCTA Cycle, on average. FC from this bus was higher at full weight than that at empty weight by about $15 \%$. The ratios of FC between empty weight and full weight ranged from 0.85 on the OCTA and the Braunschweig cycles to 0.89 on the Paris Cycle which indicated that the auxiliary loads consumed about $10 \mathrm{hp}$ during the OCTA and the Braunschweig cycles and about $15 \mathrm{hp}$ during the Paris 
Cycle (assuming 75\% drivetrain efficiency), as shown on the predicted model in Figure 31. $\mathrm{CO}_{2}$ emissions followed the same trend as FC from this bus. Distance-specific NOx emissions from this bus were higher at full weight than those at empty test weights for all cycles. NOx emissions increased by approximately $7 \%$ when the test weight increased by about $28 \%$ from the empty weight to full weight. However, no difference in NOx emissions at half and full weights was observed. $\mathrm{NOx} / \mathrm{CO}_{2}$ ratios from this bus on the three cycles changed little with test weights.

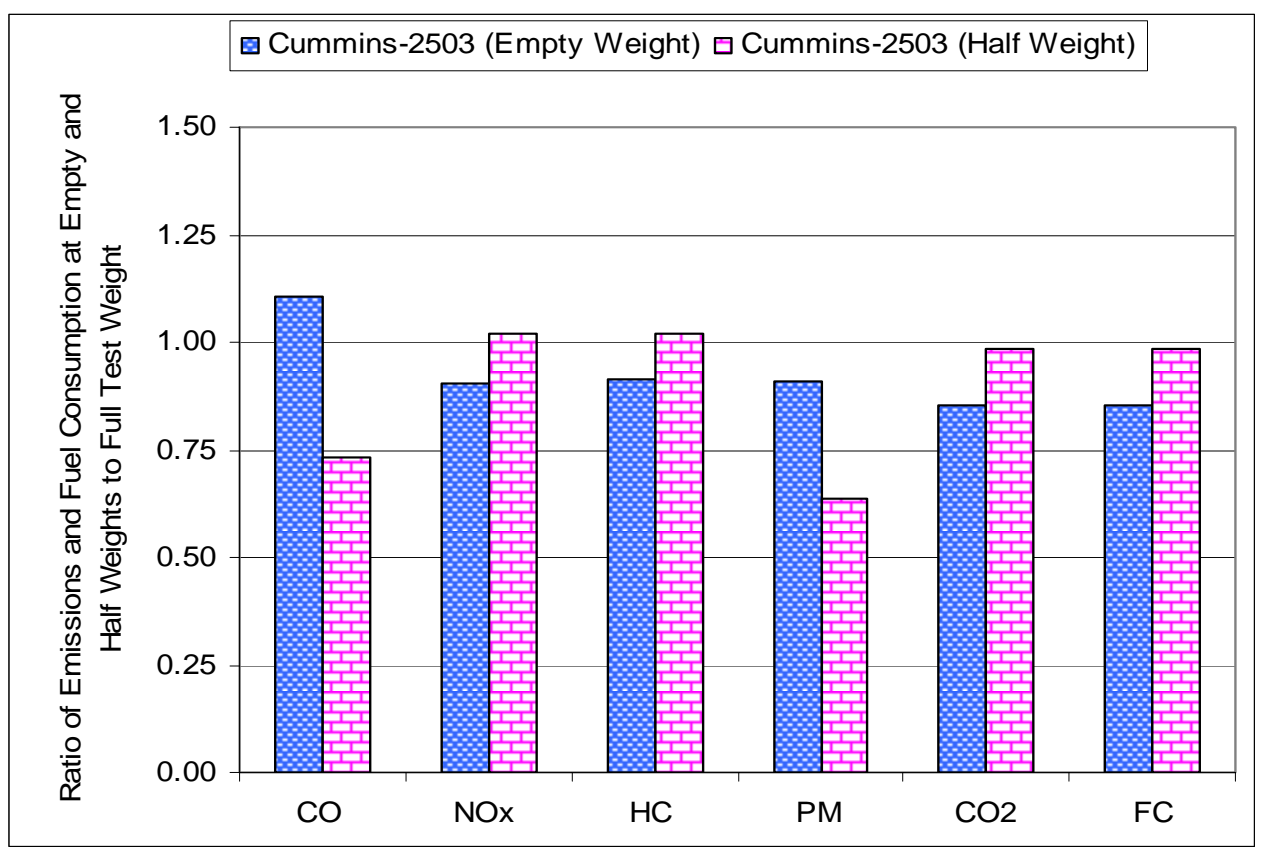

Figure 39: Ratio of emissions and fuel consumption at empty weight and half weight to those at full test weight from the Cummins CNG bus on the OCTA Cycle 


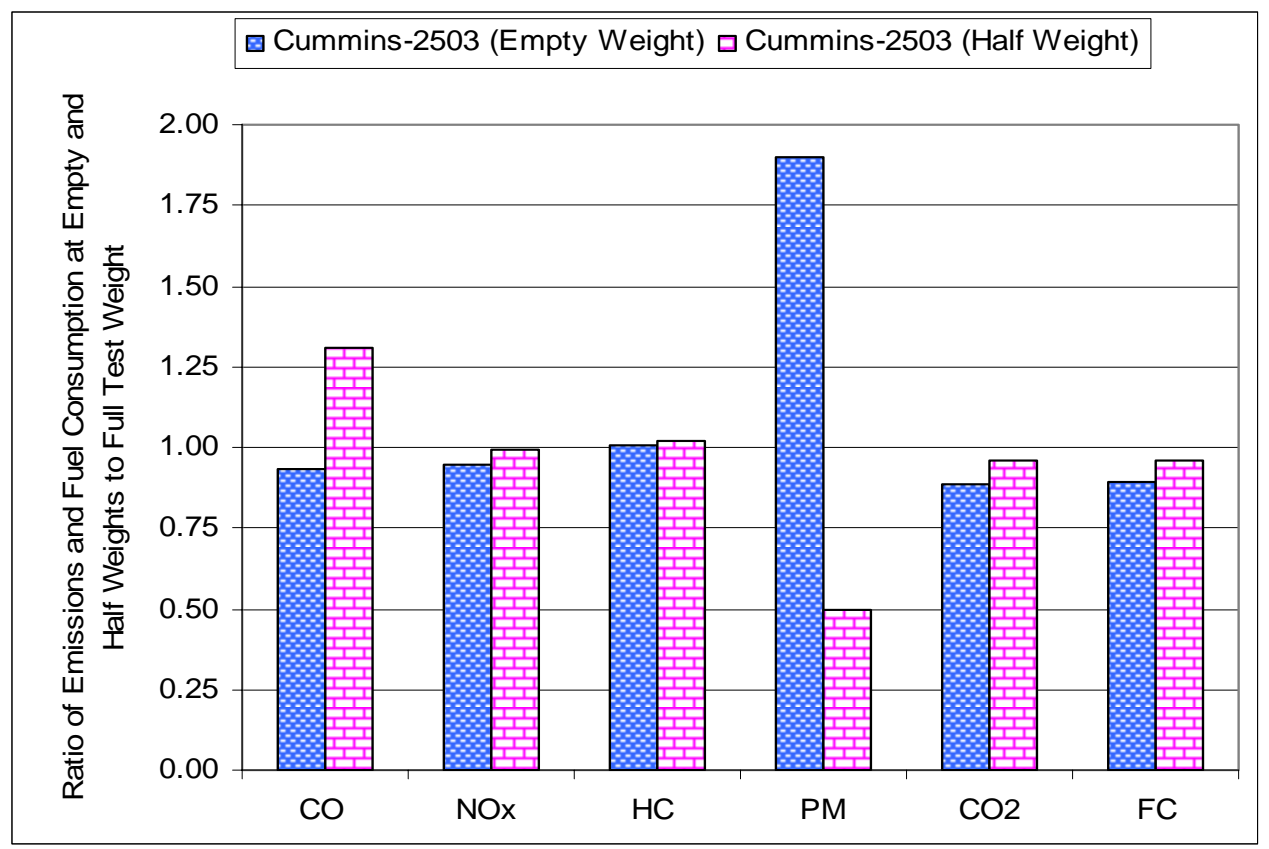

Figure 40: Ratio of emissions and fuel consumption at empty weight and half weight to those at full test weight from the Cummins CNG bus on the Paris Cycle

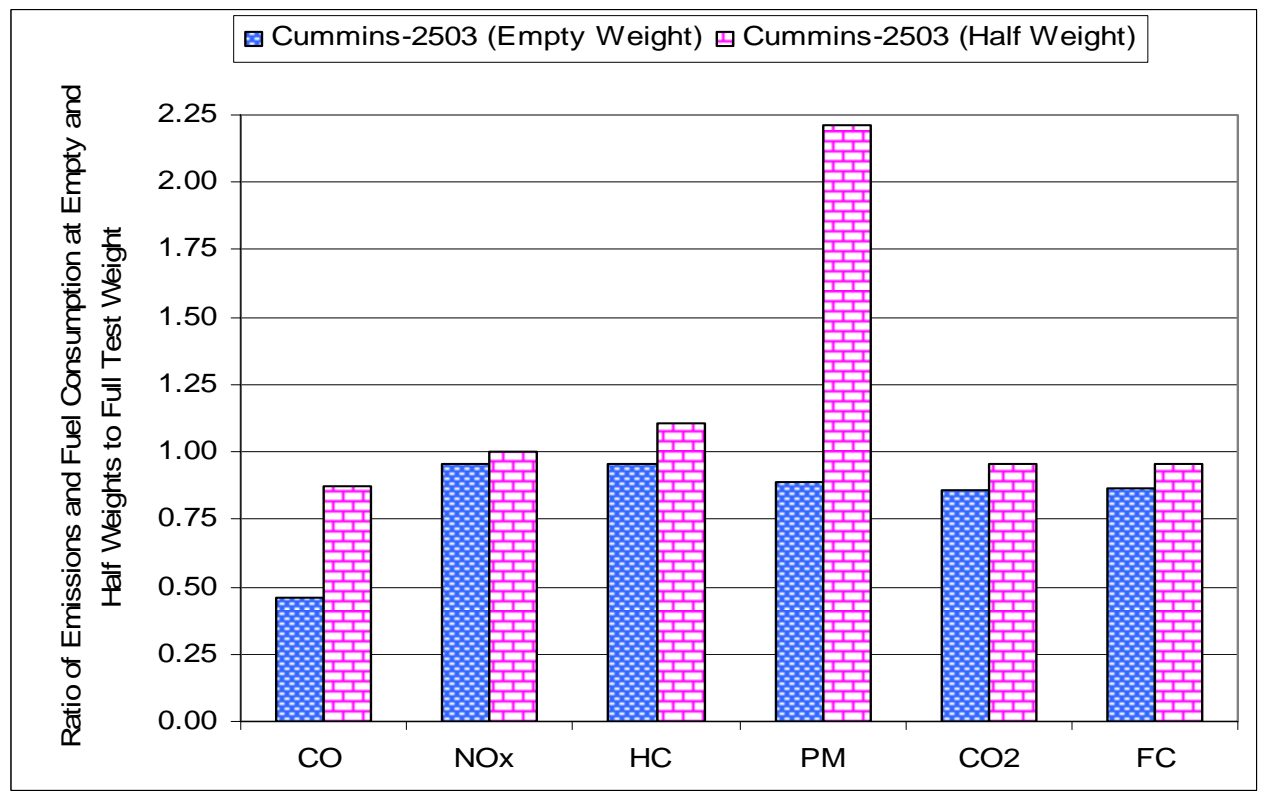

Figure 41: Ratio of emissions and fuel consumption at empty weight and half weight to those at full test weight from the Cummins CNG bus on the Braunschweig Cycle 


\section{Retrofitted Diesel Bus}

The weight effect on emissions and FC from the retrofitted diesel bus on the OCTA, the Paris, and the Braunschweig cycles are presented in Figure 42, Figure 43, and Figure 44, respectively. FC from this bus increased with increasing weight on all cycles. On average, FC from this bus increased by approximately $19 \%$ and $6 \%$ for about $32 \%$ and $14 \%$ increases in test weights, respectively. The ratios of FC between empty weight and full weight were $0.84,0.82$, and 0.85 for the OCTA, the Paris, and the Braunschweig cycles, respectively. Therefore, it could be interpreted from Figure 31 that the auxiliary loads demanded from the bus were about $10 \mathrm{hp}$ during the OCTA and the Braunschweig cycles, and about $5 \mathrm{hp}$ during the Paris Cycle.

$\mathrm{CO}, \mathrm{PM}$, and $\mathrm{HC}$ emissions from this bus were very low. The bus emitted about 0.24 $\mathrm{g} / \mathrm{mile}$ of $\mathrm{CO}, 0.01 \mathrm{~g} / \mathrm{mile}$ of PM, and $0.28 \mathrm{~g} / \mathrm{mile}$ of $\mathrm{HC}$, on average on the Paris Cycle. $\mathrm{CO}$ emissions were higher at full weight than those at empty test weights. PM emissions were not affected by the test weights. HC emissions from this bus at full weight were higher than those at empty weight on the Paris and the Braunschweig cycles but did not change on the OCTA Cycle. NOx emissions at full weight were higher than those at empty test weight, although mixed trends were observed for NOx at half weight. NOx emissions from this bus increased by about $8 \%, 10 \%$, and $23 \%$ on the OCTA, the Braunschweig, and the Paris cycles, respectively, for test weight increase of about $32 \%$ from empty weight to full weight. $\mathrm{NOx} / \mathrm{CO}_{2}$ ratios from this bus on the three cycles were not influenced by the test weights. 


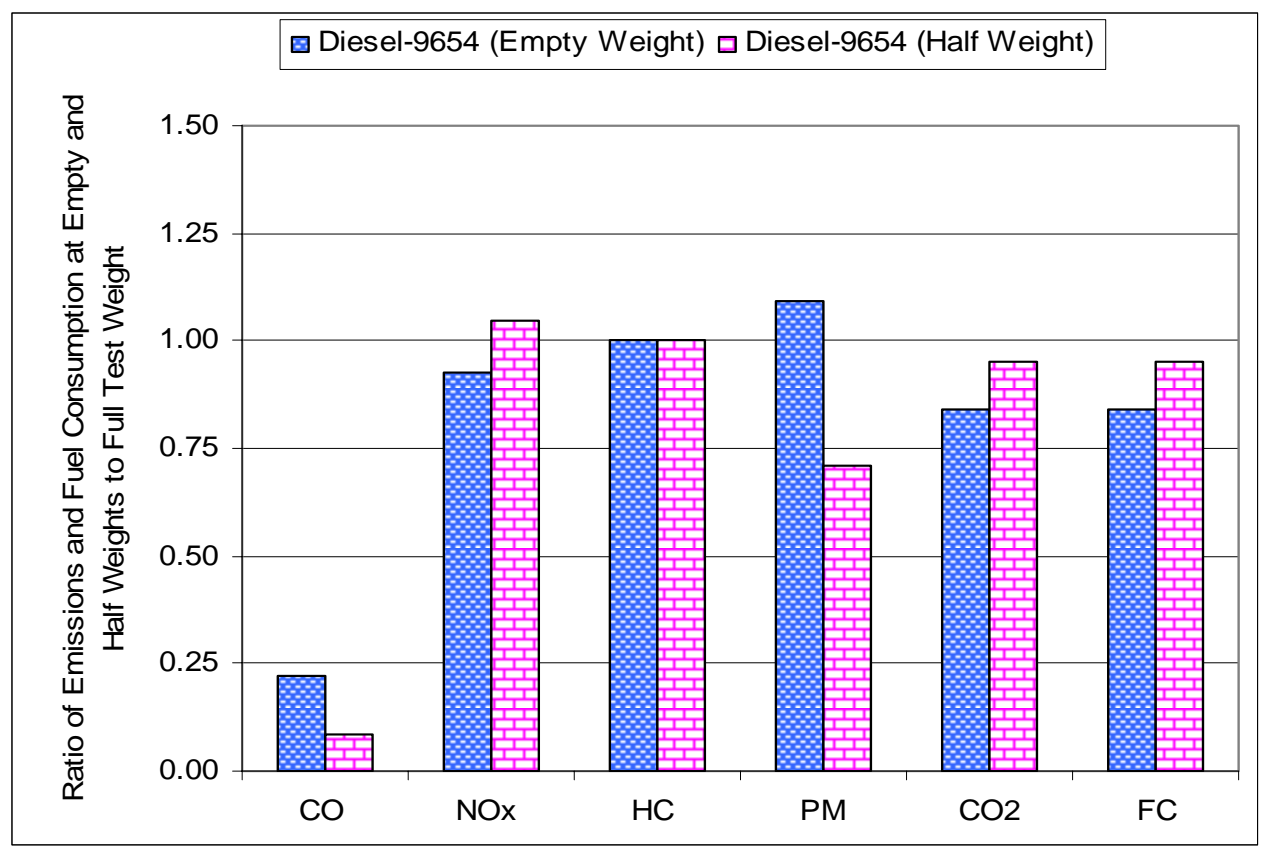

Figure 42: Ratio of emissions and fuel consumption at empty weight and half weight to those at full test weight from the retrofitted diesel bus on the OCTA Cycle

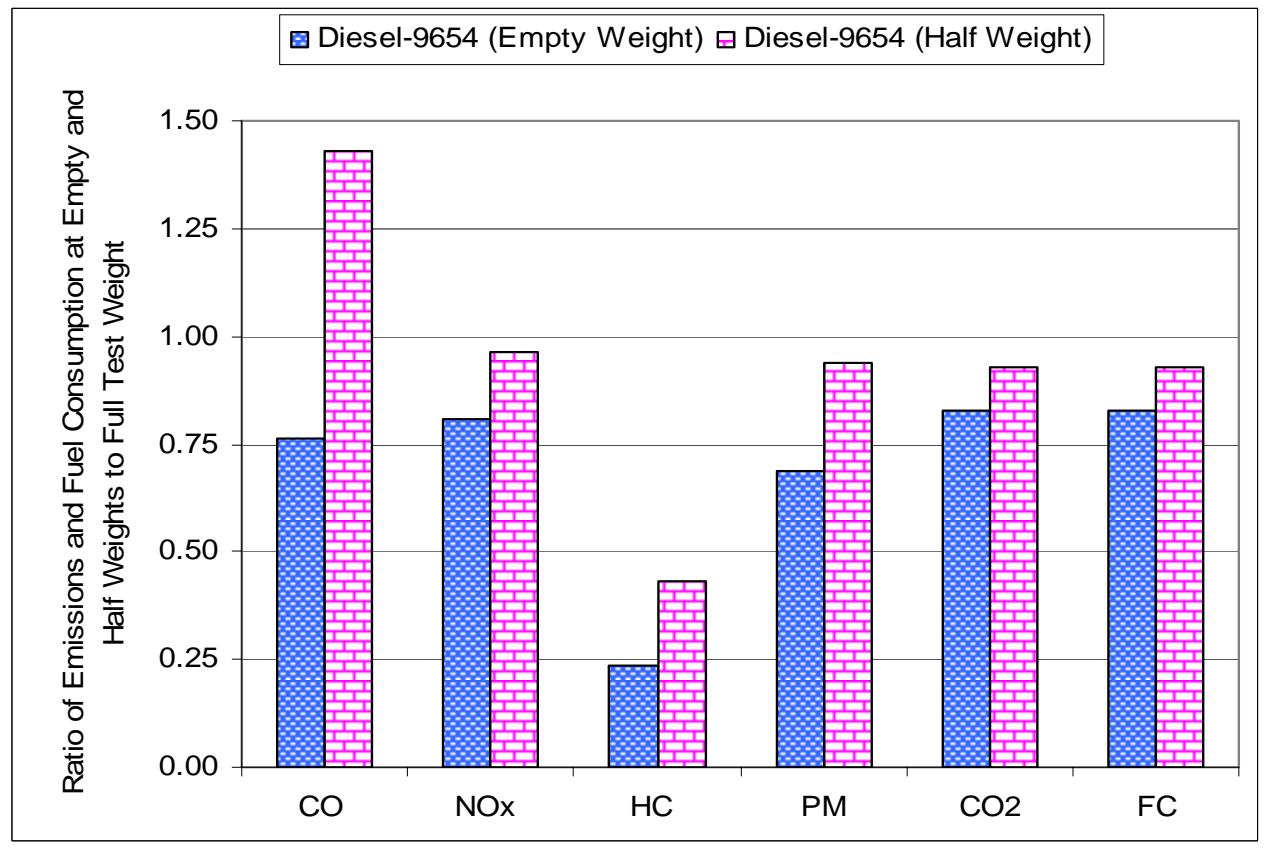

Figure 43: Ratio of emissions and fuel consumption at empty weight and half weight to those at full test weight from the retrofitted diesel bus on the Paris Cycle 


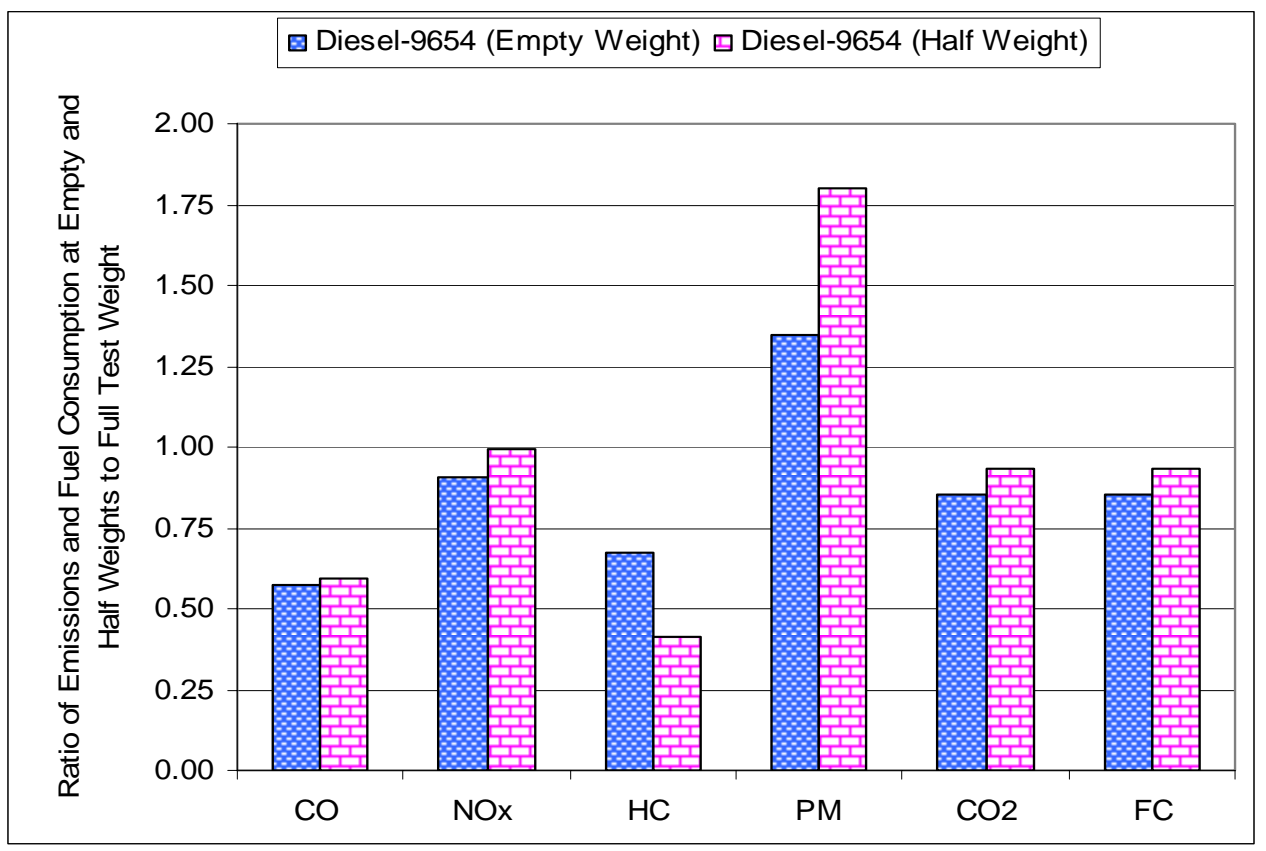

Figure 44: Ratio of emissions and fuel consumption at empty weight and half weight to those at full test weight from the retrofitted diesel bus on the Braunschweig Cycle

\section{WEIGHT EFFECT ON TRUCKS}

Effect of operating weights on FC was further examined on heavy heavy-duty diesel trucks (HHDDT) tested during the E-55/59 program [108]. This was done to compare the analytical method used for passenger weight effect on buses. FC data from thirty-six HHDDT, tested on the Transient mode of the HHDDT Schedule were analyzed. All these trucks were tested at 30,000 lbs and 56,000 lbs of operating weight while twelve of these trucks were also tested at 66,000 lbs.

Here, FC ratios for three loads were interpreted from the road-load equation using Equation 5 and considering 70\% drivetrain efficiency with auxiliary load ranging from 5 to $25 \mathrm{hp}$, as shown in Figure 45. FC ratio between 30,000 lbs and 66,000 lbs operating weight varied from 0.61 to 0.78 while this ratio between $30,000 \mathrm{lbs}$ and $56,000 \mathrm{lbs}$ and 
between $56,000 \mathrm{lbs}$ and $66,000 \mathrm{lbs}$ operating weights varied from 0.68 to 0.83 and 0.89 to 0.94 , respectively.

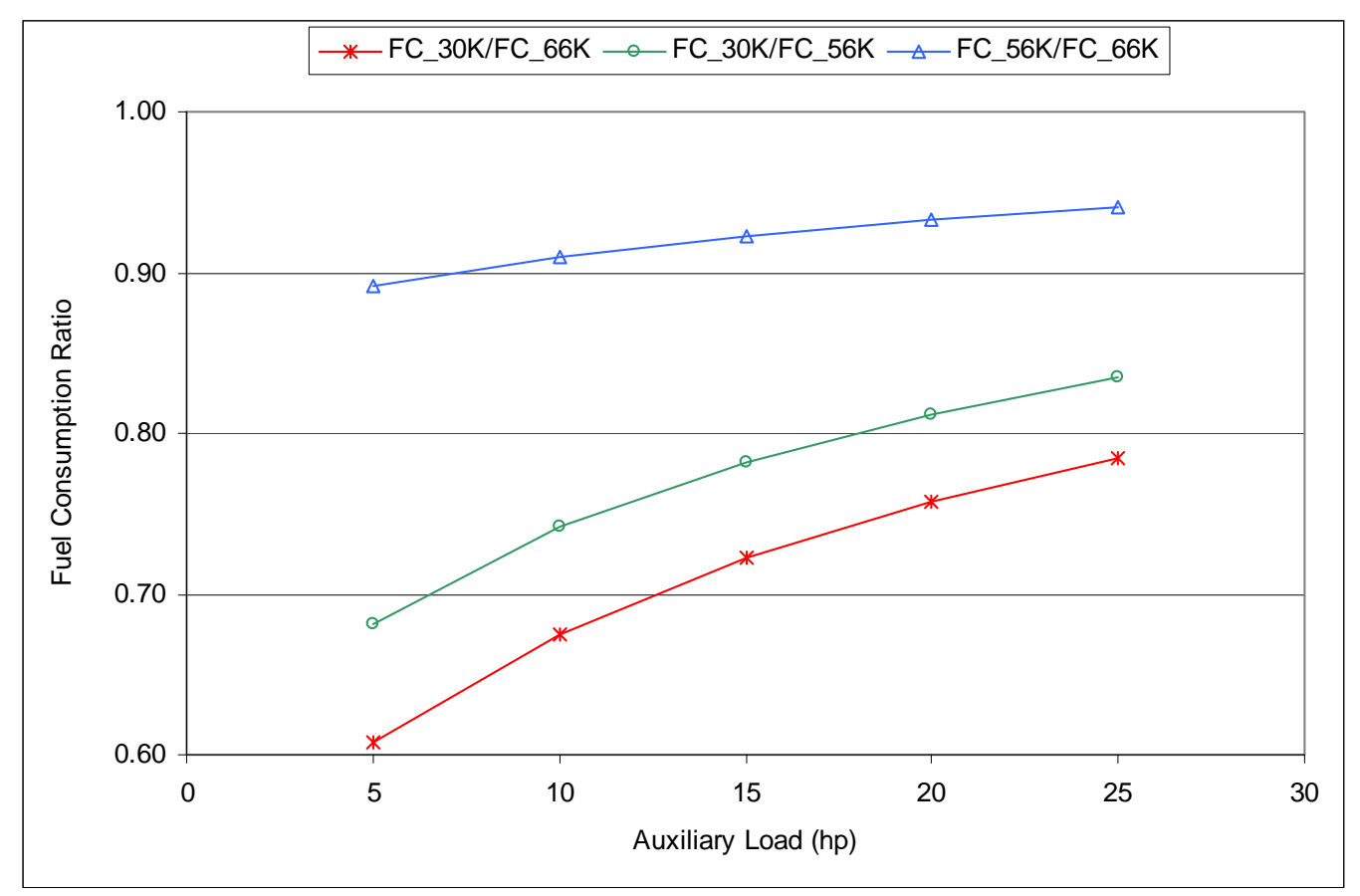

Figure 45: Theoretical ratio of FC between 30,000lbs, 56000lbs, and 66,000lbs from thirty-six HHDDT calculated from the road load equation with $70 \%$ drivetrain efficiency

Experimental FC from these trucks for these three weight ratios were compared with the theoretical prediction. Experimental FC ratio between 30,000 lbs and 66,000 lbs operating weight varied from 0.52 to 0.73 while these ratios between $30,000 \mathrm{lbs}$ and $56,000 \mathrm{lbs}$ and between $56,000 \mathrm{lbs}$ and $66,000 \mathrm{lbs}$ operating weights varied from 0.66 to 0.90 and 0.73 to 0.97 , respectively, as shown in Figure 46. The experimental ratios followed the theoretical prediction very closely but varied over a wide range indicating wide variations in auxiliary loads. 


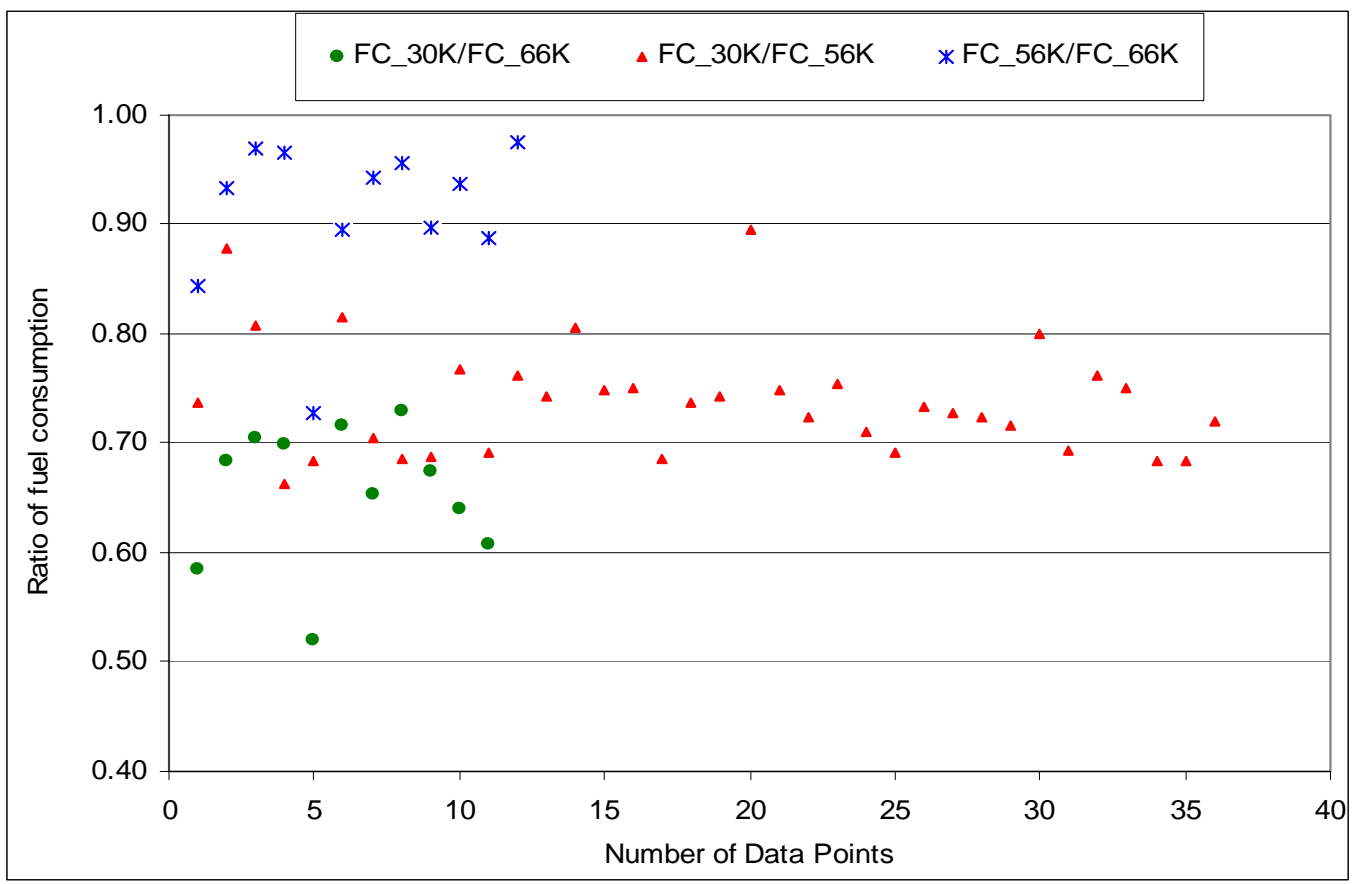

Figure 46: Ratio of FC between 30,000lbs, 56000lbs, and 66,000lbs from thirty-six HHDDT

\section{SUMMARY ON WEIGHT EFFECT}

In this analysis the effect of operating weight on FC was explained using the road load equation and a simple model for drivetrain efficiency and auxiliary loads. Analysis showed that FC was affected by the power demanded of the engine, which was governed by wind drag, rolling resistance, inertia load, auxiliary load and the drivetrain and fuel conversion efficiency. A prediction model was then developed to project the ratio of fuel consumption between empty weight and full test weight. It was found that the predicted ratios would vary from approximately 0.83 to 0.94 depending on component efficiencies, the amount of power demanded by the auxiliary loads, and the nature of driving cycles.

This predictive model was compared with FC data collected from a John Deere CNG bus, a Cummins CNG bus, and a retrofitted diesel bus. Results showed that FC from these buses increased once the test weight was increased from empty weight to full weight. It 
was found that the ratio of fuel consumption between the empty weight and full test weights ranged from 0.91 to 0.93 for the John Deere CNG bus, from 0.85 to 0.89 for the Cummins CNG bus, and from 0.83 to 0.85 for the retrofitted diesel bus. These findings supported the predicted ratios developed for FC.

NOx emissions from the John Deere CNG bus were not found to follow these ratios. NOx emissions from the John Deere bus were higher at empty weight than those at full weight by about $10 \%$. This bus also exhibited higher NOx emissions at half weight than those at full weights. The exact cause for the different trend in NOx emissions at these weights could not be determined. It was suspected that this could be due to the variations between test runs, ambient temperature and humidity, and due to different transmission behavior. It was worth mentioning that NOx emissions from natural gas lean-burn engines were also very sensitive to air-fuel ratio. The ratio of NOx emissions between the empty weight and the full weight varied from 0.90 to 0.95 for the Cummins CNG bus and from 0.81 to 0.92 for the diesel bus over these cycles. For CNG buses a $28 \%$ increase in test weight yielded about 12\% increase in FC but no significant increase in NOx emissions when the data for both of the buses on all three cycles were averaged. For the diesel bus a $32 \%$ increase in weight yielded in about 19\% increase in FC and about $14 \%$ increase in NOx emissions, on average. $\mathrm{HC}$ emissions from $\mathrm{CNG}$ and diesel buses did not follow any trend with test weight. CO and PM emissions from these buses were very low and were insensitive to test weights.

Weight effect analysis was further extended to thirty-six HHDDT, tested during the E$55 / 59$ program in order to compare the weight effect results obtained from three transit buses. These trucks were tested at three operating weights. Experimental FC data from the Transient Cycle showed that changes in FC for corresponding changes in operating weights closely followed the theoretical prediction inferred from the road-load equation. 


\section{EFFECT OF ROAD GRADE AND TERRAIN ON FUEL CONSUMPTION}

\section{DEFINING ROAD GRADE AND TERRAIN}

The American Association of State Highway and Transportation Officials (AASHTO) defined road grade as the rise or fall in vertical distance divided by the horizontal distance for that particular route. While discussing road grade, it was imperative to discuss terrains as they were inter-related and they had profound effect in designing road grade [84]. Terrains were classified into three types by AASHTO: flat or level terrain, rolling terrain, and mountainous terrain. Road elevations were occasional and smooth in flat terrain, while in rolling terrain natural slope consistently rose and fell below the road grade. Elevations in mountainous terrain were abrupt and steep. A graphical representation of road grade with rolling and mountainous terrains on the OCTA Cycle is presented in Figure 47. Note that the cycle started with a zero percentage grade and completed its route and ended at the same grade.

By definition, rolling terrain with high grade percentage could cause vehicles to reduce their speeds at constant power while mountainous terrain, generating steeper grade could cause some trucks to significantly compromise their speed. It was observed that passenger cars could overcome 4-5\% grade without compromising their speeds [84]. AASHTO recommended that road grade for commercial and business areas should be less than 5\% [84]. A minimum road grade of $0.5 \%$ was also recommended by AASHTO for smooth drainage. AASHTO also pointed out the importance of weight-power ratio of a vehicle in maintaining its driving speed. A truck with weight-power ratio of $200 \mathrm{lb} / \mathrm{hp}$ was expected to maintain $60 \mathrm{mph}$ speed at 3\% uphill grade [84]. Therefore, an underpowered bus would have to sacrifice its speed at uphill driving while an over-powered bus would have minimum problem there.

The basic definition of road grade provided complexity in determining road grade for a particular bus route. This is especially true in transit applications, for a closed circuit of activity on a road, the average grade would be zero. To avoid inconsistency, road grade, 
in this dissertation, was mimicked with a sine wave and described in terms of the nature of terrain. A 5\% road grade on rolling terrain implied ascending a rolling hill in a sinusoidal way reaching 5\% maximum grade followed by descending to the $5 \%$ level in the same way and completing the cycle at the same elevations where it started. It was acknowledged that sinusoidal representation of grade was an approximation of road grade and might not truly represent the road elevation with respect to its distance.

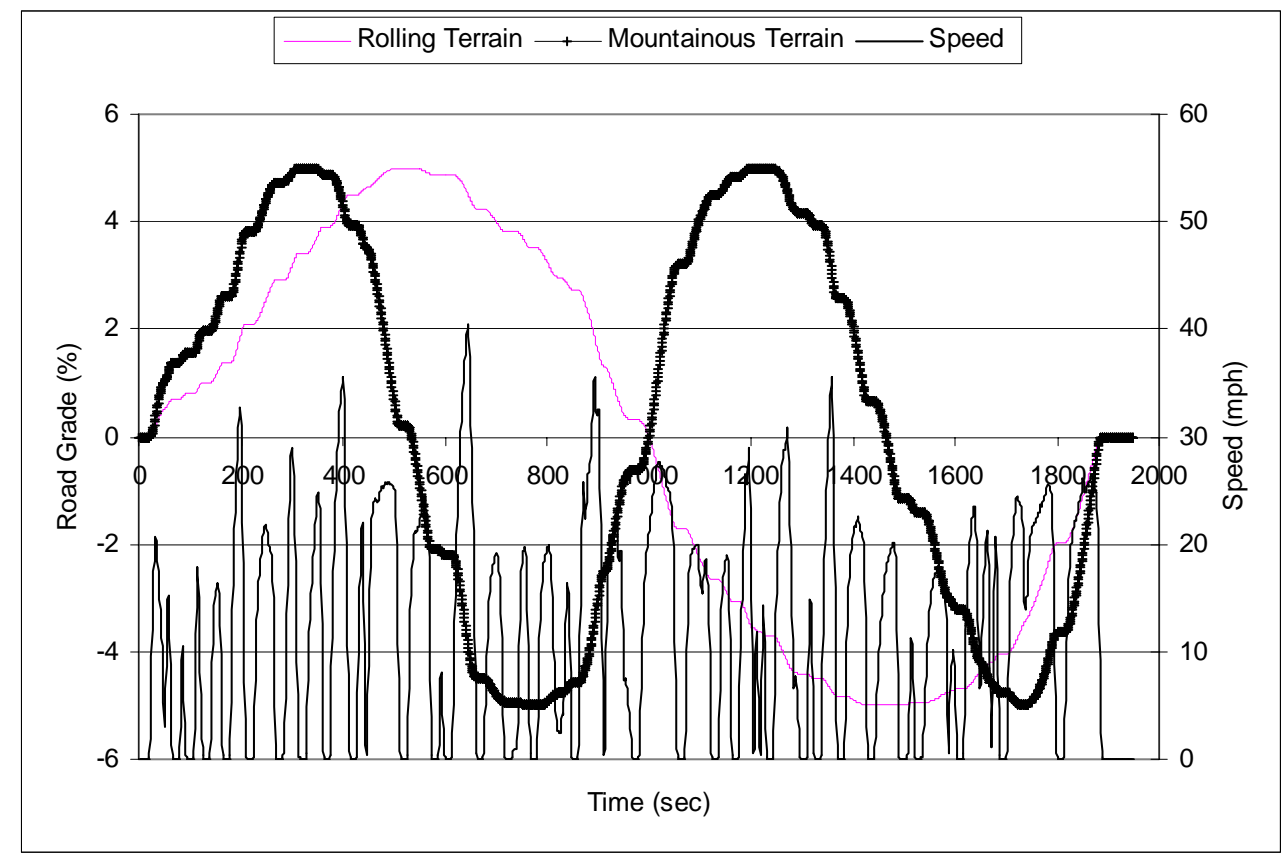

Figure 47: Representation of road grade on OCTA Cycle against cycle duration for different terrains

The graphical representation of terrain in Figure 47 was determined with respect to the distance traveled on that cycle but showed the time of the cycle in order to compare grade percentage with cycle speed. The same terrain, if plotted against distance traveled would have been represented as shown in Figure 48. In Figure 48 the grade increase or decrease is a continuous function with distance while in Figure 47 the small straight line on the grade represented idle time when no distance was traveled, and hence, no change in grade was encountered. 


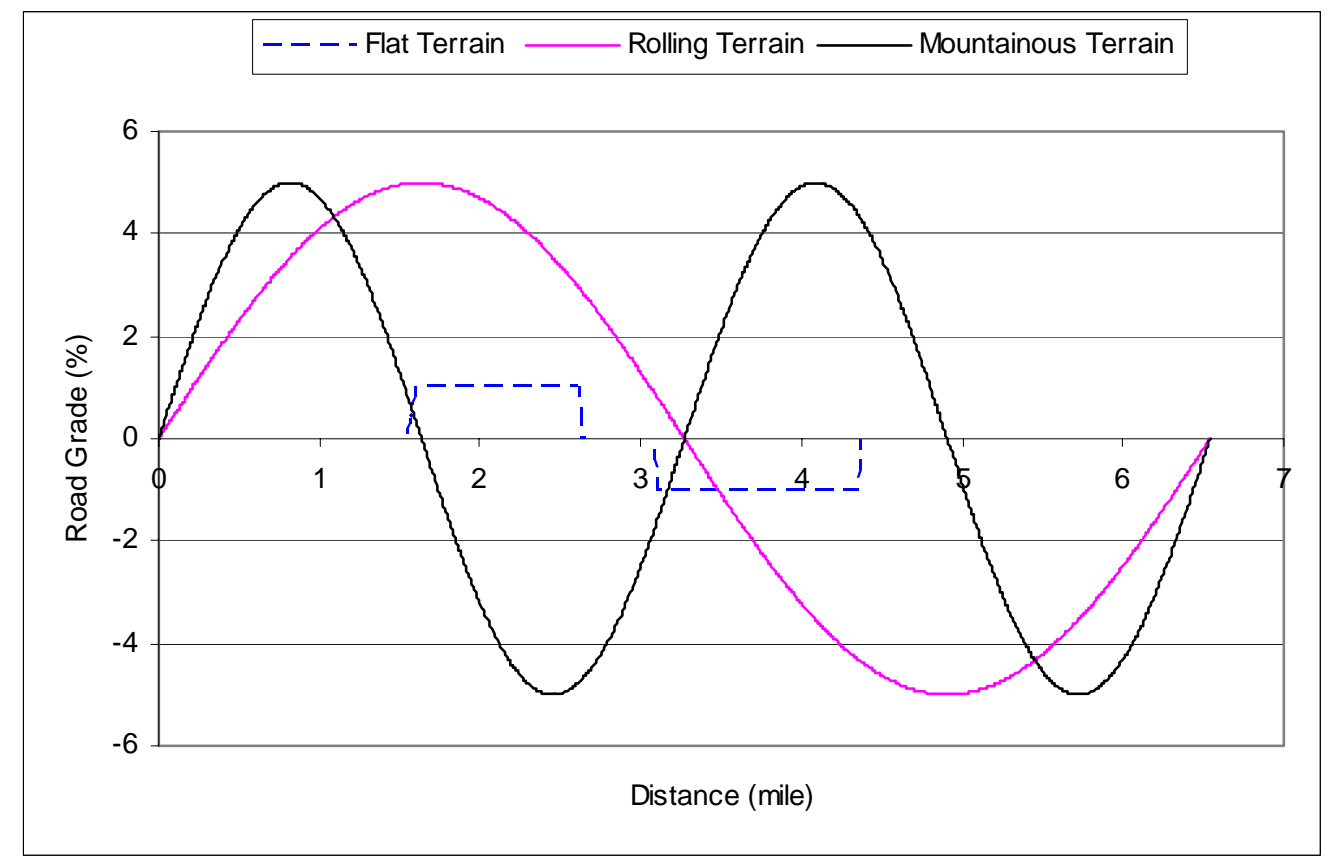

Figure 48: Representation of road grade on OCTA Cycle against distance traveled for different terrains

Alternately road grade and terrain could be produced with respect to the time traveled on that cycle as shown in Figure 49, where road grade was determined from the cycle duration. As a result, grade was represented as a continuous function of cycle time. Note that here the cycle was started at negative grade followed by uphill and downhill driving and returning to the elevations where it started. However, this method failed to capture the fact that any change to road grade was not possible when the bus was idling. Therefore, grade representation in this dissertation was calculated as continuous function of distance but presented with time to relate corresponding speed. 


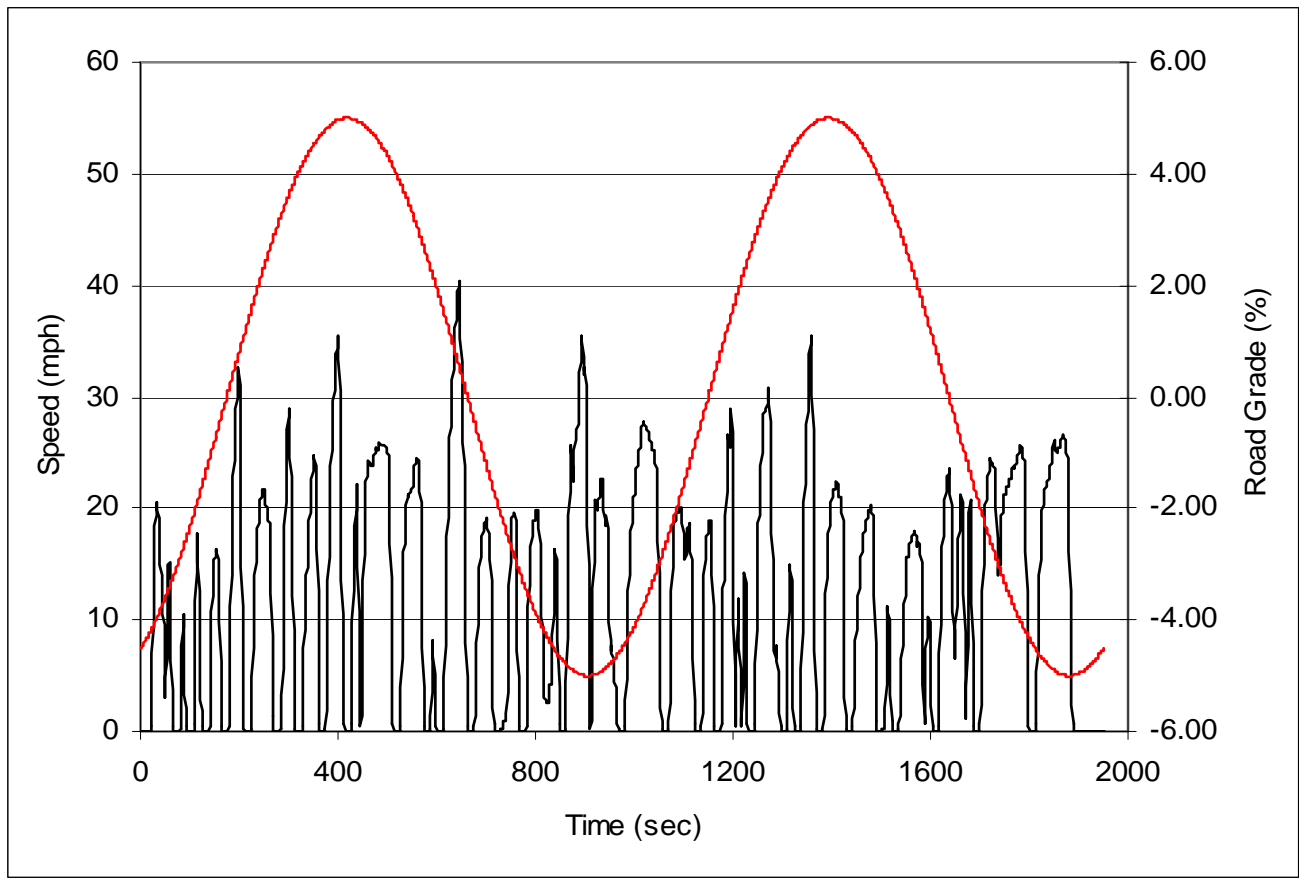

Figure 49: Representation of road grade on OCTA Cycle for mountainous terrain determined from cycle time.

\section{MODELING ROAD GRADE EFFECT ON FUEL CONSUMPTION}

The effect of road grade on total load and FC was analyzed by assigning a road grade to a drive cycle. The grade effect was included in the road-load equation for a drive cycle and an empirical relationship was developed to account for the difference in $\mathrm{FC}$ with or without grade.

FC rate with no grade as shown in Equation 4 was expressed as:

$\mathrm{m}_{\mathrm{f} \text { ng }}=\left[1 / \mathrm{y}_{\mathrm{d}}(\mathrm{AHP})_{\mathrm{ng}}+\mathrm{HP}_{\mathrm{aux}}\right] /\left(\mathrm{y}_{\mathrm{f}} * \mathrm{Q}_{\mathrm{HHV}}\right) \quad$ [Equation 6]

Taking road grade into effect FC with road grade then became:

$\mathrm{m}_{\mathrm{f} \mathrm{wg}}=\left[1 / \mathrm{y}_{\mathrm{d}}(\mathrm{AHP})_{\mathrm{wg}}+\mathrm{HP}_{\mathrm{aux}}\right] /\left(\mathrm{y}_{\mathrm{f}} * \mathrm{Q}_{\mathrm{HV}}\right) \quad$ [Equation 7] 
Therefore, the ratio of FC with and without road grade was expressed as:

$\mathrm{m}_{\mathrm{fwg}} / \mathrm{m}_{\mathrm{fng}}=$

$\left(1 / \mathfrak{y}_{\mathrm{d}}(\mathrm{AHP})_{\mathrm{wg}}+\mathrm{HP}_{\text {Aux }}\right) /\left(1 / \mathrm{y}_{\mathrm{d}}(\mathrm{AHP})_{\mathrm{ng}}+\mathrm{HP}_{\text {Aux }}\right) \quad$ [Equation 8]

In this equation the ratio of FC depended only on the ratio of power demanded with and without road grade, provided the vehicle operated at a fixed weight. Therefore, for any particular drive cycle, $\mathrm{FC}$ would be a function of cycle average speed and road grade. However, it needed to be remembered that engine efficiency was not constant. Therefore, a cycle that demanded continuous high power probably got more benefit than an under power cycle as the engine could have operated on a high efficient area in the speedtorque map.

Equation 8 was applied to the speed-time traces of the Commuter Cycle, where a 5\% maximum road grade was also assigned as shown in Figure 50. While integrating the road-load equation over the Commuter Cycle with road grade, it was assumed that the driver would have pressed the brake when the negative road grade exceeded drag, rolling, and inertia load, combined. A comparison of the difference in total load with and without road grade is presented in Figure 51. It was found that addition of road grade would result in about $28 \%$ additional FC considering the vehicle had $75 \%$ drivetrain efficiency and that the auxiliary power demand was about $7.5 \mathrm{~kW}(10 \mathrm{hp})$. 


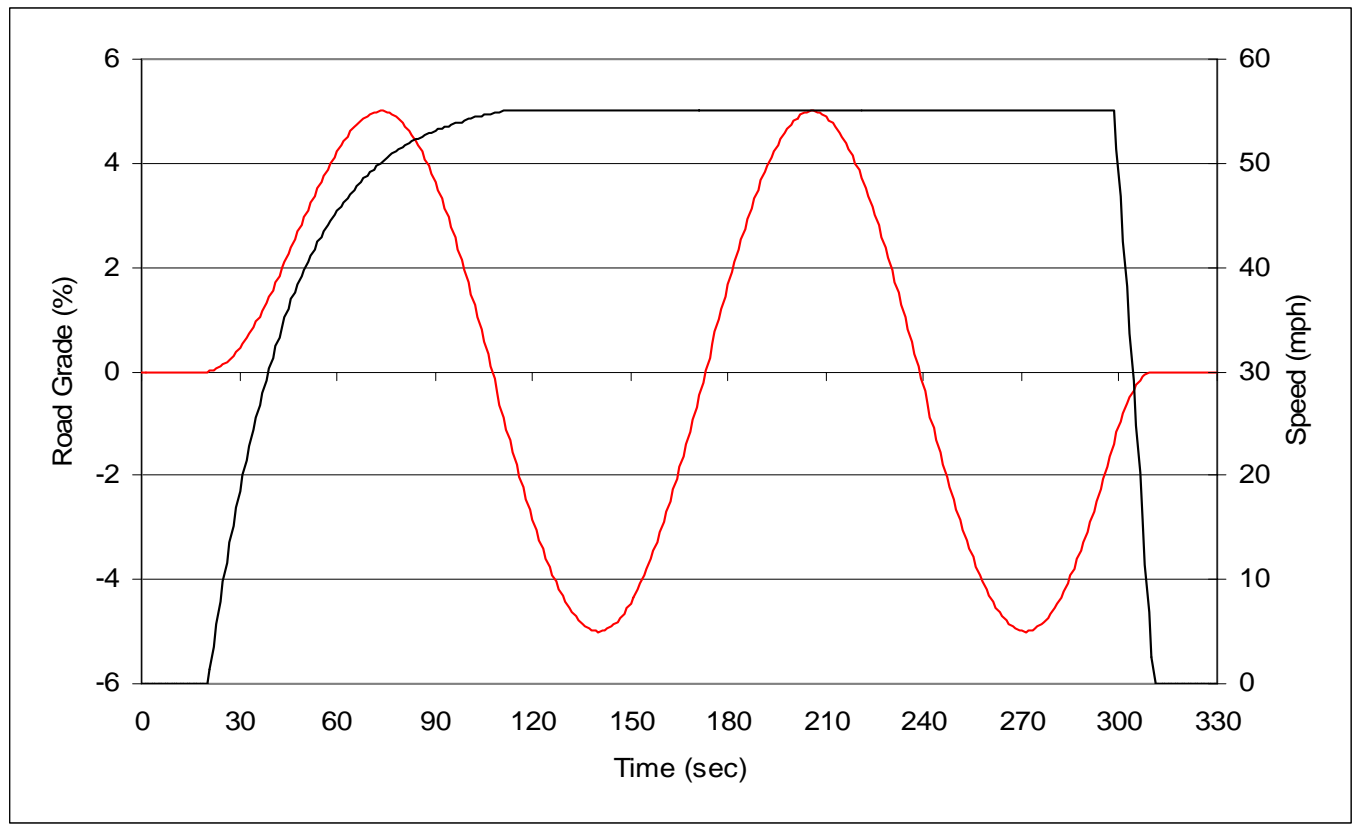

Figure 50: The Commuter Cycle with 5\% maximum road grade on a mountainous terrain

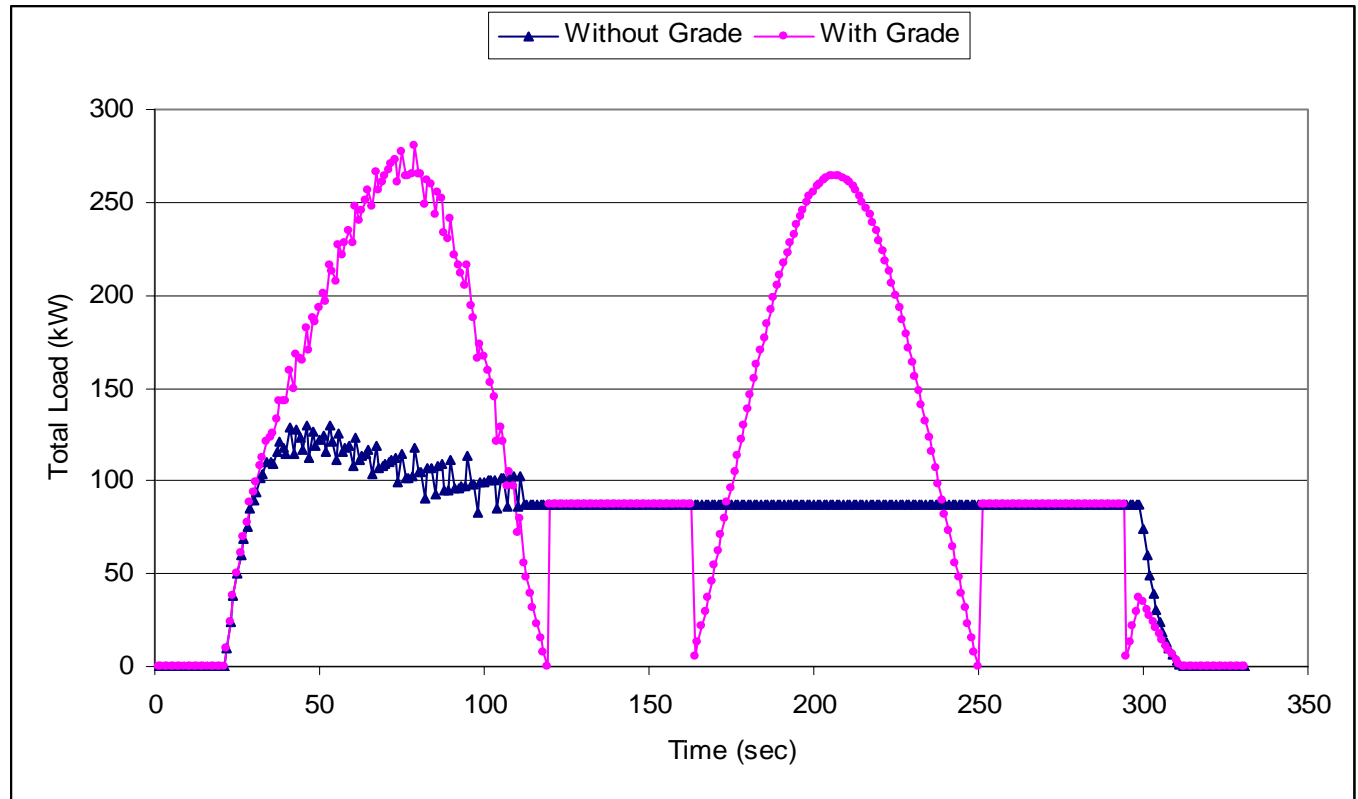

Figure 51: Comparison of the total load for a transit bus with and without road grade on the Commuter Cycle 
It was not conceivable that bus routes would always start at $0 \%$ grade. A bus route might have started at some uphill grade followed by downhill grade or vice versa. Effects of phase shift, therefore, were considered before computing the grade effect on FC. In this analysis a bus was assumed to follow the OCTA Cycle and various combinations of road grades were imposed on its route. Two such combinations are presented in Figure 52 and Figure 53. It was found that change in phase shift for $5 \%$ mountainous grade on the OCTA Cycle caused a variation in its total load from about $15 \mathrm{~kW}-\mathrm{hr}$ to $18 \mathrm{~kW}-\mathrm{hr}$. Therefore, an effort was made to create a representative number of combinations and the average total load was considered.

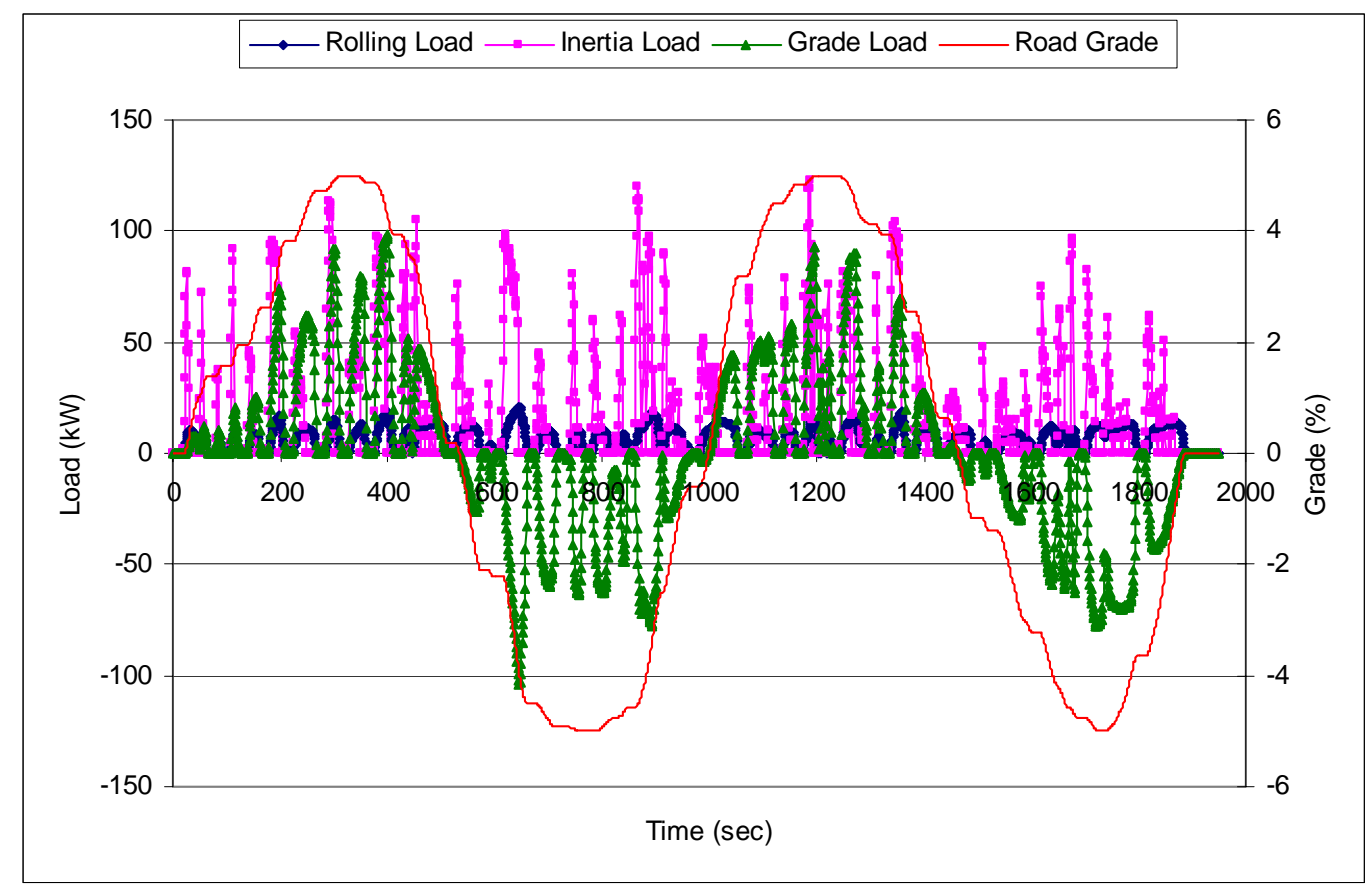

Figure 52: Continuous rolling, inertia, and grade load for $5 \%$ maximum road grade with no phase shift on the OCTA Cycle 


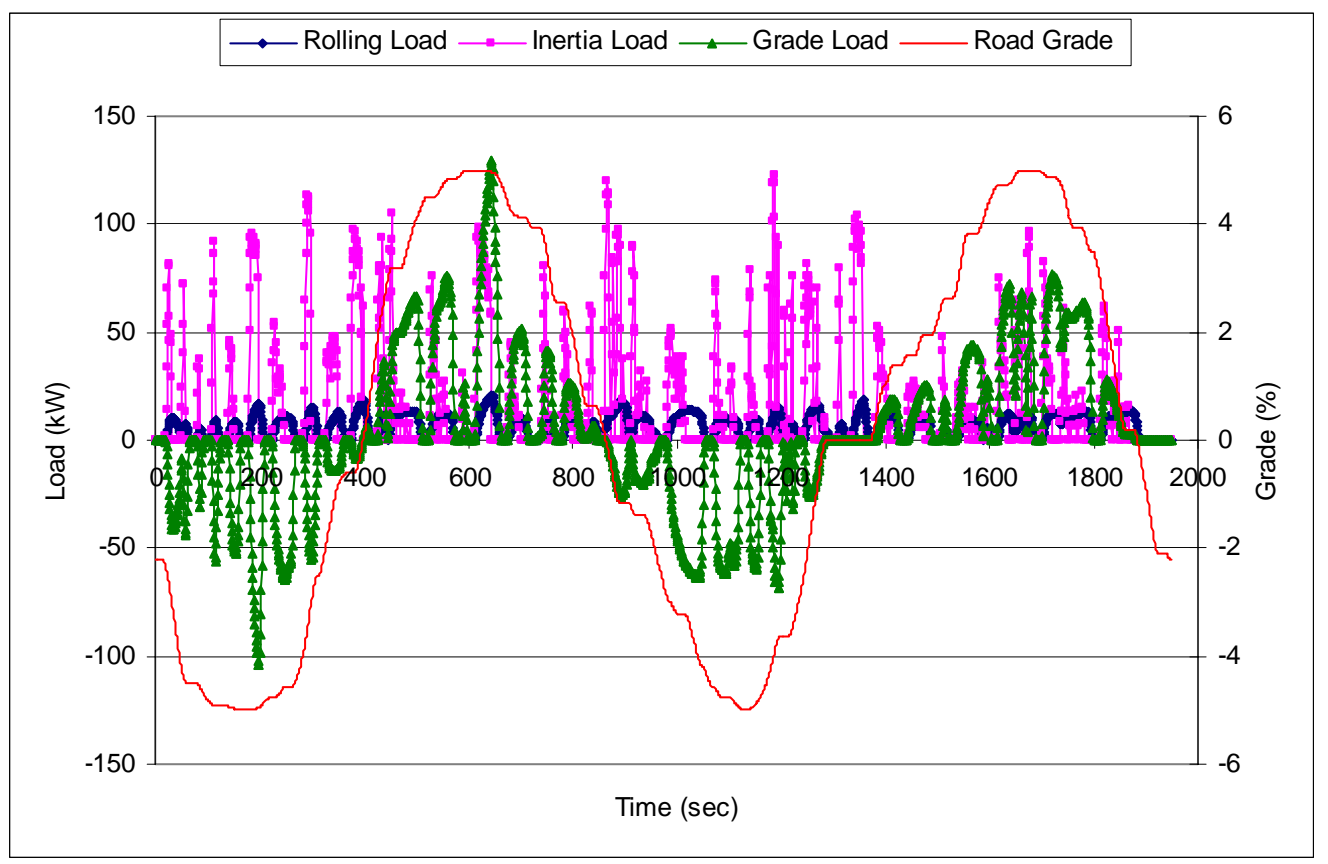

Figure 53: Continuous rolling, inertia, and grade load for $5 \%$ maximum road grade with 1.1 mile distance shift on the OCTA Cycle

However, caution must be exercised while analyzing grade effect on heavy-duty truck cycles. Because they did not have truck stop system at regular interval like bus cycles and their idle periods were longer than the bus cycles. Consider 5\% maximum grade effect on the UDDS cycle with no distance shift, as shown in Figure 54. In this case the road grade resulted in an additional power demand of $4.7 \mathrm{~kW}-\mathrm{hr}(42 \%)$. When this grade was imposed with various distance shift, additional power demand varied from $0.0 \mathrm{~kW}-\mathrm{hr}$ $(0 \%)$ to $10.7 \mathrm{~kW}-\mathrm{hr}(96 \%)$. Therefore, a greater number of combinations for road grade would have to be considered for truck cycles. Note that the braking line on the negative grade load in Figure 54 resulted from the adjustment of grade load to zero i.e. service braking when negative grade load exceeded the load resulted from drag, rolling, and inertia loads. 


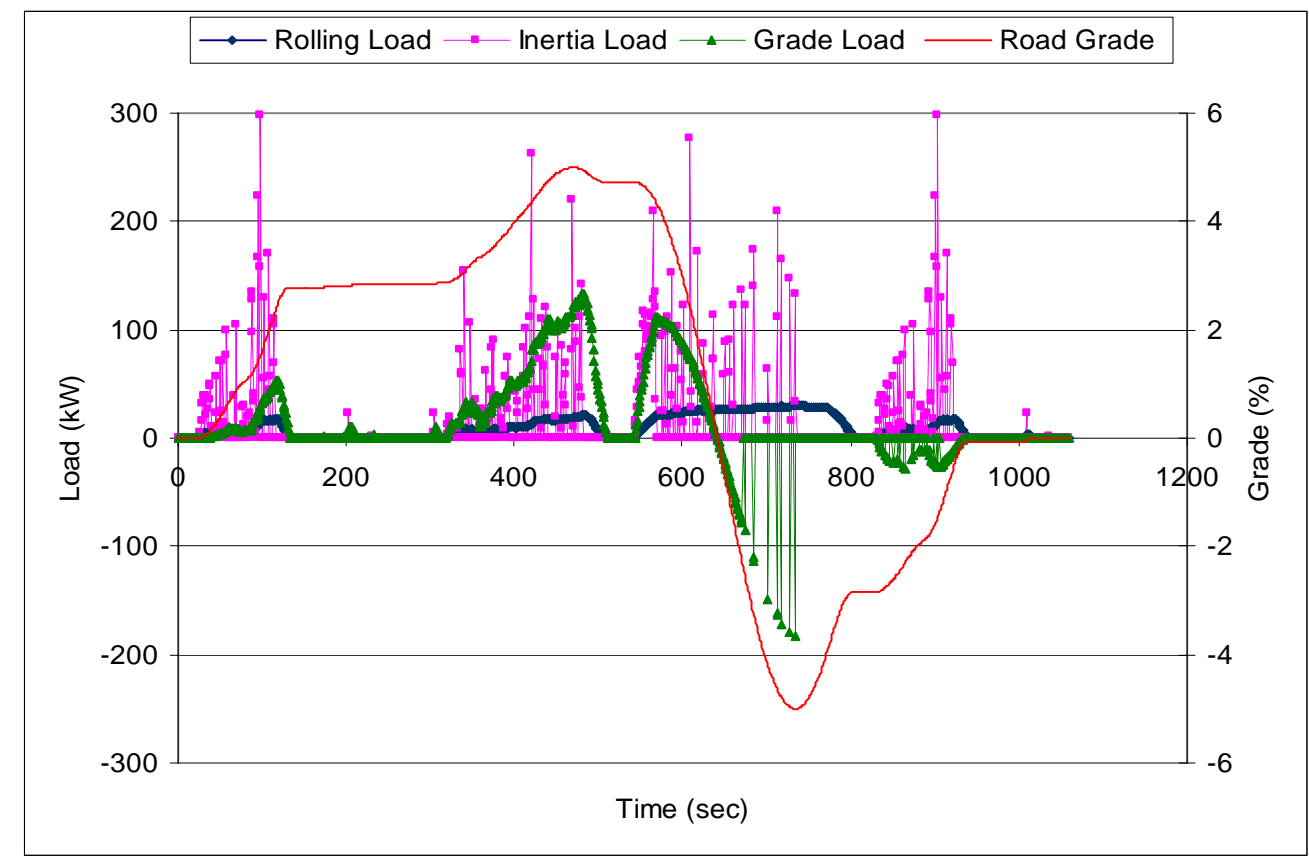

Figure 54: Continuous rolling, inertia, and grade load for $5 \%$ maximum road grade with no distance shift on the UDDS Cycle

Presence of road grade on a transit route could develop two scenarios for any vehicle. In the first scenario the vehicle might be able to deliver the extra power demanded from the engine and follow the speed-time trace. This was more likely to happen for low and medium speed cycles with low road grade. In the second case the vehicle might be unable to provide additional power demanded from the engine resulting in reduced speed at uphill grade. This scenario was more likely to take additional time to complete the same route. These two cases are presented in detail in the following paragraphs.

A heavy-duty vehicle, such as a transit bus was considered to follow a speed-time schedule. To examine grade effects, it was valuable to impose an undulating terrain on the speed-time trace. Since the original cycle was developed for use on flat terrain simulation, it was possible that the modeled power demand from the bus might have exceeded the actual bus power when road grade was imposed. Since one output of the modeling effort might be a cycle-averaged emissions mass, and since the emissions rate was undefined at power levels above the engine maximum power, an approach was 
developed to address these high power events. In reality, in following a route, a bus would simply reach maximum power demand on a grade and continued to use maximum power until the target speed was achieved or until the grade was reduced. Consider Figure 55, Figure 56, and Figure 57. Figure 55 shows the speed-time trace of a segment from the CBD Cycle and its corresponding power without any road grade.

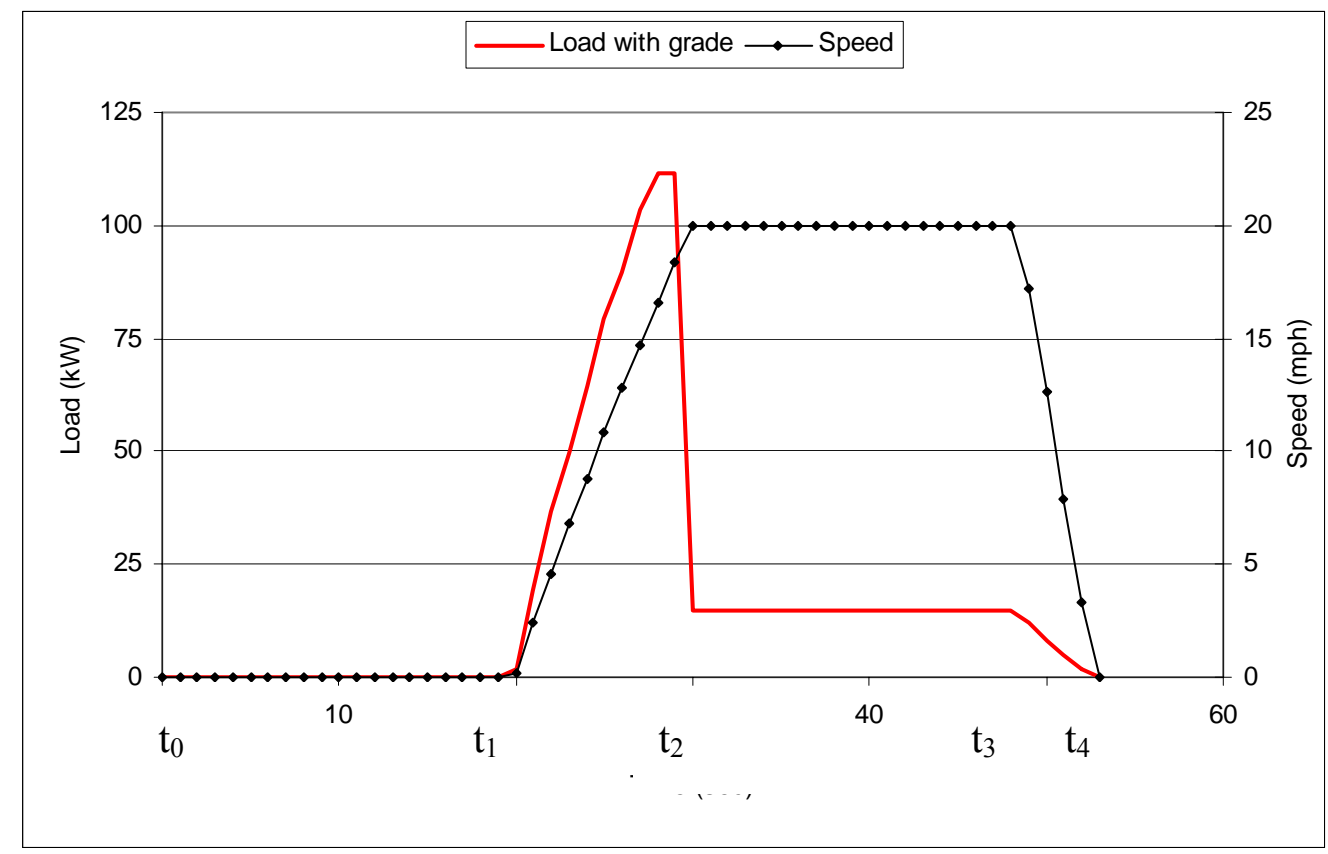

Figure 55: Actual power demand to follow the speed-time trace on a flat grade

In Figure 56 the same target trace was applied but a steady uphill grade was imposed. Applying steady uphill grade would result in higher power demand that might not be available from the engine. In reality, this bus would have taken a longer period of time to achieve its required speed. Although it might be tempting simply to increase the acceleration period, this would cause the bus to move further during the acceleration period, and the cruise period needed to be reduced if the cycle total distance needed to be preserved. 


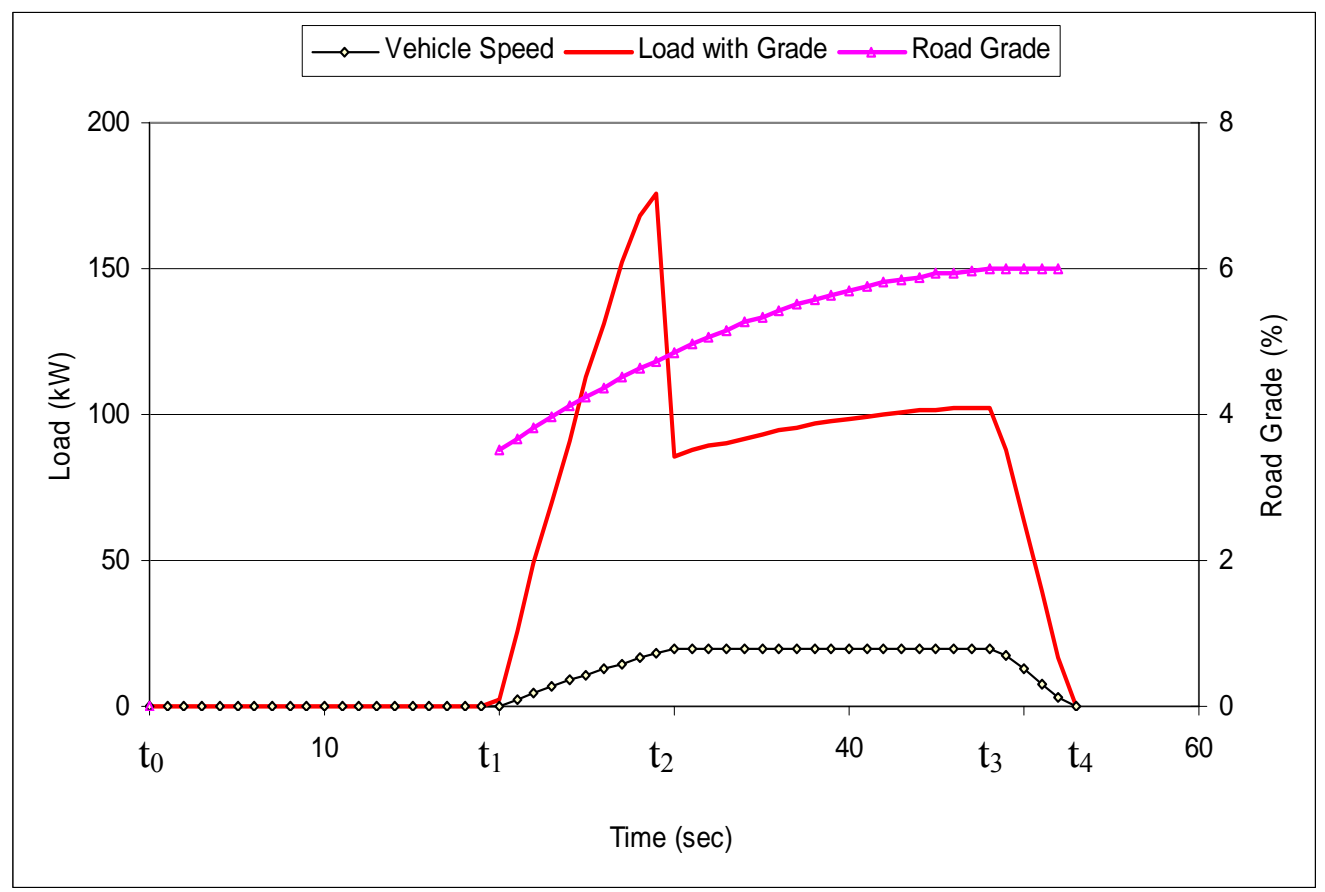

Figure 56: Actual (unrealistic) power demand to follow the speed-time trace with grade

In Figure 57, the bus was limited to actual maximum power of about $151 \mathrm{~kW}$, therefore, the bus could spend in reality a longer time in accelerating and less time in cruising. (The actual maximum power of a $280 \mathrm{hp}$ rated bus with $75 \%$ drivetrain efficiency and about $10 \mathrm{hp}$ auxiliary power comes to about $202 \mathrm{hp}$ or $151 \mathrm{~kW}$ ). In this case, acceleration period was greater than that from Figure 56 and while cruise time was less. That is, from Figure 56 and Figure 57,

$\left(t_{2}^{\prime}-t_{1}\right)>\left(t_{2}-t_{1}\right)$, and

$\left(t_{3}^{\prime}-t_{2}^{\prime}\right)<\left(t_{3}-t_{2}\right)$

Also, $t_{2}{ }^{\prime}>t_{2}, t_{3}{ }^{\prime}>t_{3}$, and $t_{4}{ }^{\prime}>t_{4}$ so that the latter part of the cycle was delayed when the grade was imposed. 


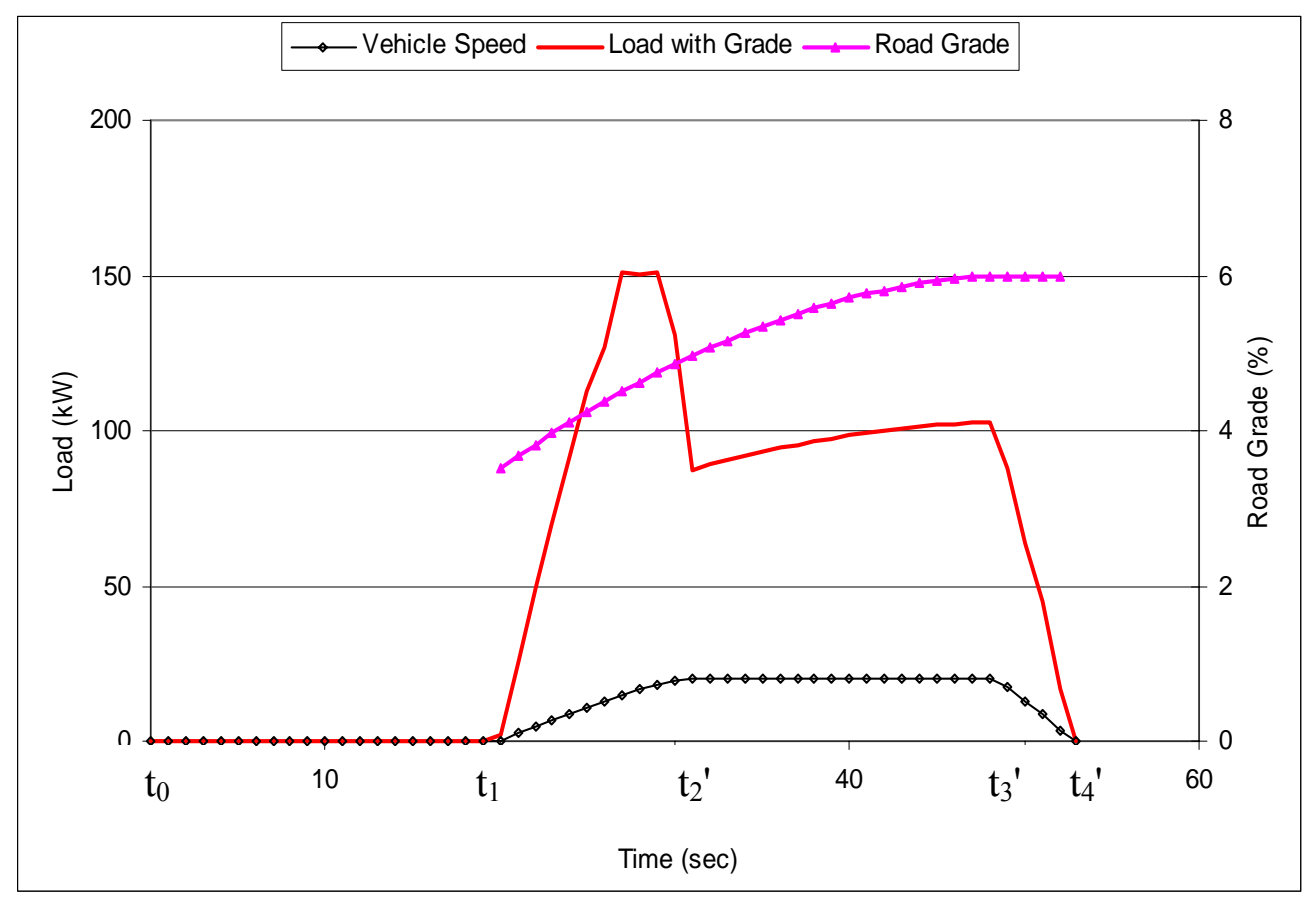

Figure 57: Modified (realistic) power demand to follow the speed-time trace with grade

Assuming that emissions were produced at a rate of $\mathrm{m}_{\mathrm{fp}}$ at full power, then for the zero grade case during full power acceleration the emissions mass produced from Figure 55 is

$\mathrm{M}_{\mathrm{ng}}=\mathrm{m}_{\mathrm{fp}}\left[\mathrm{t}_{2}-\mathrm{t}_{1}\right]=10 \mathrm{~m}_{\mathrm{fp}} \quad$ [Equation 9]

For the case in Figure 57 it was,

$\mathrm{M}_{\mathrm{wg}}=\mathrm{m}_{\mathrm{fp}}\left[\mathrm{t}_{2}{ }^{\prime}-\mathrm{t}_{1}\right]=11 \mathrm{~m}_{\mathrm{fp}} \quad$ [Equation 10]

In the imaginary case in Figure 56, if it were assumed that emissions would increase proportionately with power beyond the engine maximum power, the emissions produced during acceleration would be 
$\mathrm{M}_{\mathrm{wg}}=\mathrm{m}_{\mathrm{fp}}\left(\int_{\mathrm{t} 1}^{t 2} P 2(t) d t\right) / P_{1} \quad$ [Equation 11]

Where, $P_{1}=151 \mathrm{~kW}$

From Figure 56, we got $\mathrm{M}_{\mathrm{wg}}=7 \mathrm{~m}_{\mathrm{fp}}$

Therefore, emissions mass produced in Figure 57 was greater than emissions mass produced in the case of Figure 56. It was because more work was done in aerodynamic and rolling load was generated in Figure 57 than that in Figure 56.

Conversely, in Figure 57, the emissions from the cruise section, Mc, were reduced than the case in Figure 56 because less time was spent on cruising.

From Figure 56, $\mathrm{Mc}=\mathrm{m}_{\mathrm{c}}\left[\mathrm{t}_{3}-\mathrm{t}_{2}\right]=18 \mathrm{~m}_{\mathrm{c}}$,

[Equation 12]

From, Figure 57, Mc $=\mathrm{m}_{\mathrm{c}}\left[\mathrm{t}_{3}-\mathrm{t}_{2}{ }^{\prime}\right]=17 \mathrm{~m}_{\mathrm{c}}$

[Equation 13]

Therefore, the total emissions during both acceleration and cruising sections were:

For Figure $56, \mathrm{M}_{\mathrm{T}}=\left(7 \mathrm{~m}_{\mathrm{fp}}+18 \mathrm{~m}_{\mathrm{c}}\right)$, and

For Figure 57, $\mathrm{M}_{\mathrm{T}}=\left(11 \mathrm{~m}_{\mathrm{fp}}+17 \mathrm{~m}_{\mathrm{c}}\right)$

The difference therefore, $\mathrm{M}_{\mathrm{d}}=\left(4 \mathrm{~m}_{\mathrm{fp}}-\mathrm{m}_{\mathrm{c}}\right) \quad$ [Equation 14],

This difference was dominated by the acceleration event. This was natural for this scenario where a very small segment was considered and a small part of this segment needed power above the available engine power.

Also, the difference was dominated by the emissions rate produced at full power. This difference was also computed in a simple but different way taking into consideration the 
difference in aerodynamic and rolling losses between these two events for their respective acceleration time, as shown below.

$$
\mathrm{M}_{\mathrm{d}}=\left(\left\{\left(0.5 \mathrm{C}_{\mathrm{D}} \rho \mathrm{Av} \mathrm{v}^{3}+\mu \mathrm{mgv}\right) *\left[\mathrm{t}_{2}^{\prime}-\mathrm{t}_{1}\right]\right\}-\left\{\left(0.5 \mathrm{C}_{\mathrm{D}} \rho \mathrm{Av} \mathrm{v}^{3}+\mu \mathrm{mgv}\right) *\left[\mathrm{t}_{2}-\mathrm{t}_{1}\right]\right\}\right) * \mathrm{~m}_{\mathrm{fp}} / \mathrm{P}_{1}
$$

[Equation 15]

Calculating the aerodynamic and rolling loads from Figure 56 and Figure 57,

$\mathrm{M}_{\mathrm{d}}=1.5 \mathrm{~m}_{\mathrm{fp}}$

For low speed cycles, aerodynamic effect could be neglected and hence Equation 15 became

$\mathrm{M}_{\mathrm{d}}=\left(\left\{\mu \mathrm{MgV} *\left[\mathrm{t}_{2}^{\prime}-\mathrm{t}_{1}\right]\right\}-\left\{\mu \mathrm{Mgv} *\left[\mathrm{t}_{2}-\mathrm{t}_{1}\right]\right\}\right) * \mathrm{~m}_{\mathrm{fp}} / \mathrm{P}_{1} \quad$ [Equation 16]

Calculating the rolling loads from Figure 56 and Figure 57,

$\mathrm{M}_{\mathrm{d}}=0.07 \mathrm{~m}_{\mathrm{fp}}$

Therefore, it could be argued that while calculating the change in emissions and FC for road grade for a particular cycle, a method as shown in Figure 56 could be followed instead of adjusting each and every acceleration event due to the restriction in actual maximum engine power shown in Figure 57 since the difference between these two methods was found to be insignificant. This would eliminate the need for adjusting cycle speed for grade where demanded power exceeded the actual maximum power of the engine.

This logic was further supported by calculating the difference in FC using Equation 8 for the above mentioned scenarios applied to rolling or mountainous terrain. For rolling and mountainous terrains with $6 \%$ maximum road grade, it was found that no significant difference resulted in projecting FC demand due to road grade between the two methods 
shown in Figure 56, and Figure 57. Therefore, for the purpose simplicity, in this dissertation, the difference in FC due to road grade was calculated using the method shown in Figure 56, where cycle road load was allowed to demand power beyond 151 $\mathrm{kW}$ in order to maintain its speed-time trace.

\section{EFFECT OF ROAD GRADE ON FUEL CONSUMPTION FOR SELECTED DUTY CYCLES}

In this section the effect of road grade was observed on selected bus cycles. These cycles included the NYBus Cycle, the ADEME-Paris Cycle, the OCTA Cycle, the Braunschweig Cycle, and the KCM Cycle. Road grade was included in the road load equation and the percentage of FC increase due to road grade was computed. The bus was considered to have no passenger and was assumed to consume about $7.5 \mathrm{~kW}$ (about 10 hp) to run its auxiliary loads.

Varying road grades from $1 \%$ to $5 \%$ with different combinations were considered on rolling and mountainous terrains for NYBus, the ADEME-Paris, the OCTA, the Braunschweig, and the KCM cycles, and their average effect on total load and corresponding effect on $\mathrm{FC}$ was recoded. An occasional $0.5 \%$ maximum positive/negative grade was considered for level terrain also. For the level terrain the road grade was plotted at several phases and the average effect was recorded. Percentage increase in FC due to road grade on the NYBus, the Paris, the OCTA, the Braunschweig, and the KCM cycles are presented in Table 5 , Table 6 , Table 7 , and Table 8 , respectively.

While applying the road grade to the cycles it was observed that at high negative grade on some cycles the total load became negative due to high negative load from road grade. In that moment service braking was assumed to have been applied and the total load was considered zero, as shown in Figure 58 for the 1200 to $1600 \mathrm{sec}$ duration of the KCM Cycle with 5\% negative grade. This was supported by Sovran et al. who demonstrated that if the tractive force was negative then retarding or service braking was required at the tire/road interface of the wheels [75]. 


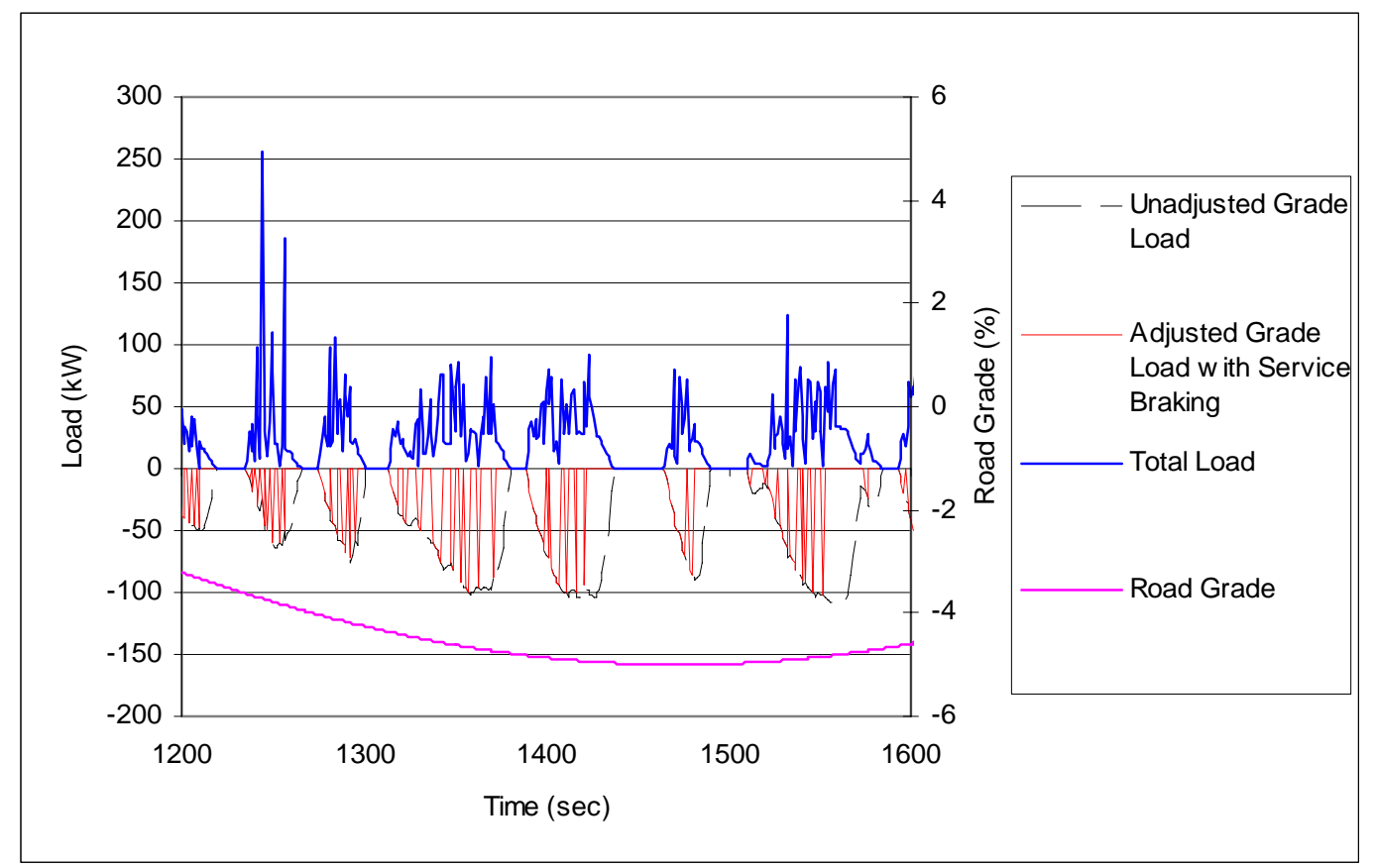

Figure 58: Adjustment of grade load with service braking demonstrated on the KCM Cycle from 1200 to $1600 \mathrm{sec}$

The results showed that the effect of road grade on FC was affected by the average speed of the cycle. An occasional flat grade of either $\pm 0.5 \%$ grade had negligible effect FC. Hence, they were not included in these tables. For the NYBus Cycle, inclusion of 5\% maximum road grade increased $\mathrm{FC}$ by about $7 \%$ on rolling and mountainous terrains while for the OCTA Cycle, FC increased by about 27\% and 25\%, respectively.

Table 5: Percentage increase in FC due to road grade on the NYBus Cycle

\begin{tabular}{|l|c|c|c|c|c|c|c|c|c|c|c|}
\hline Terrain & \multicolumn{5}{|c|}{ Rolling } & \multicolumn{5}{c|}{ Mountain } \\
\hline Road Grade & $1 \%$ & $2 \%$ & $3 \%$ & $4 \%$ & $5 \%$ & $1 \%$ & $2 \%$ & $3 \%$ & $4 \%$ & $5 \%$ \\
\hline $\begin{array}{l}\text { Total Load without } \\
\text { Grade (kW-hr) }\end{array}$ & \multicolumn{7}{|c|}{1.60} & \multicolumn{5}{c|}{1.60} \\
\hline $\begin{array}{l}\text { Total Load with } \\
\text { Grade (kW-hr) }\end{array}$ & 1.64 & 1.76 & 1.87 & 1.96 & 2.06 & 1.62 & 1.78 & 1.88 & 1.98 & 2.08 \\
\hline $\begin{array}{l}\text { Increase in FC with } \\
\text { Grade (\%) }\end{array}$ & 0.52 & 2.36 & 3.90 & 5.29 & 6.6 & 0.30 & 2.57 & 4.13 & 5.54 & 7.00 \\
\hline
\end{tabular}


Table 6: Percentage increase in FC due to road grade on the Paris Cycle

\begin{tabular}{|l|c|c|c|c|c|c|c|c|c|c|}
\hline Terrain & \multicolumn{5}{|c|}{ Rolling } & \multicolumn{5}{c|}{ Mountain } \\
\hline Road Grade & $1 \%$ & $2 \%$ & $3 \%$ & $4 \%$ & $5 \%$ & $1 \%$ & $2 \%$ & $3 \%$ & $4 \%$ & $5 \%$ \\
\hline $\begin{array}{l}\text { Total Load without } \\
\text { Grade (kW-hr) }\end{array}$ & \multicolumn{9}{|c|}{7.30} & \multicolumn{7}{c|}{7.30} \\
\hline $\begin{array}{l}\text { Total Load with } \\
\text { Grade (kW-hr) }\end{array}$ & 7.45 & 8.02 & 8.52 & 9.14 & 9.79 & 7.42 & 8.01 & 8.41 & 8.91 & 9.58 \\
\hline $\begin{array}{l}\text { Increase in FC with } \\
\text { Grade (\%) }\end{array}$ & 1.15 & 5.70 & 9.72 & 14.6 & 19.8 & 0.89 & 5.60 & 8.85 & 12.7 & 18.1 \\
\hline
\end{tabular}

Table 7: Percentage increase in FC due to road grade on the OCTA Cycle

\begin{tabular}{|l|l|l|l|l|l|l|l|l|l|l|}
\hline Terrain & \multicolumn{7}{|c|}{ Rolling } & \multicolumn{7}{c|}{ Mountain } \\
\hline Road Grade & $1 \%$ & $2 \%$ & $3 \%$ & $4 \%$ & $5 \%$ & $1 \%$ & $2 \%$ & $3 \%$ & $4 \%$ & $5 \%$ \\
\hline $\begin{array}{l}\text { Total Load } \\
\text { without Grade } \\
\text { (kW-hr) }\end{array}$ & \multicolumn{9}{|c|}{13.1} & \multicolumn{6}{c|}{13.1} \\
\hline $\begin{array}{l}\text { Total Load with } \\
\text { Grade (kW-hr) }\end{array}$ & 13.2 & 14.2 & 15.3 & 16.5 & 18.0 & 13.2 & 14.1 & 15.4 & 16.6 & 17.8 \\
\hline $\begin{array}{l}\text { Increase in FC } \\
\text { with Grade (\%) }\end{array}$ & 0.60 & 6.10 & 11.8 & 18.7 & 26.5 & 0.50 & 5.95 & 12.3 & 18.8 & 25.3 \\
\hline
\end{tabular}

Table 8: Percentage increase in FC due to road grade on the Braunschweig Cycle

\begin{tabular}{|l|l|l|l|l|l|l|l|l|l|l|}
\hline Terrain & \multicolumn{5}{|c|}{ Rolling } & \multicolumn{5}{c|}{ Mountain } \\
\hline Road Grade & $1 \%$ & $2 \%$ & $3 \%$ & $4 \%$ & $5 \%$ & $1 \%$ & $2 \%$ & $3 \%$ & $4 \%$ & $5 \%$ \\
\hline $\begin{array}{l}\text { Total Load } \\
\text { without Grade } \\
\text { (kW-hr) }\end{array}$ & \multicolumn{7}{|c|}{14.1} & \multicolumn{5}{c|}{14.1} \\
\hline $\begin{array}{l}\text { Total Load with } \\
\text { Grade (kW-hr) }\end{array}$ & 14.1 & 15.3 & 16.5 & 17.7 & 19.0 & 14.1 & 15.4 & 16.5 & 17.8 & 19.2 \\
\hline $\begin{array}{l}\text { Increase in FC } \\
\text { with Grade (\%) }\end{array}$ & 0.48 & 6.73 & 12.8 & 18.9 & 25.7 & 0.38 & 6.98 & 12.8 & 19.5 & 26.4 \\
\hline
\end{tabular}


Table 9: Percentage increase in FC due to road grade on the KCM Cycle

\begin{tabular}{|l|c|c|c|c|c|c|c|c|c|c|}
\hline Terrain & \multicolumn{5}{|c|}{ Rolling } & \multicolumn{5}{c|}{ Mountain } \\
\hline Road Grade & $1 \%$ & $2 \%$ & $3 \%$ & $4 \%$ & $5 \%$ & $1 \%$ & $2 \%$ & $3 \%$ & $4 \%$ & $5 \%$ \\
\hline $\begin{array}{l}\text { Total Load } \\
\text { without Grade } \\
\text { (kW-hr) }\end{array}$ & \multicolumn{7}{|c|}{27.1} & \multicolumn{5}{c|}{27.1} \\
\hline $\begin{array}{l}\text { Total Load with } \\
\text { Grade (kW-hr) }\end{array}$ & 27.2 & 28.8 & 30.7 & 32.9 & 35.5 & 27.2 & 28.2 & 31.3 & 34.5 & 36.8 \\
\hline $\begin{array}{l}\text { Increase in FC } \\
\text { with Grade (\%) }\end{array}$ & 0.26 & 5.3 & 10.9 & 17.8 & 25.7 & 0.12 & 3.18 & 12.9 & 22.7 & 29.9 \\
\hline
\end{tabular}

\section{SUMMARY ON GRADE EFFECT}

Road grades were defined in relation to flat, rolling, and mountainous terrain. While analyzing grade effect on $\mathrm{FC}$, a road grade was assigned to a drive cycle and an equation for the ratio for FC with and without grade was developed. It was observed that ratio of FC depended only on the ratio of power demanded with and without grade provided the vehicle operated on a fixed weight and had uniform auxiliary power in these two modes.

This analysis was then applied to a number of drive cycles to compute the effect of road grade on FC on these cycles for varying grades on rolling and mountainous terrain. However, it was acknowledged that road grades were not constant for a particular route and its origin might not have coincided with the origin of a bus route, and therefore, the effect of phase shift was demonstrated. Varying phase shifts were analyzed for a drive cycle and their average effect on the total load and FC was considered. An analysis was also carried out to examine the consequences of a vehicle not being able to deliver the additional power demanded from the engine due to the presence of high road grade. In this case, the vehicle was likely to have more acceleration time to reach its designated speed and was likely to take more time to complete its route. Finally, the effect of varying road grades on FC was observed for rolling and mountainous terrains and they were tabulated for the NYBus, the Paris, the OCTA, the Braunschweig, and the KCM cycles. 


\section{MODELING FUEL CONSUMPTION FOR A DIESEL TRANSIT BUS}

\section{MODELING STRAEGY}

Here, a prediction model for FC was developed for diesel transit buses for a specific route considering its average speed, passenger loading, and road grade. The average speed was determined from the route's speed limit and the number of stops on that route, followed by determining FC from the experimental data. Finally, correction factors were applied for passenger weight and road grade. Modeling flowchart was designed as follows:

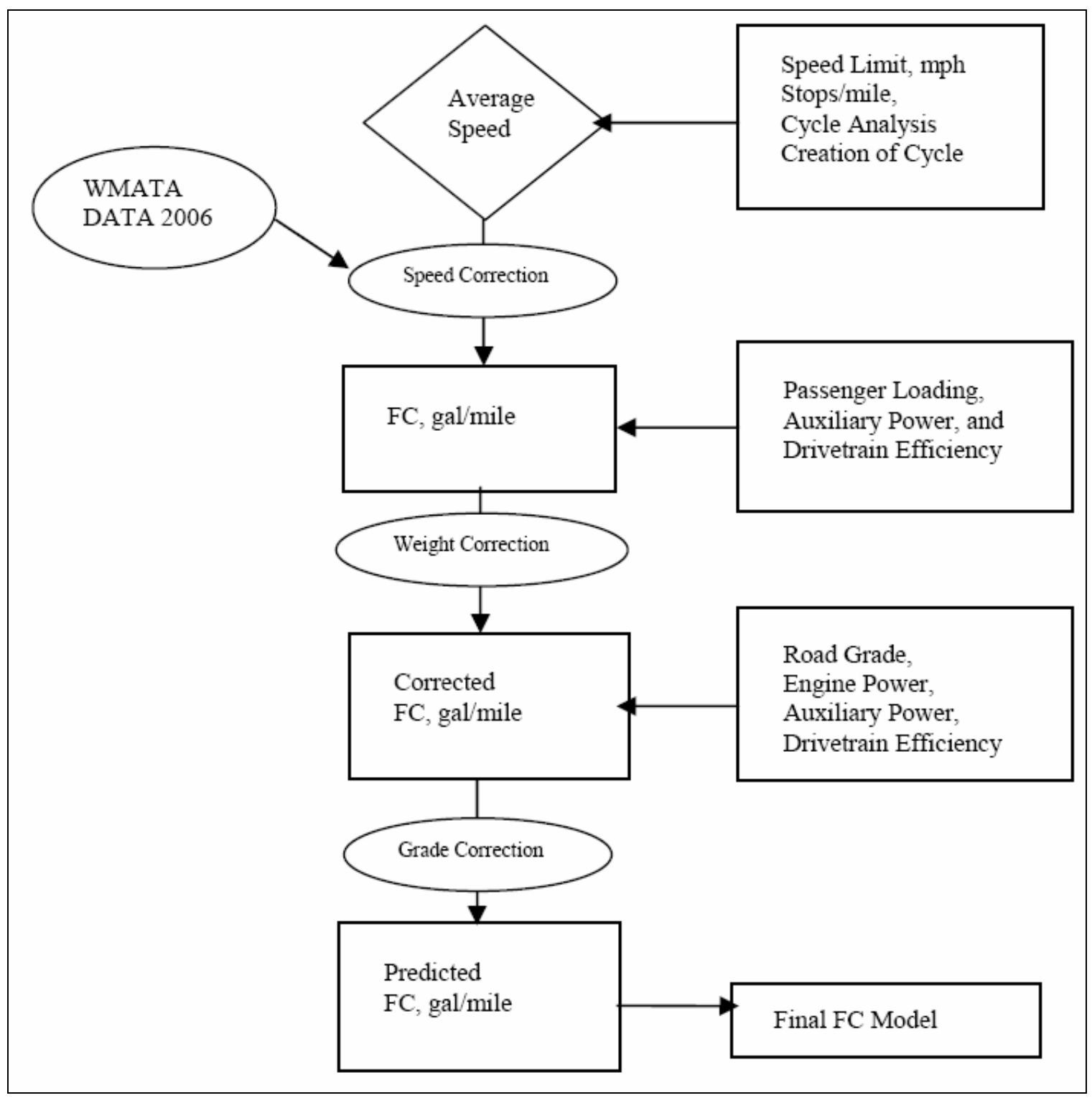


STEP I: DETERMINING AVERAGE SPEED FROM TRIP DURATION, SPEED LIMIT, AND NUMBER OF STOPS

In this step the target user, transit operators in this case, would be asked to provide speed limit and the number of stops in his route, if they were not aware of the average speeds of their routes. This analysis was performed using cycle statistics of other transit bus cycles, including the NYBus, the ADEME-Paris, the Manhattan, the WMATA, the OCTA, the Mexico City Schedule (MCS) that includes MX1, MX2, and MX3 segments, the Beeline, the Braunschweig, and the KCM cycles. From these cycles, first, the average time spent in a stop was determined followed by the determination of average acceleration time to attain the speed limit and average deceleration time to come to a stop. The following assumptions were made during this analysis.

a. The bus was expected not to exceed the speed limit

b. The bus tried to achieve the cruising speed in each acceleration

c. The bus did stop for a specific time at the bus stop

d. Acceleration and deceleration time for every peak was uniform

With these assumptions, distance covered during the acceleration and deceleration was calculated as:

$\mathrm{S}_{\mathrm{a} / \mathrm{d}}=\left(\mathrm{N}_{\mathrm{S}} * \mathrm{~T}_{\mathrm{a} / \mathrm{d}}\right) *\left(\mathrm{~V}_{\max } * 0.55\right) \quad$ [Equation 17]

where,

$\mathrm{N}_{\mathrm{S}}=$ Total number of stops

$T_{a / d}=$ Average time taken for every acceleration and deceleration event in hour $\mathrm{V}_{\max }=$ Maximum speed of the route or the speed limit in mph 
Note that the average speed during the acceleration and deceleration period was $55 \%$ of the maximum speed which was computed from chassis drive cycles, including the Paris, the WMATA, the OCTA, the MCS, the Braunschweig, and the Beeline cycles.

The total distance, $\mathrm{S}_{\mathrm{T}}$ for a cycle included distances during acceleration and deceleration and the cruise mode, which was calculated as:

$\mathrm{S}_{\mathrm{T}}=\left(\mathrm{N}_{\mathrm{S}} * \mathrm{~T}_{\mathrm{a} / \mathrm{d}}\right) *\left(\mathrm{~V}_{\max } * 0.6\right)+\left(\mathrm{T}_{\text {cycle }}-\left(\mathrm{N}_{\mathrm{S}} *\left(\mathrm{~T}_{\mathrm{a} / \mathrm{d}}+\mathrm{T}_{\mathrm{S}}\right)\right)\right) * \mathrm{~V}_{\max } \quad$ [Equation 18]

where,

$\mathrm{T}_{\text {cycle }}=$ Cycle duration in $\mathrm{hr}$ and

$\mathrm{T}_{\mathrm{S}}=$ Duration at a stop in $\mathrm{hr}$

Therefore, average speed was calculated as follows:

$\mathrm{V}_{\text {avg }}=\left(\left(\mathrm{N}_{\mathrm{S}} * \mathrm{~T}_{\mathrm{a} / \mathrm{d}}\right) *\left(\mathrm{~V}_{\max } * 0.6\right)+\left(\mathrm{T}_{\text {cycle }}-\left(\mathrm{N}_{\mathrm{S}} *\left(\mathrm{~T}_{\mathrm{a} / \mathrm{d}}+\mathrm{T}_{\mathrm{S}}\right)\right)\right) * \mathrm{~V}_{\text {max }}\right) / \mathrm{T}_{\text {cycle }}$

[Equation 19]

All parameters in Equation 19 were determined from cycle analysis. It was found that these cycles took about $21 \mathrm{sec}$, on average for acceleration to $30 \mathrm{mph}$ speed while they took about $14 \mathrm{sec}$ deceleration time to come to stop from $30 \mathrm{mph}$. The average time for a stop was about $20 \mathrm{sec}$.

The projected average speeds for these cycles, calculated from Equation 19 were compared with their actual average speed and it was observed that this correlation induced an $\mathrm{R}^{2}$ value of 0.65 , as shown in Figure 59 . 


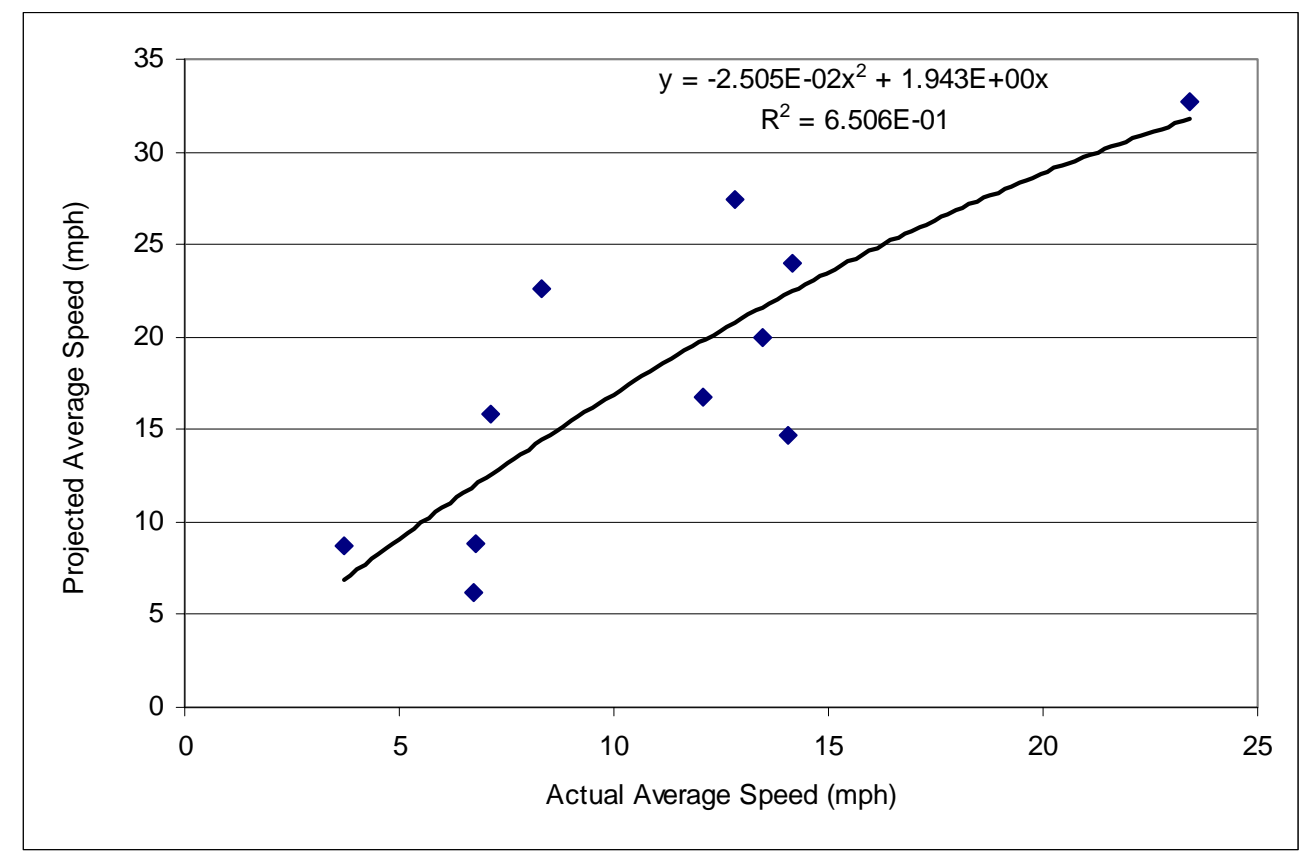

Figure 59: Relationship between the actual average speed and the projected average speed of selected cycles

The variation between actual and projected average speeds could be attributed to the following reasons. $20 \mathrm{sec}$ duration at bus stop of was, however, conservative. The NYBus, WMATA, MX2, and MX3 cycles were found to have about $30 \mathrm{sec}$ of stoppage time at each bus stop. Also, the buses were not found to reach its maximum speed or the speed limit in each acceleration event. For example, the NYBus, WMATA and the MX1 cycles reached its speed limit once in its entire duration. Also, the time taken for acceleration and deceleration was not uniform for all cycles.

\section{STEP II: DETERMINING FUEL CONSUMPTION FROM AVERAGE SPEED}

In the second step, FC was determined with the help of FC trend developed from the WMATA data and using the average speed computed from Equation 17. The correlation equation between FC and average speed, developed from the trend in Figure 26, was used in this step. FC for selected speeds for the Cummins diesel bus is provided in Table 10. It needed to be mentioned here that FC data taken from the WMATA program did not 
include the effect of air conditioning (A/C). The effect of A/C load on FC would ave o be developed and would be an addition to this model.

Table 10: Projected FC for diesel buses for selected average speed

\begin{tabular}{|l|l|}
\hline $\begin{array}{l}\text { Average Speed } \\
(\mathrm{mph})\end{array}$ & $\begin{array}{l}\text { Projected FC } \\
\text { (gal/mile) }\end{array}$ \\
\hline 2 & 0.52 \\
\hline 4 & 0.38 \\
\hline 6 & 0.32 \\
\hline 8 & 0.28 \\
\hline 10 & 0.25 \\
\hline 12 & 0.23 \\
\hline 14 & 0.21 \\
\hline 16 & 0.20 \\
\hline 18 & 0.19 \\
\hline 20 & 0.18 \\
\hline
\end{tabular}

STEP III: DETERMINING CORRECTION FACTOR FOR PASSENGER WEIGHT

FC and emissions from the diesel bus were measured at half passenger weight. Therefore, a weight correction factor (WCF) was developed to consider for the effect of empty and full passenger loading on FC.

FC for the retrofitted diesel bus at half passenger weight was $0.391 \mathrm{gal} / \mathrm{mile}$ on the Paris Cycle. At full passenger weight FC increased by about $7 \%$ and for empty passenger weight it reduced by $11 \%$. The same bus, on the OCTA Cycle consumed $0.296 \mathrm{gal} / \mathrm{mile}$ at half passenger weight. FC increased by about $5 \%$ for full passenger weight and reduced by $12 \%$ for empty passenger weight. On the Braunschweig Cycle, the bus 
consumed $0.281 \mathrm{gal} / \mathrm{mile}$ at half weight while it consumed $0.301 \mathrm{gal} / \mathrm{mile}$ and 0.257 gal/mile at full weight and empty weights, respectively. On average, there was a decrease in FC by about $10 \%$ for the empty weight and an increase of about $7 \%$ for full weight. Similar observations were made from the road load equation on this bus on the same cycle. It was observed that FC would have increased by $3 \%$ to $9 \%$ and decrease by $3 \%$ to $9 \%$, depending on the average speed of cycles if the bus was operated at full passenger weight and empty passenger weight, respectively, in comparison to its half weight operation. Empirical relations were developed from these findings for the full and half passenger weights as shown in Figure 60.

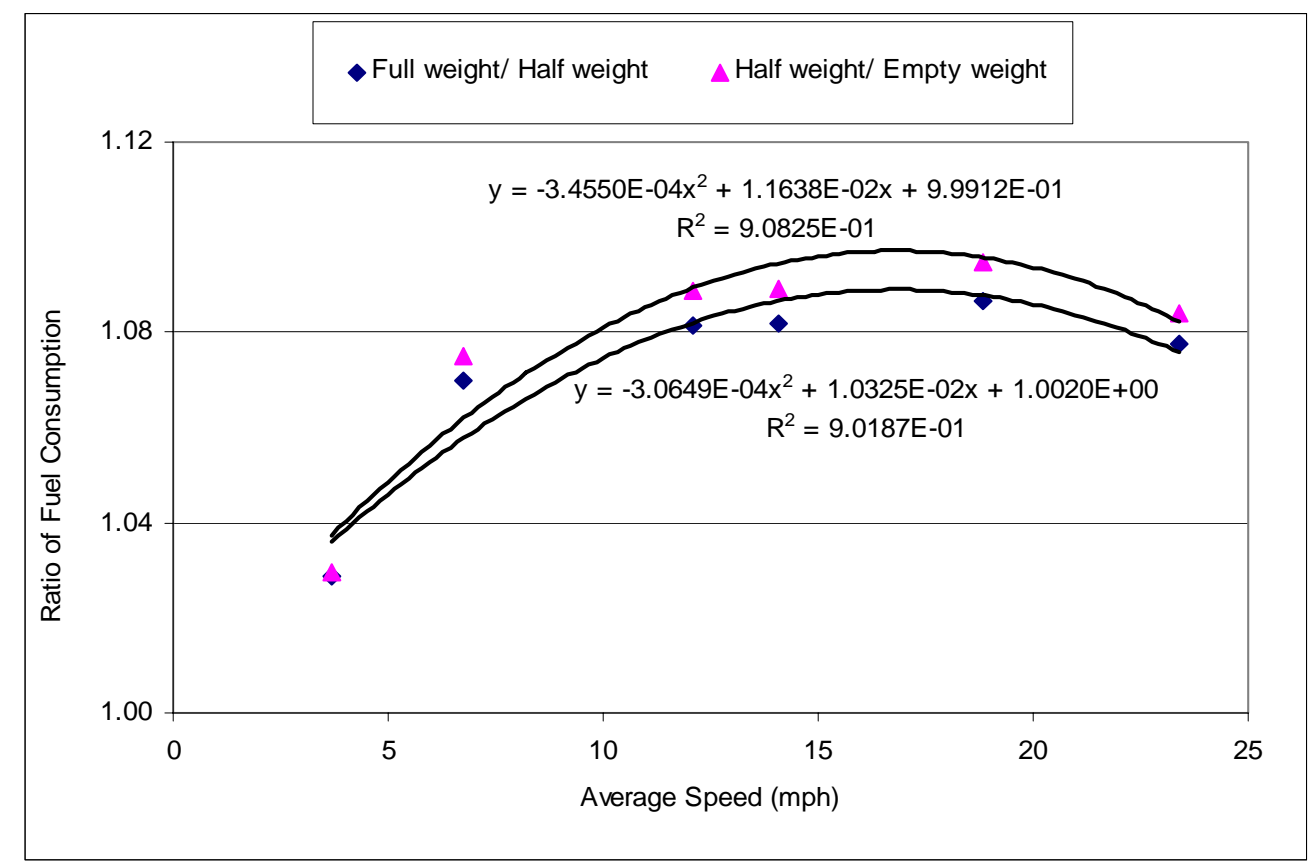

Figure 60: Ratio of fuel consumption between full and half passenger weights and between half and no passenger weights. 
STEP IV: DETERMINING CORRECTION FACTOR FOR TERRAIN AND ROAD GRADE

Two inputs, the type of terrain and the percentage of grade need to be determined in order to compute the increase in FC for grade. While analyzing grade it was observed that the percentage increase in FC with grade was largely affected by average speed. Percentage increase in FC for the NYBus, the Paris, the OCTA, and the KCM cycles for different grade on rolling, and mountainous terrains are presented in Figure 61 and Figure 62, respectively. On rolling terrain the percentage increase in $\mathrm{FC}$ for $5 \%$ grade on the NYBus Cycle (3.69mph average speed) was about $7 \%$ while it was about $20 \%$ and $27 \%$ on the Paris $(6.77 \mathrm{mph})$ and the OCTA $(12.08 \mathrm{mph})$ cycles, respectively. However, the percentage increase was moderate at higher speed cycles, because aerodynamic load dominated their total loads. The FC increase with road grade generated a good correlation with $\mathrm{R}^{2}$ values ranging from 0.87 to 0.94 on the rolling terrain and from 0.92 to 0.99 on the mountainous terrain. Therefore, for any bus cycle, the grade correction factor (GCF) was computed using the correlations from Figure 61 and Figure 62 for rolling and mountainous terrains, respectively. For example, GCF, computed for a 3\% grade on rolling and mountainous terrains are presented in Table 11, and Table 12, respectively. 


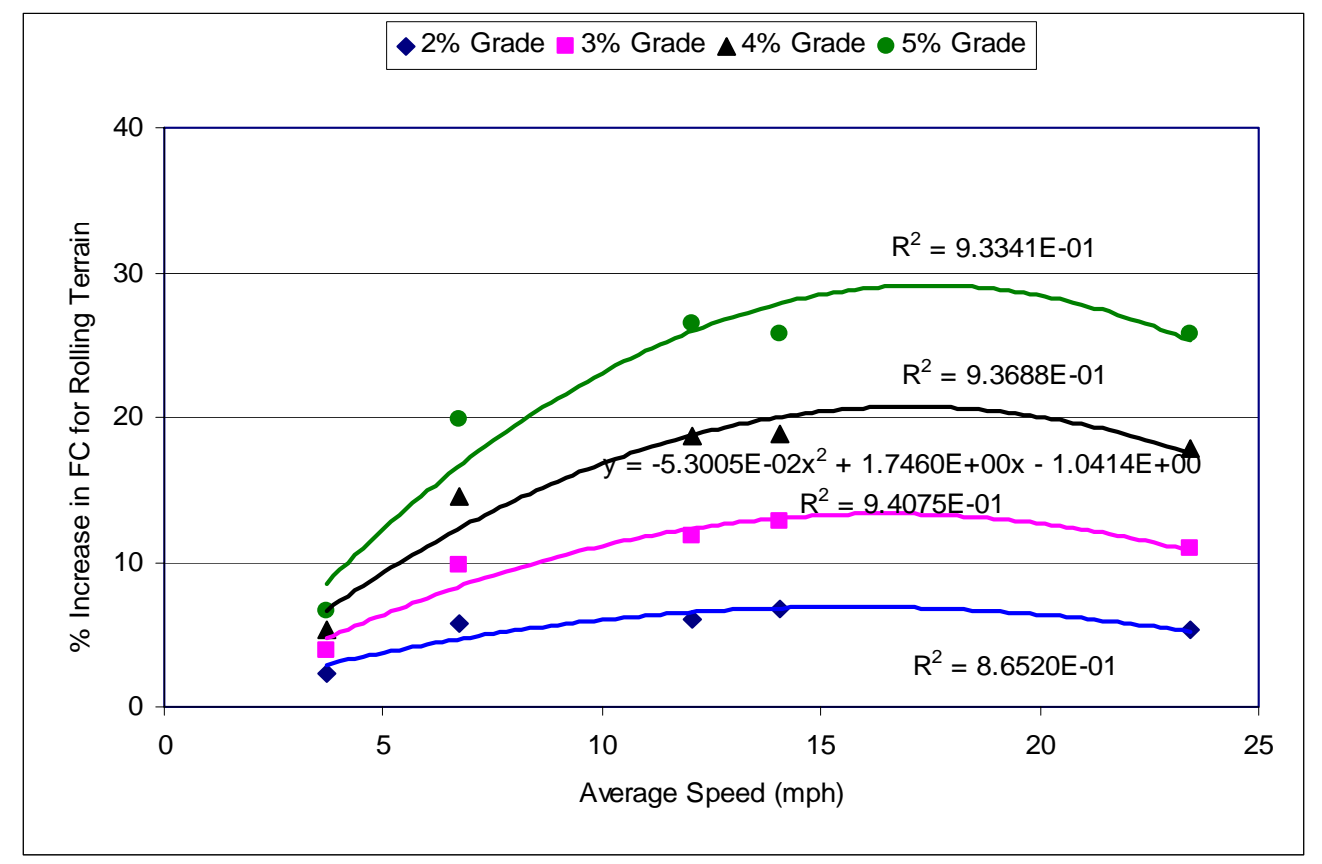

Figure 61: Percentage increase in FC for different grade on rolling terrain

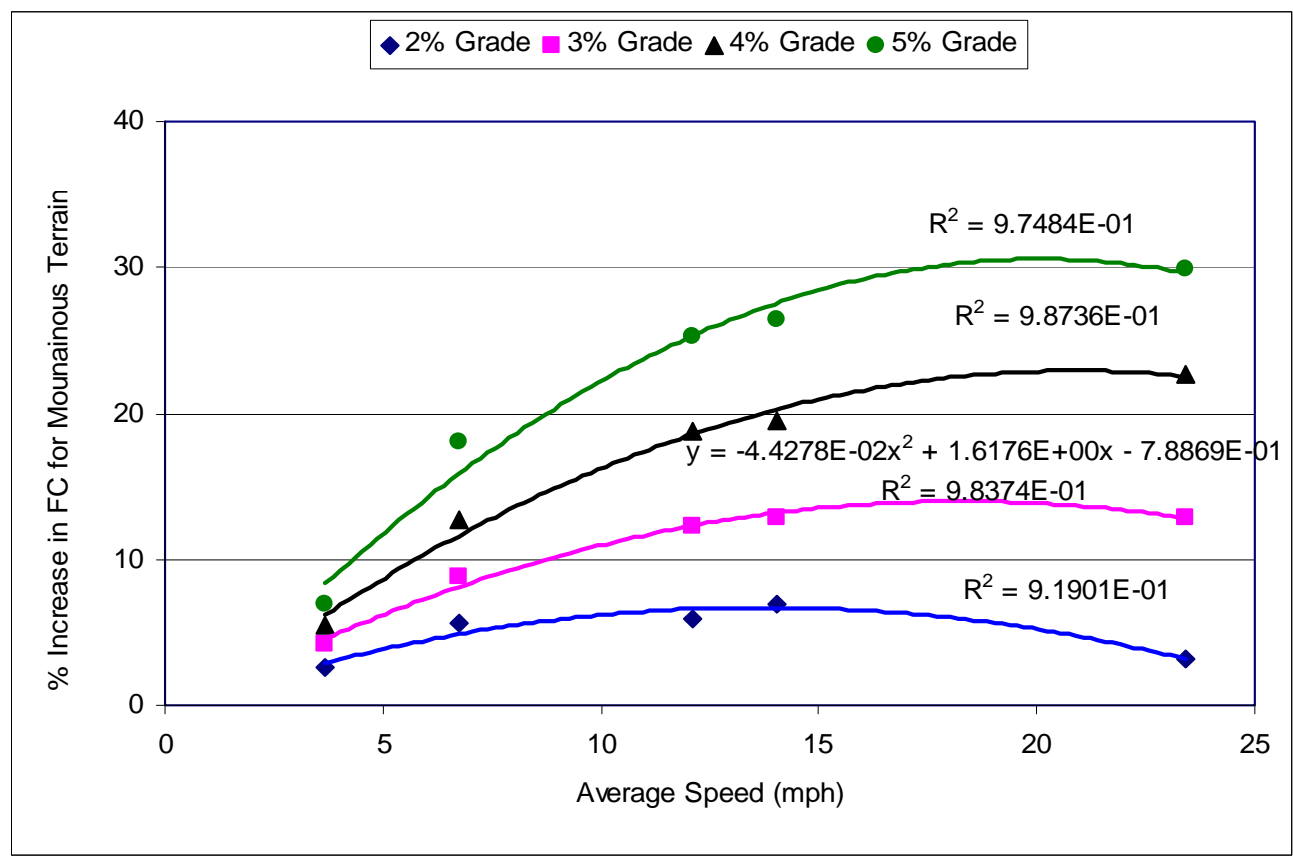

Figure 62: Percentage increase in FC for different grade on mountainous terrain 
Table 11: GCF developed for $3 \%$ road grade on a rolling terrain

\begin{tabular}{|l|l|}
\hline $\begin{array}{l}\text { Average Speed } \\
(\mathrm{mph})\end{array}$ & GCF \\
\hline 4 & 1.05 \\
\hline 6 & 1.08 \\
\hline 8 & 1.09 \\
\hline 10 & 1.14 \\
\hline 12 & 1.27 \\
\hline 14 & 1.36 \\
\hline 16 & 1.41 \\
\hline 18 & 1.42 \\
\hline 20 & 1.39 \\
\hline
\end{tabular}

Table 12: GCF developed for $3 \%$ road grade on a mountainous terrain

\begin{tabular}{|l|l|}
\hline $\begin{array}{l}\text { Average Speed } \\
(\mathrm{mph})\end{array}$ & GCF \\
\hline 4 & 1.05 \\
\hline 6 & 1.07 \\
\hline 8 & 1.09 \\
\hline 10 & 1.11 \\
\hline 12 & 1.22 \\
\hline 14 & 1.32 \\
\hline 16 & 1.38 \\
\hline 18 & 1.40 \\
\hline 20 & 1.38 \\
\hline
\end{tabular}


FC data generated from this model was validated with the real-world data from transit buses published in literatures. Chandler et al. [109] collected some real-world FC data from King County Metro Transit, Long Beach Transit, and New York City Transit. New York City Transit had about 3,669 diesel buses while the King County Metro had 1,137 diesel buses in their fleet. Long Beach Transit had only 169 diesel buses. The operating speed for New York City Transit, King County Metro Transit, and Long Beach Transit was about $6.35 \mathrm{mph}, 12.3 \mathrm{mph}$, and $13.8 \mathrm{mph}$, respectively. In New York City Transit the $1999 \mathrm{MY}$ Orion V buses had FC of about $0.42 \mathrm{gal} / \mathrm{mile}$, on average. With $6.35 \mathrm{mph}$ average speed, this model predicted FC of about $0.31 \mathrm{gal} / \mathrm{mile}$ for the $2006 \mathrm{MY}$ buses without $\mathrm{A} / \mathrm{C}$ and without any corrections for passenger weight and grade. The FC increased to $0.33 \mathrm{gal} / \mathrm{mile}$ after assigning half passenger loading and ignoring the effect of grade for the New York City. In King County Metro the 2004 MY New Flyer 60-foot diesel articulated buses demonstrated FC of about $0.39 \mathrm{gal} / \mathrm{mile}$. These buses were $150 \%$ heavier than 40 -foot buses and were designed to carry 58 passengers. For their average speed the model predicted $0.23 \mathrm{gal} / \mathrm{mile}$ for the $2006 \mathrm{MY}$ buses. The predicted FC increased to $0.30 \mathrm{gal} / \mathrm{mile}$ considering the additional weight of these buses compared to conventional 40-foot buses and accounting for half passenger loading, on average. For $\mathrm{KC}$ Metro transit a 3\% rolling grade was also assigned following the grade profile presented in the KCM Cycle. The predicted FC then increased to $0.38 \mathrm{gal} / \mathrm{mile}$ with this grade profile. Long Beach Transit achieved a FC of 0.29 gal/mile from its $2002 \mathrm{MY}$ diesel fleet. The FC value estimated from the model was $0.23 \mathrm{gal} / \mathrm{mile}$ for their average speed with half passenger loading. The predicted FC values for New York City Transit, Long Beach Transit, and King County Metro Transit were about 22\%, 21\%, and 3\% less than that the real-world values, respectively. The difference between the predicted and real-world values could primarily be attributed to the improvement in diesel technology over the years, from 1994 MY to 2006 MY for New York City Transit buses and from 2002 MY to 2006 MY for Long Beach buses. The difference could also be attributed to real-world passenger loading, fan and accessory power consumption, use of $\mathrm{A} / \mathrm{C}$ or heating, and the driving profile. 


\section{CONCLUSIONS}

This dissertation focused on developing a prediction model for fuel consumption (FC) from diesel transit buses in North America that was primarily intended for the transit operators and managers. The effect of average speed, passenger weights, road grade, and terrain on emissions and FC were also analyzed in this process. The research considered regulated emissions and FC data collected from thirteen 40-foot transit buses including six buses with lean-burn natural gas technology, three hybrid-electric diesel buses, two retrofitted diesel engine buses and two new diesel buses. These data were collected using a chassis dynamometer laboratory, operated by West Virginia University. More than twenty available chassis cycles were analyzed to understand the effect of average drive cycle speed on other cycle properties. It was found that properties of cycles like standard deviation of speed, percentage of idle, and stops per unit distance were closely related with average cycle speed.

While observing the effect of average speed on emissions and FC, it was found that distance-specific emissions of NOx from these buses were low when driven on high speed cycles such as the Commuter and the Arterial phases of SAE J1376 and high when driven on low speed cycles such as the NYBus, Manhattan, or Paris cycles while distance-specific $\mathrm{FC}$, inferred from the $\mathrm{CO}, \mathrm{HC}$, and $\mathrm{CO}_{2}$ emissions using carbon balance was high at low speed cycles and low at high speed cycles. PM, CO, HC from these buses did not provide a strong correlation with average speed except HC. HC emissions from the CNG buses were very high compared to those from diesel and hybrid buses and they developed a good correlation with cycle average speed.

Then the effect of operating weight on FC was explained using the road load equation and a model for drivetrain efficiency and auxiliary loads. Analysis showed that FC was governed by the power demanded of the engine, which was affected by wind drag, rolling resistance, inertia load, auxiliary load and the drivetrain and fuel conversion efficiency. A prediction model was developed to project the ratio of FC between empty weight and full test weight. It was found that the predicted ratios would vary from approximately 0.83 to 
0.94 depending on component efficiencies, the amount of power demanded by the auxiliary loads, and the nature of driving cycles. This predictive model was compared with FC data collected from three 40-foot transit buses powered with a John Deere leanburn natural gas engine, a Cummins lean-burn natural gas engine, and a DDC Series 50 retrofitted diesel engine. Experimental results showed that FC from these buses increased once the test weight was increased from empty weight to full weight. It was found that the ratio of FC between the empty weight and full test weights ranged from 0.88 to 0.91 , on average for the CNG buses and from 0.83 to 0.85 for the retrofitted diesel bus. These findings supported the predicted ratios developed for FC.

The analysis on the passenger weight effect was followed by the effect of road grade and terrain on FC. It was important to define road grade in association with road terrain. Once defined, road grade for a particular terrain was included in the road load equation and the percentage increase in $\mathrm{FC}$ with road load was observed. Varying road grade from $1 \%$ to $5 \%$ was considered on rolling and mountainous terrains for diesel buses on some selected cycles. The percentage increase in FC due to road grade on these cycles showed that the effect of road grade on FC was affected by the average speed of the cycle. On rolling terrain the percentage increase in FC for 5\% maximum grade was higher on high speed cycles than that on the low speed cycles. However, the percentage increase was moderate when only high speed cycles were compared. The FC increase with road grade also generated a good correlation with average speed of the cycle on rolling and mountainous terrains.

Finally all these analyses were taken to construct a simple predictive model for FC projection for a 40 -foot diesel bus. Here, the average speed of a bus route was determined from its speed limit, number of stops, and route duration. Once the average speed was determined, it was used to calculate FC from the speed correction developed from the WMATA data followed by determination of the weight correction factor (WCF) for full and no passenger weight. Finally, a grade correction factor (GCF) was included to consider for the effect of terrain and the percentage of road grade. Validation of this model was performed with the real-world FC data reported from three transit agencies. 
The difference in FC values were attributed to the improved efficiency of new diesel buses, use of $\mathrm{A} / \mathrm{C}$ or heating, difference in fan load, and different driving profile.

This dissertation has potential for modeling FC in transit applications and is expected to attract considerable attention from transit operators. The predictive model would provide 'the tool' that the transportation community was looking for. It is also likely to give an insight into the planning and selection of bus technologies for transit application. It is acknowledged that this model is developed for a 40 -foot diesel bus, therefore, models for $\mathrm{CNG}$ and diesel hybrid-electric buses will have to be developed. This model deals with 40-foot transit buses, the most common form of transit buses in the U.S. The necessity for developing FC model for 60 -foot articulated buses is duly recognized. It is also acknowledged that many models of this kind will be needed for the transit industry to make their fleet the most cost-effective and most efficient. 


\section{RECOMMENDATIONS FOR FUTURE RESEARCH}

This dissertation focused on developing a predictive modeling tool for transit managers and operators. It primarily focused on predicting FC from diesel buses from average speed of drive cycles and by incorporating correction factors for passenger weight and road grade. This research demonstrated that the average speed of a cycle was the most important parameter that defined the cycle. However, other cycle parameters including percentage idle and acceleration/deceleration also affected emissions formation and FC. Therefore, future research on developing emissions and FC modeling tool from a collection of parameters by matrix inversion method is recommended. These parameters might include average speed, percentage of idle, acceleration/deceleration, and stops per unit distance.

This research developed a correction factor for three passenger weights; empty weight for no passenger, half weight for $50 \%$ passenger and full weight for fully laden transit bus. However, passenger loading would not be uniform and identical in real-world traffic. Also, the experimental data were collected for diesel and $\mathrm{CNG}$ buses on three drive cycles only. There was inconsistency in NOx emissions trend from a CNG bus, which exhibited comparatively low NOx at full weight than that at half and empty weights. Therefore, FC and emissions data could be collected on a number of cycles for future analysis that would include transit buses across all technologies.

This dissertation also developed a correction factor for grade and terrain from the roadload equation. The researcher acknowledged that a very limited research was performed on grade effect on emissions and FC. No experimental emissions and FC data for varying road grades were available since data from the chassis dynamometer were considered for this dissertation. Also, road grade and terrain were plotted on the drive cycles that might have already included grade effect in them. Therefore, mobile or portable emissions measurement systems could be utilized to collect data for varying grade on different terrains. That would allow development of an accurate correction factor for road grade and terrain. 
Finally, predictive model proposed in this dissertation was applicable to diesel buses only and qualitative difference for $\mathrm{CNG}$ and hybrid-electric buses were not addressed. This model might be applied to hybrid-electric and natural gas buses provided future research looks into the variable divetrain efficiencies for hybrid buses and addresses the part-load efficiencies for natural gas buses. Also, this model considered data from 40-foot transit buses only. Therefore, research in collecting data from 60 -foot transit buses and subsequent modeling were also recommended. Development of similar modeling tools for other bus technologies will enable transit operators to the efficient route assignment of bus technologies and lead to an effective and efficient transit management.

\section{REFERENCES}

1. U.S. Census Bureau, "International Database, World Population: 1950-2050," June 2009.

2. Molina, M.J., and Molina, M.T., "Megacities and Atmospheric Pollution, 2004 Critical Review," Journal of the Air \& Waste Management Association, Vol. 54, pp. 644-680, 2004.

3. Levinson, H.S., "Bus Transit in the 21st Century - Perspectives and Prospects," Transportation Research Record, Vol. 1760, pp. 42-46, 2001.

4. Kennedy C., Miller, E., Shalaby, A., Maclean, H., and Coleman, J., "The four pillars of Sustainable Urban Transportation," Transportation Reviews, Vol. 25, pp. 393-414, 2005.

5. Gilbert, R., "Sustainable Mobility in the City," Presentation to URBAN 21, Global Conference on the Urban Future, Berlin, Germany, 2000.

6. Advani, M. and Tiwari, G., "Review of Capacity Improvement Strategies for Bus Transit Service,” Indian Journal of Transport Management, Vol. 30, pp. 363-391, 2006.

7. American Public Transportation Association (APTA), "2009 Public Transportation Fact Book," $60^{\text {th }}$ Edition, 2009. Also available at 
http://www.apta.com/research/stats/documents09/2009_apta_fact_book_with_out er_covers.pdf.

8. Marlowe, C.L., "Development of Computational Tools for Modeling Engine Fuel Economy and Emissions," MS thesis submitted to the College of Engineering and Mineral Resources at West Virginia University, Morgantown, WV, 2009.

9. National Transit Database (NTD), Federal Transit Administration (FTA) of U.S. Department of Transportation (DOT), “2007 National Transit Summaries and Trends," Washington D.C., October 2008.

10. American Public Transportation Association (APTA) Transit Resource Guide, “Transit Bus Fuels and Air Quality, Revised June 2006," Available at http://www.apta.com/research/info/briefings/briefing_5.cfm.

11. Energy Information Administration, "Alternatives to Traditional Transportation Fuels 2007 (Part I - Supplier data)," released in April 2009. Also available at www.eia.doe.gov/cneaf/alternate/page/atftables/atf14-20_05.html.

12. International Association of Public Transport, "Public Transit Statistics Report, Latest Figures on the Urban Bus Fleet in the European Union," Available at http://www.uitp.org/mos/pics/stats/survey_bus_fleet.pdf. Accessed on October 10, 2007.

13. Lloyd, A.C. and Cackette, T.A., "Diesel Engines Environmental Impact and Control," Journal of the Air \& Waste Management Association, Vol. 51, pp. 809847, 2001.

14. Coroller, P. and Plassat, G., "Comparative Study on Exhaust Emissions from Diesel and CNG-Powered Urban Buses," Proceedings of the Diesel Engine Emissions Reduction Conference (DEER), Newport, RI, 2003.

15. Ahlvik, P., "Natural Gas," DieselNet Technology Guide, Alternative Diesel Fuels, Also available at www.dieselnet.com/tech/fuel cng.html.

16. Wang, W., Gautam, M., Sun, X., Bata, R., Clark, N., Palmer, G.M., and Lyons, D., "Emissions Comparisons of Twenty-Six Heavy-Duty Vehicles Operated on Conventional and Alternative Fuels," SAE Technical Paper 932952, 1993. 
17. Clark, N.N., Gadapati, C.J., Kelly, K., White, C.L., Lyons, D.W., Wang, W., Gautam, M., and Bata, R.M., "Comparative Emissions from Natural Gas and Diesel Buses," SAE Technical Paper 952746, 1995.

18. Clark, N.N., Gautam, M., Lyons, D.W., Bata, R.M., Wang, W., Norton, P., and Chandler, K., "Natural Gas and Diesel Transit Bus Emissions: Review and Recent Data,” SAE Technical Paper 973203, 1997.

19. Clark, N.N., Lyons, D.W., Rapp, B.L., Gautam, M., Wang, W., Norton, P., White, C., and Chandler, K., "Emissions from Trucks and Buses Powered by Cummins L-10 Natural Gas Engines," SAE Technical Paper 981393, 1998.

20. Norton, P., Frailey, M., Clark, N.N., Lyons, D.W., Gautam, M., Add, J.M., and Beck, N.J., "Chassis Dynamometer Emissions Measurements from Trucks and Buses using Dual-Fuel Natural Gas Engines," SAE Technical Paper 1999-01$3525,1999$.

21. McCormick, R.L., Graboski, M.S., Alleman, T., Herring, A.M., and Nelson, P., "In-Use Emissions from Natural Gas Fuelled Heavy-Duty Vehicles," SAE Technical Paper 1999-01-1507, 1999.

22. Clark, N.N., Gautam, M., Rapp, B.L., Lyons, D.W., McCormick, R.L., Graboski, M.S., Alleman, T., and Norton, P., "Diesel and CNG Transit Bus Emissions Characterization by Two Chassis-Dynamometer Laboratories: Results and Issues,” SAE Technical Paper 1999-01-1469, 1999.

23. Weaver, C.S., Turner, S.H., Balam-Almanza, M.V., and Gable, R., "Comparison of In-Use Emissions from Diesel and Natural Gas Trucks and Buses," SAE Technical Paper 2000-01-3473, 2000.

24. Frailey, M., Norton, P., Clark, N.N., and Lyons, D.W., "An Evaluation of Natural Gas versus Diesel in Medium-Duty Buses,” SAE Technical Paper 2000-01-2822, 2000 .

25. Pelkmans, L., Keukeleere, D.D., Bruneel, H., and Lenaers, G., "Influence of Test Cycle Characteristics on Fuel Consumption and Emissions of City Buses," SAE Technical Paper 2001-01-2002, 2002.

26. Kamel, M., Lyford-Pike, E., Frailey, M., Bolin, M., Clark, N., Nine, R., and Wayne, S., "An Emissions and Performance Comparison of the Natural Gas 
Cummins Westport Inc. C-Gas Plus versus Diesel in Heavy-Duty Trucks," SAE Technical Paper 2002-01-2737, 2002.

27. Brodrick, C-J., Sperling, D., Dwyer, H.A., and Becker, C., "Emissions from Conventional and Hybrid Electric Transit Buses Tested on Standard and San Francisco Specific Driving Cycles,” SAE Technical Paper 2002-01-3117, 2002.

28. Lev-On, M., LeTavec, C., Uihlein, J., Alleman, T.L., Lawson, D.R., Vertin, K., Thompson, G.J., Gautam, M., Wayne, S., Zielinska, B., Sagebiel, S., Chatterjee, S., and Hallstrom, K., "Chemical Speciation of Exhaust Emissions from Trucks and Buses Fueled on Ultra-Low Sulfur Diesel and CNG," SAE Technical Paper 2002-01-0432, 2002.

29. Ayala, A., Kado, N.Y., Okamoto, R.A., Holmen, B.A., Kuzmicky, P.A., Kobayashi, R., and Stiglitz, K.E., "Diesel and CNG Heavy-Duty Transit Bus Emissions over Multiple Driving Schedules: Regulated Pollutants and Project Overview," SAE Technical Paper 2002-01-1722, 2002.

30. Walkowicz, K., Proc, K., Wayne, S., Nine, R., Campbell, K., and Wiedemeier, G., "Chassis Dynamometer Emissions Measurements from Refuse Trucks Using Dual-Fuel $^{\mathrm{TM}}$ Natural Gas Engines," SAE Technical Paper 2003-01-3366, 2003.

31. Ullman, T.L., Smith, L., Anthony, J.W., Slodowske, W.J., Trestrail, W.M., Bunn, W., Lapin, C.A., and Wright, K.J., "Comparison of Exhaust Emissions, Including Toxic Air Contaminants, from School Buses in Compressed Natural Gas, Low Emitting Diesel, and Conventional Diesel Engine Configurations," SAE Technical Paper 2003-01-1381, 2003.

32. Lanni, T., Frank, B.P., Tang, S., Rosenblatt, D., and Lowell, D., "Performance and Emissions Evaluation of Compressed Natural Gas and Clean Diesel Buses at New York City's Metropolitan Transit Authority," SAE Technical Paper 200301-0300, 2003.

33. Wayne, W.S., Clark, N.N., Nine, R.D., and Elefante, D., “A Comparison of Emissions and Fuel Economy from Hybrid-Electric and Conventional Drive Transit Buses," Energy \& Fuels, Vol. 18, pp. 257-270, 2004.

34. Wayne, W.S., Clark, N.N., Gautam, M., Thompson, G.J., and Lyons, D.W., "Natural Gas Heavy-Duty Transit Bus Emissions Testing - Washington 
Metropolitan Area Transit Authority," Final Report submitted by West Virginia University to the National Renewable Energy Laboratory (NREL), Golden, Colorado, 2005.

35. Clark, N.N., Borrell, E.R., McKain, D.L., Paramo, V.H., Wayne, W.S., Vergara, W., Barnett , R. A., Gautam, M., Thompson, G., Lyons, D.W., and Schipper, L., "Evaluation of Emissions from New and In-Use Transit Buses in Mexico City," Paper No. 06-1092, 85th Annual Meeting of the Transportation Research Board, Washington D.C., 2006.

36. Energy Efficiency and Renewable Energy (EERE), U.S. Department of Energy (DOE), “Technologies: Hybrid Electric Vehicles," Available at http://www1.eere.energy.gov/vehiclesandfuels/technologies/systems/hybrid_elect ric vehicles.html.

37. Clark, N.N., Wayne, W.S., Zhen, F., Khan, A.S., Schiavone, J., Chambers, C.A., and Chandler, K.L., "A Review of the Performance of Hybrid-Electric Bus Technology on Fuel Economy and Emissions," Presented at 2006 APTA Bus \& Paratransit Conference, CA, 2006.

38. Wayne, W.S., "Characterization of Emissions from a Gasoline Powered HybridElectric Transit Bus," Final Report submitted by West Virginia University to Omnitrans of San Bernardino, 1700 West Fifth Street San Bernardino, CA, 2002.

39. McKain D.L., Clark, N.N., Balon, T.H., Moynihan, P.J., Lynch, S.A., and Webb, T.C., "Characterization of Emissions from Hybrid-Electric and Conventional Transit Buses," SAE Technical Paper 2000-01-2011, 2000.

40. Meyer, N. and Rideout, G., "Allison EP System Electric Hybrid Test Program Regulated Emissions and Fuel Economy Results," ERMD Report 02-25-1, Environmental Technology Center, Emissions Research and Measurement Division, Environment Canada, 335 River Road, Ottawa, ON, K1A 0H3, Canada, 2002.

41. Meyer, N. and Rideout, G., "Orion VII Transit Bus Equipped with BAE SYSTEMS Hybrid Drive TM Propulsion System (MY2004): Emissions and Fuel Economy Test Report,” ERMD Report\#: 04-18, Environmental Technology 
Center, Emissions Research and Measurement Division, Environment Canada, 335 River Road, Ottawa, ON, K1A 0H3, Canada, 2004.

42. Clark, N.N., McKain, D.L., Xie, W., Norton, P., and Balon, T. H., "Hybrid Diesel-Electric, Heavy-Duty Bus Emissions: Benefits of Regeneration and Need for State of Charge Correction," SAE Technical Paper 2000-01-2955, 2000.

43. The Northeast Advanced Vehicle Consortium (NAVC), M.J. Bradley \& Associates Inc., and West Virginia University, "Hybrid-Electric Drive heavyDuty Vehicle Testing Project," Final Report submitted to the Defense Advanced Research Projects Agency, 2000.

44. Chandler, K. and Walkowicz, K., "Emissions, Fuel Economy, and In-use Performance Evaluation of King County Metro Transit's Hybrid Buses," Presented at 2006 APTA Bus \& Paratransit Conference, Orange County, CA, 2006.

45. Emission Standards, http://www.dieselnet.com/standards/us/hd.html, Accessed on August 10, 2007.

46. Clark, N.N., Schiavone, J., and Chandler, K., "Assessment of Hybrid-Electric Transit Bus Technology," TCRP C-15 Interim Report Prepared for Transit Cooperative Research Program, Transportation Research Board (TRB), National Research Council, 2006.

47. Samuel, S., Morrey, D., Fowkes, M., Taylor, D.H.C., Austin, L., Felstead, T., and Latham, S., "The Most Significant Vehicle Operating Parameter for Real-World Emissions Levels," SAE Technical Paper 2004-01-0636, 2004.

48. Kean, A.J., Harley, R.A., and Kendall, G.R., "Effects of Vehicle Speed and Engine Load on Motor Vehicle Emissions," Environmental Science \& Technology, Vol. 37, pp. 3739-3746, 2003.

49. Ramamurthy, R., Clark, N.N., Atkinson, C.A., and Lyons, D.W., "Models for Predicting Transient Heavy-Duty Vehicle Emissions," SAE Technical Paper 982652, 1998.

50. Clark, N.N., Tehranian, A., Jarrett, R.P., and Nine, R.D., "Translation of Distance-Specific Emissions Rates between Different Heavy-Duty Vehicle Chassis Test Schedules,” SAE Technical Paper 2002-01-1754, 2002. 
51. Yanowitz, J., Graboski, M.S., Ryan, L.B.A., Alleman, T.A., and McCormick, R.L., "Chassis Dynamometer Study of Emissions from 21 In-Use Heavy-Duty Diesel Vehicles," Environmental Science \& Technology, Vol. 33, pp. 209-216, 1999.

52. Clark, N.N., Kern, J.M., Atkinson, C.A., and Nine, R.D., "Factors Affecting Heavy-Duty Diesel Vehicle Emissions," Journal of the Air \& Waste Management Association, Vol. 52, pp. 84-94, 2002.

53. Ramamurthy, R. and Clark, N.N., "Atmospheric Emissions Inventory Data for Heavy-Duty Vehicles," Environmental Science \& Technology, Vol. 33, pp. 5562, 1999.

54. Brodrick, C-J, Laca, E.A., Burke, A.F., Farshchi, M., Li, L., and Deaton, M., "Effect of Vehicle Operation, Weight, and Accessory Use on Emissions from a Modern Heavy-Duty Diesel Truck," Journal of the Transportation Research Board, No. 1880, pp. 119-125, 2004.

55. Nine, R.D., Clark, N.N., and Norton, P., "Effect on Emissions of Multiple Driving Test Schedules Performed on Two Heavy-Duty Vehicles," SAE Technical Paper 2000-01-2818, 2000.

56. Taylor, S., Clark, N., Gautam, M., and Wayne, W.S., "Diesel Emissions Prediction from Dissimilar Cycle Scaling," Journal of Automobile Engineering, Proc. Instn Mech. Engrs Vol. 218, Part D, pp. 341-352, 2004.

57. Environmental Protection Agency (EPA), "Motor Vehicle Emission Simulator (MOVES)," Available at http://www.epa.gov/otaq/models/moves/index.htm.

58. California Air Resources Board (CARB), "The EMission FACtors (EMFAC) Model," Available at http://www.arb.ca.gov/msei/onroad/latest_version.htm.

59. Gajendran, P. and Clark, N.N., "Effect of Truck Operating Weight on HeavyDuty Diesel Emissions," Environmental Science \& Technology, Vol. 37, pp. 4309-4317, 2003.

60. Thompson, E.D., Ansari, M., and Eberhard, G.A., "A Truck and Bus Chassis Dynamometer Developed for Fuels and Lubricants Research," SAE Technical Paper 902112, 1990. 
61. Nine, R.D., Clark, N.N., Daley, J.J., and Atkinson, C.M., "Development of a Heavy-Duty Chassis Dynamometer Driving Route," Proceedings of the Institute of Mechanical Engineers, Part D., Journal of Automobile Engineers, Vol. 213, pp. 561-574, 1999.

62. Strimer, C., Carder, D.K., Gautam, M., and Thompson, G.J., "Impact of Vehicle Weight on Truck Behavior and Emissions, Using On-Board Measurement," SAE Technical Paper 2005-01-3788, 2005.

63. Krishnamurthy, M. and Gautam, M., "Comparison of Averaging Techniques Employed in Calculating Not-to-Exceed Emissions for Heavy-Duty Vehicles," SAE Technical Paper 2005-01-3787, 2005.

64. Clark, N.N., Wayne, W.S., Khan, A.S., Lyons, D.W., Gautam, M., McKain, D.L., Thompson, G.J., and Barnett, R., "Effects of Average Driving Cycle Speed on Lean-Burn Natural Gas Bus Emissions and Fuel Economy," SAE Technical Paper 2007-01-0054, 2007.

65. Pelkmans, L., Keukeleere, D.D., and Lenaers, G, "Emissions and Fuel Consumption of Natural Gas Powered City Buses versus Diesel Buses in RealCity Traffic," 7th International Conference on Urban Transport and the Environment in the 21st Century, Greece, 2001.

66. Conley, J.J. and Clark, N.N., "Optimal Hybrid Vehicle Design Using Real-World Data to Determine Actual Regenerative Braking Energy Recovery,” Institution of Mechanical Engineering Conference: Total Vehicle Technology, University of Sussex, U.K., 2002. Appears in edited proceedings, R.K. Stobart \& P.R.N. Childs, Editors, Professional Engineering Publishing, Bury St. Edmunds, UK.

67. Kern, J., Clark, N., and Nine, R., "Factoring Terrain Effects into Vehicle Emissions Modeling and Inventory," 10th CRC On-Road Vehicle Emissions Workshop, CA, 2000.

68. Thompson, G.J., Clark, N.N., Atkinson, R.J., Luzader, Z., VanScoy, F.L., Baker, V., and Chandler, J., "Development of an Interface Method for Implementing Road Grade in Chassis Dynamometer Testing," Proceedings of the 2004 Fall Technical Conference of the ASME Internal Combustion Engine Division, CA, 2004. 
69. Samuel, S., Morrey, D., Taylor, D.H.C., and Fowkes, M., "Parametric Study into the Effects of Factors Affecting Real-World Vehicle Exhaust Emissions Levels," SAE Technical Paper 2007-01-1084, 2007.

70. Simpson, A.G., "Parametric Modeling of Energy Consumption in Road Vehicles," Ph.D. Thesis, The University of Queensland, 2005.

71. Nesamani, K.S. and Subramanian, K.P., "Impact of Real-World Driving Characteristics on Vehicular Emissions," JSME International Journal, Series B, Vol. 49, pp. 19-26, 2006.

72. Cappiello, A., Chabini, I., Nam, E.K., Lue, A., and Zeid, M.A., “A Statistical Model of Vehicle Emissions and Fuel Consumption," Proceedings of the IEEE 5th International Conference on Intelligent Transportation System, 2002.

73. Giannelli, R.A., Nam, E.K., Helmer, K., Younglove, T., Scora, G., and Barth, M., “Heavy-Duty Diesel Vehicle Fuel Consumption Modeling Based on Road Load and Power Train Parameters," SAE Technical Paper 2005-01-3549, 2005.

74. Barth, M., Younglove, T., and Scora, G., "Development of a Heavy-Duty Diesel Modal Emissions and Fuel Consumption Model," California PATH Research Report, UCB-ITS-PRR-2005-1, 2005.

75. Sovran, G. and Blaser, D., "A Contribution to Understanding Automotive Fuel Economy and Its Limits," SAE Technical Paper 2003-01-2070, May 2003.

76. Khanipour, A., Ebrahimi, K.M., and Seale, W.J., "Conventional Design and Simulation of an Urban Hybrid Bus," International Journal of Applied Science, Engineering and Technology, Vol. 4, pp. 88-94, 2008.

77. Petrushov,V.A. "Improvement in Vehicle Aerodynamic Drag and Rolling Resistance Determination from Coast-Down Tests," Proc of the Instn of Mech Engrs, Vol. 212, Part D, pp. 369-380, 1998.

78. Wolf-Heinrich, H., "Aerodynamics of Road Vehicles, From Fluid Mechanics to Vehicle Engineering," 4th Edition, pp. 422, Society of Automotive Engineers, Warrendale, PA, 1998.

79. Protection of the Environment. Code of Federal Regulations, Part 86, Subpart N, Title 40. U.S. Government Printing Office, Washington D.C., 2005. 
80. "Fuel Economy Measurement Test (Engineering Type) for Trucks and Buses," Society of Automotive Engineers, Document No. J1376 (Cancelled in December 1997), 1997.

81. "Recommended Practice for Measuring Fuel Economy and Emissions of HybridElectric and Conventional Heavy-Duty Vehicle," Society of Automotive Engineers, Document No. J2711, 2002.

82. Kelly, K.J., Modeling Tools for Predicting the Impact of Rolling Resistance on Energy Usage and Fuel Efficiency for Realistic Driving Cycle, Paper no. 31C, Int. Tire Exhibition \& Conference, 2002.

83. Park, J.H., Kong, J.H., Jo, H.S., Park, Y.I., and Lee, J.M., "Measurement of Road Gradients for the Development of Driving Modes Including Road Gradients," Proc of the Instn of Mech Engrs, Vol. 215, Part D, pp. 977-986, 2001.

84. American Association of State Highway and Transportable Official (AASHTO), "A Policy on Geometric Design of Highways and Streets," Fifth Edition, 2004.

85. Montana Department of Transportation, "Road Design Manual, Vertical Alignment," 2006.

86. McKain, D.L., Atkinson, R.J., Clark, N.N., and Mucino, V.H., "Development of a Driving Schedule to Mimic Transit Bus Behavior in Mexico City," SAE Technical Paper 2006-01-3394, 2006.

87. Wayne, W.S., Clark, N.N., Nine, R.D., and Rosepiler, S., "Washington Metropolitan Area Transit Authority Diesel Emissions Control Retrofit Project," Final Report by the West Virginia University, Morgantown, WV, 2002.

88. Test Cycles, http://www.dieselnet.com/standards/cycles/etc.html, Accessed on August 10, 2007.

89. Wayne, W.S., Nine, R., Clark, N.N., and Schiavone, J.J., "Diesel Engine Retrofit Program, Interim Task Report: Emissions Results," Presented to Westchester County Department of Transportation, 2002.

90. Clark, N.N., Gautam, M., Wayne, W.S., and Riddle, W., Nine, R.D., Lyons, D.W., Xu, S., "Examination of Heavy Heavy-Duty Diesel Truck Chassis Dynamometer Schedule," SAE Technical Paper 2004-01-2904, 2004. 
91. Pelkmans, L., "Influence of Vehicle Test Cycle Characteristics on Fuel Consumption and Emissions of City Buses," SAE Technical Paper 2001-01-2002, 2002.

92. Khan, A.S., Clark, N.N., Thompson, G.J., Wayne, W.S., Gautam, M., Lyons, D.W., and Hawelti, D., "Idle Emissions from Heavy-Duty Diesel Vehicles Review and Recent Data," Journal of the Air \& Waste Management Association, Vol. 56, pp. 1404-1419, 2006.

93. Federal Highway Administration, US Department of Transportation, "Status of the Nation's Highways, Bridges, and Transit: 2004 Conditions and Performance," A Report to Congress, February 2006.

94. O’Keefe, M.P., Pedersen, D., Simpson, A., and Kelly, K., “Duty Cycle Characterization and Evaluation towards Heavy Hybrid Vehicle Applications," SAE Technical Paper 2007-01-0302, 2007.

95. Clark, N.N., Gautam, M., Bata, R.M., Wang, W.G., Loth, J.L., Palmer, G.M., and Lyons, D.W., "Design and Operation of a New Transportable Laboratory for Emissions Testing of Heavy-Duty Trucks and Buses," International Journal of Vehicle Design, Heavy Vehicle Systems. Vol. 2, pp. 308-322, 1995.

96. Lyons, D., Bata, R. M., Wang, W.G., Clark, N.N., Palmer, G.M., Gautam, M., Howell, A., Loth, J., and Long, T. Jr., "Design and Construction of a Transportable Heavy Duty Vehicle Emission Test Laboratory,” ISATA Paper No. 920450, 25th International Symposium on Automotive Technology and Automation (ISATA), Florence, Italy, 1992.

97. Gautam, M., Clark, N., Lyons, D., Long, T. Jr., Howell, A., Loth, J., Palmer, G.M., Wang, W., G., and Bata, R. M., "Design Overview of a Heavy Duty Mobile Vehicle Emissions Testing Laboratory,” ASME DE - Vol. 40, Advanced Automotive Technologies, pp.199-207, 1991.

98. Wu, Y., Carder, D., Shade, B., Atkinson, R., Clark, N., and Gautam, M., “A CFR1065-Compliant Transportable/On-Road Low Emissions Measurement Laboratory with Dual Primary Full-Flow Dilution Tunnels," Paper ICES200976090, Proc. of ASME Internal Combustion Engine Division 2009 Spring Technical Conference, 2009. 
99. Tu, J., Perhinschi, M.G., Wayne, W.S., Marlowe, C., Tamayo, S., and Clark, N.N., "Development of Duty Cycle Generator Based on Genetic Algorithm for Emissions and Fuel Economy Modeling," $19^{\text {th }}$ CRC On-Road Vehicle Emissions Workshop, San Diego, CA, March 2009.

100. Dawood, V. and Emadi, A., "Performance and Fuel Economy Comparative Analysis of Conventional, Hybrid, and Fuel Cell Heavy-Duty Transit Buses," Proceedings of the IEEE Semiannual Vehicular Technology Conference, Orlando, FL, 2003.

101. "Integration and Validation," Office of Energy Efficiency and Renewable Energy, FreedomCAR and Vehicle Technology, United States Department of Energy, Annual Progress Report, 2004.

102. Rousseau, A., Kwon, J.C., Sharer, P.B., Pagerit, S., and Duoba, M., "Integrating Data, Performing Quality Assurance, and Validating the Vehicle Model for the 2004 Prius Using PSAT,” SAE Technical Paper 2006-01-0667, 2006.

103. Heywood, J.B., "Internal Combustion Engine Fundamentals," McGraw-Hill International Editions, pp. 52, Singapore, 1988.

104. U.S. Department of Energy $21^{\text {st }}$ Century Truck Partnership, "Roadmap and Technical White Papers,” Document No. 21CTP-0003, 2006.

105. TIAX LLC, “Assessment of Fuel Cells as Auxiliary Power Systems for Transportation Vehicles," Presentation to the $21^{\text {st }}$ Century Truck Program, Washington D.C., 2003.

106. Virden, J. and Howden, K., "The $21^{\text {st }}$ Century Truck Partnership - Fuel Cell Technologies for Auxiliary Power," Alternatives to Truck Engine Idling Workshop, 2004.

107. Weather History for BWI, MD. Also available at http://www.wunderground.com/history/airport/BWI/2006/5/24/DailyHistory.html ?req city $=$ NA\&req state $=$ NA\&req statename $=$ NA. Accessed on March 14, 2007.

108. Clark, N.N., Gautam, M., Wayne, W.S., Lyons, D.W., and Thompson, G., "Heavy-Duty Vehicle Chassis Dynamometer Testing for Emissions Inventory, Air Quality Modeling, Source Apportionment, and Air Toxics Emissions 
Inventory," CRC Report No. E-55/59 - Final Report submitted by West Virginia University to Coordinating Research Council (CRC), CRC, 3650 Mansell Road, Suit 140, Alpharetta, GA, 2007. Also available at www.crcao.com .

109. Chandler, K., Clark, N.N., Zhen, F., Wayne, W.S., Schiavone, J.J., and Chambers, C., "Hybrid-Electric Transit Bus Performance in North America," Transportation Research Board (TRB) Paper No. 07-3004, $86^{\text {th }}$ TRB Annual Meeting, Washington D.C. 2007. 


\section{APPENDICES}

\section{TEST CYCLES}

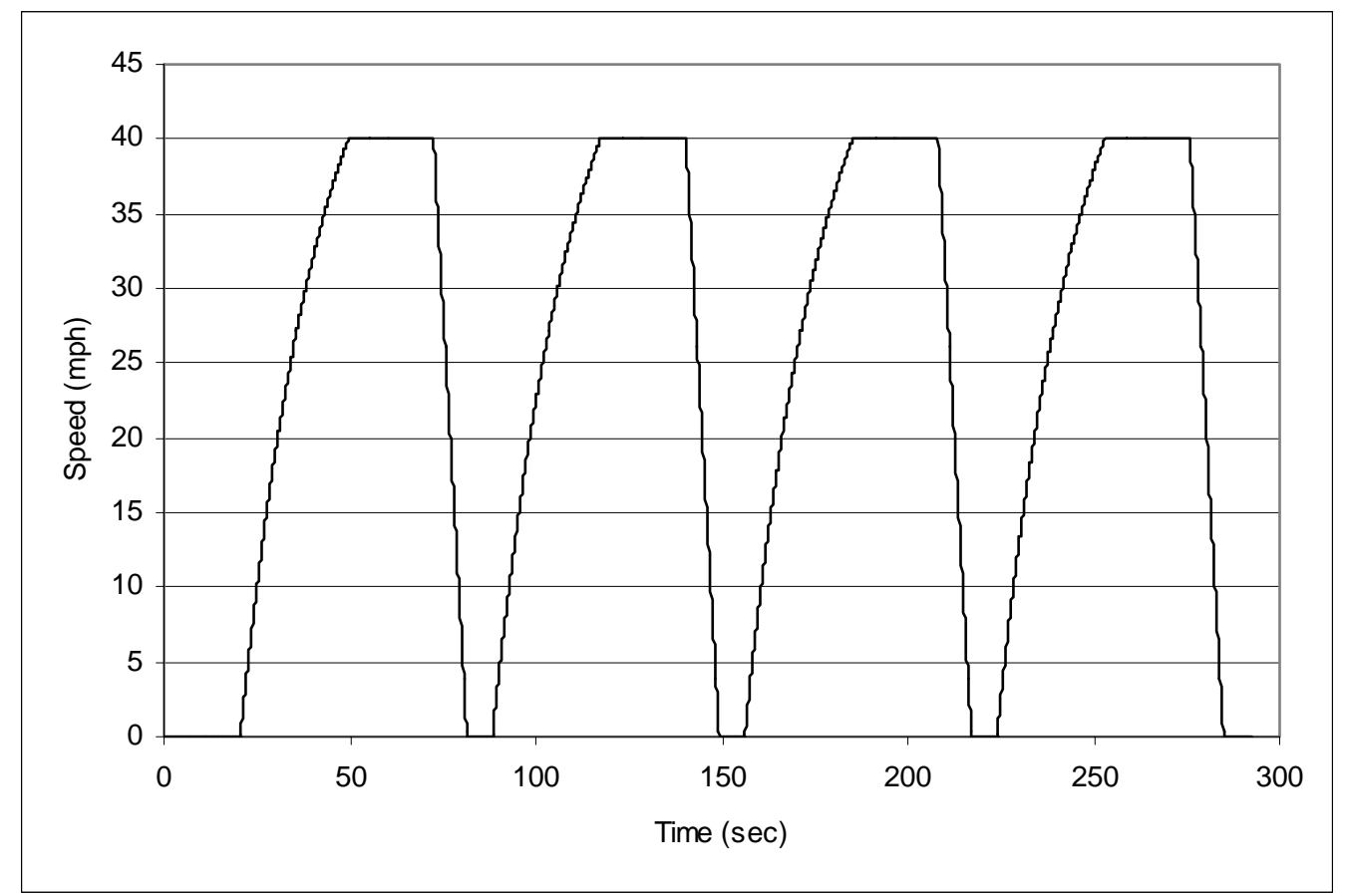

Figure 63: The Arterial Cycle

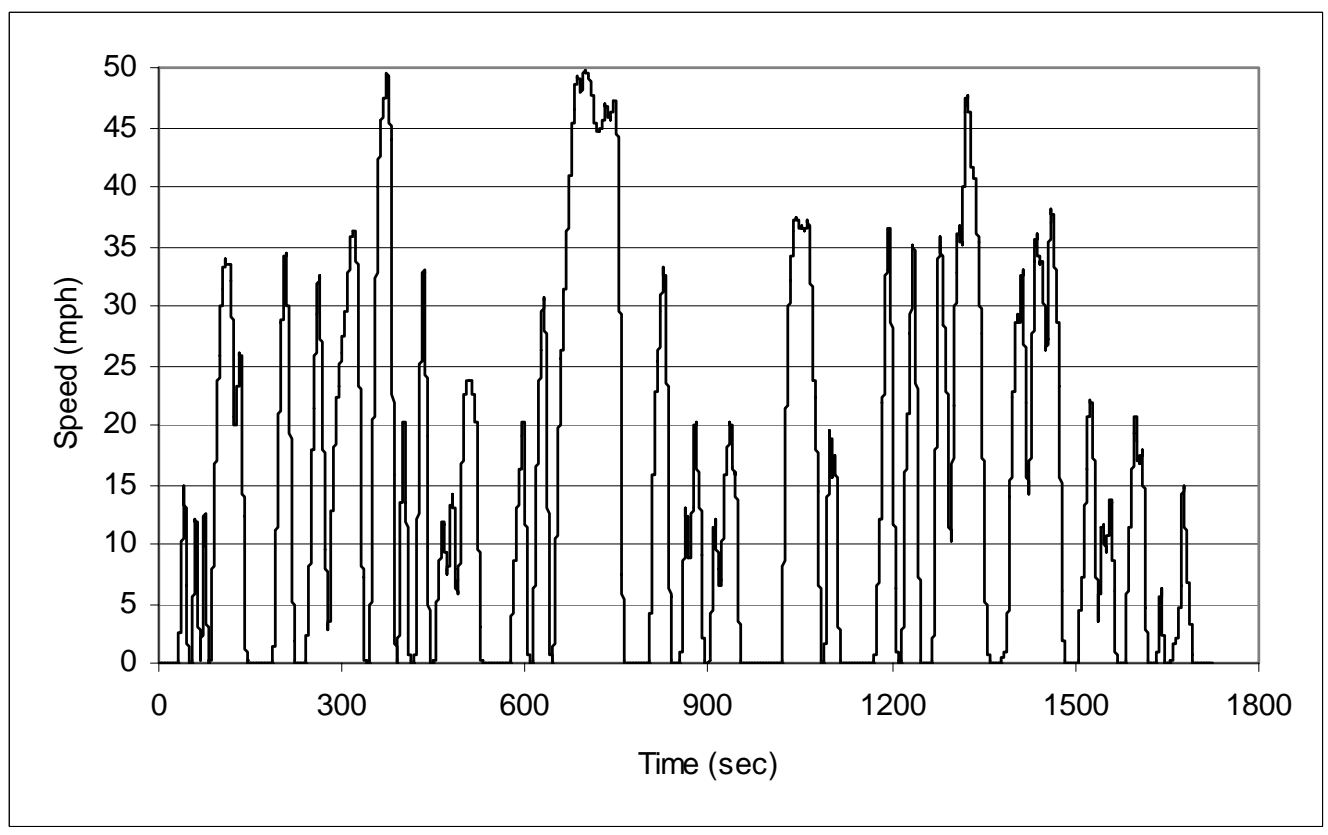

Figure 64: The Beeline Cycle 


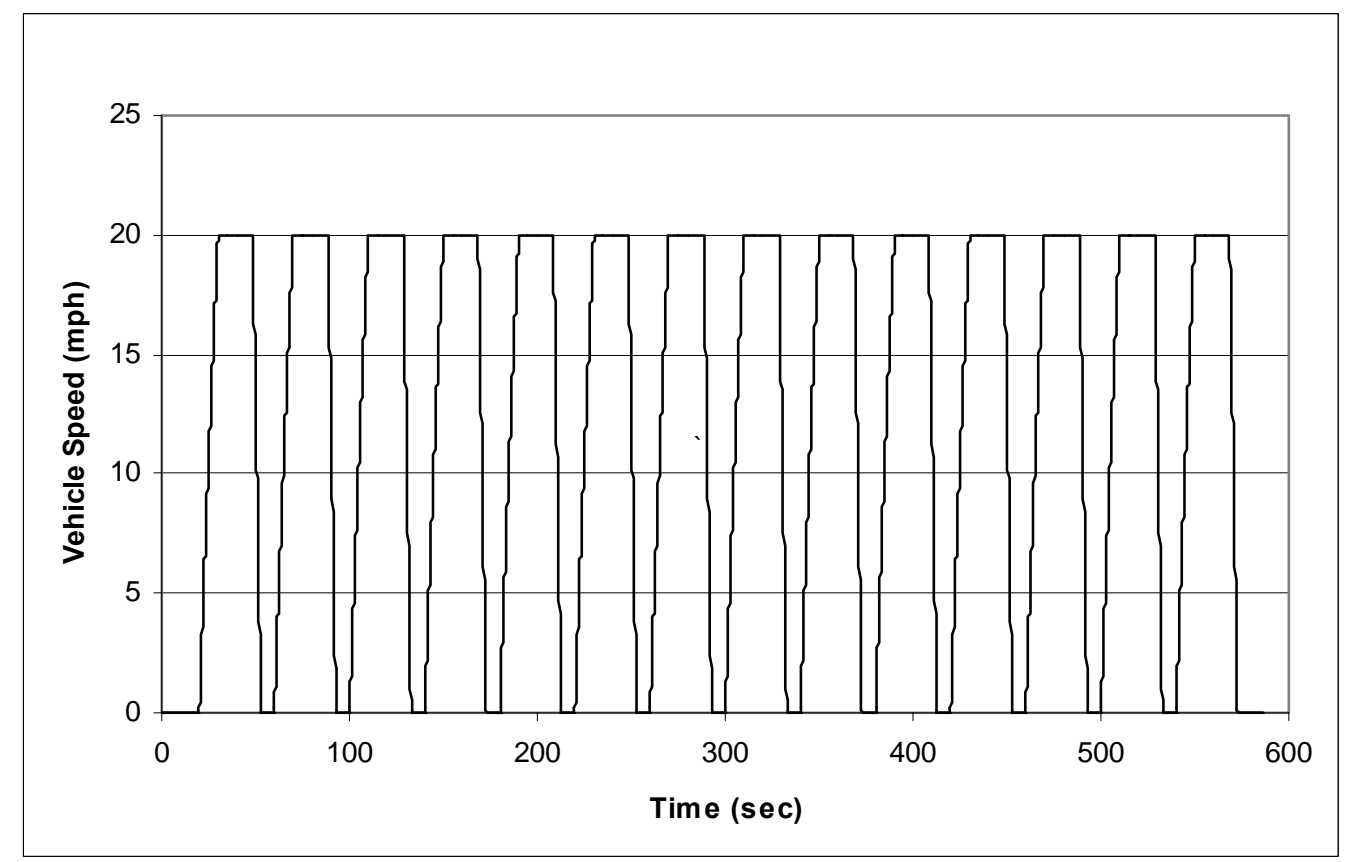

Figure 65: The Central Business District (CBD) Cycle

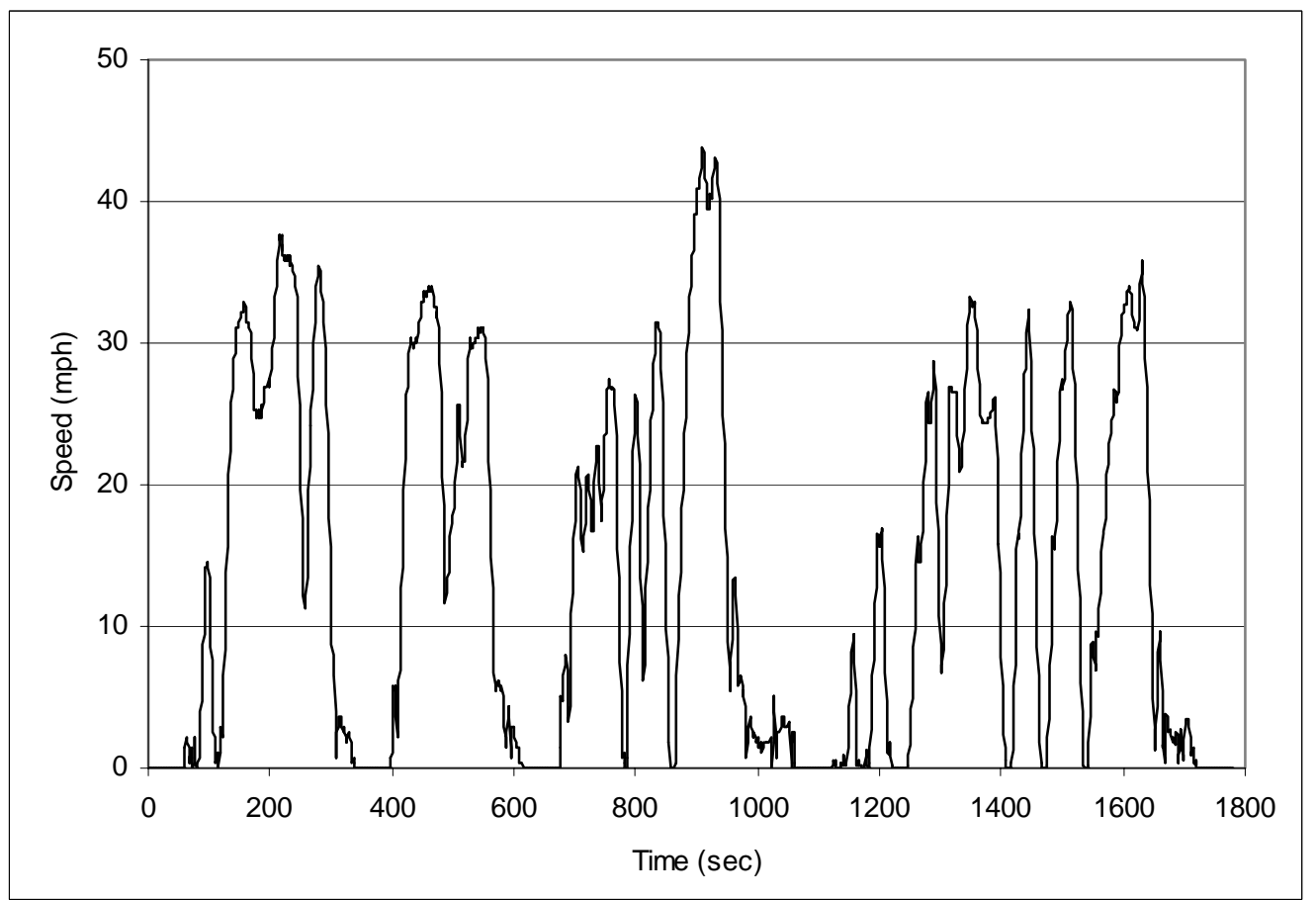

Figure 66: The City Suburban Heavy-Duty Vehicle Cycle (CSHVC) 


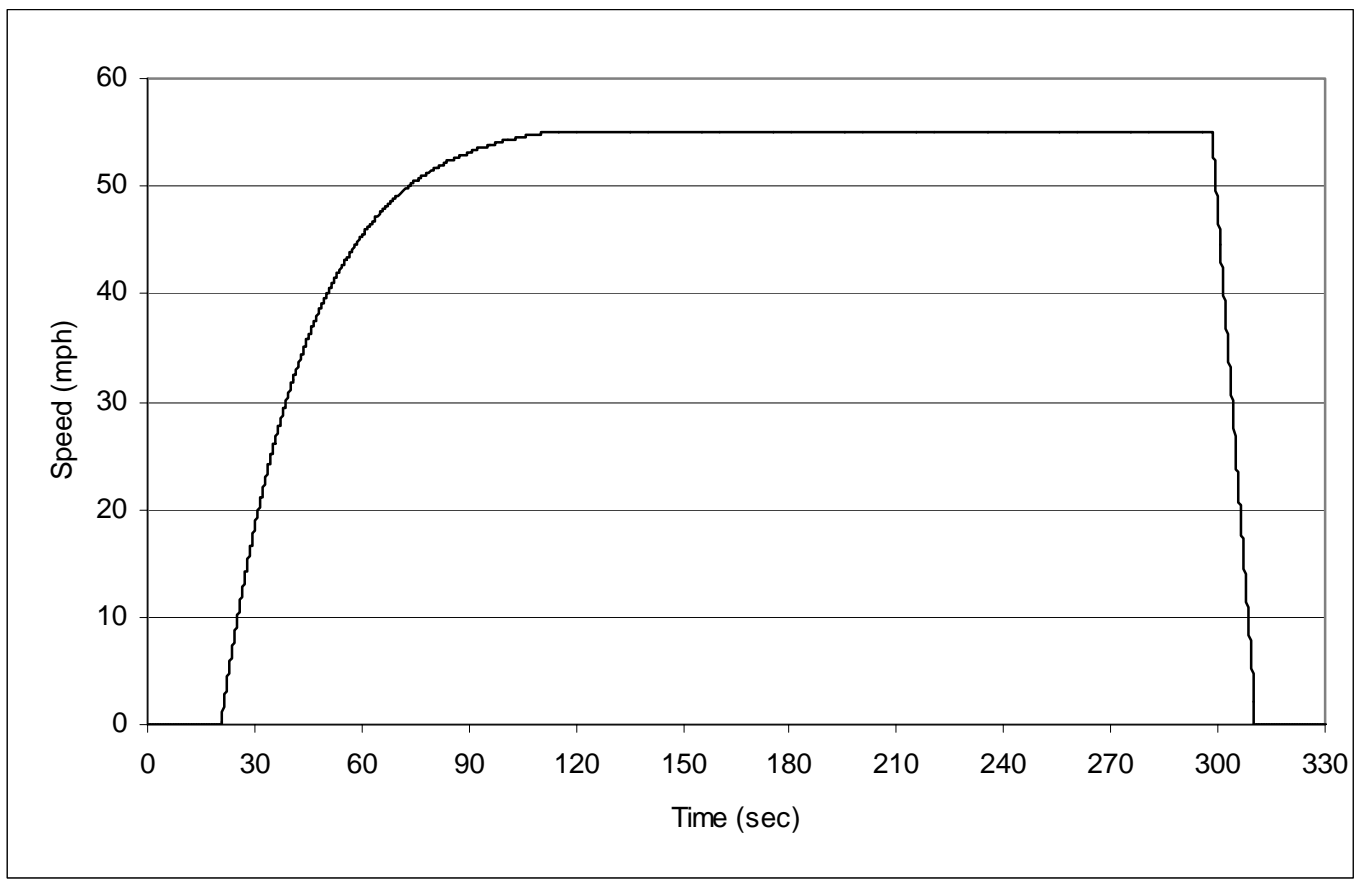

Figure 67: The Commuter Cycle

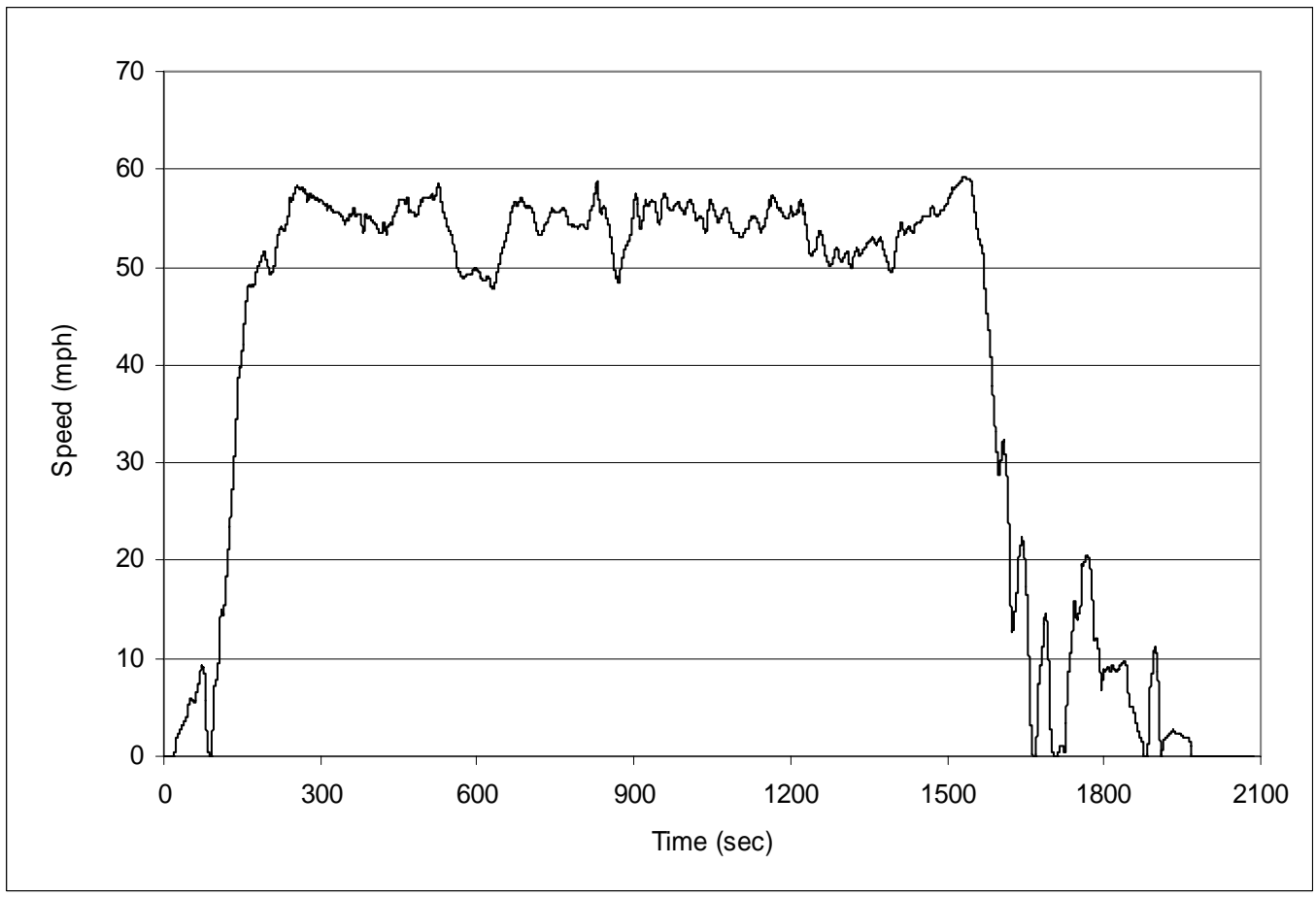

Figure 68: The Cruise Mode of the HHDDT Schedule 


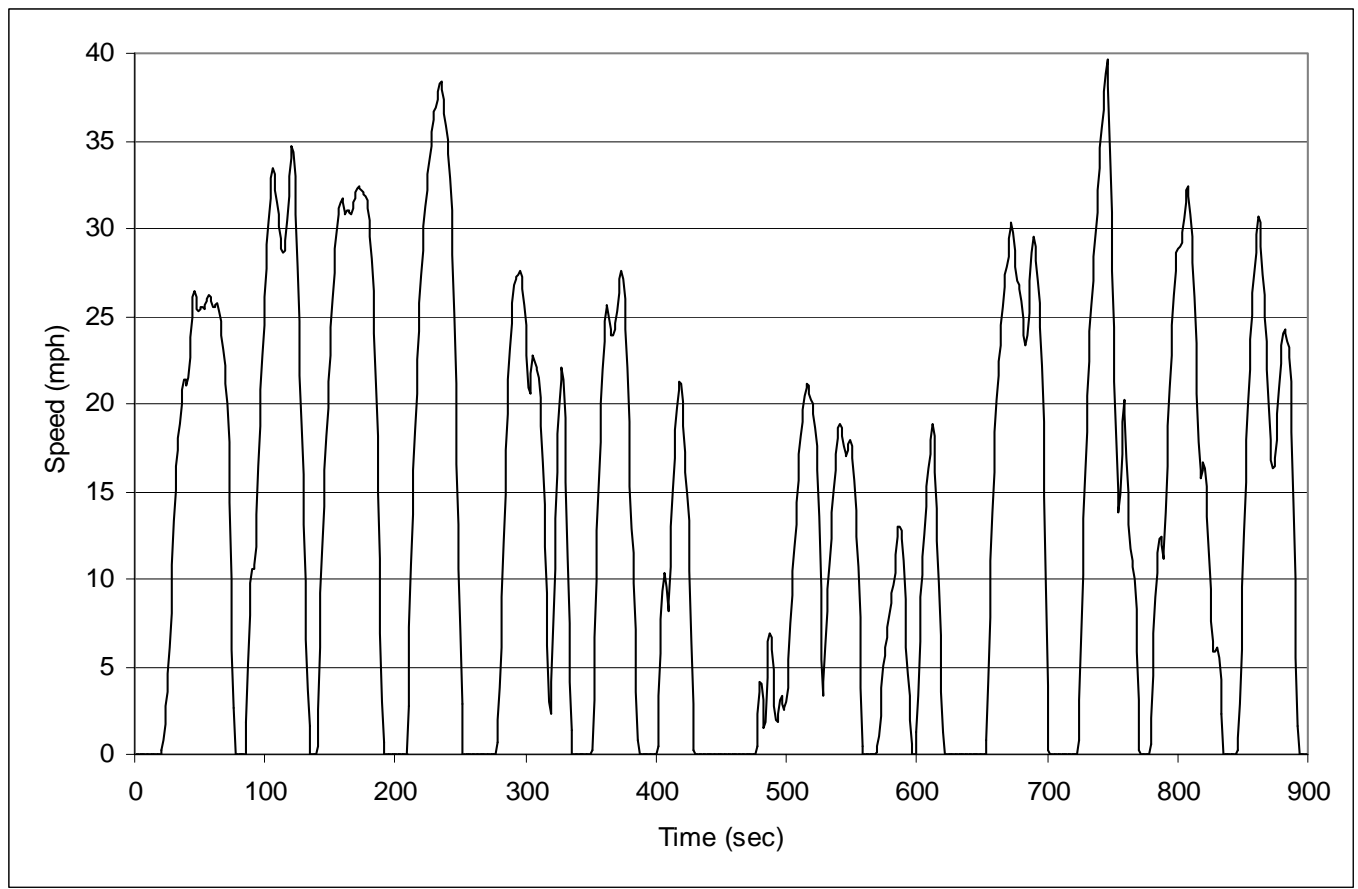

Figure 69: The Dutch Urban Bus Driving Cycle (DUBDC)

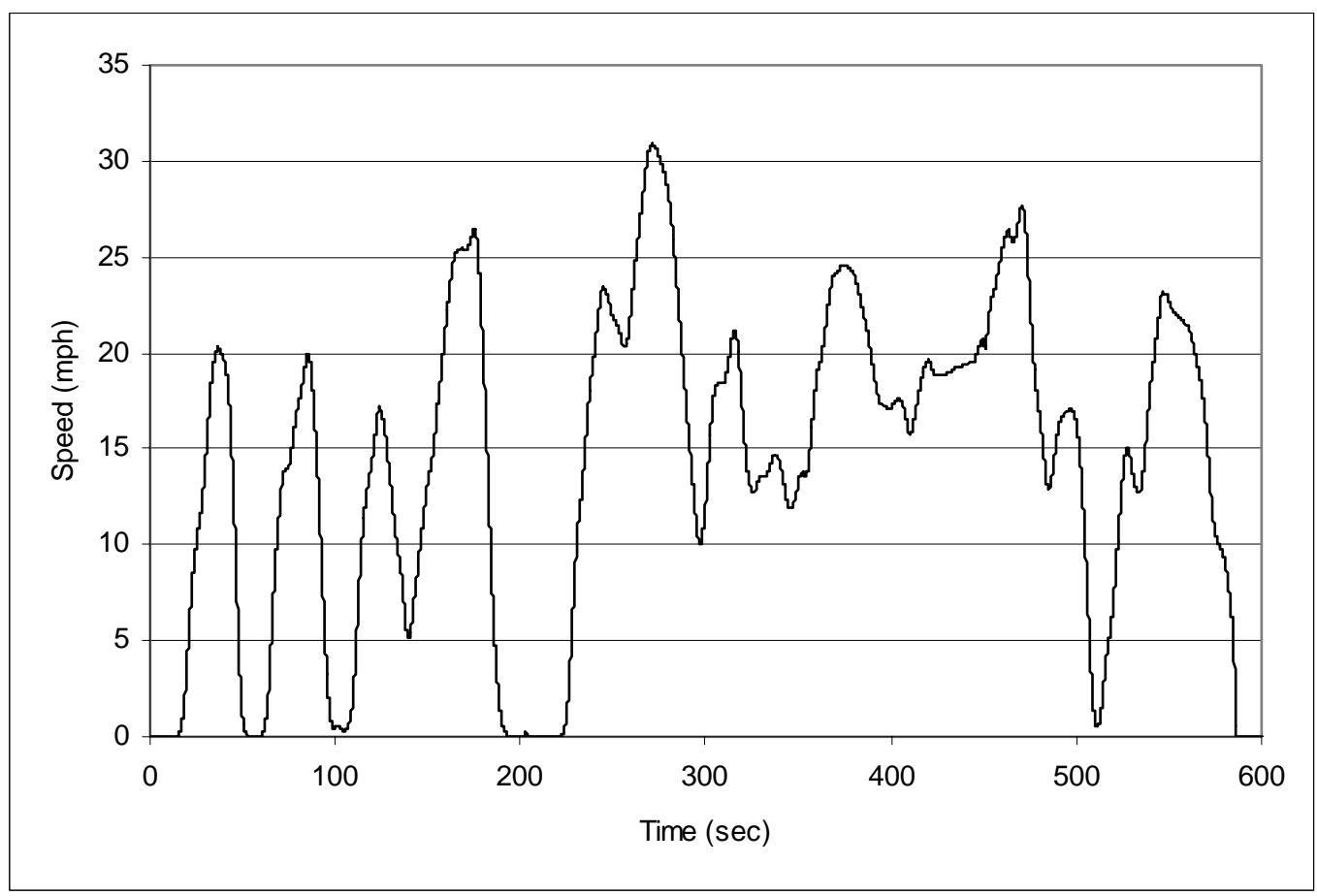

Figure 70: The European Transient Cycle (ETC), segment 1 (ETC-URBAN). 


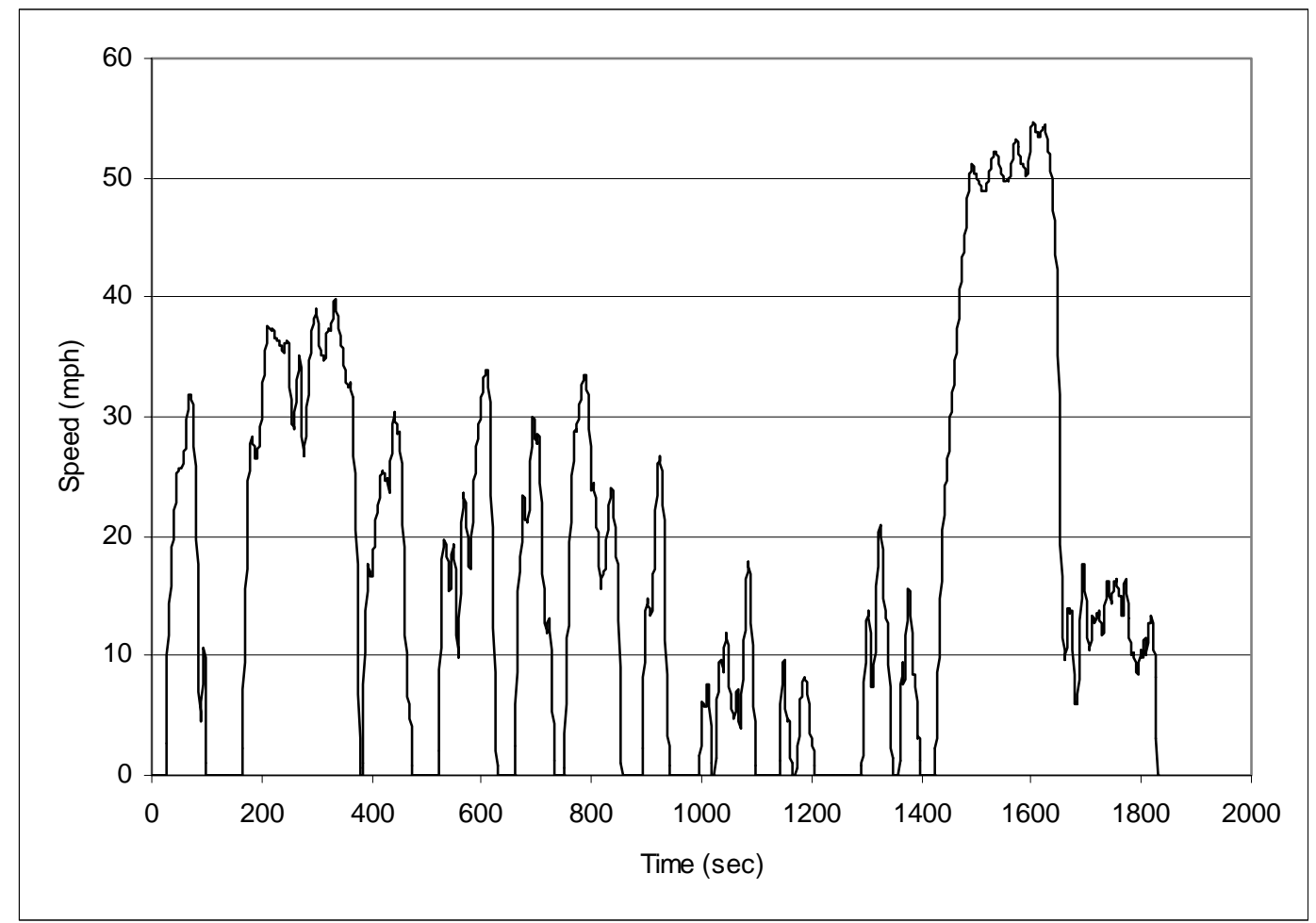

Figure 71: The Japan Transient Driving Cycle (JE05)

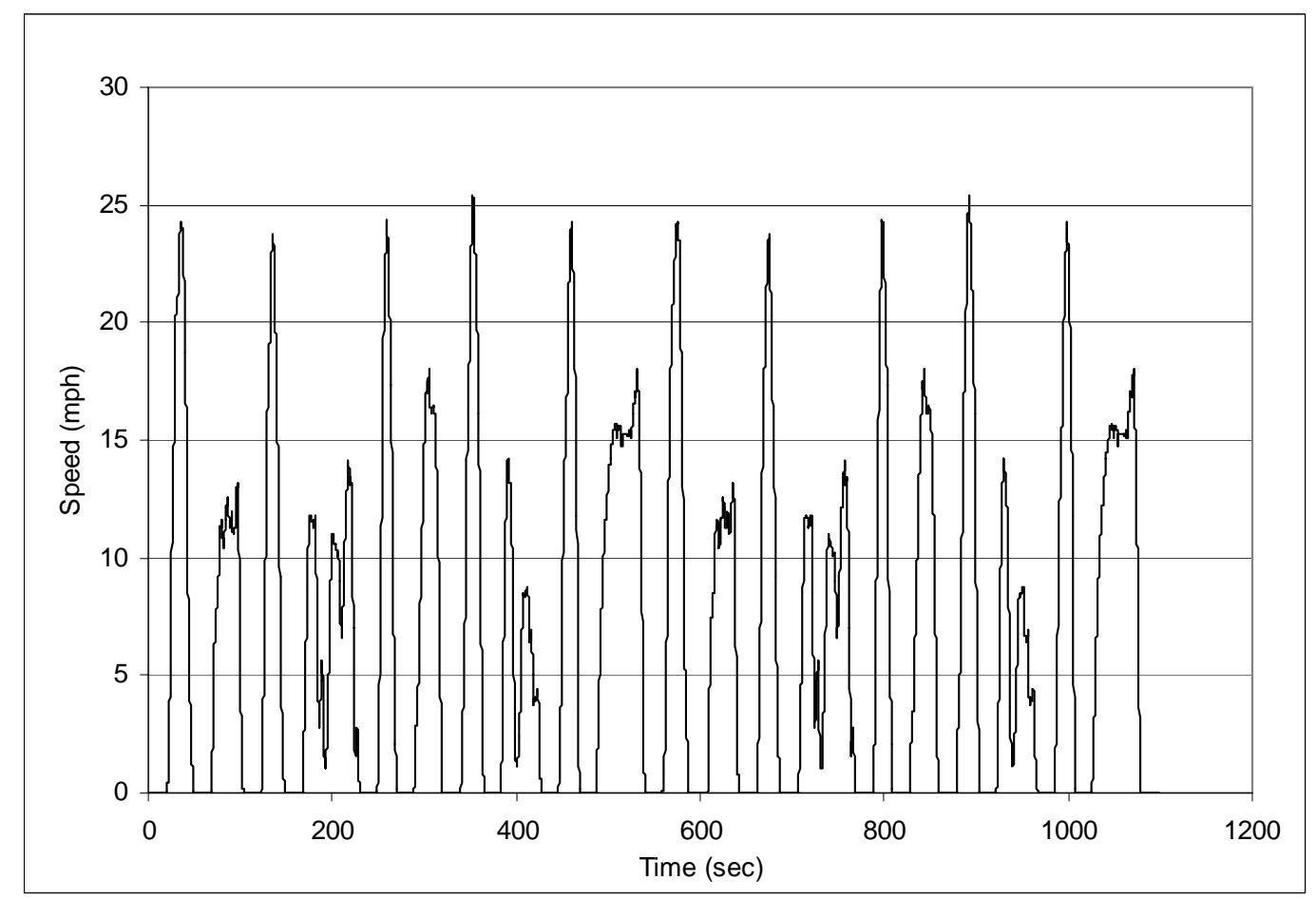

Figure 72: The Manhattan Cycle 


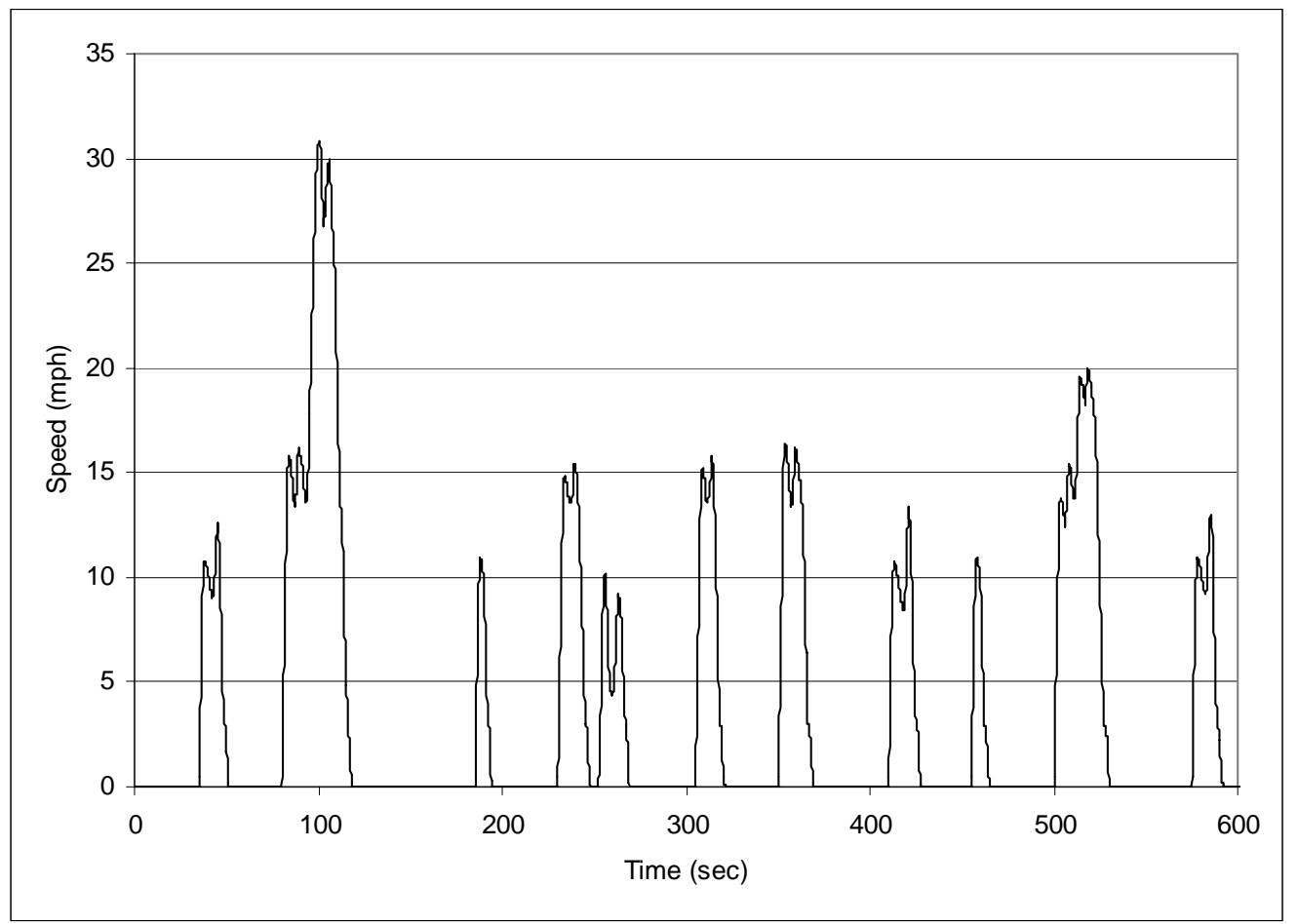

Figure 73: The New York Bus (NYBus) Cycle

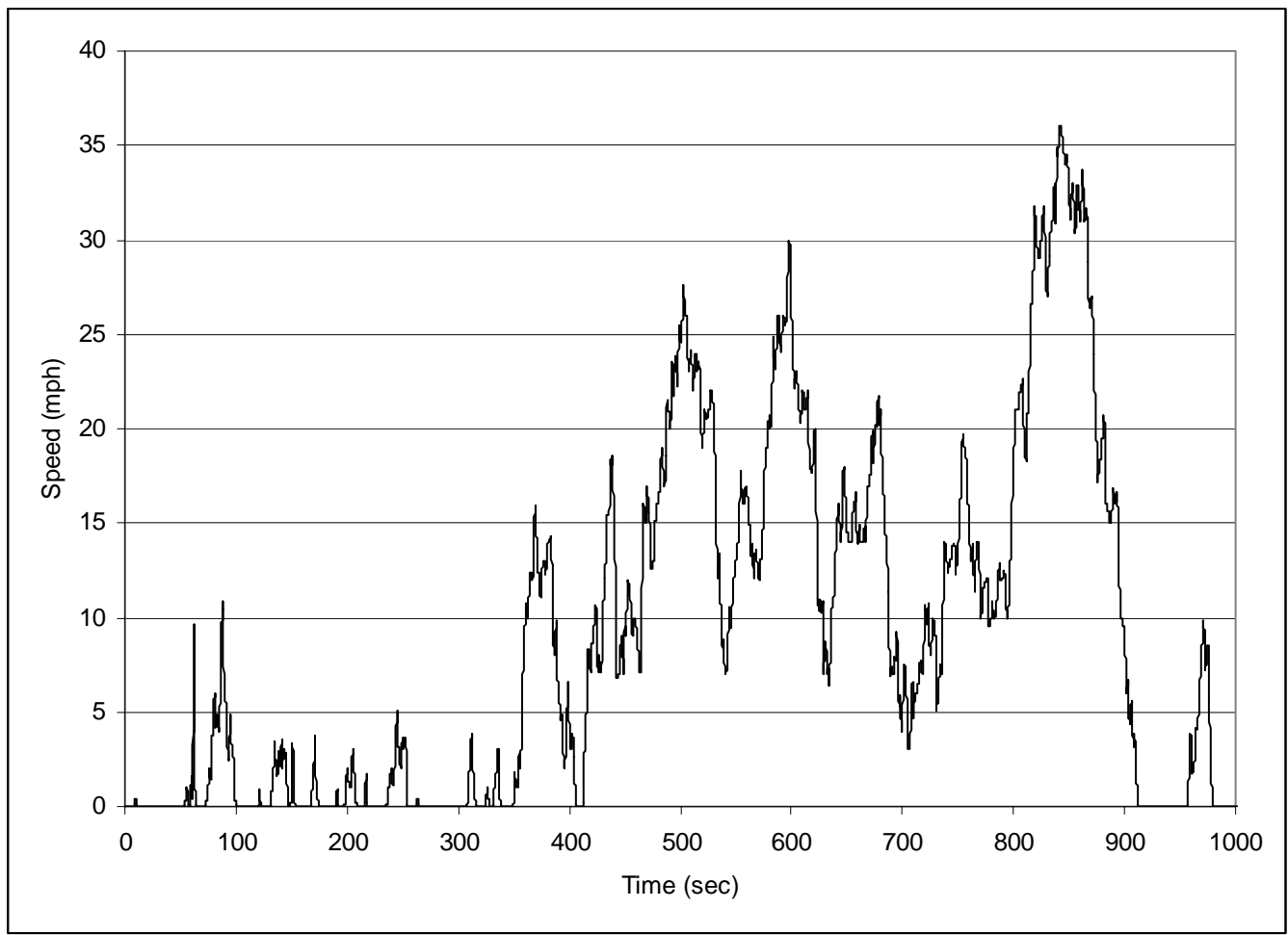

Figure 74: The New York Composite (NYComp) Cycle 


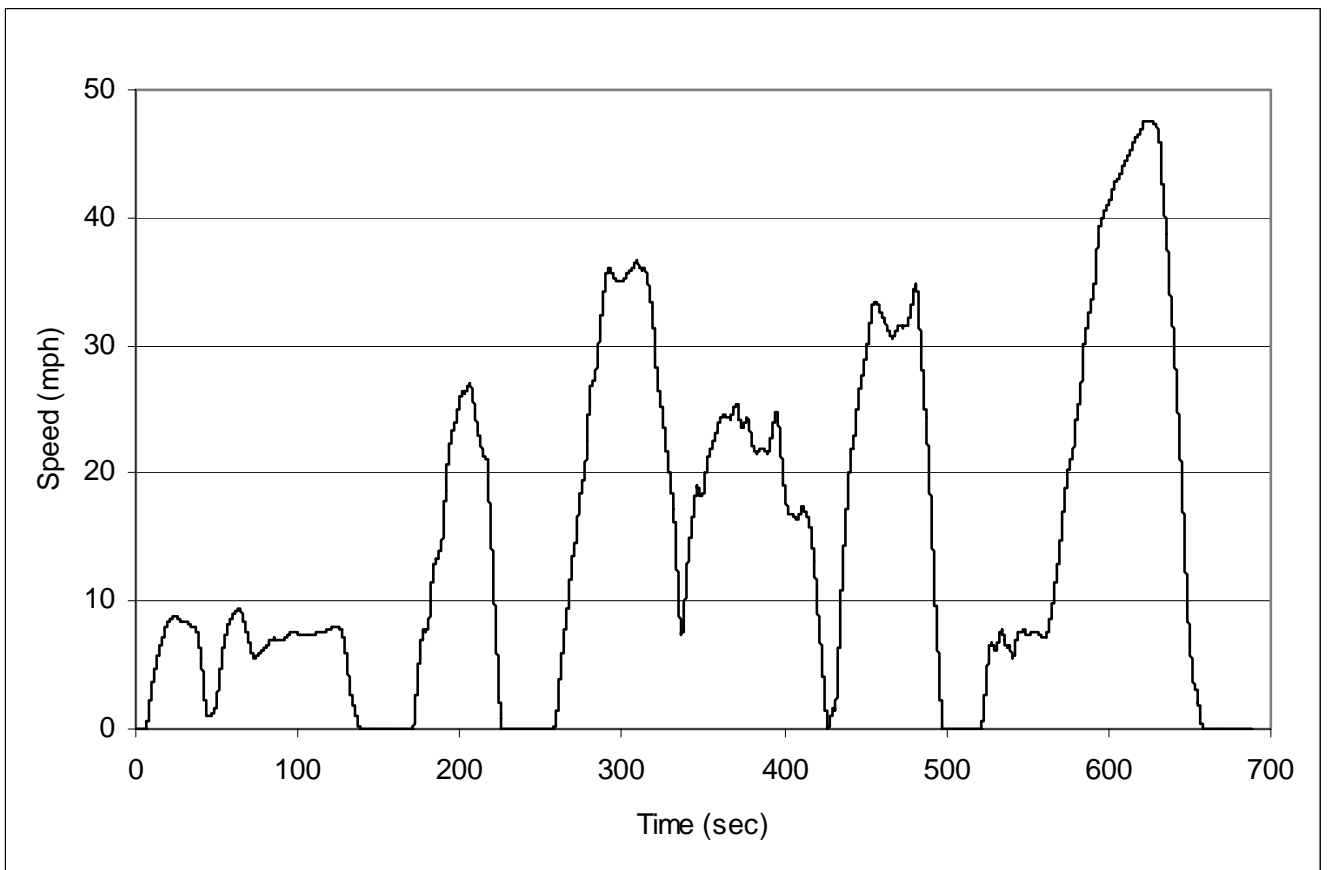

Figure 75: The Transient Phase of the HHDDT Schedule

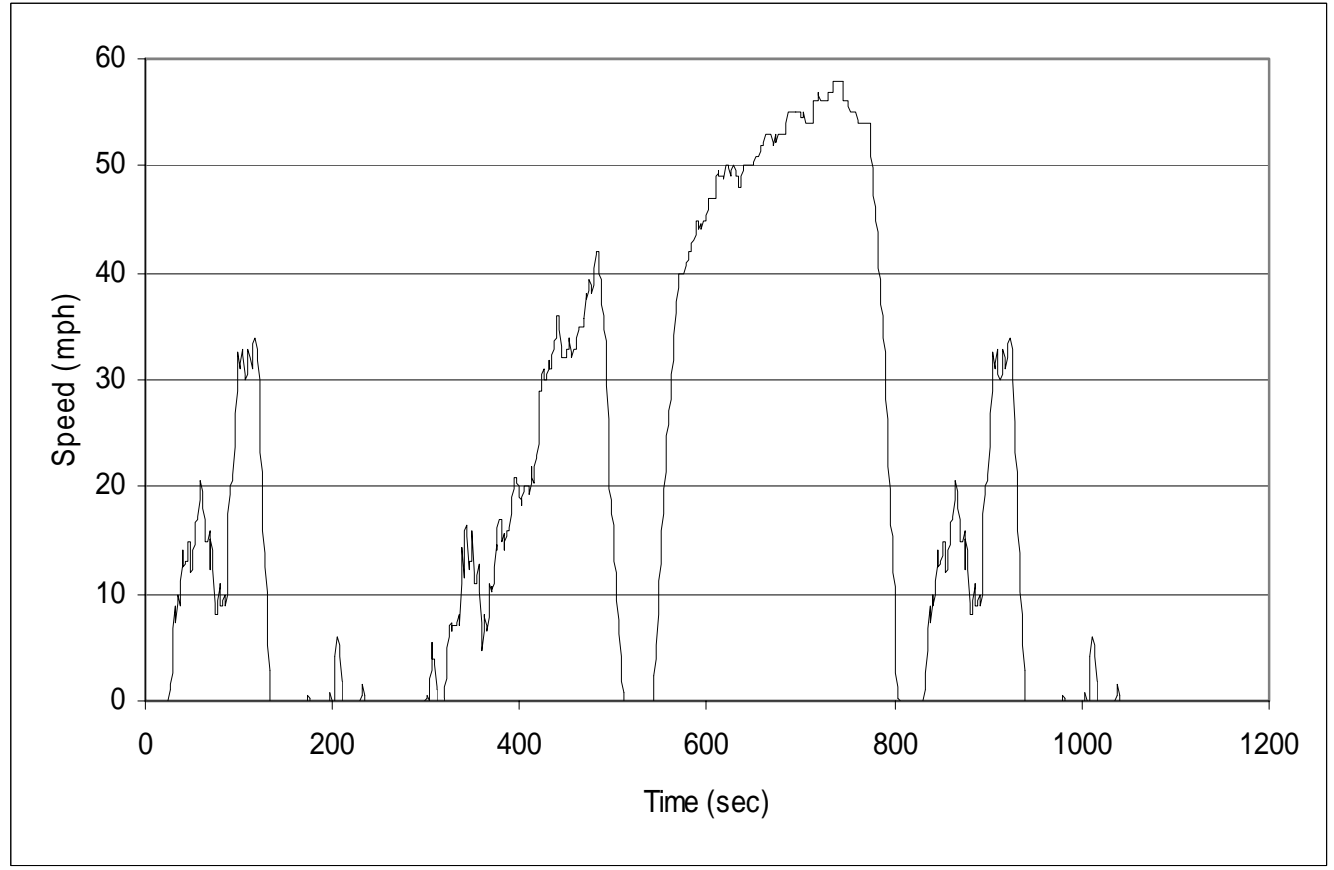

Figure 76: The Urban Dynamometer Driving Schedule (UDDS) 


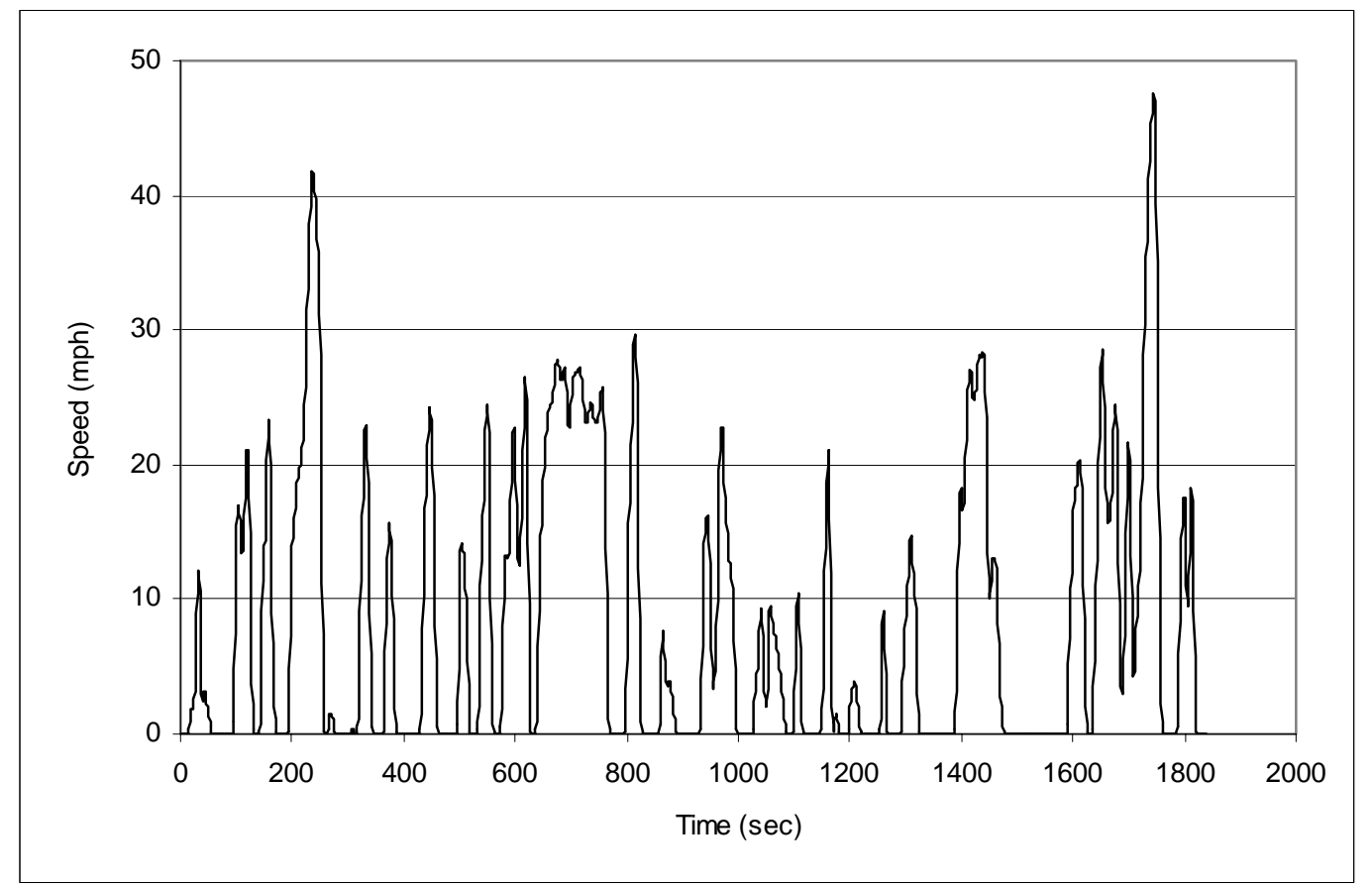

Figure 77: The Washington Metro Area Transit Authority (WMATA) Cycle

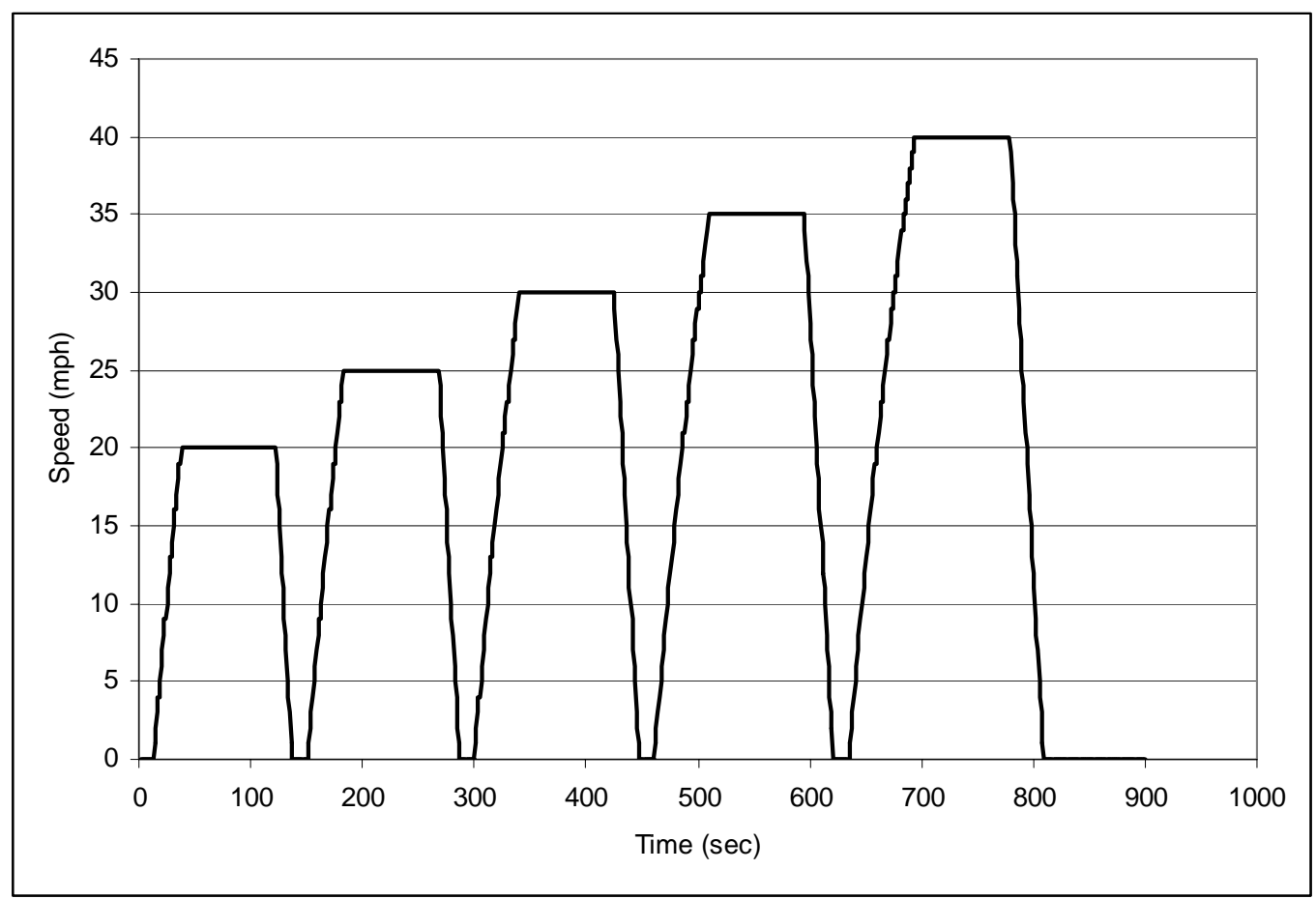

Figure 78: The WVU 5-Peak Cycle 


\section{CYCLE PROPERTIES}

Table 13: Relevant properties of drive cycles, in order of ascending average speed

\begin{tabular}{|l|c|c|c|c|c|c|}
\hline \multicolumn{1}{|c|}{ Cycle ID } & $\begin{array}{c}\text { Time } \\
(\mathrm{sec})\end{array}$ & $\begin{array}{c}\text { Distance } \\
(\mathrm{mile})\end{array}$ & $\begin{array}{c}\text { Average } \\
\text { Speed } \\
(\mathrm{mph})\end{array}$ & $\begin{array}{c}\text { Standard } \\
\text { Deviation } \\
(\mathrm{mph})\end{array}$ & $\begin{array}{c}\text { Idle } \\
(\%)\end{array}$ & $\begin{array}{c}\text { Stops } \\
\text { per } \\
\text { mile }\end{array}$ \\
\hline Idle & 1800 & 0.00 & 0.00 & 0.00 & 100 & N/A \\
\hline NYBus & 600 & 0.61 & 3.69 & 6.48 & 65.7 & 20.0 \\
\hline Paris & 1909 & 3.55 & 6.74 & 7.37 & 34.9 & 12.1 \\
\hline Man & 1099 & 2.07 & 6.77 & 7.33 & 37.1 & 10.2 \\
\hline WMATA & 1839 & 4.25 & 8.32 & 10.3 & 39.2 & 6.12 \\
\hline NYComp & 1029 & 2.51 & 8.77 & 9.44 & 32.5 & 7.17 \\
\hline OCTA & 1950 & 6.54 & 12.1 & 10.3 & 23.7 & 4.89 \\
\hline CBD & 586 & 2.01 & 12.4 & 8.46 & 21.6 & 7.45 \\
\hline Braunsch-weig & 1750 & 6.88 & 14.1 & 11.5 & 26.2 & 4.26 \\
\hline ETC-Urban & 600 & 2.36 & 14.1 & 8.44 & 11.3 & 1.28 \\
\hline Beeline & 1724 & 6.79 & 14.2 & 14.7 & 27.6 & 3.68 \\
\hline CSHVC & 1700 & 6.73 & 14.3 & 13.0 & 22.1 & 1.99 \\
\hline Transient & 688 & 2.85 & 14.9 & 13.4 & 18.4 & 1.75 \\
\hline UDDS & 1060 & 5.54 & 18.8 & 19.8 & 33.3 & 2.35 \\
\hline KCM & 1964 & 12.8 & 23.4 & 18.1 & 18.9 & 1.88 \\
\hline Arterial & 292 & 2.00 & 24.7 & 15.7 & 16.6 & 2.00 \\
\hline Commuter & 330 & 4.08 & 43.6 & 19.5 & 12.3 & 0.25 \\
\hline
\end{tabular}


EMISSIONS AND FUEL CONSUMPTION (FC) DATA

Table 14: Summary of emissions and FC data from the three John Deere lean-burn CNG buses (cycle name is followed by bus number mentioned in Table 1).

\begin{tabular}{|l|c|c|c|c|c|c|}
\hline Cycle & $\begin{array}{c}\mathrm{CO} \\
(\mathrm{g} / \mathrm{mile})\end{array}$ & $\begin{array}{c}\text { NOx } \\
(\mathrm{g} / \mathrm{mile})\end{array}$ & $\begin{array}{c}\mathrm{HC} \\
(\mathrm{g} / \mathrm{mile})\end{array}$ & $\begin{array}{c}\mathrm{PM} \\
(\mathrm{g} / \mathrm{mile})\end{array}$ & $\begin{array}{c}\mathrm{CO}_{2} \\
(\mathrm{~g} / \mathrm{mile})\end{array}$ & $\begin{array}{c}\mathrm{FC} \\
(\mathrm{gal} / \mathrm{mile})\end{array}$ \\
\hline NYBus-2639 & 0.460 & 30.90 & 51.10 & 0.140 & 5182 & 0.763 \\
\hline NYBus-2621 & 0.323 & 44.20 & 54.80 & 0.110 & 4853 & 0.699 \\
\hline NYBus-2640 & 0.310 & 36.30 & 57.70 & 0.031 & 5273 & 0.781 \\
\hline Paris-2639 & 0.009 & 20.16 & 23.75 & 0.015 & 2794 & 0.410 \\
\hline Paris-2621 & 0.031 & 18.80 & 28.60 & 0.020 & 2772 & 0.408 \\
\hline Paris-2640 & BDL & 27.00 & 28.60 & $\mathrm{BDL}$ & 2964 & 0.437 \\
\hline Man-2639 & 0.214 & 18.50 & 25.10 & 0.015 & 2972 & 0.437 \\
\hline Man-2621 & 0.403 & 25.20 & 28.30 & 0.027 & 2823 & 0.415 \\
\hline Man-2640 & 0.420 & 25.40 & 23.70 & 0.057 & 2853 & 0.418 \\
\hline WMATA-2639 & BDL & 11.60 & 13.60 & 0.009 & 2266 & 0.330 \\
\hline WMATA-2621 & 0.203 & 11.00 & 19.30 & 0.012 & 2242 & 0.329 \\
\hline WMATA-2640 & 0.137 & 18.60 & 21.05 & 0.006 & 2307 & 0.338 \\
\hline OCTA-2639 & BDL & 11.00 & 12.10 & 0.009 & 1823 & 0.266 \\
\hline OCTA-2621 & 0.067 & 12.80 & 17.40 & 0.013 & 1768 & 0.260 \\
\hline OCTA-2640 & 0.078 & 14.20 & 16.70 & 0.010 & 1938 & 0.284 \\
\hline Braun-2639 & 0.106 & 13.10 & 13.40 & 0.016 & 1748 & 0.256 \\
\hline Braun-2621 & 0.249 & 13.10 & 12.70 & 0.022 & 1707 & 0.249 \\
\hline Braun-2640 & BDL & 12.00 & 18.20 & 0.022 & 1808 & 0.266 \\
\hline NY-Comp-2640 & 0.060 & 28.50 & 23.60 & 0.014 & 2304 & 0.339 \\
\hline CBD-2640 & 0.046 & 9.72 & 16.80 & 0.023 & 1813 & 0.267 \\
\hline ETCUrban-2640 & 0.034 & 12.60 & 17.80 & 0.013 & 1500 & 0.222 \\
\hline Beeline-2640 & 0.055 & 10.00 & 14.90 & 0.020 & 1888 & 0.276 \\
\hline CSHVC-2640 & 0.041 & 9.28 & 13.40 & 0.011 & 1578 & 0.231 \\
\hline Transient-2640 & BDL & 12.30 & 16.10 & BDL & 1561 & 0.230 \\
\hline UDDS-2640 & 0.046 & 13.80 & 11.50 & 0.025 & 1507 & 0.221 \\
\hline KCM-2640 & BDL & 11.50 & 10.00 & 0.039 & 1467 & 0.214 \\
\hline ART-2640 & 0.025 & 7.81 & 8.02 & BDL & 1387 & 0.202 \\
\hline COMM-2640 & 0.053 & 5.60 & 6.39 & 0.053 & 1133 & 0.165 \\
\hline
\end{tabular}


Table 15: Summary of emissions and FC data from the three Cummins lean-burn CNG buses

\begin{tabular}{|l|c|c|c|c|c|c|}
\hline Cycle & $\begin{array}{c}\mathrm{CO} \\
(\mathrm{g} / \mathrm{mile})\end{array}$ & $\begin{array}{c}\mathrm{NOx} \\
(\mathrm{g} / \mathrm{mile})\end{array}$ & $\begin{array}{c}\mathrm{HC} \\
(\mathrm{g} / \mathrm{mile})\end{array}$ & $\begin{array}{c}\mathrm{PM} \\
(\mathrm{g} / \mathrm{mile})\end{array}$ & $\begin{array}{c}\mathrm{CO}_{2} \\
(\mathrm{~g} / \mathrm{mile})\end{array}$ & $\begin{array}{c}\mathrm{FC} \\
(\mathrm{gal} / \mathrm{mile})\end{array}$ \\
\hline NYBus-2501 & 2.269 & 53.00 & 63.40 & 0.058 & 5020 & 0.746 \\
\hline NYBus-2502 & 2.478 & 64.20 & 86.80 & 0.063 & 5021 & 0.752 \\
\hline NYBus-2503 & 2.228 & 71.10 & 77.10 & 0.047 & 5410 & 0.806 \\
\hline Paris-2501 & 1.079 & 34.70 & 43.80 & 0.013 & 3031 & 0.452 \\
\hline Paris-2502 & 3.767 & 40.71 & 59.81 & 0.017 & 2966 & 0.448 \\
\hline Paris-2503 & 1.286 & 33.40 & 54.20 & 0.010 & 3015 & 0.452 \\
\hline Man-2501 & 1.527 & 35.40 & 45.20 & 0.021 & 3202 & 0.476 \\
\hline Man-2502 & 2.373 & 37.30 & 61.10 & 0.024 & 3188 & 0.481 \\
\hline Man-2503 & 1.090 & 33.50 & 56.60 & 0.015 & 3263 & 0.490 \\
\hline WMATA-2501 & 0.407 & 21.50 & 26.30 & 0.014 & 2545 & 0.375 \\
\hline WMATA-2502 & 0.833 & 23.90 & 31.40 & 0.013 & 2468 & 0.366 \\
\hline WMATA-2503 & 0.453 & 21.20 & 31.30 & 0.008 & 2524 & 0.375 \\
\hline OCTA-2501 & 0.433 & 19.60 & 22.70 & 0.027 & 2164 & 0.368 \\
\hline OCTA-2502 & 1.084 & 21.30 & 30.44 & 0.013 & 2156 & 0.319 \\
\hline OCTA-2503 & 0.415 & 19.80 & 31.50 & 0.007 & 2234 & 0.321 \\
\hline Braun-2501 & 0.886 & 21.60 & 28.90 & 0.031 & 2129 & 0.332 \\
\hline Braun-2502 & 1.312 & 24.40 & 38.40 & 0.021 & 2121 & 0.316 \\
\hline Braun-2503 & 0.520 & 18.50 & 32.40 & 0.025 & 2092 & 0.319 \\
\hline NY-Comp-2503 & 1.491 & 29.90 & 58.60 & 0.022 & 2405 & 0.313 \\
\hline CBD-2503 & 0.231 & 21.02 & 29.25 & BDL & 2082 & 0.310 \\
\hline ETCUrban-2503 & 0.115 & 13.90 & 23.70 & 0.011 & 1600 & 0.239 \\
\hline Beeline-2503 & 0.362 & 17.70 & 22.20 & 0.015 & 2200 & 0.324 \\
\hline CSHVC-2503 & 0.362 & 13.10 & 23.00 & 0.003 & 1738 & 0.258 \\
\hline Transient-2503 & 0.200 & 12.60 & 19.30 & 0.019 & 1619 & 0.240 \\
\hline UDDS-2503 & 0.253 & 14.30 & 21.70 & 0.023 & 1646 & 0.244 \\
\hline KCM-2503 & 0.297 & 12.60 & 17.30 & 0.012 & 1662 & 0.245 \\
\hline ART-2503 & 0.274 & 11.80 & 14.20 & $\mathrm{BDL}$ & 1693 & 0.248 \\
\hline COMM-2503 & 0.116 & 6.04 & 9.48 & 0.018 & 1308 & 0.191 \\
\hline
\end{tabular}


Table 16: Summary of emissions and FC data from the two Retrofitted DDC diesel buses

\begin{tabular}{|l|c|c|c|c|c|c|}
\hline Cycle & $\begin{array}{c}\mathrm{CO} \\
(\mathrm{g} / \mathrm{mile})\end{array}$ & $\begin{array}{c}\text { NOx } \\
(\mathrm{g} / \mathrm{mile})\end{array}$ & $\begin{array}{c}\mathrm{HC} \\
(\mathrm{g} / \mathrm{mile})\end{array}$ & $\begin{array}{c}\mathrm{PM} \\
(\mathrm{g} / \mathrm{mile})\end{array}$ & $\begin{array}{c}\mathrm{CO}_{2} \\
(\mathrm{~g} / \mathrm{mile})\end{array}$ & $\begin{array}{c}\mathrm{FC} \\
(\mathrm{gal} / \mathrm{mile})\end{array}$ \\
\hline NYBus-9643 & 1.835 & 71.60 & 0.44 & 0.051 & 8542 & 0.885 \\
\hline NYBus-9654 & BDL & 45.10 & BDL & 0.070 & 6484 & 0.671 \\
\hline Paris-9643 & 0.476 & 35.60 & 0.16 & 0.014 & 4895 & 0.508 \\
\hline Paris-9654 & 0.316 & 24.90 & 0.22 & 0.015 & 3777 & 0.391 \\
\hline Man-9643 & 1.078 & 35.60 & 0.03 & 0.009 & 5297 & 0.549 \\
\hline Man-9654 & 0.119 & 24.20 & 0.31 & 0.018 & 4031 & 0.418 \\
\hline WMATA-9643 & 0.627 & 29.80 & 0.11 & 0.003 & 4327 & 0.448 \\
\hline WMATA-9654 & 0.066 & 21.00 & 0.23 & 0.010 & 3296 & 0.341 \\
\hline OCTA-9643 & 0.176 & 22.70 & 0.03 & 0.010 & 3464 & 0.358 \\
\hline OCTA-9654 & 0.055 & 15.40 & 0.18 & 0.008 & 2859 & 0.296 \\
\hline Braun-9643 & 0.396 & 19.10 & 0.00 & 0.009 & 3475 & 0.360 \\
\hline Braun-9654 & 0.129 & 13.70 & 0.14 & 0.016 & 2712 & 0.281 \\
\hline NY-Comp-9654 & 0.028 & 17.80 & 0.06 & 0.014 & 2596 & 0.269 \\
\hline CBD-9654 & 0.045 & 13.40 & 0.09 & 0.029 & 2722 & 0.282 \\
\hline ETCUrban-9654 & BDL & 11.10 & 0.12 & 0.028 & 1934 & 0.200 \\
\hline Beeline-9654 & 0.071 & 16.00 & 0.09 & 0.011 & 2842 & 0.294 \\
\hline CSHVC-9654 & 0.044 & 13.20 & 0.09 & 0.011 & 2207 & 0.229 \\
\hline Transient-9654 & 0.188 & 11.80 & 0.25 & 0.014 & 2004 & 0.207 \\
\hline UDDS-9654 & 0.057 & 11.94 & 0.08 & 0.015 & 2159 & 0.224 \\
\hline KCM-9654 & 0.071 & 9.90 & 0.12 & 0.067 & 2140 & 0.222 \\
\hline ART-9654 & BDL & 11.60 & 0.03 & 0.042 & 2284 & 0.236 \\
\hline COMM-9654 & BDL & 5.74 & 0.01 & 0.019 & 1826 & 0.189 \\
\hline
\end{tabular}


Table 17: Summary of emissions and FC data from the two Cummins ISM diesel buses

\begin{tabular}{|l|c|c|c|c|c|c|}
\hline Cycle & $\begin{array}{c}\mathrm{CO} \\
(\mathrm{g} / \mathrm{mile})\end{array}$ & $\begin{array}{c}\text { NOx } \\
(\mathrm{g} / \mathrm{mile})\end{array}$ & $\begin{array}{c}\mathrm{HC} \\
(\mathrm{g} / \mathrm{mile})\end{array}$ & $\begin{array}{c}\mathrm{PM} \\
(\mathrm{g} / \mathrm{mile})\end{array}$ & $\begin{array}{c}\mathrm{CO}_{2} \\
(\mathrm{~g} / \mathrm{mile})\end{array}$ & $\begin{array}{c}\mathrm{FC} \\
(\mathrm{gal} / \mathrm{mile})\end{array}$ \\
\hline NYBus-6146 & 9.092 & 18.10 & 2.151 & 0.378 & 6064 & 0.630 \\
\hline NYBus-6150 & 10.060 & 19.58 & 2.504 & 0.427 & 6254 & 0.650 \\
\hline Paris-6146 & 4.397 & 10.88 & 0.989 & 0.244 & 3239 & 0.336 \\
\hline Paris-6150 & 4.912 & 10.91 & 0.876 & 0.218 & 3253 & 0.338 \\
\hline Man-6146 & 3.299 & 12.14 & 0.769 & 0.237 & 3461 & 0.359 \\
\hline Man-6150 & 5.529 & 12.05 & 1.315 & 0.239 & 3407 & 0.354 \\
\hline WMATA-6146 & 4.548 & 8.94 & 0.892 & 0.167 & 2943 & 0.306 \\
\hline WMATA-6150 & 4.590 & 9.25 & 1.060 & 0.170 & 2927 & 0.304 \\
\hline OCTA-6146 & 1.412 & 7.75 & 0.365 & 0.147 & 2330 & 0.242 \\
\hline OCTA-6150 & 2.488 & 8.61 & 0.654 & 0.148 & 2328 & 0.242 \\
\hline Braun-6146 & 1.302 & 7.78 & 0.311 & 0.144 & 2222 & 0.230 \\
\hline Braun-6150 & 1.528 & 8.45 & 0.329 & 0.136 & 2260 & 0.234 \\
\hline CBD-6146 & 2.169 & 9.11 & 0.731 & 0.222 & 2434 & 0.253 \\
\hline CBD-6150 & 2.723 & 9.15 & 0.882 & 0.194 & 2346 & 0.244 \\
\hline NY-Comp-6150 & 4.110 & 7.90 & 1.030 & 0.140 & 2037 & 0.212 \\
\hline ETCUrban-6150 & 2.538 & 6.95 & 0.842 & 0.103 & 1738 & 0.181 \\
\hline Beeline-6150 & 2.004 & 8.23 & 0.513 & 0.151 & 2506 & 0.260 \\
\hline CSHVC-6150 & 1.711 & 6.32 & 0.374 & 0.096 & 1856 & 0.193 \\
\hline Transient-6150 & 2.622 & 6.55 & 0.837 & 0.090 & 1812 & 0.188 \\
\hline UDDS-6150 & 1.714 & 6.24 & 0.545 & 0.120 & 1892 & 0.196 \\
\hline KCM-6150 & 0.899 & 6.31 & 0.314 & 0.100 & 1832 & 0.190 \\
\hline ART-6150 & 0.916 & 6.63 & 0.335 & 0.115 & 1929 & 0.200 \\
\hline COMM-6150 & 0.638 & 5.11 & 0.309 & 0.098 & 1651 & 0.171 \\
\hline
\end{tabular}


Table 18: Summary of emissions and FC data from the three diesel hybrid-electric buses

\begin{tabular}{|l|c|c|c|c|c|c|}
\hline Cycle & $\begin{array}{c}\mathrm{CO} \\
(\mathrm{g} / \mathrm{mile})\end{array}$ & $\begin{array}{c}\mathrm{NOx} \\
(\mathrm{g} / \mathrm{mile})\end{array}$ & $\begin{array}{c}\mathrm{HC} \\
(\mathrm{g} / \mathrm{mile})\end{array}$ & $\begin{array}{c}\mathrm{PM} \\
(\mathrm{g} / \mathrm{mile})\end{array}$ & $\begin{array}{c}\mathrm{CO}_{2} \\
(\mathrm{~g} / \mathrm{mile})\end{array}$ & $\begin{array}{c}\mathrm{FC} \\
(\mathrm{gal} / \mathrm{mile})\end{array}$ \\
\hline NYBus-6001 & 0.330 & 17.42 & 0.254 & 0.055 & 3899 & 0.404 \\
\hline NYBus-6003 & 0.000 & 15.96 & 0.168 & 0.035 & 3778 & 0.391 \\
\hline Paris-6001 & 0.735 & 11.04 & 0.192 & 0.016 & 2318 & 0.240 \\
\hline Paris-6003 & 0.165 & 11.36 & 0.090 & 0.005 & 2535 & 0.263 \\
\hline Man-6001 & 0.014 & 11.30 & 0.191 & 0.005 & 2454 & 0.254 \\
\hline Man-6003 & 0.074 & 11.07 & 0.104 & 0.013 & 2504 & 0.259 \\
\hline WMATA-6001 & 0.479 & 9.95 & 0.048 & 0.010 & 2199 & 0.228 \\
\hline WMATA-6003 & 0.000 & 9.76 & 0.009 & 0.003 & 2230 & 0.231 \\
\hline OCTA-6001 & 0.095 & 8.29 & 0.006 & 0.044 & 1836 & 0.190 \\
\hline OCTA-6003 & 0.000 & 8.81 & 0.000 & 0.006 & 1972 & 0.204 \\
\hline Braun-6001 & 0.031 & 8.10 & 0.060 & 0.014 & 1779 & 0.184 \\
\hline Braun-6003 & 0.000 & 7.40 & 0.000 & 0.004 & 1709 & 0.177 \\
\hline NY-Comp-6003 & 0.000 & 8.69 & 0.000 & 0.016 & 2027 & 0.210 \\
\hline CBD-6003 & 0.000 & 8.29 & 0.099 & 0.017 & 1869 & 0.194 \\
\hline ETCUrban-6003 & 0.010 & 6.75 & 0.040 & 0.017 & 1546 & 0.160 \\
\hline Beeline-6003 & 0.000 & 8.14 & 0.002 & 0.006 & 1954 & 0.202 \\
\hline CSHVC-6003 & 0.000 & 6.81 & 0.001 & 0.007 & 1552 & 0.161 \\
\hline Transient-6003 & 0.081 & 7.17 & 0.048 & 0.012 & 1659 & 0.171 \\
\hline UDDS-6003 & 0.050 & 7.55 & 0.019 & 0.029 & 1771 & 0.183 \\
\hline KCM-6003 & 0.000 & 7.75 & 0.054 & 0.035 & 1716 & 0.178 \\
\hline ART-6003 & 0.000 & 7.48 & 0.027 & 0.012 & 1764 & 0.183 \\
\hline COMM-6003 & 0.000 & 7.02 & 0.014 & 0.061 & 1603 & 0.166 \\
\hline
\end{tabular}

